Old Dominion University

ODU Digital Commons

Theses and Dissertations in Urban Services -

Urban Management

College of Business (Strome)

Spring 1993

\title{
Managerial Roles and Entrepreneurship in Non-Profit Urban Arts Agencies in Virginia
}

\author{
Beth Joan Novitch Rossheim \\ Old Dominion University
}

Follow this and additional works at: https://digitalcommons.odu.edu/urbanservices_management_etds

Part of the Arts Management Commons, Nonprofit Administration and Management Commons, and the Urban Studies and Planning Commons

\section{Recommended Citation}

Rossheim, Beth J.. "Managerial Roles and Entrepreneurship in Non-Profit Urban Arts Agencies in Virginia" (1993). Doctor of Philosophy (PhD), dissertation, , Old Dominion University, DOI: 10.25777/d4mf-ax35 https://digitalcommons.odu.edu/urbanservices_management_etds/25

This Dissertation is brought to you for free and open access by the College of Business (Strome) at ODU Digital Commons. It has been accepted for inclusion in Theses and Dissertations in Urban Services - Urban Management by an authorized administrator of ODU Digital Commons. For more information, please contact digitalcommons@odu.edu. 


\section{MANAGERIAL ROLES AND ENTREPRENEURSHIP \\ IN NON PROFIT URBAN \\ ARTS AGENCIES IN VIRGINIA}

by

Beth Joan Novitch Rossheim

B.A., 1960 Jackson College, Tufts University

M.A., 1981 Old Dominion University

A Dissertation Submitted to the Faculty of

Old Dominion University in Partial Fulfillment of the

Requirements for the Degree of

DOCTOR OF PHILOSOPHY

URBAN SERVICES

OLD DOMINION UNIVERSITY

January 1993

Approved by:

-

Leonard Ruchelman. Ph.D. ,

(Director)) 
Copyrighted by Beth N. Rossheim, 1992

All Rights Reserved

Reproduced with permission of the copyright owner. Further reproduction prohibited without permission. 


\author{
ABSTRACT \\ MANAGERIAL ROLES AND ENTREPRENEURSHIP IN NON-PROFIT \\ URBAN ARTS AGENCIES IN VIRGINIA \\ Beth Joan Novitch Rossheim \\ Old Dominion University, 1992 \\ Director: Dr. Leonard Ruchelman
}

The future of the arts in Virginia depends on knowing how arts agencies are functioning and surviving at a time of resource decline. What roles do managers play in administering agencies? What business and management skills do managers use to maintain an agency and to relate to the community? How do managers handle cutbacks? Does entrepreneurship create more viable arts agencies?

Bivariate data analysis separated managers into four role groups: entrepreneur, administrator, artist, and caretaker, according to their perceived degree of programmatic creativity and documented access to organizational resources. Managerial role types were compared wit'l management behaviors to discern significant differences. Data revealed that the entrepreneur is mostly found in visual arts agencies, is highly creative and attentive to business matters, and tends to work alone. The administrator is generally found in large music and theatrical agencies, manages a highly complex organization with a large staff, budget, and board; this type does not emphasize creativity. The artist, predictably the most highly creative, lacks sufficient managerial skills to maintain a stable organization, and is largely located in smaller music, theatre or dance agencies. The caretaker, found in every type of agency, lacks creative purpose and resources, and is in constant peril of merger or termination.

All role types employ the same basic cutback strategies, but vary in their positive attempts to increase revenues and audiences according to role type and agency type. In 
light of extemal pressures, the entrepreneur is not distinguished from other role types in demonstrating greater agency viability. 


\section{TABLE OF CONTENTS}

LIST OF TABLES $\quad$ T.................................................... vii

LIST OF FIGURES $\quad$..................................................... xiii

\section{Chapter}

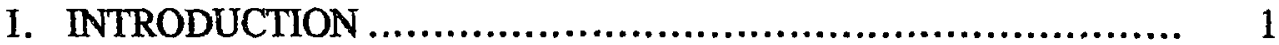

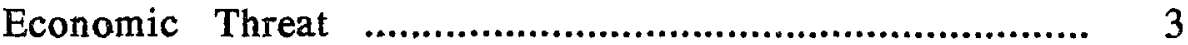

Political Pressures........................................................... 3

Arts in Virginia ............................................................. 4

Arts Management........................................................ 5

Role Types of Arts Managers................................................ 6

Role Behaviors of Arts Managers................................... 9

Research Problem ........................................................... 10

Managerial and Agency Demographics................................. 11

Research Questions ...................................................... 12

Research Objectives.................................................... 12

Significance of the Arts...................................................... 12

II. REVIEW OF THE RELATED LITERATURE........................ 14

Introduction....................................................... 14

Role Theory .................................................. 14

Arts Managers' Roles....................................................... 18

Role Definitions .................................................... 18

Arts Management......................................................... 20

Arts Managers and Entrepreneurship ............................... 26

Entrepreneurial Management................................................ 27

Entrepreneurial Process .................................................. 28

Identifying the Entrepreneur ................................................ 29

Entrepreneurship and Organizational

Life Cycle .............................................. 31

Entrepreneurship and Recession ................................... 34 
TABLE OF CONTENTS (continued)

$\begin{array}{lll}\text { Chapter Page } & \text { Pas }\end{array}$

III. RESEARCH METHODS ....................................., 36

Population........................................................ $\quad 36$

Research Model ................................................ 37

Procedure ........................................................ 39

Questionnaire......................................................... 40

Validity ......................................................... 41

Statement of Hypotheses and Relationship to

Questionnaire and Theory ....................................... 42

Hypothesis One.................................................. 42

Hypothesis Two, Part One..................................... 46

Hypothesis Two, Part Two ................................... 50

Hypothesis Three....................................................... 54

Hypothesis Four................................................... 59

Data Analysis ...................................................... 60

Index Construction........................................ 62

Guttman Scales .......................................... 67

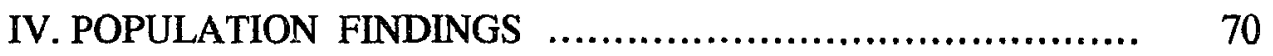

Introduction................................................. 70

Part One, Profile of Managers and Agencies ............................ 71

Overview of the Population .................................... 71

Managerial Characteristics .................................... 71

Agency Characteristics........................................... 75

Managerial Attitudes Toward
Business Management .......................................... $\quad 80$

Part Two, Anticipation of Role Types............................. 84

Evidence of Role Clusters.................................... 84

Profile of the Entrepreneur .................................... 84

Profile of the Caretaker .............................................. 86

Profile of the Administrator ............................... 88

Financing the Arts and
the Administrator $\ldots \ldots \ldots \ldots \ldots \ldots \ldots \ldots \ldots \ldots \ldots \ldots \ldots \ldots \ldots \ldots \ldots \ldots \ldots$

Profile of the Artist.......................................... 92

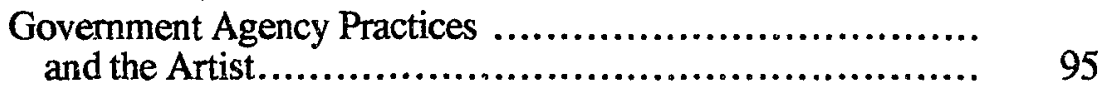


TABLE OF CONTENTS (continued)

Chapter Page

V. ROLE ANALYSIS................................................. 99

Introduction...................................................... 99

Research Question 1 ................................................. 99

Data Analysis................................................... 100

Hypothesis 1 .............................................. 105

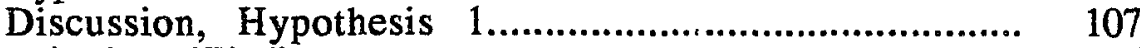

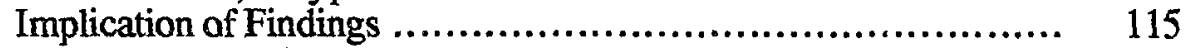

Programmatic Creativity ........................................ 115

Generating Revenue .............................................. 116

Influence of Agency Type ........................................... 117

Influence of Agency Age............................................... 118

Influence of Agency Structure........................................... 119

Role Types and Attitude Toward Change............................. 121

Research Question 2, Part One .................................... 125

Data Analysis..................................................... 125

Hypothesis 2, Part One ...................................... 127

Discussion, Hypothesis 2, Part One.................................. 128

Research Question 2, Part Two .................................. 133

Data Analysis...................................................... 133

Hypothesis 2, Part Two............................................. 136

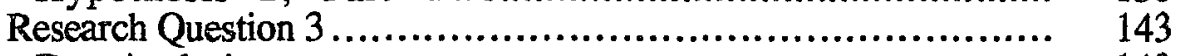

Data Analysis..................................................... 143

Hypothesis 3 ....................................................... 147

Research Question 4 ............................................ 154

Introduction................................................... 154

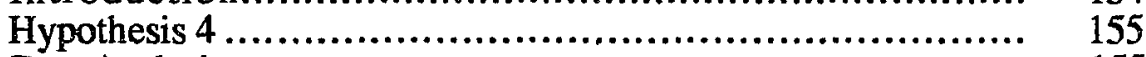

Data Analysis................................................. 155 


\section{TABLE OF CONTENTS (continued)}

Chapter

VI. SUMMARY AND CONCLUSIONS.

Background to the Study......................................... 171

Research Approach ................................................ 171

Population Profile....................................................... 172

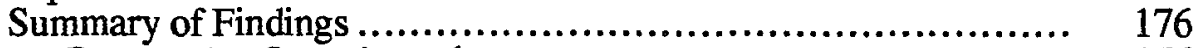

Research Question 1............................................... 176

Research Question 2............................................. 177

Research Question 3................................................ 180

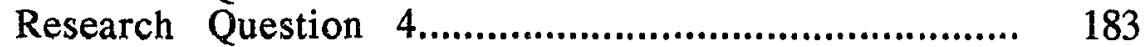

Too few Entrepreneurs ................................... 183

Non-Profit Obstacles to Entrepreneurship......................... 184

Internal Obstacles to Entrepreneurship............................. 185

Conclusions........................................................ 187

Termination as a Failure to Adapt ............................. 189

Change as Adaptation .......................................... 190

Opposition to Change ........................................... 192

A New Arts Mission ......................................... 193

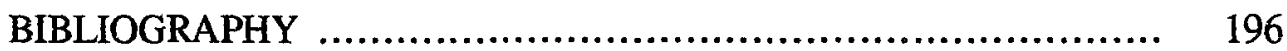

\section{APPENDICES}

A. Guidelines, Virginia Commission for the Arts.................. 209

B. Sample for Arts Management Questionnaire .................. 210

C. Arts Management Questionnaire ........................... 213

D. Pretest Cover Letter ......................................... 214

E. Sample Cover Letter.......................................... 215

F. Additional Studies.......................................... 216

$\mathbf{v i}$ 


\section{LIST OF TABLES}

Table

Page

1. Managerial Functions in Mintzberg, Gulick, and

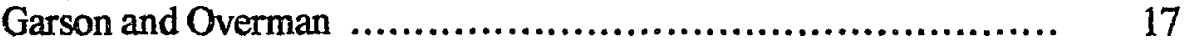

2. Correlations of Items to Index on Creativity ....................... 64

3. Correlations of Items to Index on Access to

Resources $\quad$........................................................ 64

4. Correlations of Items to Index on Internal

Agency Management Tasks........................................ $\quad 65$

5. Correlations of Items to Index on External

Agency Management Tasks....................................... 65

6. Correlations of Items to Index on Active

Cutback Strategies ............................................. 66

7. Correlations of Items to Index on Passive Cutback Strategies

8. Correlations, Means and Standard Deviations

of Six Indexes by Each Other............................................ 67

9. Urban Area of Respondents............................................ 71

10. Age of Respondents .......................................... 72

11. Gender of Respondents............................................ 72

12. Educational Level of Respondents ................................ 73

13. Major Field in Art of Respondents ............................... 73

14. Business or Management Education of Respondents................ 73

vii 


\section{LIST OF TABLES (continued)}

Table

15. Administrative Experience of Respondents ....................... 74

16. Position Characteristics............................................. 75

17. Managerial Salaries of Respondents .............................. 75

18. Agency Types...................................................... 76

19. Characteristics of Arts Agency Staffs............................. 76

20. Agency Longevity ............................................ 77

21. Agency Lifecycle ............................................. 77

22. Agency Service/Performance Change Over Three Years ............. 78

23. Descriptive Statistics for Agency Revenues.......................... 79

24. Agencies Earning $50 \%$ of Revenue by Services or Performances ................................................... 80

25. Agencies Receiving $40 \%$ Percent of Revenue from Grants and Donations................................................... 80

26. Managerial Attitudes Toward Business Management ................. 82

27. Correlations Among Variables Suggesting Entrepreneurial Traits in Arts Managers................................................ 86

28. Correlations Among Variables Suggesting Caretaker Traits in Arts Managers

29. Correlations Among Variables Suggesting Administrative Traits in Arts Managers.................................................. 91

30. Correlations Among Variables in Arts Financing......................... 92

31. Correlations Among Variables Suggesting Artist Traits in Arts Managers 


\section{LIST OF TABLES (continued)}

Table

Page

32. Correlations Among Variables Associated with Government Sponsored Agencies

33. Division of Respondents into Four Roles by Programmatic Creativity and Access to Organizational Resources

34. Correlations, Means and Standard Deviations for Items in Creativity Index

35. Correlations, Means and Standard Deviations for Items in Access to Resources Index.

36. Mean Values of Creativity and Access to Resources Index Scores by Managerial Role

37. Analysis of Variance: Role Types (Independent Variable) by Creativity (Dependent Variable.

38. Analysis of Variance: Role Types (Independent Variable) by Access to Organizational Resources (Dependent Variable).

39. Creativity Index Variables by Role Type 108

40. Access to Resources Index Variables by Role Type 109

41. Age by Managerial Role Type 109

42. Education by Managerial Role Type 110

43. Agency Type by Role Type 110

44. Agency Longevity by Role Type

45. Organizational Lifecycle by Manager's Role Type

46. Agency Structure by Role Type

47. Analysis of Variance: Management Structure (Independent Variable) by Total Gross Revenues (Dependent Variable) 


\section{LIST OF TABLES (continued)}

Table

Page

48. Mean Revenues by Four Management Structures

49. Characterization in Percentages of Organizational Lifecycle by Manager's Role Type.................................... 121

50. Attitude Statements by Role Type................................ 124

51. Correlations, Means and Standard Deviations of Items in Internal Agency Management Index

52. Mean Values of Internal Agency Management Index

53. Analysis of Variance: Role Type (Independent Variable Variable) by Internal Agency Management Index Scores (Dependent Variable)

54. Involvement with Internal Agency Management Variables by Role Types...

55. Correlations, Means and Standard Deviations of Items in External Agency Management Index.

56. Mean Values of External Agency Management Index Scores by Role Type

57. Analysis of Variance: Role Type (Independent Variable) by External Agency Management Tasks (Dependent Variable)

58. Involvement with External Agency Management Tasks by Role Type

59. Correlations, Means and Standard Deviations of Items in Active Cutback Index.

60. Correlations, Means and Standard Deviations of Items in Passive Cutback Index

61. Mean Values of Active Cutback Strategies Index Scores by Role Type 


\section{LIST OF TABLES (continued)}

Table

Page

62. Analysis of Variance: Role Types (Independent Variable) by Active Cutback Stratgeis Index (Dependent Variable) .

63. Mean Values of Passive Cutback Strategies Index Scores by Role Type

64. Analysis of Variance: Role Type (Independent Variable) by Passive Cutback Strategies Index (Dependent Variable)

65. Involvement with Cutback Strategy Variables by Role Differences

66. Agency Lifecycle by Role Type ................................ 156

67. Agency Staffs, Volunteer and Artistic by Role Type.................... 158

68. Agency Staffs, Business and Board by Role Type....................... 159

69. Service and Performance Change 1989 by Role Type............... 160

70. Service and Performance Change 1990 by Role Type................ 160

71. Service and Performance Change 1991 by Role Type................ 161

72. Mean Values of Roles by Total Gross Revenue 1991 from IRS $\$ 990$

73. Analysis of Variance: Role Type (Independent Variable)

by Total Gross Revenue 1991 from IRS \#990 (Dependent

Variable)

74. Mean Values of Role by Percent Earned Income

166

75. Analysis of Variance: Role Types (Independent Variable)

by Percent Earned Income (Dependent Variable).

76. Mean Values of Roles by Amount of Contribution.

77. Analysis of Variance: Role Types (Independent Variable) by

Amount of Contribution (Dependent Variable) 


\section{LIST OF TABLES (continued)}

Table

78. Mean Value of Roles by Percent of Contributions

79. Analysis of Variance: Role Types (Independent Variable) by Percent of Contributions (Dependent Variable).

80. Mean Value of Roles by Does Agency Earn One-half Income?.

81. Analysis of Variance: Role Types (Independent Variable) by Does Agency Earn One-half Income?

82. Mean Values of Roles by Grants and Donations Equal $40 \%$ Percent of Agency Income...

83. Analysis of Variance: Role Type (Independent Variable) by Grants and Donations Equal 40\% Percent of Agency Income

84. Mean Value of Roles by Percent Profit or Loss

85. Analysis of Variance: Role Types (Independent Variable) by Percent Profit or Loss (Dependent Variable).

86. Distribution of Findings that Support, Fail to Support and Partially Support Hypotheses......................................... 173

87. Factor Analysis of Managerial Tasks ............................... 216

88. Multiple Regression, Indexes by Demographic Variables and Role Types. 


\section{LIST OF FIGURES}

Figure

Page

1. Managerial Roles................................................ 9

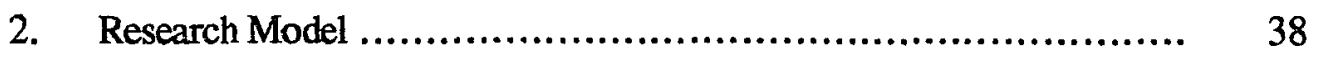

3. Divison of Respondents into Four Roles by Program Creativity and Access to Organizational Resources.................. 62

4. Service and Performance Change (Growth) by Role Type and Year .................................................. 162

5. Service and Performance Change (Decline) by Role Type and Year

6. Service and Performance Change (Stable) by Role Type and Year 


\section{MANAGERIAL ROLES AND ENTREPRENEURSHIP \\ IN NON-PROFIT URBAN ARTS AGENCIES IN VIRGINIA}

\section{CHAPTER I \\ INTRODUCTION}

Something about the imminent closure of a century evokes either optimism or pessimism, or both in extreme degrees. Either emotion derives from the centennial urge to review past performance, to compare it with previous eras and with our stated goals. This is how we set our benchmarks--our measures for the next century. For the arts, which have in one century moved from fledgling local "societies" to the corporate foundations of the early days, and then to the modern government-sponsored programs, it is a fitting time to evaluate their development and status. This stock-taking comes after two periods of federal support that generated great optimism in the American arts (The Federal Arts Project and the National Endowment for the Arts), but, contrary to expectations, we find the arts now wracked by internal dissent, political invective, and budgetary wrangling. There are tensions between political conservatives and liberals regarding the nature of art and censorship, among competing arts lobbies and special interest groups for budgetary allocations, and between idealists and realists regarding the value of the arts in our society. Within arts agencies, the artists and business managers argue over who should govern the organization. All of these hotly debated issues spell troubled times for the arts in general and especially for us in Virginia. 
The arts in America have always been viewed as stepchildren of the government, never completely disregarded, yet never fully acknowledged and funded as in other western societies. For a brief flowering in the mid-1960s, however, there arose a federal commitment to the arts that caused a national ripple. The years from 1965-1980 were golden for the arts, when museums and arts agencies proliferated in every urban and rural center in the nation, but the cycle has come full circle with a decided change in the government's fiscal priorities and a sweeping political shift to the right. Now the arts are viewed as the lowest priority and the least worthy of government spending. States and localities are decimating their arts' budgets, causing arts agencies to cut back their programs, restructure their organizations and consider termination.

The question is no longer which agencies shall prosper or expand, but which agencies shall survive. Within the last three years all three major sources of funding began to diminish: government, corporate and individual. Actually, government spending in the arts has not matched a $31 \%$ inflation rate since 1981, according to a United States Department of Commerce cost-of-living index. Further, the rush to merge or take-over by large and small corporations has caused a slowdown in the amount of discretionary income that these entities were willing to donate. Other factors impacting arts agencies have included the increasing price of tickets, the abolition of the charitable deduction in income tax for non-itemizers, and the elimination of tax deductions based on the appreciated value of arts gifts (the 1986 tax code allows donors to deduct only the purchase price of an artifact). Additionally, audiences for classical arts programs are diminishing as the population ages and schools have made little effort to train a new generation of artssupporters. The government is still considering taxing endowment funds and profitmaking centers run by non-profit organizations. The agencies at greatest risk lack committed patrons and a stable fiscal base--both elements of managerial time and skill. 


\section{Economic Threat}

The greatest threat facing the arts is the budget crisis. While the United States has harbored a major fiscal deficit for five administrations (the budget has not been balanced since the presidency of Lyndon B. Johnson in 1969), a serious economic situation combined with an increasing national deficit has provoked some dramatic responses. Cuts of every kind are proposed, with cultural arts on the front line. Already the arts are hurting from recent restrictions on tax deductions for arts gifts, and this new wave of reduced funding will have a multi-leveled effect on many segments of our society.

\section{$\underline{\text { Political Pressures }}$}

Several major political shifts in the country have produced unexpected and serious problems for the arts. Of course, there was always, a chorus of dissenters who felt that art was not the business of government, beginning with the Reagan Administration, which attempted to eradicate the NEA in 1981 and ended by decreasing support for the arts by $24 \%$ percent (in constant dollars) in the years 1981-1989.

A more enduring threat to the arts has come from the philosophical/ideological shift to the right, which has produced a highly vocal fundamentalist interest group. Led by evangelists such as M.G. "Pat" Robertson, Donald Wildmon, and conservative North Carolina Senator Jesse Helms, who find the arts in violation of comrnunity standards on morality (on the basis of two isolated photographic exhibitions), this grass roots movement presents the latent American threat to art--that art is inimical to American experience (Bolton 1992). Issues in the arts have become symbolic of the great debate over changes in American society--that we are a decaying society that is moving away from traditional families, fundamental religious practices and patriotic devotion to country. The arts are used by the political right to represent some ideas, symbols and images that certain political and religious factions view as society's corrupting influences, threatening the established way of life in America (Bolton 1992). Ironically, the arts are also used by the political left 
to represent the potentially oppressive nature of government, especially in its ability to limit a wide-ranging expression of ideas.

\section{Arts in Virginia}

In 1990, the arts were a major industry in Virginia, employing 2,449 individuals in organizations that paid 1.7 million dollars in sales, admissions and payroll taxes. (In Hampton Roads alone, there were over 300 arts agencies, which brought 38 million dollars into the economy in 1990.) The situation changed dramatically in January 1991, however, when Governor L. Douglas Wilder slashed the anticipated arts budget of 5.3 million by $81 \%$, reducing the amount to $\$ 1.02$ million out of a $\$ 26$ billion dollar state budget. Virginia plunged from 37th in the nation in per capita spending for the arts to one of the lowest, dipping from $\$ 0.88$ cents per capita to $\$ 0.24$ cents with the new allocation (Daily Press, July 21, 1991).

The repercussions across the state were swift and disheartening. Programs and performances were cancelled, galleries were closed or operated on a reduced visiting schedule, personnel were laid off, and grant monies were reduced or eliminated. The reduced level of state spending on the arts is expected to diminish the quality of public arts presentations, curtail museum exhibits, conservation programs, and collecting plans, and reduce community recreational programming. A shortage of funds also may create an adversarial situation between fledgling and established agencies.

Fears for the future of the arts in the Commonwealth are voiced in the media, the classroom and the corporate boardroom as well, despite the demonstrated value of the arts in community development, the tourist industry, and urban revitalization (Cwi 1981, Whitt 1987). The number of ways in which the arts contribute to the health of an urban area are known and widely acknowledged both on a practical and a theoretical level (Blau and Hall 1986, Whitt 1987, Klink 1987, Cwi 1981, and Cwi and Moore 1982). 


\section{Arts Management}

There are special factors in arts agencies that make them an especially appealing and interesting research topic from both a theoretical and an empirical viewpoint. Theory on management differentiates a non profit business from a proprietary business by a variety of measures. The for profit business operates from a stable, hierarchical structure that produces a product and measures its success in profitability. The non profit business, according to Rohrer (1985), has unique structural properties that often lead to problematic management. Non profit organizations often form vague goals because they take action on issues in response to the expressed desires of interest groups. They are constantly distressed financially from their labor-intensive, charity dependent structure. They have great difficulty evaluating performance when their goals are poorly defined. Rohrer (1985) cautions that poor management in non-profit organizations should not be attributed hastily to a lack of ability to function in a business environment.

From an empirical point of view, arts agencies have a unique management problem that can best be described as a conflict of goals. Artistic and business leaders vie for power in controlling both the mission and the resource distribution of the agency. Each presents a view of the arts that is mutually exclusive: the artist sees the agency goal as high quality creative expression, while the business manager view the goal as fiscal solvency.

There are patterns of operation in non profit arts agencies that can be described as contributing to this management impasse. Experience suggests that performing or visual arts agencies, in their emergent phase, must be started by a leader skilled in the craft of the agency, who is equally skillful in recruiting, programming and motivating a core staff. Only in the very rarest of instances can a performing or visual arts agency can be formed by a totally administrative manager (with no artistic background) who hires an artistic staff. At the point of agency incorporation as a non profit, however, the creative leader is required to turn over the policy-making duties of the agency to a board of directors. The creative leader thus relinquishes his/her autonomy and vision for the future of the agency to a 
relatively inexperienced and disinterested group. The board may decide to turn over control of the agency to a business manager in order to safeguard the agency's fiscal viability, which immediately ignites a power struggle within the managerial staff and possibly between the creative/artistic manager and the board of directors.

On the other hand, a second type of arts agency, the presenting or sponsoring agency, may be initiated by a purely administrative leader with some knowledge of the arts. The same process here works in reverse. As the agency incorporates and designates a board of directors, there may be a decision to hire an artistic director to plan creative and original program elements. Here again, the conflict between the administrative leader and the program manager can escalate into a power struggle.

Each of these two types of agency represents an empirically defined type of management deriving from a conceptualization of the task (Gasse 1978). The artistic manager, according to Rohrer (1985), operates from the level of intuitive decision-making, a less complex process, sometimes called "soft box," which is marked by the individualism of the manager, i.e. his/her vision of the agency and personal response to every facet of operation. The administrative manager operates far differently, becoming heavily immersed in rational decision-making and helping the organization to grow by means of standard business practices, including long-range and strategic planning (Gasse 1978). For the purpose of this research we are interested in looking at both types of managers, as well as a subdivision of each type.

\section{Role Types of Arts Managers}

Essential to this research is the role of the arts manager as measured by two strengths that constitute the central focus of this study: artistic innovation and access to financial and organizational resources. These two variables represent the core forces which must be marshalled and fused in an arts agency, because without either artistic creativity or financial resources, the arts agency ceases to function. Young $(1983,158)$ includes these 
two variables in his list of four "social-performance criteria [that] were established for service-producing sectors." He names these variables innovation and efficiency. Svara (1990) uses two highly similar commodities in his study of municipal leaders, differentiating these leaders on the basis of effective policy initiation and implementation. By developing role types on the basis of these two factors, creativity in programming and organizational skills, we can produce four types of managers: 1) entrepreneur, 2) artist, 3) administrator, and 4) caretaker.

An arts manager with a sufficient funding base can evolve into an entrepreneur, one who is innovative and aggressive in pursuing a well-managed, high quality, well-funded, administratively sound and creative agency, or can perform as an artist, a manager with more vision than resources or organizational skills. On the other hand, an analytical manager may value organizational and administrative skills over creative programming, leading to the orientation of administrator. Finally, a manager whose agency demonstrates neither creative programs nor administrative and organizational skills may be viewed as a caretaker, one who is struggling to maintain an agency presence.

The selection of these four specific roles derives from several key studies that discuss primary managerial roles in a wide variety of organizations. The manager appears as agenda-setter or networker (Rohrer 1985, Kotter 1982), disseminator of shared values (Peters and Waterman 1982), integrator (the one who meshes and analyzes people and events) (Hurst 1984), and entrepreneur (Young 1983, and (Mintzberg 1973). Rohrer (1985) relates this organizational research to the area of arts management. She describes the roles of cultural arts managers, using Mintzberg's (1973) detailed observational method, and finds four prominent roles: caretaker, leader, liaison and entrepreneur, respectively.

The caretaker is an "administrator [who] perpetually scans the environment for information [from many sources] " (Fleischaker-Suarez 1982, 226). [These] conserverbased agencies will attempt to adjust their programs and services to avoid a major collapse. 
... management practices will tend to become stagnant. . .innovative only in minor ways" (Young 1983, 134).

The leader (our term is administrator), is an individual who sets the tone for the organization by developing standards, work methods and an emotional climate (Fleischaker-Suarez, 1982).

The liaison (our term is artist) is one who initiates constant contact with the external environment in order to build a storehouse of information vital to the agency (FleischakerSuarez, 1982).

The entrepreneur is the "proactive" initiator who utilizes his/her "technical knowledge and conceptual skills."(Fleischaker-Suarez, 222). 
Managerial Roles

\begin{tabular}{ll}
\hline \hline Role Theory & Research Roles \\
\hline & Correspondence \\
$\begin{array}{l}\text { 1. Monitor (Mintzberg) } \\
\text { Conserver (Young 1983) }\end{array}$ & 1. Caretaker \\
$\begin{array}{l}\text { 2. Leader/Broker (Rohrer) } \\
\quad \text { Professional (Young 1983) }\end{array}$ & 2. Administrator \\
$\begin{array}{l}\text { 3. Liaison (Rohrer 1985) } \\
\text { Zealot (Downs 1967) } \\
\text { Reformer (Svara 1990) } \\
\text { Believer (Young 1983) }\end{array}$ & 3. Artist \\
4. Entrepreneur/Innovator (Rohrer) \\
$\quad$ Architect (Young 1983)
\end{tabular}

Source: Rohrer (1985), Fleischaker-Suarez (1982), Mintzberg (1973), Downs (1967) Young (1983), and Svara (1990)

Figure 1. Role Correspondence

\section{Role Behaviors of Arts Managers}

The study will investigate several aspects of arts management in order to portray more completely the tactics and strategies identified with each managerial role. These include internal responsibilities (organization structure), external responsibilities (environmental structure) and cutback strategies. Internal responsibilities are composed of the agency goals or mission; the structure, including the Board of Directors; the institution of basic management practices such as budgeting, performing a marketing audit and analysis, and fundraising, as well as planning in short and long term for personnel, facilities, and finances. External responsibilities include political lobbying by the manager, community relationships between the manager and powerful interest groups, competitive 
strategies of the manager, and assessment of the regional economic stability. Cutback strategies are the means by which managers adapt their agencies to fiscal constraints.

Managers' personal attitudes toward standard business practices are surveyed in order to allow for the expression of psychological factors that may be intimately involved with management style (Gasse 1978). Attitudinal variables include beliefs relating to business and the arts, agency growth, uncertainty and change, use of scientific methods and practices in business, functioning of Boards of Directors and use of authority, the role of fate in business, and the place of competition in business of the arts.

The study attempts to discover the existence and the extent of entrepreneurial activity in urban arts agencies under conditions of retrenchment. The entrepreneur is described as a risk-taker, a "proactive" energizer who can both conceptualize and recognize an opportunity, and who possesses the business background and access to venture capital necessary to ignite production. Entrepreneurial activities have been studied enthusiastically for the past several decades in the profit sector, and more recently in bureaucracies in order to determine the relationship between innovation and personality, education, experience and economic environment. Further, entrepreneurship has been expanded to include not only single business owners, but also individuals within corporations who promote a "business within a business" and are called "intrapreneurs" (Hisrich 1986). In the public sector we now find attention paid to bureaucratic entrepreneurs who can work within the context of a public agency to champion a new or unique policy through a thicket of political and economic constraints to emerge with new regulations, commissions and programs (Bellone 1988). Because there has been little attention to the non profit entrepreneur, this study will analyze entrepreneurship among non profit arts managers.

\section{The Research Problem}

The central problem in this study is to determine how arts agencies in Virginia are securing their own viability. Are there specific roles that arts managers are adopting to 
cope with the new requirements of arts administration? Are arts agencies changing from relatively unsophisticated associations to small businesses, skilled in fundraising, marketing, merchandizing and programming? Do arts managers currently have the necessary experience and education to deal with business issues effectively? Under current conditions of retrenchment, what kinds of cutback strategies and innovative planning are arts managers employing to survive? This research focuses on non profit arts agencies, the "third sector" of industry after for-profit and government, which since the mid-1960s has relied upon all levels of government funding for maintenance. The study looks at the managers or executive directors of these arts agencies to determine what shifts, if any, are taking place in the way that arts agencies conduct themselves. The transition from an artistic experience to a business venture in the arts has been occurring sporadically for some years as more professional managers enter the non-profit and arts fields, but necessity has hastened that process in the era of retrenchment.

\section{Managerial and Agency Demographics}

In order to gain a fuller understanding of the managers and agencies in this study, questions were posed to determine the demographic features of both the arts managers and their agencies. Questions that were directed toward managers included age, race, region, gender, education, major field in art, business or management education, administrative experience and salary range. Similarly, managers were asked to profile their agencies in terms of agency structure, type, staff sizes, longevity, lifecycle and revenues. Managers were also asked to characterize their agencies in terms of growth or decline over a three year period, 1989 to 1991 . The year 1989 was critical for the arts as the inception of declining government support of the arts as well as the rise of a confrontational debate over arts sponsorship vs. censorship (Bolton 1992). A final section questions arts managers' attitudes toward administration, with a focus on the use of business techniques. 


\section{Research Questions}

1) What is the distribution of arts managers as they are assigned to different role types, i.e., entrepreneur, administrator, artist and caretaker, on the basis of creativity and access to organizational resources?

2) How does each role type perform the management tasks involved in running an agency and representing the agency in the larger community?

3) What are the similarities and differences of each role type in instituting cutback procedures to cope with a recessionary economy?

4) Is the role type entrepreneur more successful in maintaining an agency over time than the others?

\section{Research Objectives}

1) To determine the kinds of managerial competencies of urban arts managers in Virginia

2) To determine the roles of arts managers

3) To assess the efficacy of entrepreneurship in comparison to aother managerial roles

4) To identify managerial strategies for copying with fiscal stress

\section{Significance of the Arts}

The arts are a recognized source of income and jobs, a way to attract new businesses and to promote general community development. It is commonplace for businesses surveying an area for relocation to question the quality of schools, health care and the arts. The arts have been instrumental in rejuvenating city centers and in providing an impetus to in-town living. With the stimulus of the arts, cities have been able to turn decaying areas of the existing environment into gathering places and commercial centers. The arts are a multiplier of dollars; it is estimated that every arts dollar spent generates at least three to four dollars in tourist income, such as food, lodging, and souvenirs. 
The arts constitute a significant factor in the liveability index of cities, repeatedly cited by major surveyors of city desirability. For cities that are stumbling to regain their stability, image, and vitality, the loss of the arts may mean a rapid loss in the race for population and industrial/corporate presence. The value of the arts in stimulating the growth and viability of the city accounts for the fact that cities allocate amounts ranging from a low of $\$ .83$ per capita (Boston) to a high of $\$ 12.88$ per capita (Miami Beach) to support the arts (Cwi and Moore 1982). The arts are not simply frills, but a necessary part of human existence. The quality of life depends on many such niceties. Try to envision a world without books, music, art, parks, museums, theatres, and the like.

The value of the arts for economic enhancement, education, or personal enrichment are the more obvious defenses. John Fitzgerald Kennedy reminded us that the arts also play a singular role as symbols and guardians of freedom in a democratic society. $\mathrm{He}$ warned that "the artist, however faithful to his personal vision of reality, becomes the last champion of the individual mind and sensibility against an intrusive society and an officious state. ..." (Sorenson 1988).

Given the significance of the arts, it is important that they survive and remain viable. If this is to happen they must have sound management. Although the arts manager is critical to the effective management of arts agencies, very little is known about the individuals who perform these tasks and the kinds of skills they bring to bear. The purpose of this study is to fill this gap by viewing managerial roles in urban arts agencies in Virginia. 


\title{
CHAPTER II
}

\section{REVIEW OF THE RELATED LITERATURE}

\author{
Introduction
}

The literature to be reviewed in this section is of necessity wide ranging to encompass the several theories that undergird this study. The aim is to provide the reader with a broad understanding of current and widely held concepts by which we can assess the data from the study. Topics covered include role theory, managerial roles, entrepreneurial management, arts management, and cutback management.

\section{Role Theory}

Roles, according to Biddle $(1979,58)$ characterize observable, patterned human behavior, by one or more persons, which is confined by an environment or contextual surrounding. A role is also a means of classifying or categorizing individuals in their positions to help us to understand their behaviors (Myers 1990, Vander Zanden 1987). Katz and Kahn (1978) relate role to behavior by identifying the "standardizing patterns" that identify the role player (43). They find roles to be intentionally specific, but surrounded by areas of ambiguity at the intersection between the role and its justification, such as a norm or a value judgement.

Katz and Kahn (1978) find that a role, in order to be successfully integrated in a worker, requires the individual's acceptance of the purpose (value judgement) or objective of the organization, as well as its manner of conducting business (norm) (44). In this way, role is interconnected with the two concepts of norm and value in the organizational setting. 
In a management role, an individual assumes the responsibilities of all aspects of role fulfillment, which Katz and Kahn call a "depersonalizing demand" (46). They offer an alternative in the individual who insists on maintaining his integrity and and identity regardless of the institutional demands. When workers cannot perform their assigned roles without compromising their values and subsuming their personal goals, they are said to be experiencing role "malintegration" (Biddle 1979, 77). Under these conditions workers may find themselves choosing one role or another on the basis of the role features that most closely resemble their own talents and beliefs.

In this study, the concept of role is used heuristically as a means of identifying predictable managerial behaviors in an organizational setting. Biddle $(1979,71)$ refers to roles under these conditions as functional, i.e., the manager performs certain behaviors because of the organizational expectations surrounding his job. The managerial role specifies the direct activities in which a manager must engage. This study attempts to determine four such functional roles by administering a questionnaire designed to group managers into four distinct roles on the basis of two managerial behaviors: creativity and administrative skill in accessing organizational resources. The research asks: what role does the manager play within his/her agency? What behaviors are associated with this role? What attitudes are associated with this role? Does one role exceed others in demonstrating agency viability? This exploratory study does not attempt to determine role congruence, i.e., the relationship between one's reported behavior and perceived behavior. In fact, the managers interviewed for this research were neither introduced to the concept of role, nor offered the opportunity to select their own role from a preset list of options. This study is involved with determining the existence of four definitive roles and exploring the degree to which they are held by a percentage of arts managers.

Role theory was utilized for managers by Mintzberg (1989), who applied direct observation to capture and categorize the behaviors that managers displayed in their daily work. In his research Mintzberg (1973) extrapolated from actual managerial work the 
variety of roles that a manager assumed in his organization by asking questions such as: "What kinds of activities does the manager perform? What basic roles can be inferred from the study of the manager's activities? What variations exist among managerial jobs? To what extent can basic differences be attributed to the situation, the incumbent, the job, the organization and the environment?" (Gartner 1989).

Mintzberg (1989) reconfigured the managerial tasks of Gulick and Urwick (POSDCORB) into a set of codified behaviors or roles, dividing the managers' roles into three major categories: interpersonal, informational and decisional, with ten subcategories. The ten subcategories or specific roles are: Figurehead, Leader, Liaison, Monitor, Disseminator, Spokesman, Entrepreneur, Disturbance handler, Resource allocator and Negotiator (Mintzberg 1989). Several researchers have replicated Mintzberg's studies, essentially reaping the same findings (Rohrer 1985). These studies identify definitively both the functions of the manager and the roles that managers assume to carry out those functions. Rohrer (1985) feels that Mintzberg's seminal work presents a coherent case for a unity of management tasks and behaviors--i.e., he displays within the totality of the managers' actions the variety of jobs and roles which a manager must perform. While the manager may lean heavily toward or display more promise in a single role, such as entrepreneur, by necessity he must also perform to some degree all of the other roles in order to execute his job adequately. Table 1 demonstrates that the core of management is still the tasks and roles. 
Table 1.--Managerial Functions in Mintzberg, Gulick, and Garson and Overman

\begin{tabular}{llll}
\hline $\begin{array}{l}\text { Type of } \\
\text { Function }\end{array}$ & Mintzberg 1 & $\begin{array}{l}\text { Gulick } \\
\text { (POSDCORB) }\end{array}$ & $\begin{array}{l}\text { Garson and Overman } \\
\text { (PAFHRIER) }\end{array}$ \\
\hline Interpersonal & Figurehead & No counterpart & No counterpart \\
& Leader & Organizes, staffs & $\begin{array}{l}\text { Dispersion of } \\
\text { POSDCORB } \\
\text { functions }\end{array}$ \\
& Liaison & No counterpart & No counterpart \\
Informational & Monitor & Plans, reports & Policy analysis \\
& Disseminator & Directs, coordinates & Information mgmt \\
& Spokesman & No counterpart & External relations \\
& Entrepreneur & No counterpart & $\begin{array}{l}\text { Human resources } \\
\text { management }\end{array}$ \\
& $\begin{array}{l}\text { Disturbance } \\
\text { handler }\end{array}$ & No counterpart & No counterpart \\
& $\begin{array}{l}\text { Resource } \\
\text { allocator }\end{array}$ & Budgeting & Financial management \\
& Negotiator & No counterpart & No counterpart \\
\hline
\end{tabular}

1 Henry Mintzberg, The Nature of Managerial Work (New York: Harper and Row, 1973).

2 Luther Gulick, "The Dynamics of Public Administration Today as Guidelines for the Future," Public Administration Review 43 (May /June 1983): 193-198.

${ }^{3}$ G. David Garson and E.S. Overman, Public Management Research in the United States (New York: Praeger, 1983).

Source: Adapted from Graham and Hayes $(1986,27)$ 


\section{Arts Managers' Roles}

This research identifies four specific arts management roles and relates those roles to performance in the areas of internal organizational structure and external environmental opportunities and constraints. The roles selected for inclusion--entrepreneur, administrator, artist and caretaker--represent past research by Rohrer (1985), Young (1983), Mintzberg (1973), Downs (1967) and Fleischaker-Suarez (1982), who have identified the most common managerial roles in the arts. Kotter (1974) identifies five types of mayors, which closely parallel our four arts managers.

A matrix of the four roles details the two parameters by which management roles were decided: artistic creativity/innovation, and access to financial and organizational resources. The basic intellectual skills that form this matrix are imagination and organization. For the purpose of arts management, imagination translates into a manager's ability to produce creative programs, and organization into his/her skill in developing a stable and functioning agency. This matrix in its concept, function, and use is patterned after Svara (1990), who outlines the roles of municipal leaders in four cells on the basis of high and low skills policy initiation and policy implementation.

\section{Role Definitions}

The four roles selected for inclusion are described as:

\section{1) Entrepreneur}

"As entrepreneur, the manager seeks to innovate, to improve his/her organization by adapting it to changing conditions in the environment. Once the need for a new idea has been identified, the manager-as-entrepreneur initiates a development project utilizing his ever-available resources. The project development may involve any aspect of organizational functioning such as public relations, new services, or a staff morale campaign. These projects emerge as a series of small decisions and actions over time. 
They involve use of technical knowledge and conceptual skills" (Fleischaker-Suarez 1982, 222). The entrepreneurial manager may also spearhead a major project or turnaround for the agency if he/she detects either the pressing need for a dramatic change or an unusual immediate opportunity that will greatly benefit the agency. This manager is skillful in the use of making contacts in the arts, political, government, media and corporate worlds in order to gather information--the roles of liaison and monitor. Kotter $(1974,118)$ calls this individual the program entrepreneur because he/she is so closely identified with task accomplishment.

\section{2) Administrator}

The administrative-manager is constantly attentive to all the structural aspects of the organization's resources (staffing, budgeting, facilities, fundraising, and directing) and continues to maintain a standard program for the agency in a predictable and stable manner. Kotter $(1974,115)$ describes this role as the executive or "project-oriented" individual who rules with heavy use of the bureaucratic process in the interest of change over maintenance. $\mathrm{He} /$ she is less concerned, however, with communicating a dramatic sense of forward motion to the organization in the form of an innovation, a vision, new goals, innovative programs or creative solutions to current challenges. The administrative manager is knowledgeable in the skills related to a prudent use of material and human resources.

\section{3) Artist}

The artist-as-manager, closely related to Downs's (1967) zealot or Kotter's (1974) personality/individualist, concentrates more on artistic programming and creative talent, and less on involvement in the organizational and financial aspects of the agency. "He tends to count heavily on an individualistic task accomplishment process and only occasionally on bureaucratic and entrepreneurial processes" (Kotter 1974, 112). The artist-as-manager is foremost a specialist in an artistic area and is in charge of presenting performances or 
exhibitions. Issues of innovative or experimental artistic creation take precedence over matters of organizational structure and environmental pressures. The agency flourishes because of the talent of the creative manager and his/her sense of public taste and acceptance. The agency rests solely on the artistic talent and charismatic personality of the artist-as-manager. The artist-manager combines the skill of the professional performer with the spirit and enthusiasm of a zealot.

\section{4) Caretaker}

The caretaker-manager is painfully aware of the static programming of the agency and the accompanying dwindling resource base, but is personally unable to reverse the downward spiral. Where a caretaker manager runs a fiscally stable agency, he/she tends to have little major impact on the agency, husbanding minor changes that do not test the current strategy of the agency (Kotter 1974). Kotter's (1974) similar mayoral type, the Caretaker Mayor, displays the use of power in the interest of preserving traditional agendas and deferring change (112). The caretaker arts manager attempts to maintain the programming and structure of the agency in the face of limited resources, always hoping that fate or a generous board member will rescue the agency. The manger makes feeble attempts to revive the agency spirit and vision, but, either unwilling or unable to innovate, generally he/she simply minds the store until the eventual demise.

\section{Arts Management}

Arts organizations fall into five basic categories, divided by their mission: Performing Arts, such as music, dance, opera or theatre; Display Arts, i.e., museums, art galleries, specialized societies and libraries; Educational Arts, such as schools, libraries and informal classes; Funding Agencies, such as state arts agencies, local arts agencies, private funding foundations and consortia; and Expansion Arts, encompassing community art centers, artists' cooperatives and craft guilds (Wehle 1975). Added to this list should also 
be Multi-cultural Arts, National and State Service Organizations, Multidisciplinary Arts Organizations, Presenting Agencies, and Publishing Associations (Virginia Commission for the Arts, Agencies in Virginia 1991). Given the diversity of the arts disciplines and the variety of their missions, one might ask what kinds of specialized management skills are required to sustain and program these organizations? What kinds of training, education, experience, skills, contacts and attitudes characterize the managers of these agencies? According to Drucker (1992), management as a relevant topic for non profit agencies is a fairly recent phenomenon:

"Twenty years ago non profit institutions tended to believe that they did not have to 'manage' because they did not have a 'bottom line.' More and more of them have since learned that they have to manage especially well precisely because they lack the discipline of the 'bottom line'... In general there has been a shift from emphasis on the 'good cause' to emphasis on accountability and results" (Drucker 1992, 228-229).

The management of arts organizations does not differ substantially from general management activities as described by Mintzberg (1973). The chief responsibilities of the manager lie in the three areas described by Mintzberg as interpersonal, informational, and decisional skills. The difference between management in the for profit and non profit sectors lies mostly in the use of professional labor and the direction by a volunteer board of directors, as well as in two minor areas, the reluctance to use standard business practices and the need to contend with trustee or director turnover (Rohrer 1985).

Professional involvement in an arts organization means the presence of a trained, experienced creative artist who either doubles as director or who leads the arts programming of the agency. Tension is likely to arise as the agency values and creative goals of the artistic director conflict with standard business practices as envisioned by the administering director. Both talents are vital for success of the organization--the artistic director providing the authenticity for the agency and the administrator providing a secure financial base of operations. An adversarial relationship between these two leaves some 
doubt regarding the true locus of decision making, and conflict regarding the goals and objectives of the organization (Rohrer 1985).

The cause of tensions between artistic directors and business managers stems from the low esteem in which the arts community views a business orientation. The attitude of arts managers toward standard business practices, both in the general society and in the context of arts agencies tends to be negative. Artists tend to see formal management as an inhibiting structure that stifles creativity; they prefer to acknowledge their poor management skills rather than take on the onerous task of learning new ones (Jeffri 1980,188). They have traditionally been content to disregard money as irrelevant, which has caused many arts groups to suffer a poor reputation regarding their business practices. They often delay, default and refuse to pay bills on time (Horowitz 1978, 109). Maintaining a credible business reputation is little valued by many arts groups, who consider it a distasteful, humdrum by-product of producing art. The idea of becoming a professional in certain aspect of the arts also finds little favor with committed artists (Jeffri 1980, 6).

Arts agencies are further characterized by a lack of interest or credibility in the value of helping the agency to grow. The traditional emphasis upon business growth by American business ideology has been lost on arts agencies. While the variety of motives for growth of a business--"organizational self-realization, adventure and risk, prestige and power, executive salaries, profit, cost control, revenues, monopolistic power, stability and survival" certainly have relevancy in some measure to arts agencies (especially regarding survival, prestige and power, adventure and risk, organizational self-realization), arts managers decry business growth as the avenue to fruition (Gasse 1978, Starbuck 1965). The arts manager sees that growth will necessitate bringing a business manager on board who will ultimately have the power to fire the arts manager (Jeffri 1980, 138). In only a few cases is the arts manager senior to the business manager in a large arts agency. Additionally, some arts managers who are also artists are reluctant to expand their agencies, because they will have to sacrifice their individual motives for group goals (Jeffri 1980,5). 
Arts agencies may also refuse to increase the scope of their agencies for fear of appearing to pander to materialism. They display an attitude signaling that success means having "sold out" (Horowitz 1978, 105) and they lack the initiative and confidence necessary for a professional outlook toward marketing their own product and service. For too long, there has been a tradition in the arts of waiting until someone else discovers you (Jeffri 1980, 89).

The use of a volunteer board of directors poses unique problems for a non profit manager. The board, which ultimately is legally responsible for maintenance of the agency, generally has little background or experience in the running of an arts agency, yet it exerts tremendous influence on the manager (Rohrer 1985,6). The board may construct ambiguous goals because it holds vague ideas regarding its legal responsibility and specific tasks (Middleton 1987). Horowitz (1978) finds that arts managers, especially those from an artistic background, tend to be wary of an authority structure, seeing it as posing a real threat to their longevity. They view a board of directors as an impediment to artistic freedom, a group of outsiders (even if in actuality they are friends or associates), who have been brought in to handle aspects of art that they themselves created, conceived and implemented. They are fully aware that these board members, basically artistic illiterates, when initiated into the responsibilities of trusteeship may take upon themselves authority never imagined, nor desired, by the artistic director, including the authority to fire or replace the artistic director. Whereas the artistic director may be accustomed to wielding total centralized power in an agency, a trustee may view the agency as managed best by a professional administrator and the activities of the agency as decentralized best into autonomous units. The difficulties for an artistic director in training and educating a new and constantly changing board of directors is rigorous enough, but the psychological burden of knowing that one must surrender this agency to a group of strangers who have the authority to fire one forces many arts managers to treat their boards of directors casually, informing them of as little as possible and maintaining a constant state of 
disorganization and uninvolvement (Horowitz 1978,14). Obviously, this state of business affairs is not conducive for innovation or entrepreneurial activity--sometimes it defies survival.

Another impediment for the arts manager is the tendency of the board of directors to assume a highly conservative attitude toward the agency's programming and growth. Young (1985) points out that the inherent conservatism of most non profit agencies has at least part of its genesis in the threat of change--the ability to challenge the current order. Schlesinger $(1986,424-425)$ cites the fear of change as that which hinders innovation and preserves the established order in an organization. He demonstrates that the benefits of preserving the old order transcend monetary advantages and speak clearly to a vested interest in one's beliefs, values, social position or prevailing organization. One who would break new pathways must contend with naysayers who cannot be easily silenced or convinced without precedents, statistics or facts. In an innovative situation,

the success of everything depends upon intuition, the capacity of seeing things in a way which afterwards proves to be true, even though it cannot be established at the moment, and of grasping the essential fact, discarding the unessential, even though one can give no account of the principles by which this is done. (Schumpeter 1934 in Schlesinger 1986).

Further reasons for board conservatism lie in the affiliations of the board members, or their social and business peers. Some board members are reluctant to propose or sanction any innovation in the agency for fear of engendering ill will in their social or business relationships.

Rohrer $(1985,7)$ lists two further aspects of cultural management that differentiate it from standard management duties: decision making based on intuitive and trial and error processes instead of standard business practices, and the constant turnover in volunteer members of the board of directors.

Jeffri (1980) points out that arts agencies are slow to accept the necessity of altering their operating procedures, unlike businesses and professionals, who readily accept the notion that change is an inevitable constant in the business environment. Arts managers 
view business practices in such a negative light that they are reluctant to learn and adopt any of the accepted management skills for fear of diluting their idealistic stance. While many arts managers recognize that management may be a proven pathway to survival, they are slow to request training and to disseminate business practices for the arts (Jeffri 1980,6). Arts managers hold tenuous views about the ability of rational business practices to forecast future needs. The practice of rational management relies heavily upon a methodology devised to explain, describe and predict future events (Gasse 1978, 102). For arts managers, who have had little experience with the managerial tasks of assessing the environment and postulating different financial, marketing, and production scenarios, the idea of foretelling the future by extrapolating from the past using statistical or technical means may be completely foreign and frightening. Management is in the business of foretelling the need and markets for products and services. Arts managers seldom think in terms of needs or markets, but more likely in terms of creating programs and meeting production needs. While the two points of view are not necessarily antithetical, they are divergent. Arts managers holding a dim view of running an agency according to charts, graphs, surveys and predictions and are not likely to embrace the belief in rational decision making. In some arts circles, it is believed that intuitive decision-making is better than business-oriented studies (Horowitz 1978, 14).

Artists see change as a negative progression, trading artistic integrity for financial stability. Given the low status of materialism (in theory) among artists, financial stability thus becomes a low priority (Jeffri 1980,5). While arts management faculty at universities (Jeffri 1980,82) stress that the agency and its artistic director must embrace change and growth, the options are couched in the alternatives of producing more art or raising more money (Jeffri 1980,62). Since arts managers are witnessing a cataclysmic change in the survival of arts agencies, the opportunity to change by adopting management practices (vs. potential demise) may be a necessity rather than just an option. For managers who have 
started their own agencies and believe fully in the mission of their art, change to a managerial process may be a radical change (Gasse 1978).

\section{Arts Managers and Entrepreneurship}

Young (1984) discusses the functioning of the non profit manager as an entrepreneur. The role of the agency director is the most pivotal factor in determining the potential for enterprise of the agency (Crimmins and Keil 1983): "An entrepreneurially oriented director will encourage new enterprise, reexamine those in which the organization is already engaged, and diversify the organization's funding base in as many ways as possible" (Crimmons and Keil 1983). Young (1985) states that a manager's influence over an agency is strongest at the beginning of a venture, when he/she is able to exercise the most complete control over the enterprise. The personal characteristics of a manager directly influence the formation and continuation of a new venture, especially the manager's attitude toward business, his education, experience, personal values, and demographics (Bearse 1982, Young 1985). Gasse (1978) has demonstrated that the manager's attitude toward business practices has a vital impact upon his/her willingness to enlarge the scope of business from single-owner to institution. In the case of arts agencies, the personal talents and leadership of a single individual are paramount to success; the loss of a leader may mean extinction (Jeffri 1980). So influential is the leader of an arts agency that the attitudes of this individual toward the practice of business becomes a vital component in the success potential of the agency.

In Rohrer's study $(1985,91)$, which postulated that cultural leaders would not play a major entrepreneurial role in their organizations (leaving that function to their board of directors), the results surprised the researcher. Arts managers performed the role of entrepreneur a major portion of the time, exceeded only by the role of monitor. Her findings indicate that arts directors are the entrepreneurial initiators of change, based on their proximity to information, opportunities and challenges. As a result of their 
entrepreneurial orientation, arts managers spend over a third of their time strategizing for the agency. Rohrer $(1985,91)$ cites a need for arts managers to cultivate strong interpersonal skills along with creativity and the ability to process information.

\section{Entrepreneurial Management}

The term entrepreneur is open to a myriad of interpretations. The earliest description presents a creative leader who produces some irrevocable change in one of five areas of business development: 1) introduce a new product, 2) introduce a new way to produce a product, 3) open a new market for a product, 4) locate a new source of raw materials for the manufacture of a product, and 5) organize or reorganize an industry (Schumpeter 1934, Lachman 1980, Liebenstein 1968, Carland et al. 1984). This description has essentially held constant in the more than 30 studies that have since sampled and defined the entrepreneur (Gartner 1989); however, the role has been broadened to include any major business proprietor (Hartman 1959) or group of business proprietors (Ely and Hess 1937, Lavington 1922), as well as individuals who work within companies to devise creative divisions or solutions (Cole 1959). In general, the term is now applied to any motivated, aggressive individual who starts and owns a new business or a new unit within a business (Hornaday and Aboud 1971, Hornaday and Bunker 1970, Davids 1963, McClelland 1961, Wainer and Rubin 1969, Draheim 1972, Howell 1972, Liles 1974).

The distinction between a manager and an entrepreneur rests on the concept of change. A manager is defined as one who coordinates and directs the policies and processes determined by the goals of the organization while an entrepreneur sets policy, plans and instigates action toward a goal (Litzinger 1965, Hartman 1959). Again, while management is largely a continuous, stable coordinating function, entrepreneurship is a sporadic process characterized by uncertainty and change (Backman 1983). 


\section{Entrepreneurial Process}

Entrepreneurship is a three-to-five part staged process of creating an enterprise, with the stages partially overlapping but including: 1) perception of the opportunity, 2) planning the enterprise, 3) implementing the process in order to begin production, 4) growth and maturity (Quinn and Cameron 1983, Palumbo, Musheno and Maynard-Moody 1987, Kazanjian 1984). The behaviors utilized in these stages differ according to the specific goal, but in general they incorporate conceptualizing the project, strategizing the implementation of the project, motivating staff to actualize the business, and evaluating the results.

Certain characteristics of an organization influence entrepreneurship, such as: 1) agency mission, 2) value systems, 3) creative potential in the agency, 4) technical sophistication of the agency, 5) degree of organized professionalism in the agency, 6) social status of agency, 7) degree of dominance in the field by a few organizations, and 8) ease of entry (Young 1985). Organizational properties tested in this research survey include creative potential, professionalism, and technical or business sophistication of the agency.

Hage and Aiken (1970) list several further organizational characteristics that foster innovation, including greater complexity, less centralization of authority, less formalization, less stratification, less emphasis on efficiency, and heightened job satisfaction. These factors may be found either in young or small agencies or in agencies undergoing dramatic changes. Theorists postulate that greater task diversity in an organization promotes innovation generation and adoption (Wilson 1966). Even agencies that have reached maturity can spur entrepreneurship by "unifying objectives, [fostering] competition, [establishing] deadlines and [assigning] hands-on work" (McCurdy 1991, 314). 


\section{Identifying the Entrepreneur}

There are two primary methods for identifying the entrepreneur: the trait approach, defining the entrepreneur by his/her personality characteristics and background; and the behavioral approach, analyzing the activities and behaviors of the entrepreneur (Gartner 1989). According to the trait approach, an entrepreneur is known by his/her creative business skills, especially the capacity to maneuver strategically for positive business results (Carland et al. 1984). Trait studies define the entrepreneur as a self-confident achiever, a persevering, diligent individual with foresight and the ability to perform positively in the face of a challenge (Hornaday and Tieken 1983, McClelland 1961).

According to the behavioral approach, entrepreneurship is an integral part of the creation of a new business or organization. Economists cite entrepreneurial behavior as the natural outgrowth of a competitive capitalist economy that encourages citizens to employ any legal means to advance their private interests (Wohl 1949). An examination of the behaviors of entrepreneurs reveals that they commonly learn and practice their skills in family businesses, where they assimilate valuable knowledge such as networking to locate resources, information and useful personal contacts (Carsrud, Gaglio and Olm 1986, Cole 1959).

Another method of identifying entrepreneurs uses a combined trait-behavioral approach, which subdivides entrepreneurship into two classes--the artist/craftsman at one pole and the businessman/administrator at the other (Smith 1967, Gasse 1978). These managerial opposites are differentiated by their administrative habits, decision-making processes, and their attitudes toward business, as well as by the type of company they manage. In this research, we are looking for both types of entrepreneurs: the artist craftsman retains the label artist and the businessman/administrator is called administrator. We have added two further types of managers that combine both traits: the entrepreneur, who has both artistic and administrative qualities and the caretaker, who has neither. 
Additional traits associated with entrepreneurs include need to control, sense of urgency, superior conceptual talent, emotional stability (Weish and White 1981), as well as imagination, capacity for innovation, alertness to new opportunities and risk-acceptance (Bearse 1982). Presumably, an organization that hires staff with strong self-actualizing personality traits will become innovative by virtue of the strength of its members (Shepard 1967). It is exactly this ability of the entrepreneur to innovate and strategize that distinguishes his behavior from simple ownership, management or administration (Gartner 1989). 


\section{Entrepreneurship and Organization Life Cycle}

Research indicates that the age and the life-cycle stage of an enterprise impacts heavily upon entrepreneurial behavior, with agency life-cycle more influential than age (Downs 1967, McCarthy 1989, Kasanjian 1984). Quinn and Cameron (1983) display evidence that organization life cycle is a chief determinant in agency behavior. They offer a model of agency life cycle that is synthesized from a population of nine varieties, all featuring sequential development in a series of readily identifiable stages. Downs's model is the most basic, featuring a three-stage development, from emergence to expansion and decline. Quinn and Cameron offer a combined life-cycle model that serves as the basis for the life cycle stages used in this research. They propose a four-stage model:

Quinn and Cameron (1983)

Four-stage Life Cycle Model
Questionnaire

Five-stage Life Cycle Model

correspondence
1) entrepreneurial stage
1) new and emerging
2) collectivity stage
2) growth
3) formalization stage
3) maturity
4) elaboration of structure stage
4) change
5) decline

For this research, Quinn and Cameron's (1983) four-stages were incorporated along with a fifth stage, decline. Quinn and Cameron (1983) address their failure to incorporate decline, citing the possibility that "in mature organizations (after the eiaboration of structure stage) life cycle models break down and change occurs metamorphically and unpredictably. The stages from birth to maturity may be the only predictable ones" (40). The fifth stage, decline, was a necessary adjunct to this research because it was vital to gauge the extent to which economically-pressed arts agencies were considering termination. 
Terms for the questionnaire were adopted from the Virginia Commission for the Arts in order to increase the familiarity of the respondents with the ideas presented. For example, grants, until 1990, were offered in the category "New and Emerging Agencies" and that notation has a unique meaning to the arts managers in this population. The following terms and their explanations were used in the research questionnaire to describe life cycle stages:

1) new and emerging: agencies that were incorporated within the last five years, feature younger managers who feel a sense of mission in establishing the organization

2) growing agencies: agencies that have established some structure by virtue of their longer years of operation, but see their opportunities for expansion and innovation as ahead of them

3) mature agencies: agencies that have significant longevity and community presence, a large staff, budget and performing/exhibiting schedule, tend to greater conservatism

4) declining agencies: agencies that have failed to thrive as a result of decreased audience response, poor management, scant community support or other creative/administrative deficit

5) changing agencies: organizations that are attempting to adapt to a changing environment by evaluation and renewal of their mission/administration/programmatic aspects

Quinn and Cameron (1983) also noted the association of certain managerial features with specific life cycle stages. Stage one: the entrepreneurial or new and emerging organization is affiliated with "flexibility, growth, resource acquisition and the development of external support "(43). Stage two: agency collectivity or growth shows a greater affinity toward "informal communication and structure, a sense of family and cooperativeness among members, high member commitment and personalized leadership" (44). Stage three: organization formalization or maturity features "stability, efficiency of production, rules and procedures, and conservative trends... goal setting and goal attainment, productivity, 
efficiency information management-communication and stability-control" (44). Stage four: elaboration or change is marked by "[a need to] monitor the external environment in order to renew itself or expand its domain" (44). Stage five: decline is not included in Quinn and Cameron's (1983) discussion, but is presumed to be marked by a deceleration of activity, reduction of staff, and attempt to merge or terminate business.

Several aspects of the life cycle relationship to managerial behavior are germane to this research. The relationship between agency life cycle and increasing conservatism becomes evident upon comparison of the effectiveness criteria for stages one and three. Quinn and Cameron (1983) demonstrate that agencies are more likely to innovate when they are young, small and operating in a competitive market that demonstrates rapid technological change. The age and life cycle of an organization feeds directly into the ability of the manager to affect change and innovation. There is a "Law of Increasing Conservatism" inhibiting innovations in aging organizations, often coupled with the "Law of Diminishing Control," which poses that the larger an organization, the weaker the control over its actions (Downs 1967). Downs's theories have never been fully tested, but a review of NASA with special attention to agency deterioration as a result of age largely confirms his thesis (McCurdy 1991). McCurdy finds that increased age is related to an aging work force, increased bureaucracy, reduced involvement in hands-on tasks, reduced ability to innovate and a diminished interest in taking risks. Thus we might expect younger organizations to be more mobile, more receptive to new ideas and methods of an entrepreneurial manager. According to Downs (1967), this is accurate, especially as younger organizations are dominated by motivated, charismatic leaders. Conversely, we anticipate that the sequential staging of agencies from stage one (entrepreneurial or new and emerging) to stage three (formalization, or maturity), will be marked by a diminution in innovation, flexibility and, in the case of arts agencies, creative programming. 


\section{Entrepreneurship and Recession}

The entrepreneur as manager receives special attention in this study because of his/her importance to any agency or industry facing recessionary constraints. For the non profit agency, Young (1985) poses two negative scenarios in which entrepreneurial behavior appears prevalent: the initiative scene, which encompasses a shifting environment, and the problem-response scene, which occurs in an obsolete environment. He also presents one positive scenario, the evolutionary scene, which occurs in a stable environment. Young (1985) cautions that agencies that have relied heavily upon past staffing and methods in a period of change (the initiative scene) will have difficulty adapting to a situational crisis. Similarly, agencies operating without strategic or long-range planning (the problem-response scene) may fall into a critical situation which requires dramatic turnaround management, a form of entrepreneurship.

Shapiro and Sokol (1982) add to the list of entrepreneurial stimuli in a recession, the presence of chronic unemployment, the imposition of import or export controls, the need to find new sources of capital and a need to extract greater productivity (87). Shapiro and Sokol also cite specific negative extremes that incite entrepreneurship such as unemployment, war or persecution (79). The current economic cutbacks in arts funding from government, corporate and private funding sources constitute an extreme and potentially life-threatening situation for many arts agencies, paralleling Young's (1985) problem response scene and Shapiro and Sokol's (1982) negative extremes. According to both theorists, some critical agencies with opportunities and motivation to innovate will develop entrepreneurial miethods to survive.

\section{The Future for the Arts}

For the past thirty years, the arts have been assured of government patronage bolstered by a healthy and growing economy. How will they fare under new, less favorable conditions? Several possibilities exist. The arts will experience a shake-out of 
less stable and less popular art forms, and the field will contract. The first victims of financial instability will be agencies that serve a single client (e.g., Cultural Experiences Unlimited, serving the disadvantaged) and agencies without an ability to generate funds (e.g., Cultural Alliance, which is an arts service organization). Other casualties will be arts fields that are now overpopulated and cannot sustain a regular audience or client base.

Some agencies may decide to combat financial hardships by turning into a for profit, admission-only business that capitalizes on a popular art form. Others will engage in an unrelated business enterprise in fields such as real estate, product or service marketing, retailing, publishing or travel. Some agencies will engage in a merger process with companion organizations that have similar values, mission and culture. Groups of agencies banding together can effect economies of scale in facilities, materials and staffing. New alliances of non profit agencies assisted by for-profit businesses may arise to serve the needs of the community, rather than let it lose pivotal arts agencies. In all arts agencies there will be a paring down of programs, staff, and material to achieve the greatest economies.

For arts managers with entrepreneurial instincts and an aggressive and opportunistic board of directors, there will be opportunities for growth and stability even in a cutback economy. Agencies can plan to produce programs with a greater popular interest in order to reach a wider segment of the admission-paying population. They can devise and implement profit-making adjunct activities that capitalize on the mission of the agency and the embedded expertise of the staff. Managers can take definite steps to inculcate a business orientation into the agency by requiring standard accounting practices, basic market research, rational decision-making methods and strategic planning. 


\section{CHAPTER III}

\section{RESEARCH METHODS}

\section{Population}

There are approximately 580 Virginia arts agencies that have incorporated as non profit agencies under the IRS 501(c)(3) ruling and that perform, present or exhibit on a regular schedule within the Commonwealth of Virginia. The target population for this study included all top-level managers, managing directors, or other-named leaders of 123 agencies located in the three urban Metropolitan Statistical Areas of Hampton Roads, Richmond, and Northern Virginia that have been awarded grants for Fiscal Year 1991 by the Virginia Commission for the Arts (VCA). This target population was selected because its artistic quality and business acumen have been scrutinized by several levels of peer review.

The VCA awards grants based largely upon the recommendation of its six regional panels, which are citizen groups composed of arts-knowledgeable individuals who meet twice annually to review applications from their home areas. Thus, applicants from Hampton Roads are reviewed initially by a panel composed of eight Hampton Roads' residents selected on the basis of their long-standing involvement in and/or knowledge of the arts. Following panel review, grant applications are reviewed by both the VCA staff and the entire Virginia Commission. The dual criteria of artistic creativity and managerial competence comprise the primary concerns of the VCA, the regional panels, and the Commission staff. A positive assessment by this three-tiered VCA process indicates that 
an agency has been found administratively stable, artistically creative, and legally responsible.

This method of selection insured that the target population represented the highest caliber of Virginia arts organizations in terms of artistic output and organizational skill, increasing the likelihood that data could be generalized to urban arts agencies beyond Virginia. By selecting only the most qualified agencies, the study has reduced the likelihood of subject mortality, the drop-out rate due to agency failure. These agencies also offered the best opportunity to analyze entrepreneurial management techniques as well as the dynamics of the urban arts environment.

The final target population consisted of 123 top managers of non profit private and public arts agencies in Virginia's three urban centers--Hampton Roads, Richmond, and Northern Virginia--which were reviewed by the granting process of the VCA and awarded monetary grants for 1991 or Fiscal Year 1990-91.

\section{Research Model}

The research was designed in three stages, demonstrated in Figure 2: to describe managers' roles, focusing on the two variables of creative programming and managerial access to organizational resources; to examine the relationships between these four role types and specific managerial behaviors; and to determine whether there are significant differences between role types that affect agency viability. 
Managerial Roles in Urban

Virginia Arts Agencies

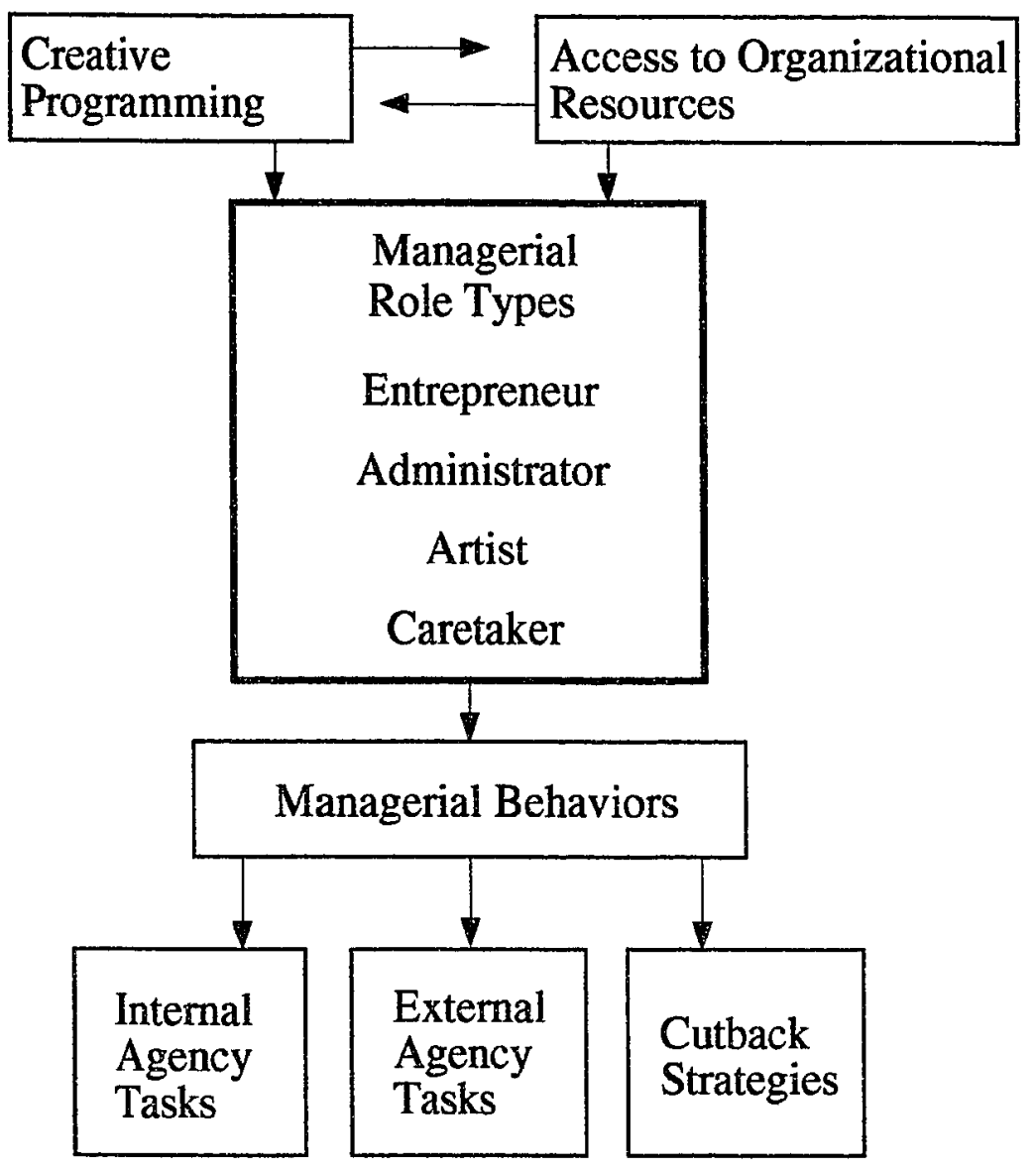

Figure 2. Research Model 
The research model reveals the twin pillars of managerial creativity and managerial access to resources that are central to this study. While in life these two talents range widely, it seems unlikely that any individual could manage an arts agency, however modest, without some measure of both artistic creativity and business resourcefulness. The task in designing this research was to operationalize some specific levels of creativity and access to resources in order to design a tentative typology of arts managers. The next problem was determining whether these qualities, in four different combinations, were associated with distinct managerial behaviors

Creativity, an elusive, abstract and difficult to quantify quality, is measured in this study only by the manager's perception of his/her performance. However, for the variable of access to organizational resources, the study asked for specific responses based on documented evidence.

The research model, Figure 2, outlines the two basic tasks of management: constructing and maintaining a stable functioning organizational framework (Internal Agency Performance) and networking and communicating the agency's presence and service to the greater community (External Agency Performance). The discussion of the research provides support for the selection of these two areas as basic management tasks, and managerial attitudes on business issues are added to the model to enrich the study.

\section{Procedure}

Questionnaires containing a cover letter explaining the purpose of the the research, the promise of confidentiality and a discussion of the potential uses for the results were mailed to individual managers of the 123 selected arts agencies in the three urban areas. A follow-up phone call introduced the researcher and asked for participation by each subject. A date was set for administering the survey by telephone (or, rarely, in person) at a prearranged time. Answers were recorded by the researcher, eliminating the need for the subject to return the survey. Cooperation was extremely good in this research. One 
hundred eighteen managers responded, which is $95.9 \%$ percent of the 123 agencies selected. Managers were willing to respond to nearly all of the survey questions, hesitating only in the area of budgets and estimates of percentages of growth or decline. As a necessary backup, therefore, responses to the fiscal questions were taken from several sources, including managerial responses, VCA funding applications and IRS data submitted on Form \#990 or \#990 PF (required annually of every non profit organization earning annual revenues over $\$ 25,000$ ). IRS data were available under the Freedom of Information Act from both the specific agency and from the IRS. The researcher dealt directly with the IRS, which was able to supply all available documents over a ten week period.

Interviews were conducted during an eight-week period from February 25, 1992, to April 27, 1992, mostly during mostly normal working hours and with several interviews scheduled for evenings and weekends. Respondents normally required a minimum of two contacts before the interview, one by mail with the complete questionnaire and a cover letter and a second by telephone to introduce the researcher and request a telephone appointment.

Reaction to the survey, which lasted from 30 to 90 minutes, was generally positive. The usual interview lasted for one hour, including time to generate a spontaneous discussion of arts management's current problems and direction. Data from the questionnaire was entered on a coding sheet that was compiled electronically to create an SPSSx data file. The analysis proceeded in several stages: frequencies, correlations, crosstabulations, indexes, Guttman scales, and analyses of variance.

\section{Survey Questionnaire}

A six-part survey, designed by the researcher with material adapted from the existing surveys and literature of Covin and Slevin (1986), Gasse (1978), Ogum (1990), Raymond and Greyser (1978), Kotter (1982), Hay (1990), and Levine (1978), posed questions in the following areas: 


\section{Section A: Managerial Demographics}

2. Section B:

Programmatic Creativity

Access to Resources

3. Section C: Internal Agency Performance

4. Section D: External Agency Performance

5. Section E: Cutback Strategy

6. Section F: Attitudes Regarding Arts Management

\section{Survey Validity}

The survey designed for this study extrapolated questions from management literature and several existing surveys that were designed to define and measure entrepreneurship, arts management skills, managerial roles and cutback measures. While no parts of these surveys were used in their original form or as a complete section, certain questions were used as a guide to the questionnaire employed in this research. In all aspects, the questions employed resembled these influential studies and were consonant with the literature that described managerial role and managerial behavior, with specific reference to arts management.

Materials that influenced entrepreneurship questions included:

1) Covin and Slevin. 1986. The Development and Testing of an Organizational Level Entrepreneurship Scale.

2) Ogum, George. 1990. The Impact of Corporate Entrepreneurship on Financial Performance of Nonprofit Organization. 
A survey that influenced questions on managerial attitudes toward business practices was:

3) Gasse, Yvon. 1977. Entrepreneurial Characteristics and Practices. A Study of the Dynamics of Small Business Organizations and Their Effectiveness in Different Environments.

Literature that guided questions in arts management included:

4) Raymond, Thomas J.C. and Stephen A. Greyser. 1978. The Business of Managing the Arts.

5) Kotter, John P. 1982. The General Managers.

Literature that suggested questions on cutback management included:

6) Levine, Charles H. 1978. Organizational Decline and Cutback Management.

7) Hay, Robert. 1990. Strategic Management in Nonprofit Organizations. An Administrator's Handbook.

\title{
STATMENT OF HYPOTHESES AND RELATIONSHIP TO QUESTIONNAIRE AND THEORY
}

\author{
Hypothesis 1
}

Arts managers play a variety of roles. These can be differentiated on the basis of the manager's program creativity and access to organizational resources.

Relationship of hypothesis to survey

Data were collected for the first hypothesis from Section B, Question 1, Artistic and Business Philosophy and Style. Items in Question 1 referred only to managerial 
creativity in programming. Twelve questions comprised this portion of the survey. Only seven questions were retained. Ancillary questions regarding the media, community or board's reaction to controversial arts programs were deleted after a considerable number of interviews demonstrated that most managers shied away from any controversial programs or issues. Questions that addressed levels of creativity in arts managers' agency programming included:

1) Percentage of arts programming different from 1990

2) Percentage of arts programming consisting of original works in 1991

3) Percentage of programming risky for your locale

4) Percentage of programming that is thought to provide leadership in your field, i.e., other agencies will copy these programs

5) Percentage of programming considered experimental

6) Percentage of programming accompanied by educational or interpretive programing

7) Percentage of programming that generated controversy in the popular media.

Data were also collected for the first hypothesis from Section B, Question 2 , Artistic and Business Philosophy and Style. Items in Question 2 referred only to managerial ability to access organizational resources for the agency. There were 10 questions in the Access to Organizational Resources portion of the survey; eight of these were retained to determine a score. One deleted question asked if the manager had an unrelated business activity which generated $10 \%$ percent of agency budget. The answer was so uniformly negative that the question was regarded as non-contributory. A second deleted question asked if the manager anticipated establishing an endowment fund in the future and was deemed too vague to be meaningful. Questions that measured an arts manager's ability to access organizational resources were:

1) Received local government grants last four years 
2) Produced at least $50 \%$ percent of agency budget in 1991 from earned income

3) Produced at least $40 \%$ percent of agency budget in 1991 from grants and donations

4) Have met agency fundraising goals each year for past two years

5) Agency owns fixed assets

6) Received funding from corporate sponsors in 1991

7) Incurred no loans or other debts for past two years

8) Have an endowment fund in place.

\section{Relationship of hypothesis to theory}

Promoting artistic creativity and generating ample organizational resources constitute the heart of an arts manager's responsibility. Discussions of agency and managerial competence by the VCA concentrate solely on these two aspects of behavior.

The expectation that management roles can be captured by four general types derives from the theories of Mintzberg (1973), Young (1983), Svara (1990), Kotter (1982), and Rohrer (1985), all of whom describe managerial types or roles as characterized by typical sets of behaviors. The selection of the four specific arts management roles of entrepreneur, administrator, artist and caretaker derives from the work of Rohrer (1985), who concludes that the most significant roles in cultural agency management are, in her terminology, caretaker, leader, entrepreneur and liaison.

Gasse's (1978) management study finds that entrepreneurship ranges along a continuum, from the "craftsman-entrepreneur" who undertakes and maintains an enterprise alone, to the institutional entrepreneur, who marshals the forces of a bureaucracy and attendant business methods to run an enterprise. In this study, we see that the artist and the entrepreneur act similarly to Gasse's craftsman, while the administrator behaves more like the institutional entrepreneur. 
Questions for Program Creativity were influenced by Covin and Slevin's (1986) entrepreneurial scale, which focused on generally accepted managerial/organizational behaviors such as risk-taking, innovation and proactiveness. These three concepts were used as focal points for questions on programmatic creativity.

Questions for Access to Organizational Resources were compiled by the researcher after discussion with members of the VCA staff and a review of VCA agency criteria on business techniques. The performance measures that were set in these questions, e.g., produced at least $50 \%$ of agency budget from earned income, were determined after VCA review to ensure a realistic expected level of performance. 1

Questions on Managerial Attitudes toward Business were adapted from Gasse's (1978) Business and Managerial Ideology Scale, which includes items on managerial attitudes toward business. Items used by Gasse $(1978,69)$ in his Managerial Ideology Scale were pretested and refined until he derived a high degree of correlation between items in the scale. Gasse also selected only items correlating highly with the total score achieved by summing the individual correlations. The Managerial Ideology Scale also demonstrated a high level of reliability, as examined by a test-retest method, which correlated at a level of .88. (Gasse 1978, 74). On the "Kuder-Richardson for total" test of reliability, which checks the covariance among all items at the same time, the Managerial Ideology Scale scored .78 (Gasse 1978, 75).

Demographic questions included managers' profile by age, gender, race, education in arts or business, arts management experience, and salary range. Demographic questions also covered agency characteristics such as including structure, agency type, staffs, longevity, lifecycle, and revenues (total gross revenue, percent of earned income, contributions, percent of contributions, percent of grants, and percent of profit or loss). 


\section{Hypothesis 2, Part One}

The arts agency's internal functioning will be affected by its leader's arts management role.

\section{Relationship of hypothesis to survey}

Data for hypothesis 2 were collected from Section C, Internal Agency Performance, questions 1-4, with all subquestions. The activities of planning the agency's goal and mission, developing a cooperative organization, establishing basic management techniques and instituting planning techniques were all covered here.

\section{Relationship of hypothesis to theory}

Questions on internal tasks of management were derived from Raymond and Greyser (1978) and Drucker (1992), who outline some pivotal managerial tasks for an arts agency or any non profit agency. They pose the central tasks of an agency as "goal and mission setting," or defining an artistic niche and assembling a committed, like-minded board of directors. The authors emphasize the importance of creating an organization structure capable of fulfilling the varied and discrete tasks of arts management, including forming a budgeting committee and installing board members with useful professional skills.

Raymond and Greyser place great value in marketing for an arts agency, in addition to the more conventional duties of budgeting and grant writing. They stress planning on a long range and strategic level as vital to the necessary effort of enlarging an agency's size and scope. 


\section{Internal Agency Management}

1) Organizational purpose, mission and values

Agency goals in the arts can include artistic quality, creation of new works, support of regional/area artists (performing or visual) and/or arts in education. Agency values in the arts, a broader mandate, can include organizational growth, administrative efficiency, artistic quality, citizen accessibility, artistic opportunity, artistic diversity, financial survival, or artistic creation. The organizational purpose should be defined clearly by the manager and the board of directors in terms of artistic niche, target audience, artistic approach, and agency values. An agency that cannot target its purpose and values clearly runs the risk of misplaced marketing efforts, competing or ambiguous goals, and/or misplaced artistic emphasis. Drucker (1992) points out that the agency mission and goals should be focused on action both in their concept and their specific objectives. "They [the administrators and board] avoid sweeping statements full of good intentions and focus, instead, on objectives that have clear-cut implications for the work their members perform-staff and volunteers both" (205). He finds that the path to success for agency management "is not to talk about its function, but to organize its work" (209).

The goals of the agency are linked inextricably with the board's and leader's goals and values, as well as with the culture and age of the agency. Downs (1967) proposes that the type of firm or bureaucracy, innovative or conservative, and its age exert a major influence on the style of management. He finds it unlikely that new and emerging firms will be staffed by conservative or risk-averse leaders; however, he continues to say that there are ways in which mature firms can reinvigorate themselves, largely through spin-off ventures, expansion or assumption of a new agenda (Downs 1967). This supposition, tested by Smith and Miner (1983), confirmed that there is a link between managerial opportunism and organizational growth. It is possible, then, to view long-established 
firms/agencies as inhospitable to innovative or entrepreneurial behavior on the basis of age, conservative behavior, and ingrained value systems.

\section{2) Effective Organization}

Decision-making as practiced by both the trustees or board of directors and the artistic or managing director is the crux of sound organization. Trustees are required to take an active role in running the organization, especially in the areas of policy determination and resource generation--and as the two mesh, the leaders realistically determine its programs and services. Trustees provide the necessary link between the community and the arts organization, promoting the mission of the organization to the community and relaying audience needs and preferences to management in a position called "boundary-spanning" (Middleton, 1987). The special professional skills for which trustees are selected should be paramount in the policy-making process. Trustees should rely on sound management principles rather than quixotic or summary decision-making. Most non profit boards fail to see their chief responsibilities as overseeing the manager and directing policy formation (Middleton, 1987). Drucker (1992) adds that the board needs to select a manager who will work collegially with the board, in fact assuming responsibility for those areas in which the board chairperson is weak or disinterested (222). The manager must insure sound management, involving staff and Board members in specific and measurable tasks, including realistic budgeting and planning for the longevity of the agency. While trustees should defer to the director on matters of artistic discretion, they must make sure that the agency has instituted defensible management practices by assigning to themselves the oversight responsibility. "In the effective non profit institution, every board committeeindeed, every board member-accepts a work program with specific achievement goals" (Drucker 1992, 223).

Arts agencies fall into a unique business category in that the spirit, creativity and dynamism of the organization may devolve from the special talents of one inimitable 
individual (Raymond and Greyser 1978, Crimmons and Keil 1983). This individual has, by precedent, been the artistic director. In recent times, however, the need for a business orientation has changed the model of an artist-driven agency to a management-driven agency. When arts and other non profit organizations outgrow the "seat-of-the-pants" style of the artist/advocate, they can evolve into the institutional style of organization (Gasse 1978, Jeffri 1980). When an organization is plagued by frequent financial crises, loss of the artistic director, and/or weakened financial credibility in the community, management theorists often suspect an agency in transition between individual management and institutional management (Raymond and Greyser 1978).

A model that is gaining credence is that of the dual management -artistic director in cooperation with the business director, usually with the latter in charge. Indeed, Jeffri (1980) notes that the business manager may command a larger salary than the artistic director for his/her duties, which include ensuring sound management and fiscal administration especially in the area of continual fund raising. She also notes that this may be a necessary survival tactic for the 1990 s.

\section{3) Management Practices}

Areas particularly vulnerable to management instability in the current environment include realistic budgets, effective fund raising and the development of sophisticated marketing plans. Raymond and Greyser (1978) suggest that arts agencies look for marketing opportunities by developing and promoting current services or looking for new audiences. They also need to increase their earned income potential. "Product marketing strategy can mean developing new offerings for existing markets, finding new markets for existing products or introducing new products to new markets" (Raymond and Greyser 1978). They recommend that the traditional tools of marketing, the "marketing mix," be applied seriously to arts agencies and their offerings. 
Hypothesis 2, Part Two

Managerial roles in the arts will affect the relationship between the agency and the larger environment.

\section{Relationship of hypothesis to survey}

Data for hypothesis 2 were collected in Section D, questions 1-4 of the survey, which covered lobbying for the arts, bringing the agency to the community, coping with competition in the arts world, and assessing the local/regional economy.

\section{Relationship of hypothesis to theory}

Questions on external management performance or the environmental tasks of the manager were influenced by Kotter (1978), who describes this as a series of dynamic interchanges between the manager and a variety of publics. His general comments and recommendations on managerial behaviors are adapted for arts managers.

It is reasonable to assume that the arts manager, as head of a non profit organization that gathers a significant portion of its resources from community and state support, reports systematically to all present and potential funding agencies regarding his/her agency's programs, audience response, and objective evaluations. Theoretically, an arts manager responds to his/her larger mission of keeping the arts in the foreground of the political and civic leaders by scheduling periodic meetings with local, state, and even federal legislators. $\mathrm{He} / \mathrm{she}$ can thus convey the message and the condition of all the arts with a special emphasis on his/her own situation.

In a similar fashion the arts manager can maintain a constant visibility in his/her respective community by scheduling the staff and board members for appearances at local events. This could include not only appearing for civic events, but also conducting a 
constant and consistently high-level media campaign, participating actively in several major civic groups, and networking with community power leaders to promote the agency.

Marketing is emphasized as another theoreticaily significant area for a proactive arts manager. Marketing studies could tell a manager the agency's strengths and weaknesses and provide a basis for comparison with competing arts groups. Such studies could compare price ranges and competitive attendance figures in the arts and assess an agency's name recognition in the broader community.

A final environmental task that the manager could perform might be to extend the scope of agency fundraising from individuals and institutions to small businesses and corporations. The manager could also utilize computer capabilities to establish a business/corporate data base, track fundraising efforts, and maintain updated records on corporate movement.

\section{External Agency Management}

1) Arts management and community relationship

Arts managers are responsible for setting an image of the agency in the community both by public relations, grant writing, fund raising, and serving as spokesmen. Hay (1990) outlines the strategies for image improvement as requiring quality presentations, positive attitude of staff and volunteers, media coverage, image surveys, civic involvement by management and trustees, and an evident concern for the quality of life in this community. While profit is the prime motive for most for-profit firms, quality of life is a significant objective for non profit agencies and public agencies (Stevens 1985, Hay 1990).

\section{2) Resource Availability}

The maragerial task of securing a continuing supply of resources for that arts agency is paramount and ever-present. While the United States has an unstated policy of arts support through the tax exemption and the institution of the National Endowments of 
the Arts and Humanities, as well as state and local arts commissions, the sober realities of a deficit economy are eliciting murmurs of reduced or elimination of support for the arts in the near future, which Levine (1978) calls political vulnerability. Resources from governments are not the only victims. Corporate donations are declining precipitously due to reduced profits or even deficits in corporate revenues. Individuals have likewise reacted to a recession with stringent private budgetary restraints.

Arts managers will need to plan with exquisite accuracy the probable sources of revenue as well as to cooperate with businesses and other arts agencies in order to achieve economies. Funding is more likely to be sought from earned income rather than grants or donations, and agencies will have to find ways to plan cash flow and loan sources in order to meet their budgetary needs.

Young (1985) finds that organizational change in non profit agencies is dependent heavily upon the current economic environment. In the late 1980 s the environment was characterized by scarce resources, a desire for greater efficiency, better managerial training, and more enterprising individuals who were prepared to set organizational changes into motion, and so it continues into the $1990 \mathrm{~s}$.

\section{3) Competitive Environment}

Artists in the visual arts are faced with peculiar problems regarding competition. Whereas most business firms market their products to a specific target, gearing the production and price accordingly, artists find that if they lower their prices too much, they lose respect and appear to be worthless (Jeffri 1980,96). If they maintain a non profit status, they signal to buyers that they don't really want to make money (Jeffri 1980,97). If, however, they ascribe sincerely to good management practices, they are accused by other arts groups of selling out, trading their art for success, profit and consumer pleasure (Jeffri 1980, 187). 
Non profit agencies, like their counterparts in the proprietary world, face competitive pressures for the use of their services or products (Hay 1990). While an arts agency may not have a direct rival for consumers, it may be part of a leisure activity offering both in the proprietary and the non profit sectors. An arts agency competes directly for every consumer's leisure time and discretionary funds. The agency needs to strategize carefully to promote products and services that are unique, well-focused and desired by an identifiable segment of the population. This kind of research may be anathema to agencies who continue to defend a particular artistic ideology despite negative intimations from the community. It may take a highly innovative and creative agency to preserve its artistic mission, values, and goals, while placing its products/services into a diverse and competitive marketplace.

4) Regional economic stability

The most significant environmental factor for the creation and growth of an arts agency is the stability of the local economy. Managers in every field need the opportunities found in a dynamic economy, either positive or negative (Bearse 1982). Managers also need a diverse economy that can sustain new enterprises. They require resources of information, capital, facilities, services, and personnel. They need a government that supports entrepreneurism in the forms of tax benefits, favorable regulations, and policies conducive to new ventures as well as an economy free of political or social barriers (Bearse 1982).

In more general terms, Herbert Simon (1957) offers the generalization that environment guides rational behavior (Holt 1987). Simon postulates that the denser urban environment provides a greater diversity, allowing for a full exchange of ideas and cultures. One is prompted to start a business or agency at a lower cost and risk with a large, sophisticated and diverse labor force and an equally large and diverse audience (Simon 1957, Douglas 1980, Meier 1962). 


\section{Hypothesis 3}

Arts managers will vary by role type in instituting cutback and retrenchment strategies.

\section{Relationship of hypothesis to survey}

Data for hypothesis 3 were collected in Section E of the survey, where 15 items asked managers to describe their behavior in increasingly drastic levels of retrenchment.

\section{Relationship of Hypothesis to Theory}

Hay (1990) claims that non profit organizations compete for funding and an audience not only with other similar non profit organizations, but also with the for profit world. As the economy shrinks, individuals discover the need to divide their leisure-time dollars between the fine arts and popular entertainments. The entertainment industry, which is well-versed in high-level business techniques, such as marketing and audience response studies, has a proven record of success.

Hay $(1990,198)$ also asserts that agency life/cycle, a four-stage process including development, growth, maturity and decline, affects greatly an agency's ability to compete in the marketplace. As agencies feel the added burden of decreased public and private funding, they may see their life/cycles as declining. At present the crisis has certainly placed most arts agencies in a cutback position.

\section{Cutbacks in the Arts}

As discussed earlier, the life cycle phases of any organization are proposed to include at least entrepreneurship, collectivity, formalization, and and elaboration of structure (Quinn and Cameron 1983). Kreps (1989), who defines life cycle of 
organizations as a four-step model (emergence, maintenance, restructuring, and termination) adds a final and terminal phase. He demonstrates that "many ostensibly existing organizations fail in a relatively short period of time--and with considerable regularity from one modern form to the next" (103). Kreps adds, however, that "grouping firms and other organizations into populations of the same type is one way of holding on to the presumably enduring quality of organization" (102). This reference to the mortality of organizations and their coping mechanisms to avoid decline is particularly relevant to this research. The researcher here is looking for the means by which hard-pressed arts agencies are sustaining themselves during this financial drought.

Levine (1978) finds declining organizations most commonly in the mature phase of their life cycle, staffed by a conservative population and plagued by a scarcity of resources and a heightened level of competition. Termination can be heralded by an immediate and unforeseen crisis or by a longer period of decline. Reasons for decline range from loss of a pivotal manager, environmental changes, societal changes, obsolete management practices to a failure to service the major interest group adequately (Bartunek 1988). In the public sector, decline may accompany poor decision-making, failure to increase the scope and size of the agency or faulty political alliances (Levine 1978). Public agency failure can be caused by problem depletion, when the problem no longer exists or requires treatment; environmental entropy, when the base of financial support fails; political vulnerability, caused by budget cuts; and organizational atrophy from poor management (Levine 1978). Several of these causes of organizational decline apply to arts agencies, especially political vulnerability and organizational atrophy (Levine 1978, 321).

Political vulnerability is the most immediate threat. If all levels of governments withdraw their tax exemptions or their arts subsidies, many agencies will not survive. Government funding is predicated upon several premises: 1) that the fine arts (as opposed to the popular arts) are a worthy human endeavor that cannot be self-supporting, 2) that the arts are a protected expression of a free society, 3) that certain art forms are fragile, e.g., 
native and multi-cultural arts, and need government encouragement, 4) that the arts constitute an integral part of a basic education at the elementary and secondary levels, and 5) that the arts are a catalyst to economic development. In the current and recent administrations, however, the arts have been attacked as promoters of amorality, subsidized elitism, and frivolous expenditures. Without the guaranteed support of government at many levels and the promise of a link with economic development, the arts find themselves bereft of both stable funding sources and a rationale for continued business support. With a declining base of corporate and private funding, the arts are indeed in a perilous financial state.

\section{Arts Agency Decline}

Organizational atrophy is an ever-present threat in an arts organization. Unlike profit-making organizations, arts organizations cannot take cutback steps such as borrowing money, differentiating the product, and increasing marketing research and strategies. Nor can they use the strategies of public organizations, which can face decline by changing leadership, reorganizing an agency, eliminating programs and adopting user fees (Levine 1978). They can largely implement reductive cutback measures such as reducing staff size, closing and consolidating facilities, and merging with other organizations.

The non profit arts agency also faces certain cultural and structural impediments, such as the difficulty in borrowing money to engage in new and innovative ventures due to lack of agency longevity and/or tangible equity. Without venture capital, it is infinitely more difficult for the arts agency to initiate a profit-making venture (Skloot in Powell 1987), to engage in sophisticated marketing research, to enlist first class staff and performers/exhibits, and to install a workable advertising campaign. Further, the arts agency, supported by public funds, is generally loathe to charge an admission that would 
truly cover program and production costs. To instigate such realistic pricing would eliminate a great part of the potential audience for an agency.

Again, the arts agency is likely to experience a constant turnover in personnel during a recessionary period, leaving the leadership of the agency at a critical time in temporary and less expert hands. Tension between the business manager and the artistic director regarding the goals and mission of the agency may hinder the ability of the agency to face the recessionary threat realistically. The quest for a suitable peace between these warring factions of artistic freedom and management skills during a critical period requires that agencies adopt a new business posture, one featuring experimentation, some risktaking and some innovation, as well as the generation of some more money (Jeffri 1980, 7).

Organizational atrophy in arts agencies can also appear in a unlikely form--as hostility toward business competition. Because arts agencies have long been subsidized by several different levels of government, freeing them from the pressures of the marketplace, they may be decidedly complacent regarding competition, either from similar arts groups or a wide range of other leisure-time activities and entertainments. More aggressive managers, recognizing the threat of a permanent decline in grant money, are trying to maintain a competitive edge by using agency mergers, business consortiums or by hiring an umbrella management agency to market their products/services. These tentative acts indicate a new awareness of the need for administrative innovation in order to survive.

Another unfortunate aspect of the lack of involvement in business affairs by arts managers is a tendency to rely on luck or fate to run the agency, if finances or productions fail to succeed. In many types of agencies, the expectation exists that, in a crisis situation, the agency will be rescued--either by an individual with a generous grant or by a board of directors that recognizes and deflects the critical situation (Horowitz 1978). While arts managers agonize about the constant lack of funds, some do little to remedy the situation until a crisis occurs. Even when faced with a deficit budget, some arts managers believe 
that they should not compromise their artistic freedom by altering their planned program elements (Horowitz 1978, 108). This combination of artistic intransigence and business naivete can plunge an agency into a perilous situation if grants and donations fail to materialize. 
Hypothesis 4

Arts agency viability will vary by managerial role type.

\section{Relationship of hypothesis to survey}

Data to determine an agency's viability were collected from items in Section A, questions $1-19$, as well as from budgetary data collected following the survey from the Internal Revenue Service's tax return for non profit agencies, Form \#990. Viability was measured by duration of operation since incorporation, size of budget, agency life cycle, service and performance change over two years, sizes of agency staff, including business, artistic, volunteer and board of directors, and percentage of profit or loss.

\section{Relationship of Hypothesis to Theory}

This hypothesis addresses a group of variables that define viability as the ability to build, and sustain a sufficiently large and complex organizational structure able to adapt to a changing environment. The hypothesis appears to favor the administrator role type, which more easily envisions and creates such an organization. The hypothesis derives from the theories of Smith (1967), who concludes that the "opportunistic-entrepreneur" (which we have labeled the administrator), when associated with an adaptable firm vs. a rigid organization, reaps an augmented growth rate compared to the "craftsman-entrepreneur" (which we have labeled the entrepreneur).

We have added another dimension, artistic and program creativity, to Smith's theory. Smith maintains that the vision and perspective of the leader greatly influences a small organization, especially in a beginning stage. Arts organizations are seen to be also wholly dependent upon the artistic vision of the leader. It is suggested that, regardless of 
the strength of the accumulated organizational resources, agencies cannot survive without demonstrated and consistent program creativity. This hypothesis contends that the entrepreneurial manager's artistic and proactive instincts, along with his/her innate resourcefulness will promote greater agency viability.

\section{DATA ANALYSIS}

Data analysis was performed in several stages, producing frequency tables, correlation matrixes, crosstabulations, indexes, unidimensional scales (Guttman method), and analyses of variance.

All variables, with the exception of demographics, were dichotomized by assigning dummy variables of " 0 " to the two levels of disagreement and " 1 " to the three levels of agreement. Data were collapsed only after viewing the distributions to be sure that the data would not be skewed by this procedure. Demographic variables were collapsed and recoded after a careful review of the initial results to provide a more succinct view of those data.

The process used to create the four roles follows:

1) The seven variables that described creativity and the eight variables that described access to resources were plotted on histograms to determine range and distribution. Using the means and standard deviations, values were divided into "high" (all responses above the mean) and "low" (all responses below the mean). 
2) The two variables were cross-tabulated, creating four categories, seen in Figure 3. These four categories were identified by their characteristics as follows:

- High creativity, high access to resources

- Low creativity, high access to resources

- High creativity, low access to resources

- Low creativity, low access to resources

3) Each respondent was categorized depending upon the level of creativity and access to resources. These four property spaces were assigned four role types. 
Division of Respondents into Four Roles by Programmatic Creativity and Access to Organizational Resources

Creativity

Low High

\begin{tabular}{|c|c|c|c|}
\hline \multirow{3}{*}{$\begin{array}{l}\text { Access to } \\
\text { Resources }\end{array}$} & Low & Caretaker & Artist \\
\hline & & & \\
\hline & High & Administrator & Entrepreneur \\
\hline
\end{tabular}

Source: Adapted from Svara (1990), Kotter (1982)

Figure 3. Four Managerial Role Types

\section{Index Construction}

Indexes were created to produce composite measures of single concepts reflected in the survey sections of Creativity, Access to Resources, Internal Agency Management Tasks, External Agency Management Tasks and Cutback Strategies.

Babbie (1986) indicates that the "primary purpose of index construction is to develop a method of classifying subjects in terms of some variable" (368). A respondent's score on each of the six computed indexes in this survey indicates the degree of his/her involvement in this management task. Babbie $(1986,362)$ states "an index is constructed through the simple accumulation of scores assigned to individual attributes." Items selected for the index must meet the tests for face validity, unidimensionality, and strength of relationship by correlation coefficients ( $364-365)$. 
Indexes were constructed by examining the correlations among items thought to comprise a construct measure. Items were selected for inclusion based on a criterion of $\mathrm{r}=$ less than .50 and through an examination of item to item and item to index, looking for substantial correlations. Items were selected based upon their having a significant correlation at $p=.05$. Items with correlations exceeding .50 were excluded because of problems of multicolinearity. Each item in the index was weighted equally. Cases were scored on each of the items to produce an index score for each case. As seen in Tables 2 through 7 , items in the six indexes were strongly related to the index itself at an item-toindex correlation equal to Pearson's $r=.80$ or less. The strong relationship of items-toindex in each table further validates these composite measures.

Babbie $(1989,403)$ points out the necessity for demonstrating external validation as well as item-to-index or internal validation. He defines external validation as the repetition of an indexed response at another point in a questionnaire. For example, an arts manager who displays administrative skills on the Access to Resources Index should demonstrate this enhanced administrative ability elsewhere in the questionnaire. There were numerous examples of external validation in this study; role types in most instances provided responses to questions on managerial behavior that were consistent with their indexed scores on creativity and access to organizational resources. For example, Administrators, who scored high on the Access to Resources Index, similarly scored high on items relating to Internal and External Agency Management Tasks. 
Table 2.--Correlations of Items to Index on Creativity

\begin{tabular}{lc}
\hline \hline Variable & Creativity Index \\
\hline Changed program format 1991 & $.42^{* *}$ \\
Produced original work 1991 & $.70^{* *}$ \\
Produced risky programs 1991 & $.60^{* *}$ \\
Displayed programmatic leadership 1991 & $.56^{* *}$ \\
Produced experimental programs 1991 & $.72^{* *}$ \\
Produced educational programs 1991 & $.49^{* *}$ \\
Programs generated media controversy 1991 & $.51^{* *}$ \\
\hline
\end{tabular}

* Significant at $p=<.050$

** Significant at $p=<.010$

Table 3.--Correlations of Items to Index on Access to Resources

\begin{tabular}{ll}
\hline Variable & Access to Resources Index \\
\hline Met fundraising goals 1990-1991 & $.60^{* *}$ \\
Agency owns fixed assets 1991 & $.55^{* *}$ \\
Received corporate funds 1991 & $.52^{* *}$ \\
Agency had no loans, deficits, 1990-1991 & $.41^{* *}$ \\
Agency has endowment fund 1991 & $.49^{* *}$ \\
Agency grants and donations equal 40\% revenue 1991 & $.38^{* *}$
\end{tabular}

* Significant at $\mathrm{p}=<.050$

** Significant at $\mathrm{p}=<.010$ 
Table 4.--Correlations of Items to Index on Internal Agency Management Tasks

\begin{tabular}{lc}
\hline \hline Variable & Internal Agency Management Index \\
\hline Manager has autonomy with board & $.38^{* *}$ \\
Manager/ board determine goals, objectives & $.33^{* *}$ \\
Manager evaluates goals, mission annually & $.49^{* *}$ \\
Professionals sit on board & $.31^{* *}$ \\
Separate board committee on budgeting & $.44^{* *}$ \\
Manager and board set fundraising policy & $.37^{* *}$ \\
Performed market audit in last two years & $.49^{* *}$ \\
Performed market program analysis last two years & $.50^{* *}$ \\
Subscribe to arts management journal & $.44^{* *}$ \\
Identify long-term facilities needs & $.42^{* *}$ \\
Have endowment fund established & $.45^{* *}$ \\
Separate planning committee on board & $.53^{* *}$ \\
Attend annual arts management conference & $.53^{* *}$ \\
\hline
\end{tabular}

* Significant at $\mathrm{p}=<.050$

** Significant at $\mathrm{p}=<.010$

Table 5.--Correlations of Items to Index on External Agency Management Tasks

Variable External Agency Management Index

Lobby local government

Lobby state government

$.43^{* *}$

Meet state legislators annually

$.56^{* * *}$

Contact federal legislators annually

Executed joint advertising with a corporate sponsor

$.64^{* * *}$

Manager belongs to $>1$ civic organization

$.65^{* *}$

$.48^{* *}$

$.39^{* *}$

Staff appears in community events

$.56^{* *}$

Agency has quality media program

$50^{* *}$

Manager networks in community

$.62^{* *}$

Performed market study of agency strengths and weaknesses $\quad .48^{* *}$

Manager attended 1991 regional or local arts management seminar $.54^{* *}$

Manager conducted agency name recognition study $1991 \quad .46^{* *}$

Manager assessed 1991 local economy $.63^{* *}$

Manager updated local corporations for fundraising $\quad .54^{* *}$

Manager looked to expand agency sites $1991 \quad .33^{* *}$

* Significant at $\mathrm{p}=<.050$

** Significant at $p=<.010$ 
Table 6.--Correlations of Items to Index on Active Cutback Strategies

\begin{tabular}{ll}
\hline \hline Variable & Active Cutback Strategies Index \\
\hline Introduce new services & $.50^{* *}$ \\
Revise prices & $.60^{* *}$ \\
Increase fundraising effort & $.54^{* *}$ \\
Institute new locations for programs & $.60^{* *}$ \\
Increase volunteer force & $.64^{* *}$ \\
Perform market study to identify current target market & $.41^{* *}$ \\
Perform market study to identify new markets & $.38^{* *}$ \\
Merge with or absorb another agency & $.35^{* *}$ \\
\hline
\end{tabular}

* Significant at $\mathrm{p}=<.050$

** Significant at $p=<.010$

Table 7.--Correlations of Items to Index on Passive Cutback Strategies

Variable Passive Cutback Strategy Index

Cut the budget $.65 * *$

Locate cheaper supplies and equipment $.57 * *$ Lay-off staff $.60 * *$

Appeal to board for financial rescue $.65^{* *}$

Reduce services and performances $.51^{* *}$

Consider terminating agency $.48^{* *}$

* Significant at $\mathrm{p}=<.050$

*** Significant at $\mathrm{p}=<.010$

Several indexes were moderately correlated with each other, as revealed in Table 8, including Access to Resources with Internal Agency Management Tasks ( $r=.43)$ and External Agency Management Tasks $(r=.34)$. The Internal Agency Management Tasks index was strongly correlated with the index for External Agency Management tasks $(r=.61)$. The Active Cutback Strategies index was moderately correlated with the index for Internal Agency Management Tasks $(r=.34)$ and External Agency Management Tasks 
$(\mathrm{r}=.43)$. Active and Passive Cutback Strategies indexes were moderately correlated $(r=.31)$.

Table 8.--Correlations, Means, and Standard Deviations of Six Indexes by Each Other

\begin{tabular}{|c|c|c|c|c|c|c|}
\hline Index Name & $\mathrm{Cr}$ & Rs & Im & $\mathrm{Em}$ & PCI & $\mathrm{ACI}$ \\
\hline $\mathrm{Cr}$ & 1.00 & -.10 & -.05 & .01 & .01 & .07 \\
\hline Rs & & 1.00 & $.43^{*}$ & $.34 *$ & .06 & .14 \\
\hline Im & & & 1.00 & $.61^{*}$ & .03 & $.34 *$ \\
\hline $\mathrm{Em}$ & & & & 1.00 & .12 & $.43^{*}$ \\
\hline PCI & & & & & 1.00 & $.31 *$ \\
\hline $\mathrm{ACI}$ & & & & & & 1.00 \\
\hline $\mathrm{Mn}$ & .41 & .36 & 6.6 & 7.0 & 3.1 & 2.7 \\
\hline Std & .49 & .48 & 2.5 & 3.8 & 1.8 & 1.6 \\
\hline \multicolumn{7}{|c|}{$\begin{array}{l}\text { Index Description } \\
\begin{array}{ll}\mathrm{Cr} & =\text { Creativity Index } \\
\mathrm{Rs} & =\text { Access to Resources Index } \\
\mathrm{Im} & =\text { Internal Agency Management Tasks Index } \\
\mathrm{Em} & =\text { External Agency Management Tasks Index } \\
\mathrm{PCI} & =\text { Passive Cutback Strategies Index } \pi \mathrm{P} \\
\mathrm{ACI} & =\text { Active Cutback Strategies Index }\end{array}\end{array}$} \\
\hline
\end{tabular}

* Significant at $p=<.050$

** Significant at $p=.010$

\section{Guttman Scales}

The items of the indexes were entered in Guttman scalogram analyses, achieving data reduction and summary presentation (Babbie 1986, 380). These analyses facilitate further data reduction and summary. Scales differ from indexes in that, while incorporating many of the same variables, they provide rank order measures in which a single score provides information on the total pattern of response to scale items. For example, a score of three would indicate positive responses to the first three items and negative responses on the remaining items (or items). 
For each scale, items that correlated with the index at .30 or greater were included. Scales were evaluated using coefficients of reproducibility, which "measure the degree of accuracy with which the statement responses are reproduced from knowledge of the total score(s) alone" (Edwards 1957, 188). A coefficient of reproducibility of .90 , according to Edwards, constitutes reason to accept the validity of these statements as a scale (Edwards, 191). A minimal marginal reproducibility (MMR) is necessary to determine the minimum coefficient of reproducibility (Edwards, 192).

\section{Problems}

1. The large number of variables in the questionnaire presented some difficulty.

2. The large number of respondents for a telephone survey and their scattered locations across Virginia posed difficulties in contacting and securing compliance. 


\section{NOTES}

1. There were parameters set for certain variables concerning generating revenue on the basis of discussions by the researcher and the VCA director and staff. The theory utilized for these parameters was that they should represent the percentages of revenue an agency might generate while maintaining a stable operation. Experience suggested that an agency that could not raise half of its operating revenue from earnings was likely to be in financial jeopardy as contributors and granting agencies might judge the agency unlikely to survive.

The variables involving percentage of earned income and percentage of income from grants and donations were selected as follows: 1) percentage of income earned was set at $50 \%$ percent, 2) percentage of income from grants and donations was set at $40 \%$ percent. Allowance was made for the possibility that an agency might earn $10 \%$ percent of revenues from unrelated business activities.

Skloot (in Powell 1987) discusses the reasons for the rise in non profit enterprise as a legacy of the Reagan administration, which reduced federal spending on programs heretofore delivered by non profit organizations (380). He mentions that a 1983 study by Crimmins and Keil found that a small number of non profit agencies earned over $10 \%$ percent of their revenue through enterprise. This reference and the VCA determined the parameters of the question on "unrelated business income." 


\section{CHAPTER IV}

\section{POPULATION FINDINGS}

Introduction

This chapter summarizes and discusses the demographic, educational and financial profile of the survey population, managers and agencies, in response to the following research questions:

1) What is the demographic profile of the arts managers in the target population, including age, race, region, gender, education, major field in art, business or management education, administrative experience, and salary range?

2) What are the characteristics of the agencies in the target population, including structure, agency type, staffs (artistic, business, volunteer and board), longevity, lifecycle, and revenues, including total gross revenue, percent of earned income, contributions, percent of contributions, percent of grants, percent of profit or loss, budget reported to the IRS, budget reported to VCA on grant proposal, and budget reported on questionnaire?

3) How have arts agencies grown or declined from 1989 to 1991 ?

4) What are the attitudes of arts managers to business management procedures?

The chapter is divided into two parts. Part One presents the profiles of managers and the characteristics of their agencies, followed by a summary of managerial attitudes toward business management. Part Two highlights the findings in the general population of arts managers that anticipate the existence of four separate role types. A discussion of managers by role type, including results of data analysis, appears in Chapter V. 


\section{Part One}

\section{Profile of Managers and Agencies}

\section{Overview of the Population}

The target population in this study included 118 managers of arts agencies who responded to telephone interviews. The total population was 123 agencies, and the resulting response rate was $95.9 \%$ percent. Of the 118 respondents, only 117 represented currently employed managers while one was a former employee.

\section{Managerial Characteristics}

Managers as shown in Tables 9 through 11 were clustered in the age range of 36-45 years with small a percentage at the low end, 20-25, and a sizeable group over 55. Women were over-represented (61.5\%) among managers and minorities including AfricanAmericans (5.1\%) and Hispanic-Americans (.8\%), were underrepresented, . Respondents were fairly evenly divided between the three major urban centers of Virginia, Hampton Roads, Richmond and Northern Virginia.

Table 9.--Urban Area of Respondents

\begin{tabular}{ccc}
\hline \hline Urban Area $(\mathrm{N}=117)$ & Number & Percentage \\
\hline Northern Virginia & 42 & 35.9 \\
Richmond & 41 & 35.0 \\
Hampton Roads & 34 & 29.1 \\
Total & 117 & 100.0 \\
\hline
\end{tabular}


Table 10.--Age of Respondents

\begin{tabular}{ccc}
\hline Age $(\mathrm{N}=117)$ & Number & Percentage \\
\hline $20-25$ & 03 & 2.6 \\
$26-35$ & 20 & 17.1 \\
$36-45$ & 47 & 40.2 \\
$46-55$ & 28 & 23.9 \\
55 and over & 19 & 16.2 \\
& 117 & 100.0 \\
\hline
\end{tabular}

Table 11.--Gender of Respondents

\begin{tabular}{|c|c|c|}
\hline Gender $(\mathbf{N}=117)$ & Number & Percentage \\
\hline $\begin{array}{l}\text { Male } \\
\text { Female }\end{array}$ & $\begin{array}{l}45 \\
72\end{array}$ & $\begin{array}{l}38.5 \\
61.5\end{array}$ \\
\hline Total & 117 & 100.0 \\
\hline
\end{tabular}

Tables 12 through 14 present educational level of respondents, major field in art and business/management education. Education, characterized by field of major and highest level reached, was concentrated at the Bachelor's and Master's levels. While the most common arts disciplines were music and drama, the majority of managers studied outside the arts. Over one-third of the population had no formal business or management education although another third had attended business or management seminars. Few managers held a Master's or Doctoral degree in business or management. 
Table 12.--Educational Level of Respondents

\begin{tabular}{lcc}
\hline \hline Educational Level $(\mathrm{N}=117)$ & Number & Percentage \\
\hline No college education & 4 & 3.4 \\
Seminars & 7 & 6.0 \\
Two Year Degree & 7 & 6.0 \\
Bachelor's Degree & 49 & 41.9 \\
Master's Degree & 33 & 28.2 \\
MFA or Doctoral Degree & 17 & 14.5 \\
& 117 & 100.0 \\
\hline
\end{tabular}

Table 13.--Major Field in Arts

\begin{tabular}{lcc}
\hline \hline Major Field in Art $(\mathrm{N}=117)$ & Number & Percentage \\
\hline None & 38 & 32.5 \\
Art History & 5 & 4.3 \\
Dance & 6 & 5.1 \\
Drama & 19 & 16.2 \\
Studio Art & 6 & 5.1 \\
Music & 26 & 22.2 \\
Other & 17 & 14.5 \\
& 117 & 100.0 \\
\hline
\end{tabular}

Table 14.--Business or Management Education

\begin{tabular}{lrc}
\hline $\begin{array}{c}\text { Business or Management Education } \\
(\mathrm{N}=117)\end{array}$ & Number & Percentage \\
\hline No Education in Business & 46 & 39.3 \\
High School Business Courses & 2 & 1.7 \\
Seminars & 44 & 37.6 \\
Associate's Degree & 2 & 1.7 \\
Bachelor's Degree & 8 & 6.8 \\
Master's Degree & 10 & 8.5 \\
Doctoral Degree & 5 & 4.3 \\
& & 100.0
\end{tabular}

*ategories differ from Table 12, General Educational Level of Respondents. Data were collected using the
categories above. 
Tables 15 through 17 demonstrate that arts managers were highly experienced; more than one-half have had over eight years of arts management experience. The majority of respondents were sole administrators of their agencies, while another quarter percent responded for agencies with no designated manager. The remaining managers functioned within a dual (artistic and business) system. Of salaried managers, who constituted only two-thirds of the survey population, most were low earners. Slightly over $10 \%$ percent of managers earned under $\$ 15,000$ and close to $20 \%$ percent earned between $\$ 15,000$ and $\$ 25,000$. Only $13.7 \%$ percent of the arts managers in this population earned over $\$ 41,000$. Over one-third of the respondents received no annual salary, but indicated on their responses to attitudinal questions, an extremely high level of commitment to the arts and devotion to a singular cause. It is assumed, therefore, that these managers perform without salary in order to participate in an intellectually and emotionally rewarding activity.

Table 15.--Administrative Experience of Respondents

\begin{tabular}{lcc}
\hline \hline Administrative Experience $(\mathrm{N}=117)$ & Number & Percentage \\
\hline None & 02 & 1.7 \\
Less than 1 Year & 04 & 3.4 \\
1 to 3 Years & 16 & 13.7 \\
4 to 8 Years & 33 & 28.2 \\
Over 8 Years & 61 & 52.1 \\
Missing & 01 & .9 \\
& 117 & 100.0 \\
Total & & \\
\hline
\end{tabular}


Table 16.--Position Characteristics

\begin{tabular}{ccc}
\hline \hline Position Characteristics $(\mathrm{N}=118)$ & Number & Percentage \\
\hline Sole Manager & 46 & 39.0 \\
Business Manager with & 23 & 19.5 \\
$\quad$ separate artistic director & 16 & 13.6 \\
Artistic Manager with & 33 & 28.0 \\
$\quad$ separate business director & 118 & 100.0 \\
Board-only Management & & \\
\cline { 2 - 3 } & Total &
\end{tabular}

Table 17.--Managerial Salary of Respondents

\begin{tabular}{lcc}
\hline Salary $(\mathrm{N}=117)$ & Number & Percentage \\
\hline None & 43 & 36.8 \\
Less than $\$ 15,000$ & 17 & 14.5 \\
$\$ 16,000$ to $\$ 20.000$ & 13 & 11.1 \\
$\$ 21,000$ to $\$ 25,000$ & 9 & 7.7 \\
$\$ 26,000$ to $\$ 30,000$ & 7 & 6.0 \\
$\$ 31,000$ to $\$ 35,000$ & 7 & 6.0 \\
$\$ 36,000$ to $\$ 40,000$ & 5 & 4.3 \\
Over $\$ 41,000$ & 16 & 13.7 \\
& & 100.0 \\
\hline
\end{tabular}

\section{Agency Characteristics}

Music was the most common type of agency represented, followed by theatre and dance. Agency staffing ranged from total board management (with no designated manager) to sole or dual management directed by a board and assisted by a volunteer corps and arts and business support staff. The numbers of each of these staffs varied widely according to the budget, need, and focus of each agency. Over one-third of agencies had no artistic or business staff, and twenty percent had no volunteer corps. Of those agencies with ancillary staffs, the mean artistic staff size was 6 , business staff was 3 , and volunteer corps was 60 . 
Board sizes also varied widely with a mean in this population of 20 . Tables 18 and 19 present data by agency type and staff.

Table 18.--Agency Types

\begin{tabular}{lcc}
\hline \hline Agency Types $(\mathrm{N}=117)$ & Number & Percentage \\
\hline Theatre & 15 & 12.8 \\
Music & 41 & 35.0 \\
Display Arts & 11 & 9.4 \\
Educational Arts & 9 & 7.7 \\
Arts Service Organization & 9 & 7.7 \\
Funding Agency & 2 & 1.7 \\
Community Center & 4 & 3.4 \\
Multi-Cultural Arts & 3 & 2.6 \\
Presenting Agency & 10 & 8.5 \\
Dance & 12 & 10.3 \\
Other & 1 & .9 \\
& 117 & 100.0 \\
\hline
\end{tabular}

Table 19.--Characteristics of Arts Agency Staffs

\begin{tabular}{lrrrrrr}
\hline $\begin{array}{l}\text { Variable } \\
\text { Name }\end{array}$ & $\underline{N}$ & Min. & Max. & Mean & $\begin{array}{c}\text { Standard } \\
\text { Deviation }\end{array}$ & $\begin{array}{c}\text { Coefficient of } \\
\text { Variation }\end{array}$ \\
\hline Artistic Staff & 118 & .000 & 150 & 6.69 & 18.44 & 275.6 \\
Business Staff & 118 & .000 & 25 & 2.80 & 4.70 & 167.9 \\
Volunteer Staff & 118 & .000 & 800 & 59.98 & 126.02 & 210.1 \\
Board Size & 118 & .000 & 60 & 19.75 & 12.18 & 61.7 \\
\hline
\end{tabular}

Tables 20 and 21 present data by agency longevity and lifecycle. Over one-third of the arts agencies in this population are of long duration, defined as over 15 years, while only fifteen percent were created in the last five years. However, almost half $(42.7 \%)$ of the agencies do not consider themselves in a growth stage, citing instead a changing lifecycle, which generally means a programmatic or artistic shift, a board restructuring, or a financial crisis. The issue of lifecycle, especially change, is discussed more fully with Table 49. 
Table 20.--Agency Longevity

\begin{tabular}{ccc}
\hline \hline Agency Longevity $(\mathrm{N}=117)$ & Number & Percentage \\
\hline Less than five years & 17 & 14.5 \\
6 to 9 years & 25 & 21.4 \\
10 to 15 years & 29 & 24.8 \\
Over 15 years & 40 & 43.2 \\
Missing & 6 & 5.1 \\
\cline { 2 - 3 } Total & 117 & 100.0 \\
\hline
\end{tabular}

Table 21.--Agency Lifecycle

\begin{tabular}{lcc}
\hline \hline Agency Lifecycle $(\mathrm{N}=117)$ & Number & Percentage \\
\hline Developing and Emerging & 8 & 6.8 \\
Growing & 36 & 30.8 \\
Mature & 13 & 11.1 \\
Declining & 10 & 8.5 \\
Changing & 50 & 42.7 \\
\cline { 2 - 3 } Total & 117 & 100.0 \\
\hline
\end{tabular}

Managers' assessments of changes in agency service and performance for the years 1989 to 1991 , as seen in Table 22, reflected the precarious financial state of the agencies. The percentage of managers claiming agency growth decreased by almost ten percent from 1990 to 1991 , while the percentage of managers claiming agency decline grew almost $12 \%$ percent in the same time period. As previously mentioned, 1989 was a pivotal year for the arts; in that year the debate about government sponsorship and censorship reached the level of a national debate. 
Table 22.--Agency Service and Performance Change Over Three Years

\begin{tabular}{lcc}
\hline Service and Performance Change & Number & Percentage \\
Over Three Years $(\mathrm{N}=117)$ & & \\
\hline Service/Performance Change 1989 & 86 & 73.5 \\
Growth & 11 & 9.4 \\
Decline & 13 & 11.1 \\
Stable & 7 & 6.0 \\
Missing & 117 & 100.0 \\
\multicolumn{1}{c}{ Total } & & \\
\cline { 2 - 3 } Service/Performance Change 1990 & 87 & 73.5 \\
Growth & 12 & 10.3 \\
Decline & 16 & 13.7 \\
Stable & 2 & 1.7 \\
Missing & 117 & 100.0 \\
Total & & \\
Service/Performance Change 1991 & 76 & 65.0 \\
Growth & 25 & 21.4 \\
Decline & 14 & 12.0 \\
Stable & 2 & 1.7 \\
Missing & 117 & 100.0 \\
Total & & \\
\hline
\end{tabular}

As seen in Table 23, agencies reported annual average revenues of approximately $\$ 290,000$ (mean $=\$ 294,334$ ) in 1991 , of which about one-third came from contributions. Table 24 also indicates that less than half of the population (35.6\%) of agencies were able to earn half of their revenue through service or performance fees. Managers felt greater success in generating monies through grants and donations and their responses reflected this confidence. Table 25 indicates that about two-thirds of agencies revealed that they were able to earn $40 \%$ percent of their revenues through grants and donations. Figures from the IRS returns, displayed in Table 23, indicate that contributed income comprises $35.9 \%$ percent of revenues, and grants contribute another $22.8 \%$ percent, for a total of $58.7 \%$ percent. Managers are correct, therefore, in their assessment of a greater availability of 
funds by contributions and grants than by earned income. When agency expenses were deducted from total revenues, this population revealed a mean deficit of $-2.74 \%$ percent. Tables 23 through 25 present data on agency revenues.

Table 23.--Descriptive Statistics for Agency Revenues

\begin{tabular}{|c|c|c|c|c|c|}
\hline $\begin{array}{l}\text { Variable } \\
\text { Name }\end{array}$ & Min. & Max. & Mean & $\begin{array}{l}\text { Standard } \\
\text { Deviation }\end{array}$ & $\begin{array}{l}\text { Coefficient of } \\
\text { Variation }\end{array}$ \\
\hline $\begin{array}{l}\text { Total Gross } 1 \\
\text { Revenue }(\$) \\
\text { (in thousands) } \\
(\mathrm{N}=112)\end{array}$ & 3,000 & 3,309 & 294 & 582 & 197.9 \\
\hline $\begin{array}{l}\text { Proposed Revenue } \\
\text { to VCA } 1991 \\
\text { (in thousands) } \\
(\mathrm{N}=108)\end{array}$ & 150 & 3,076 & 266 & 470 & 176.6 \\
\hline $\begin{array}{l}\text { Survey Revenue } \\
\text { (in thousands) } \\
\mathrm{N}=118 \text { ) }\end{array}$ & 1,000 & 3,200 & 323 & 612 & 189.4 \\
\hline $\begin{array}{l}\text { Percent Earned } \\
\text { Income } \\
(\mathrm{N}=99)\end{array}$ & .30 & 92.0 & 43.0 & 22.9 & 53.3 \\
\hline $\begin{array}{l}\text { Contributions } \\
(\$) \text { (in thousands) } \\
(\mathrm{N}=99)\end{array}$ & 250 & 1,376 & 99 & 225 & 227.2 \\
\hline $\begin{array}{l}\text { Percent } \\
\text { Contributions } \\
(\mathrm{N}=98)\end{array}$ & .00 & 77.0 & 35.9 & 20.5 & 57.0 \\
\hline $\begin{array}{l}\text { Percent Grant } \\
(\mathrm{N}=98)\end{array}$ & .06 & 84.0 & 22.8 & 16.2 & 70.9 \\
\hline $\begin{array}{l}\text { Percent Profit } \\
\text { or loss } \\
(\mathrm{N}=63)\end{array}$ & -121.0 & +42.0 & -2.74 & 23.8 & 868.6 \\
\hline
\end{tabular}

Source: VCA grant proposals, IRS Form \#990, Questionnaire Responses 
Table 24.--Agencies Earning 50\% Percent of Revenues by Services or Performances

\begin{tabular}{|c|c|c|}
\hline Earn $50 \%$ revenue $(\mathrm{N}=118)$ & Number & Percentage \\
\hline $\begin{array}{l}\text { Agree } \\
\text { Disagree } \\
\text { Missing }\end{array}$ & $\begin{array}{l}42 \\
60 \\
16\end{array}$ & $\begin{array}{l}35.6 \\
50.8 \\
13.5\end{array}$ \\
\hline Total & 118 & 100.0 \\
\hline
\end{tabular}

Table 25.--Agencies Receiving 40\% Percent of Revenue from Grants and Donations

\begin{tabular}{ccc}
\hline \hline $\begin{array}{l}\text { Receive 40\% revenue } \\
\text { from grants/donations }(\mathrm{N}=118)\end{array}$ & Number & Percentage \\
\hline Agree & 79 & 66.9 \\
Disagree & 24 & 20.3 \\
Missing & 15 & 12.7 \\
\cline { 2 - 3 } & 118 & 100.0 \\
\hline
\end{tabular}

Managerial Attitudes Toward Business Management

The questionnaire contained ten statements, which were designed to reflect managers' motivations for working in arts administration and reactions to an emphasis on business management. These items were included in the questionnaire in order to support the assignment of managers into four role types; motivation is considered a prime role selection indicator, especially for entrepreneurship (Young 1983, Gasse 1978).

As seen in Table 27, managers demonstrated deep idealism or commitment to a larger purpose, zealotry in Downs's (1967) terms, in their career choices by giving strong positive responses to the questionnaire statements, "I believe that when a person devotes him/herself to an idea or cause his/her life becomes meaningful," or "I feel that the main thing in life for a person is to do something that he/she considers important."

Managers indicated a heightened awareness of the crisis in the arts by unanimously positive responses to the statement, "I believe that changes in an arts agency are to be 
expected." They also reflected the common trend in arts management toward a more businesslike orientation, with strong positive responses to the statement, "I think that heavy use of business methods, techniques and practices will help to guarantee my agency's survival." Despite their present difficulties, or perhaps because of their purposive dedication, most managers continue to view themselves as influential administrators who can make judicious intuitive decisions for the agency, and withstand the stress of competition in the arts. Only $24.8 \%$ percent, however, acknowledged their strong preference for sole management, confiding that they would welcome some help in a currently overwhelming task. Few (3.4\%) managers strongly agreed that luck was a driving force in the arts world; half (50.8\%) felt that the institution of business methods would help to insure the survival of the agency. 
Table 26.--Respondents' Attitudes Toward Business Management Percent Agreement

Variable Name $(\mathrm{N}=118) \quad$ Number $\quad$ Percentage

Devotion to a cause makes life meaningful

$$
\begin{aligned}
& \text { Agree strongly } \\
& \text { Agree on the whole } \\
& \text { Somewhat agree } \\
& \text { Disagree on the whole } \\
& \text { Disagree strongly }
\end{aligned}
$$

78
21
16

Main thing in life is to do something important

Agree strongly
Agree on the whole
Somewhat agree
Disagree on the whole
Disagree strongly

Manager wishes to remain sole boss of agency

$$
\begin{aligned}
& \text { Agree strongly } \\
& \text { Agree on the whole } \\
& \text { Somewhat agree } \\
& \text { Disagree on the whole } \\
& \text { Disagree strongly } \\
& \text { not applicable }
\end{aligned}
$$

Believe changes in arts agency are to be expected

$\begin{array}{lrrr}\text { Agree strongly } & 89 & 76.1 \\ \text { Agree on the whole } & 21 & 17.9 \\ \text { Somewhat agree } & 7 & 6.0\end{array}$

Manager uses an intuitive decision-making style

$\begin{array}{lrr}\text { Agree strongly } & 37 & 31.6 \\ \text { Agree on the whole } & 30 & 25.6 \\ \text { Somewhat agree } & 42 & 35.9 \\ \text { Disagree on the whole } & 5 & 4.3 \\ \text { Disagree strongly } & 2 & 1.7 \\ \text { not applicable } & 1 & .9\end{array}$

Agency business decisions should be based on business studies and reports

$\begin{array}{lrr}\text { Agree strongly } & 20 & 17.1 \\ \text { Agree on the whole } & 20 & 17.1 \\ \text { Somewhat agree } & 49 & 41.9 \\ \text { Disagree on the whole } & 19 & 16.2 \\ \text { Disagree strongly } & 9 & 7.7\end{array}$


Table 26.--Respondents' Attitudes Toward Business (continued)

\begin{tabular}{|c|c|c|}
\hline Variable Name $(\mathrm{N}=118)$ & Number & Percentage \\
\hline \multicolumn{3}{|c|}{ Use of business methods helps to guarantee } \\
\hline \multicolumn{3}{|c|}{ agency survival } \\
\hline Agree strongly & 27 & 23.1 \\
\hline Agree on the whole & 33 & 28.2 \\
\hline Somewhat agree & 34 & 29.1 \\
\hline Disagree on the whole & 16 & 13.7 \\
\hline Disagree strongly & 6 & 5.1 \\
\hline not applicable & 1 & .9 \\
\hline \multicolumn{3}{|l|}{ Manager can influence agency events } \\
\hline Agree strongly & 69 & 59.0 \\
\hline Agree on the whole & 31 & 26.5 \\
\hline Somewhat agree & 15 & 12.8 \\
\hline Disagree on the whole & 1 & .9 \\
\hline Disagree strongly & 1 & .9 \\
\hline \multicolumn{3}{|l|}{ Competition does not interfere with } \\
\hline \multicolumn{3}{|l|}{ business operations } \\
\hline Agree strongly. & 59 & 50.4 \\
\hline Agree on the whole & 32 & 27.4 \\
\hline Somewhat agree & 13 & 11.1 \\
\hline Disagree on the whole & 7 & 6.0 \\
\hline Disagree strongly & 5 & 4.3 \\
\hline not applicable & 1 & .9 \\
\hline \multicolumn{3}{|l|}{ Events in arts world due to luck } \\
\hline Agree strongly & 4 & 3.4 \\
\hline Agree on the whole & 15 & 12.8 \\
\hline Somewhat agree & 25 & 21.4 \\
\hline Disagree on the whole & 37 & 31.6 \\
\hline Disagree strongly & 6 & 30.8 \\
\hline Total & 118 & 100.0 \\
\hline
\end{tabular}




\section{Part Two \\ Anticipation of Role Types}

\section{Evidence of Role Clusters}

The following description of clusters of managerial traits is based upon associations of variables in the target population that suggest and anticipate the actual assignment of managers into four role types. The researcher sought evidence of trait clusters characteristic of each of the four roles hypothesized: entrepreneur, administrator, artist and caretaker. There was also an effort to substantiate linkages between role type and managerial behavior. The actual assignment of respondents into four discrete role types occurs in Chapter V, with a complete data analysis by role type.

The researcher examined the Pearson's correlation matrix of 121 variables to determine the presence or absence of variables predicting four role types. Only those variables with correlations significant beyond the .010 level were considered in these analyses.

\section{Profile of the Entrepreneur}

There were correlations among clusters of variables in the areas of creative leadership and managerial access to resources as seen in Table 27, which suggested the existence of an entrepreneurial manager. Entrepreneurs, as defined in this study, are innovators who manage by adapting an organization to its current environment. Entrepreneurs are believed to follow an internal vision that is difficult to articulate or communicate, demanding that a board and staff place manifest confidence in the leader without any prior substantiated success. The data support these expectations in moderate correlations $(\mathrm{r}=.30)$ among the following variables: "percentage of your programming in 1991 that provides program leadership" and "percentage of your programming in 1991 consisting of original works never performed before?" This same leadership question was 
also moderately correlated with with the question "percentage of experimental programming in 1991," which yielded a correlation of $(r=.37)$.

Another hallmark of the entrepreneur is his/her focus on a short but intense time span to produce a product, performance, or service. The data suggest that for these managers, extensive administrative experience is not a factor in a manager's perceived administrative influence. The entrepreneurial manager in this population is guided more by an internally driven vision of a completed product, and less by previous experience, measured by a negative response $(r=-.22)$ among the variables "total years of experience in arts administration" and "I have the ability to influence the events that occur in an arts agency."

The entrepreneurial manager demonstrates personal confidence in his/her total management duties, indicated by "the manager's belief in his/her ability to influence the events in an arts agency" and comfort with the creative aspects of running an agency, seen in "the manager's assessed percentage of programming in 1991 that provided leadership the field"; the correlations to $(r=.21)$ indicate the degree of this confidence.

An entrepreneur also has the confidence and ability to access the resources to sustain his/her venture, displayed in correlations equal to $(r=.33)$ among the variables "I believe I have the ability to influence the events that occur in an arts agency" and "I produced at least $50 \%$ of agency budget in 1991 from earned income."

Finally, the entrepreneurial manager relies on his/her own abilities, demonstrated by in the variable "ability to influence events in an arts agency" (as opposed to hoping for good fortune), measured by the variable "I think that many events in the arts world turn out to be a matter of good or bad fortune," with correlations equal to $(r=-.27)$. 
Table 27.--Correlations Among Variables Suggesting Entrepreneurial Traits in Arts Managers

\begin{tabular}{lcc}
\hline \hline Variable & $\begin{array}{c}\text { Provides Creative } \\
\text { Program Leadership }\end{array}$ & $\begin{array}{c}\text { Ability to Influence } \\
\text { Agency Events }\end{array}$ \\
\hline Produces original work & $.30^{* *}$ & .17 \\
Produces experimental work & $.37^{* *}$ & $.20^{*}$ \\
Total years experience & $.24^{* *}$ & $-.22^{* *}$ \\
Creative leadership & 1.00 & $.21^{* *}$ \\
Produced 50\% of budget & -.04 & $.33^{* *}$ \\
from earned income & -.14 & $-.27^{* *}$ \\
\hline
\end{tabular}

* Significant at $\mathrm{p}=.050$

** Significant at $\mathrm{p}=.010$

\section{Profile of Caretaker}

The total population revealed a cluster of agencies that are experiencing layoffs, need a financial rescue and/or that are verging on termination or merger. The associations among these variables, seen in Table 29 , suggest the presence of a caretaker role type. The caretaker, as described in this study, manages a declining agency by carefully husbanding resources and maintaining programs, but resisting organizational change.

The groups of variables that anticipate the existence of a caretaker are all based upon a single management structure, the board-only management. A sizeable group of agencies in this population are run solely by a board of directors, with the president or program director acting also in the capacity of manager. These agencies do not employ a paid or a volunteer administrator. All management tasks are undertaken by one or more members of the board of directors. The several variables that demonstrate a level of correlation $(\mathrm{p}=$ .010) with the managerial structure "board-only management" reveal deficiencies in many standard business practices common to an arts agency.

To illustrate, there was a negative correlation $(r=-.26)$ among the variables "boardonly management" and "I have defined a specific niche for this agency in the arts for at least the past two years." The implication here is that an agency without a manager is unlikely to 
determine a specific artistic focus. A "board-managed" agency also displays business deficits in financing the agency, illustrated by a negative correlation $(r=-.25)$ among the variables "board-only management" and appointing a "separate board committee on budgeting." Further, a "board-managed" agency is unlikely to undertake critical agency evaluations, demonstrated by the variable "evaluate our mission and goals annually": correlations are equal to $(r=-.30)$. Finally, the "board-managed" agency displays an inability to raise revenues effectively, indicated by a negative correlation $(r=-.25)$ with the variable "total gross revenues as defined by IRS Form \#990."

Another cluster of variables that anticipates the existence of the caretaker role describes agencies on the verge of collapse. A terminating agency, shown in the variable "consider terminating the agency" displays an inability to attract corporate sponsors, seen in the variable "I received funding from corporate sponsors in 1991"; correlations are equal to $(r=-.24)$. Terminating agencies often desire to merge with a similar agency, reflected in the statement, "My cutback strategy is to look for a similar agency to merge or absorb my agency"; correlations are equal to $(\mathrm{r}=.34)$. The correlations $(\mathrm{r}=.22)$ among the variables "consider terminating" and "appeal to the board for a financial rescue" show that failing agencies consider private donations by the board a last resource for survival. Terminating agencies are experiencing the most severe cutbacks. There is an association $(r=.24)$ between the items "consider terminating" and the cutback strategy "reduce staff through layoffs." The picture evolving from these correlations suggests a group of agencies that are struggling under great financial duress, having neither perceived leadership nor artistic vision. 
Table 28.--Correlations Among Variables Suggesting Caretaker Traits in Arts Managers

\begin{tabular}{lcc}
\hline Variable name & $\begin{array}{c}\text { Agency } \\
\text { Managed Only by } \\
\text { Board of Directors }\end{array}$ & $\begin{array}{c}\text { Agency } \\
\text { Considering } \\
\text { Termination }\end{array}$ \\
\hline Defined artistic Niche & $-.26^{* *}$ & .06 \\
Separate committee on budgeting & $-.25^{* *}$ & -.01 \\
Evaluate mission and goals annually & $-.30^{* *}$ & .03 \\
Total gross revenue & $-.25^{* *}$ & -.09 \\
Increase fundraising & $-.20^{* *}$ & -.08 \\
Assessed economy & -.12 & .08 \\
Contact donors & -.14 & .11 \\
Have corporate sponsors & -.14 & $-.24^{* *}$ \\
Look to merge agency & .08 & $.34^{* *}$ \\
Need rescue & -.05 & $.22^{* *}$ \\
Layoff staff & -.03 & $.24^{* *}$ \\
\hline
\end{tabular}

* Significant at $\mathrm{p}=.050$

*** Significant at $\mathrm{p}=.010$

\section{Profile of the Administrator}

A group of correlations, displayed in Table 29, stress the administrative role with moderate associations among the variables length of agency operation, and total agency revenues, large business staff, large board of directors and success in attracting corporate donors. An administrator, as defined by this study, attends carefully to all the business elements of the organization in order to maintain a stable bureaucratic structure. Administrators are associated with well-established organizations that are run by conservative boards of directors.

The administrator role type is suggested here by a cluster of variables describing a complex, longstanding agency with a large staff and large budget. This description is illustrated by a moderate correlation $(r=.31)$ among the variables length of agency operation, as in "number of years since incorporation" and the total "budget of the agency, real, earned and contributed." There is another association $(r=.25)$ between longevity of operation and size of the agency, expressed as "number of business staff (management, marketing, public relations, etc.)." The board size increases as the agency ages, 
demonstrated by a moderate correlation $(r=.39)$ between agency age and "size of board of directors". Finally, agencies with a long history are more attractive to donors, expressed as a correlation $(\mathrm{r}=.22)$ between agency longevity and "received funding from corporate sponsors in 1991."

The administrator also emphasizes business management more than artistic production. The cluster of variables associated with an old and complex organization also demonstrates a negative relationship between longevity of operation and creativity, suggesting that longevity favors conservatism. For example, there are negative associations $(r=-32)$ among the variables agency age and "production of original work." There are also negative correlations $(r=-.22)$ between length of agency operation and "percentage of risky arts programs in 1991." Finally, well-established agencies avoid negative media attention, demonstrated in the association of variables $(r=-.28)$ "generated controversy in the popular media in 1991?" and length of agency operation.

The administrator role type is also associated with agencies that use business techniques adapted from the for-profit secior, demonstrated by a moderate correlation $(\mathrm{r}=$ .41) among the variables "Total gross revenue 1990-91 from IRS Form \# 990" and "I prepared or commissioned a marketing analysis within the past two years." These large budget agencies also engage in protective gestures to guarantee the flow of funding, seen in the correlations $(r=.29)$ among the variables "total gross revenue" and "I meet at least annually with state legislators from my district to encourage state government arts funding."

Managers of these large, complex agencies segment the functions of the board to provide an in-depth look at the opportunities for growth and development of the business. This business like aspect appears in correlations among the variables "total gross revenue" and "have a separate planning committee within my Board of Directors" with correlations equal to $(r=.27)$. Managers are also aware of the need for corporate involvement in the 
fiscal life of the agency, expressed as a correlation $(r=.27)$ among the variables total gross revenue and "received funding from corporate sponsors in 1991."

The most complete portrait of a well-trained, highly effective business manager in charge of an agency with a decided business orientation appears in this administrator profile. This manager not only attends to the business aspect of the agency, but also maintains close ties with his/her peers in arts management, expressed as a moderate correlation among the variables "total gross revenue" and "I attend an annual regional or national arts management conference"; correlations are equal to $(r=.47)$. The manager also maintains an on-going awareness of changes and developments in the field of arts, suggested by the association $(r=.36)$ of total gross revenue and the variable "I now subscribe to an arts management journal or newsletter which identifies new artistic opportunities such as services, products, personnel, programs or management techniques."

Finally, the manager keeps in close contact with the leaders of his/her local and regional civic, business, and political community in order to promote the agency and increase its visibility. These associations appear among the variables total gross revenue and "I now network regularly with major civic and political organization leaders in support of our agency"; correlations are equal to $(r=.27)$. 
Table 29.--Correlations Among Variables Suggesting Administrator Traits in Arts Managers

\begin{tabular}{lcc}
\hline \hline Variable Name & Agency Age & Total Gross Revenue \\
\hline Total gross revenue & $.27^{* *}$ & 1.00 \\
Size business staff & $.25^{* *}$ & $.87^{* *}$ \\
Board size & $.39^{* *}$ & $.66^{* *}$ \\
Received corporate funds 1991 & $.27^{* *}$ & $.27^{* *}$ \\
Produced original work 1991 & $-.32^{* *}$ & .12 \\
Produced risky programs 1991 & $-.22^{* *}$ & -.08 \\
Generated media controversy 1991 & $-.28^{* *}$ & .08 \\
Produced market analysis & .07 & $.41^{* *}$ \\
Met state legislators & .09 & $.29^{* *}$ \\
Established planning committee & .00 & $.27^{* *}$ \\
Received corporate funds & $.22^{* *}$ & $.27^{* *}$ \\
Attended mgmt conference & .10 & $.47^{* *}$ \\
Networked in community & $.31^{* *}$ & $.27^{* *}$ \\
Subscribe to management journal & .12 & $.36^{* *}$ \\
\hline
\end{tabular}

* Significant at $\mathrm{p}=.050$

$* *$ Significant at $\mathrm{p}=.010$

Financing the Arts and the Administrator

Several associations appeared in the examination of fiscal data, seen in Table 30, which revealed the revenue producing habits of large agencies managed by the administrator role type. The data suggested a practice in arts agencies of raising revenues by concentrating either on earned income or donated income, but not by attending to both. As either method of generating revenues rose, the other diminished. For example, there was a strong negative correlation between "Percent of earned income" and either "Percent of contributions" ( $r=-.77$ ) or "Percent of grants" $(r=-.45)$. As well, agencies which reported a high "Percentage of contributions" were negatively correlated $(r=-.65)$ with those who "Earn half of their annual revenues." The reasons for this are varied. Possibly, agencies that consistently earn substantial amounts of revenue through programming are generally unable to win large contributions or grants, because they are not perceived to be needy. It is also possible that Herbert Simon's (1957) theory of "satisficing" is operating here, which suggests that administrators will expend just enough energy to satisfy their 
perceived need. In this scenario, managers will not approach budgeting from all potential revenue sources if one source substantively suffices. Developing sources of funding an arts agency is a complex issue. The findings here are not unusual in that one would expect to find a negative relationship between grants and earned income, i.e., that as one source rises, the other will fall. However, there are other ways for managers to approach raising revenues. An entrepreneurial manager will seek all sources of income, including earned income, contributions, grants, and unrelated income. By contrast, a caretaker manager who is less involved in a revenue search will prioritize careful utilization of known sources of revenue over searching for new and available funds.

Table 30.--Correlations Among Variables in Arts Financing

\begin{tabular}{ll}
\hline \hline Variable Name & Percent of Contributed Income \\
\hline Percent earned income & $-.77^{* *}$ \\
Percent grants & $-.18^{*}$ \\
Agency earned $.50 \%$ revenues & $-.65^{* *}$ \\
\hline Significant at $\mathrm{p}=.050$ & \\
$* *$ Significant at $\mathrm{p}=.010$ &
\end{tabular}

\section{Profile of the Artist}

A final distinct profile suggested by the correlations, shown in Table 31, resembles the artist as a manager role type. The artist as defined in this study concentrates on the artistic tasks of arts management, often neglecting the agency's business aspects. The artist profile was suggested in the population by the association of variables describing creativity and management tasks.

The central questions on creativity asked how often, on an annual basis, a manager planned changes in programming format, produced original works, took artistic risks, performed experimental work or provoked controversy in the media. All of these variables 
were highly correlated with each other, producing a picture of agencies which either did or did not hold creativity as a goal.

The production of risky, original, and controversial programming was also highly correlated with newer agencies; those which are less dependent upon embedded values and operating systems, and more willing to follow their instincts. This description strongly suggests the artist role type. Moderate negative correlations among variables "agency longevity" and "produced original works in 1991" equal $(r=-32)$, suggest that creativity is more associated with newer agencies. Similarly, agency age is correlated negatively $(r=$ -22) with "percentage of risky arts programs in 1991." Agency age is also correlated negatively $(r=-.28)$ with "programs in 1991 that generated controversy in the popular media."

The inability to win local government grants was another hindrance for artistic managers and agencies, as determined by the correlations among the variables "received local government grants each year for the past four years" and "artistic risk" $(r=-.32)$, or "produced original work" ( $\mathrm{r}=-.21)$.

By withholding local government grants, communities express a lack of confidence in new and innovative agencies. This may encourage managers operating in the artist role to take definitive steps to cultivate their followers through education to effect a more stable operation. This is supported by the positive association of the variable educational or interpretive programming with both "percentage of experimental programming" $(r=.30)$ and "percentage of original work" $(r=.46)$.

The artist manager theoretically wants to exert significant control over the artistic process and program; he/she is reluctant to confide in a board of directors that might begin to question artistic and programming decisions. The artist is prepared to offer his/her creative programming and take the consequences. This theory is supported by correlations among the variables $(r=.21)$ "desire to remain the sole boss of his/her agency" and a willingness to "generate media controversy." 
There are further clusters of variables that link creative leadership with programmatic creativity and with an artistic niche, again suggesting the artist. Artistic managers have a strong sense of their own forward motion in the arts, measured by the correlations between the variables "percentage of your programming in 1991 thought to provide leadership in your field" and "produces original works" $(r=.30)$. Despite the apparent vulnerabilities in the marketplace, artist managers feel driven to perform and produce creative programs, demonstrated by the association between the variables "leadership in your field" and "produces experimental works" $(r=.37)$. Artists also focused clearly on their own segment of the arts, expressed as a relationship among the statements "provides leadership in your field" and "defined a specific artistic niche for the past two years," $(\mathrm{r}=.27)$.

The present difficulties of creative agencies are reflected in the managers' sense of a declining lifecycle. Lifecycle, as discussed earlier in the Review of the Literature, here is divided into five phases: developing, growing, maturing, declining, and changing. A negative correlation between the questions of "produces original work" and "lifecycle of the agency in 1991" $(\mathrm{r}=-.23)$, suggests that agencies that continue to promote and produce original work are suffering from a lifecycle deterioration. Many managers reported that their lifecycle had deteriorated from growth to changing, which they described as "restructuring." The managers in this study associated change with almost uniformly negative connotations, ranging from board restructuring to programmatic cutbacks to fiscal crises.

There is an essential instability in maintaining agencies that are artistically innovative, but operate with minimal government or corporate support, reflected in the relationship $(\mathrm{r}=.23)$ among the variables "provides artistic leadership" and "cutback strategy is to look for an agency merger." 
Table 31.--Correlations Among Variables Suggesting Artist Traits

\begin{tabular}{lllllll}
\hline \hline Variable & In & Gr & Ed & Sb & Ld & Lf \\
\hline Risky Programs & $.22^{* *}$ & $-.32^{* *}$ & .03 & $.15^{*}$ & $.19^{*}$ & -.09 \\
Original work & $.32 * *$ & $-.21^{* *}$ & $.46^{* *}$ & .09 & $.30^{* *}$ & $-.23^{* *}$ \\
Media Controversy & -.28 & $-.18^{*}$ & $.16^{*}$ & $.21^{* *}$ & .10 & -.12 \\
Experimental Programs & -.13 & $-.17^{*}$ & $.30^{* *}$ & -.08 & $.37^{* *}$ & -.02 \\
Artist Niche & -.12 & -.07 & $.15^{*}$ & $.24^{* *}$ & $.27^{* *}$ & -.05 \\
Agency Merger & -.03 & .03 & .09 & .01 & $.23^{* *}$ & .09 \\
\hline
\end{tabular}

Variable Description

In = Date of agency incorporation

$\mathrm{Gr}=$ Agency received local government grants over 4 years

$\mathrm{Ed}=$ Agency offers educational programs

$\mathrm{Sb}=$ Manager wishes to remain a sole boss

$\mathrm{Ld}=$ Manager assumes artistic leadership

$\mathrm{Lf}=$ Agency lifecycle, in five phases

* Significant at $p=.050$

$* *$ Significant at $p=.010$

\section{Government Agency Practices and the Artist}

A finding in this study, seen in Table 32, describes the mindset of the local government granting process. The criteria used by local governments in awarding grant monies effectively influence the management of all arts agencies in the community. For example, if the local arts commission decides that it is important to foster greater creativity and originality in the local arts community, there will be a tendency for arts managers to assume the artist role. If, however, the local government, however, determines that business techniques are a needed skill in the operation of arts agencies, the artist role type will diminish.

This study finds that local government is inhospitable to the artist role type, demonstrated by a negative association among the variables "received local government grants for the past four years" and the variables "produces original work", $(r=-.21)$, or "produces risky programs," ( $\mathrm{r}=-.32)$. A further finding revealed a negative correlation between receiving "local government grants" and "considering termination as a cutback 
strategy," ( $r=-.34)$. Clearly, local governments, which are traditionally conservative bodies, are not willing to promote, or support either highly creative work or risky ventures.

The kinds of arts agencies that are associated traditionally with government agencies offer a clue to governments' expectations regarding arts agency management. In this study, there was a small group of agencies that either were part of a local government or largely supported by a locality. These government-sponsored arts agencies appear to assume the management style of their host institutions, engaging in much administrative and bureaucratic activity, evidenced by the correlations $(r=.23)$ among the variables "operates as a government agency" and "have a program or committee to identify longterm facilities needs."

These government-sponsored agencies reveal greater stability of operation, despite the constant reductions in arts funding by municipalities. They display moderate correlations among the variables "government agencies," and "met our fundraising goal for the past two years" ( $r=.31)$ or "agency owns fixed assets" $(r=.22)$.

Managers of these government agencies are also insulated from the insecurities of low-paying private sector arts administration, evidenced by the correlations among "government agency" and "I control the artistic and management functions" $(r=30)$ or "salery range, $\$ 15,000$ to $\$ 41,000 "(r=.41)$. 
Table 32.--Correlations Among Variables Associated with Government Sponsored Arts Agencies

\begin{tabular}{lcc}
\hline Variable Name & $\begin{array}{c}\text { Agency Received } \\
\text { Local Government Grants }\end{array}$ & $\begin{array}{c}\text { Government } \\
\text { Sponsored Agency }\end{array}$ \\
\hline Original work & $-.21^{*}$ & -.07 \\
Risky programs & $-.32^{* *}$ & -.12 \\
Terminate agency & $-.22^{*}$ & -.14 \\
Met fundraising goal & .10 & $.31^{* *}$ \\
Own fixed assets & -.10 & $.22^{* *}$ \\
Long term plans & -.006 & $.23^{* *}$ \\
Sole Manager & .02 & $.30^{* *}$ \\
Salary range & $.17^{*}$ & $.41^{* *}$ \\
\hline
\end{tabular}

* Significant at $p=.050$

** Significant at $\mathrm{p}=.010$ 


\section{NOTES}

1. Total Gross Revenue was calculated by deducting Lines 1D (Grants) and 9C (Specific Fundraising Activities) from IRS Form 990, Line 12, Total Revenue. 


\title{
CHAPTER V
}

\section{ROLE ANALYSIS}

\author{
Introduction
}

This chapter presents the results of analyses focused on role type organized as follows: 1) statement of the research questions, followed by findings; 2) statement and evaluation of the hypotheses; and 3) implications of findings.

\section{Research Question 1}

Research Question 1. What are definable roles to which arts administrators can be assigned on the basis of the criteria of programmatic creativity and access to organizational resources?

Four theoretical management roles were identified, entrepreneur, administrator, artist, and caretaker:

1) The entrepreneur demonstrates energy and motivation in nearly every aspect of arts management, including high artistic creativity and access to resources.

2) The administrator has a high level of access to resources and shows a positive attitude toward standard business practices, but low artistic creativity. 
3) The artist exhibits high artistic creativity but relatively low access to resources.

4) The caretaker demonstrates low artistic creativity and minimal access to resources.

\section{Data Analysis}

All respondents were scored from 0 to 5 on the basis of each response to seven questions on creativity, creating a range of 0 to 35 possible responses while the actual scores ranged from 6 to 24. Scores were examined by histogram analysis for serious irregularity, which was absent. A decision was made to score respondents on creativity as either above or below the mean based on their total score for seven questions. The same process was repeated for the variable of access to resources, which included eight items. Analyses revealed a population mean for creativity of 2.4 (range $=0-4$; standard deviation $=1.1$ ) and a mean for access to organizational resources of 2.5 (range $=0-4$; standard deviation $=1.0$ ). Respondents were scored on each index, and their scores were compared to the population means (above or below the means). Based on these comparisons, respondents were located in one of four cells: high creativity/high resources; high creativity/low resources; low creativity/low resources; and low creativity/high resources. These categories reflect role types described in organizational research and theory (see pp. 10-13). The respondents were assigned to the categories based on the criteria below:

1) Entrepreneurs are characterized by high levels of creativity and access to resources; those respondents with a mean value on creativity greater than 2.4 , and a mean value greater than 2.5 on access to resources were assigned to role type entrepreneur. 
2) Administrators are characterized by low levels of creativity and high levels of access to resources; those respondents with a mean value on creativity less than 2.4 , and a mean value on access to resources greater than 2.5 were assigned to role type administrator. 3) Artists are characterized by high levels of creativity and low levels of access to resources; those respondents with a mean value on creativity greater than 2.4 , and a mean value on access to resources less than 2.5 were assigned to role type artist.

4) Caretakers are characterized by low levels of creativity and low levels of access to resources; those respondents with a mean value on creativity less than 2.4 and a mean value on access to resources less than 2.5 were assigned to role group caretaker.

A crosstabulation of creativity (two categories) by access to resources (two categories) produced the role matrix in Table 33, revealing that caretakers constitute the largest role group, followed by artists, administrators and entrepreneurs. Among respondents with high levels of creativity, artists lead entrepreneurs; among those with low levels of creativity, caretakers exceed administrators. Of those respondents with high levels of access to resources, administrators lead entrepreneurs by a wide margin. Among those with low levels of access to resources, caretakers exceed artists. 
Table 33.--Division of Respondents into Four Roles by Programmatic Creativity and Access to Resources

Access to Resources

Low High

Program

Creativity

\begin{tabular}{|c|c|c|}
\hline & Low & High \\
\hline Low & $\begin{array}{c}\text { Caretaker } \\
(\mathrm{N}=33) \\
34.7 \%\end{array}$ & $\begin{array}{l}\text { Administrator } \\
\qquad \begin{array}{c}(\mathrm{N}=22) \\
23.1 \%\end{array}\end{array}$ \\
\hline High & $\begin{array}{c}\text { Artist } \\
(\mathrm{N}=28) \\
29.4 \%\end{array}$ & $\begin{array}{c}\text { Entrepreneur } \\
\qquad \begin{array}{c}\mathrm{N}=12) \\
12.6 \%\end{array}\end{array}$ \\
\hline
\end{tabular}

Source: Adapted from Svara (1990), Kotter (1982)

Indexes for Creativity and Access to Resources

The seven measures of creativity were joined to form a creativity index (mean $=3.135$, range $=0-7$, Std $=1.861)$, which displayed moderate correlations among the variables "produces original work" and "produces risky programs", "produces experimental programs", and "generates media controversy". All items in the creativity index displayed strong correlations with the index itself, lending validity to this index as a measure of this single dimension of management as shown in Tables 34 and 35. 
An index created for the eight variables constituting access to organizational resources revealed some weak correlations among items, such as "met fundraising goals 1991" and "received corporate funds 1991," as well as among "received corporate funds in 1991" and "agency has an established endowment fund 1991." All of the individual items, however, were strongly correlated with the index itself, suggesting a useful combined measure. (See Table 35.)

Table 34.--Correlations, Means, and Standard Deviations for Items in Creativity Index

\begin{tabular}{|c|c|c|c|c|c|c|c|c|}
\hline $\begin{array}{l}\text { Variable } \\
\text { Name }\end{array}$ & $\operatorname{Pr}$ & Or & Rs & Ld & $\mathrm{Ex}$ & $\mathrm{Ed}$ & $\mathrm{Cn}$ & Index \\
\hline $\operatorname{Pr}$ & 1.00 & .10 & .13 & $.16^{*}$ & $.16^{*}$ & .08 & .02 & $.42^{* * *}$ \\
\hline Or & & 1.00 & $.38^{* *}$ & $.25^{* * *}$ & $.40 * *$ & .32 & $.35^{* *}$ & $.70^{* *}$ \\
\hline Rs & & & 1.00 & .15 & $.37 * *$ & .05 & $.26^{* *}$ & $.60 * *$ \\
\hline $\mathrm{Ld}$ & & & & 1.00 & $.35^{* *}$ & .14 & .13 & $.56^{* *}$ \\
\hline Ex & & & & & 1.00 & $.33^{* * *}$ & $.28 * *$ & $.72 * *$ \\
\hline Ed & & & & & & 1.00 & $.20^{*}$ & $.49 * *$ \\
\hline $\mathrm{Cn}$ & & & & & & & 1.00 & $.51^{* * *}$ \\
\hline Index & & & & & & & & 1.00 \\
\hline $\mathrm{Mn}$ & .31 & .42 & .45 & .64 & .39 & .78 & .13 & 3.13 \\
\hline Std & .46 & .49 & .50 & .48 & .49 & .41 & .33 & 1.86 \\
\hline
\end{tabular}

Variable Description

$\operatorname{Pr}=$ Annual program format change 1991

Or $=$ Produced original work 1991

Rs $=$ Produced risky programs 1991

$\mathrm{Ld}=$ Degree of programmatic leadership 1991

Ex $=$ Produced experimental programs 1991

$E d=$ Produced elucational programs 1991

$\mathrm{Cn}=$ Programs generated media controversy 1991

* Significant at $\mathrm{p}=<.050$

$* *$ Significant at $\mathrm{p}=<.010$ 
Table 35.--Correlations, Means, and Standard Deviations for Items in Access to Resources Index

\begin{tabular}{lccccccc}
\hline \hline $\begin{array}{l}\text { Variable } \\
\text { Name }\end{array}$ & Mt & At & Cr & Ln & En & Gr & Index \\
\hline Mt & 1.00 & $.23^{* *}$ & $.19^{*}$ & .07 & .12 & .05 & $.60^{* *}$ \\
At & & 1.00 & $.16^{*}$ & .04 & .12 & -.01 & $.55^{* *}$ \\
Cr & & & 1.00 & -.07 & $.17^{*}$ & .08 & $.52^{* *}$ \\
Ln & & & & 1.00 & .04 & .02 & $.41^{* *}$ \\
En & & & & & 1.00 & .07 & $.49^{* *}$ \\
Gr & & & & & & 1.00 & .38 \\
Index & & & & & & & 1.00 \\
\hline Mn & .42 & .42 & .73 & .65 & .22 & .76 & 3.17 \\
Std & .49 & .49 & .44 & .47 & .41 & .42 & 1.38 \\
\hline
\end{tabular}

Variable Description

$\mathrm{Mt}=$ Met Fundraising goals 1991

At $=$ Agency owns fixed assets 1991

$\mathrm{Cr}=$ Agency received corporate funds 1991

$\mathrm{Ln}=$ Agency had no loans, deficits, $1990-91$

$\mathrm{En}=$ Agency has endowment fund 1991

$\mathrm{Gr}=$ Agency grants/donations $=40 \%$ percent of revenue 1991

* Significant at $\mathrm{p}=<.050$

** Significant at $\mathrm{p}=<.010$

\section{Guttman Scales}

As described earlier in Research Methodology, Guttman Scales were constructed from the six indexes in order to test the unidimensionality of each indexed measure and to gauge respondents' answers more precisely.

A Guttman Scale created from seven items on the Creativity Index revealed that 45 response patterns matched valid scale types. These constituted $38.1 \%$ percent of the survey population. The descending order of scaled items was as follows: generated media controversy, produced educational programs, produced experimental programs, takes program leadership osition, produced risky programs, produced original work, and annual program format changes. The items and responses constitute a valid Guttman Scale 
with a coefficient of reproducibility of .90 , minimum marginal reproducibility of. 67 and a coefficient of scalability of .69 .

Six items from the Access to Resources Index were examined through Guttman scalogram analysis. Analysis revealed that 39 response patterns, $33 \%$ percent of the survey population, matched valid scale types. These constitute $33 \%$ percent of the survey population. The descending (from least to most observed) order of scaled items was as follows: has current endowment fund, owns fixed assets for past two years, met fundraising goals for past two years, has no loans or deficits for past two years, has corporate sponsors, and grants and donations equal $40 \%$ percent of total gross revenue. The items and responses constitute a valid Guttman scale with a coefficient of reproducibility of .89 , a minimum marginal reproducibility of .69 , and a coefficient of scalability of .65 .

\section{Hypothesis 1}

Hypothesis 1. Arts managers play a variety of roles. These can be differentiated on the basis of the manager's program creativity and access to organizational resources.

The analyses support the hypothesis that arts managers can be described and grouped based on responses to items on programmatic creativity and access to resources. An analysis of variance of the Creativity Index scores grouped by the four role types, seen in Table 40, revealed statistically significant differences among roles. The differences were significant beyond $\mathrm{p}=\mathbf{0 5 0}$. All analyses of variance were computed by the Tukey $\mathrm{B}$ method, which is used to compare the means of groups of unequal sizes. The data display differences among means of all role types. The role types, ranked in descending order by mean value on the dimension creativity, are as follows: artist, entrepreneur, administrator and caretaker. (See Table 36.) 
Table 36.--Mean Values of Creativity and Access to Resources Index Scores by Managerial Roles

\begin{tabular}{cccccc}
\hline & Entrepreneur & Administrator & Artist & Caretaker & Total \\
\hline $\begin{array}{c}\text { Creativity mean score } \\
(\mathrm{N})\end{array}$ & $\begin{array}{c}4.66^{*} \\
(12)\end{array}$ & $\begin{array}{r}2.04^{*} \\
(22)\end{array}$ & $\begin{array}{r}5.10^{*} \\
(28)\end{array}$ & $\begin{array}{r}1.72^{*} \\
(33)\end{array}$ & $\begin{array}{c}3.16 \\
(95)\end{array}$ \\
$\begin{array}{c}\text { Resources mean score } \\
(\mathrm{N})\end{array}$ & $\begin{array}{r}4.66^{*} \\
(12)\end{array}$ & $\begin{array}{r}4.63^{*} \\
(22)\end{array}$ & $\begin{array}{r}2.60^{*} \\
(28)\end{array}$ & $\begin{array}{r}2.09^{*} \\
(33)\end{array}$ & $\begin{array}{c}3.15 \\
(95)\end{array}$ \\
\hline
\end{tabular}

* Significant at $p=.050$, Tukey $B$ method

Table 37.--Analysis of Variance: Role Types (Independent Variable) by Creativity (Dependent Variable)

\begin{tabular}{lccccc}
\hline Source & SS & df & MS & F & Significance of F \\
\hline Between Groups & 228.4600 & 3 & 76.1533 & 78.003 & .0000 \\
Within Groups & 88.84529 & 91 & .976 & & \\
Total & 317.3053 & 94 & & & \\
\hline
\end{tabular}

An analysis of variance of Access to Resources Index scores grouped by role types, shown in Table 38, indicated statistically significant differences beyond the .050 level. There are significant differences between the means of several role groups, including artists and caretakers, administrators and caretakers, administrators and artists, entrepreneurs and caretakers, and entrepreneurs and artists. The differences between entrepreneurs and administrators were not significant on this dimension. The role types ranked in this dimension as entrepreneur, administrator, artist, and caretaker. (See Table 36.) 
Table 38.--Analysis of Variance: Role Types (Independent Variable) by Access to Organizational Resources (Dependent Variable)

\begin{tabular}{lrrrrr}
\hline \hline Source & \multicolumn{1}{c}{ SS } & df & MS & \multicolumn{1}{c}{ F } & Significance of $F$ \\
\hline Between Groups & 121.4682 & 3 & 40.4894 & 58.3334 & .0000 \\
Within Groups & 63.1634 & 91 & .6941 & & \\
Total & 184.6316 & 94 & & & \\
\hline
\end{tabular}

Discussion, Hypothesis 1

\section{Entrepreneurs}

As indicated in Tables 39 and 40 by the proportion of each role type who agreed with the items, entrepreneurs exercise their creativity in all areas but hesitate to produce programs that might generate media controversy. They lead the other three role types in producing original work and presenting risky programs. They are also skilled at accessing organizational resources, equaling the administrator and exceeding the other two roles in meeting fundraising goals, utilizing corporate sponsors, and raising $50 \%$ percent of total revenues in earned income. 
Table 39.--Creativity Index Variables by Role Type, Percent Agreement

\begin{tabular}{lccccccc}
\hline & Pf & Or & Rs & Pl & Ex & Ed & Cn \\
\hline $\begin{array}{l}\text { Entrepreneur } \\
\text { \% Agreement }\end{array}$ & 50.0 & 75.0 & 83.3 & 75.0 & 75.0 & 91.7 & 16.7 \\
$(\mathrm{~N})$ & $(6)$ & $(9)$ & $(10)$ & $(9)$ & $(9)$ & $(11)$ & $(2)$ \\
Administrator & 22.7 & 9.1 & 22.7 & 59.1 & 13.6 & 77.3 & 00.0 \\
& $(5)$ & $(2)$ & $(5)$ & $(13)$ & $(3)$ & $(17)$ & $(0)$ \\
Artist & 50.0 & 71.4 & 78.6 & 92.9 & 85.7 & 96.4 & 35.7 \\
& $(14)$ & $(20)$ & $(22)$ & $(26)$ & $(24)$ & $(27)$ & $(10)$ \\
Caretaker & 18.2 & 21.2 & 24.2 & 39.4 & 9.1 & 60.6 & 00.0 \\
& $(6)$ & $(7)$ & $(8)$ & $(13)$ & $(3)$ & $(20)$ & $(0)$ \\
\hline
\end{tabular}

Variable Description

Pf = Programming format changed 1991

Or $=$ Produced original work 1991

Rs $=$ Produced risky programs 1991

$\mathrm{PI}=$ Demonstrated program leadership 1991

$E x=$ Produced experimental programs 1991

$\mathrm{Ed}=$ Produced educational programs 1991

$\mathrm{Cn}=$ Generated media controversy 1991 
Table 40.--Access to Resources Index Variables by Role Type, Percent Agreement

\begin{tabular}{|c|c|c|c|c|c|c|c|c|}
\hline & $\mathrm{Gr}$ & $\mathrm{Fn}$ & $\mathrm{Fa}$ & Cs & Lo & En & $\mathrm{Ei}$ & $\mathrm{Gr}$ \\
\hline $\begin{array}{l}\text { Entrepreneur } \\
\text { \% Agreement } \\
(\mathrm{N})\end{array}$ & $\begin{array}{r}66.7 \\
(8)\end{array}$ & $\begin{array}{r}75.0 \\
(9)\end{array}$ & $\begin{array}{r}75.0 \\
(9)\end{array}$ & $\begin{array}{l}100.0 \\
(12)\end{array}$ & $\begin{array}{r}75.0 \\
(9)\end{array}$ & $\begin{array}{r}41.7 \\
(5)\end{array}$ & $\begin{array}{r}33.3 \\
(4)\end{array}$ & $\begin{array}{r}41.7 \\
(5)\end{array}$ \\
\hline Administrator & $\begin{array}{l}86.4 \\
(19)\end{array}$ & $\begin{array}{l}72.7 \\
(16)\end{array}$ & $\begin{array}{l}77.3 \\
(17)\end{array}$ & $\begin{array}{l}90.9 \\
(20)\end{array}$ & $\begin{array}{l}81.8 \\
\text { (18) }\end{array}$ & $\begin{array}{l}50.0 \\
(11)\end{array}$ & $\begin{array}{r}27.3 \\
(6)\end{array}$ & $\begin{array}{c}45.5 \\
(10)\end{array}$ \\
\hline Artist & $\begin{array}{c}46.4 \\
(13)\end{array}$ & $\begin{array}{r}21.4 \\
(6)\end{array}$ & $\begin{array}{r}28.6 \\
(8)\end{array}$ & $\begin{array}{l}60.7 \\
\quad(17)\end{array}$ & $\begin{array}{l}64.3 \\
(18)\end{array}$ & $\begin{array}{l}7.1 \\
(2)\end{array}$ & $\begin{array}{l}17.9 \\
(5)\end{array}$ & $\begin{array}{r}32.1 \\
(9)\end{array}$ \\
\hline Caretaker & $\begin{array}{l}66.7 \\
(22)\end{array}$ & $\begin{array}{r}21.2 \\
(7)\end{array}$ & $\begin{array}{l}15.2 \\
(5)\end{array}$ & $\begin{array}{l}51.5 \\
(17)\end{array}$ & $\begin{array}{l}48.5 \\
(16)\end{array}$ & $\begin{array}{l}9.1 \\
(3)\end{array}$ & $\begin{array}{r}21.2 \\
(7)\end{array}$ & $\begin{array}{r}21.2 \\
(7)\end{array}$ \\
\hline
\end{tabular}

Variable Description

$\mathrm{Gr}=$ Received local government grants past four year

$\mathrm{Fn}=$ Met fundraising goals 1991

$\mathrm{Fa}=$ Owns fixed assets 1991

$\mathrm{Cs}=$ Had corporate sponsors 1991

Lo $=$ Had no loans or deficits 1991

$\mathrm{En}=$ Has endowment fund now

$\mathrm{Ei}=$ Earned income $=50 \%$ percent revenues

$\mathrm{Gr}=\mathrm{Grants}$ and donations $=40 \%$ revenues

Entrepreneurial managers, as demonstrated in Tables 41 and 42, are likely to be younger than 55 years, and be educated at the college and the graduate level. They show confidence in their ability to run their agencies, seen in Table 49 on Attitudes Toward Business Management, but profess a weak interest in business reports and methods. They recognize the changes inherent in the arts as an industry, demonstrated by their attitudes toward the business of the arts.

Table 41.-- Age by Managerial Role Type (in percent)

\begin{tabular}{llcc}
\hline \hline & & Under 55 Years & Over 55 Years \\
\hline Entrepreneur & $(\mathrm{N}=12)$ & 91.7 & 8.3 \\
Administrator & $(\mathrm{N}=22)$ & 90.9 & 9.1 \\
Artist & $(\mathrm{N}=28)$ & 78.6 & 21.4 \\
Caretaker & $(\mathrm{N}=33)$ & 72.7 & 27.3 \\
\hline
\end{tabular}


Table 42.--Education by Managerial Role Type (in percent)

\begin{tabular}{lcccc}
\hline \hline & $\mathrm{N}$ & Less than B.A. & B.A. & Greater than B.A. \\
\hline Entrepreneur & $(\mathrm{N}=12)$ & 8.3 & 33.3 & 58.4 \\
Administrator & $(\mathrm{N}=22)$ & 4.5 & 40.9 & 54.6 \\
Artist & $\mathrm{N}=28)$ & 25.0 & 53.6 & 21.4 \\
Caretaker & $(\mathrm{N}=33)$ & 24.2 & 30.3 & 45.5 \\
\hline
\end{tabular}

Entrepreneurs also share certain demographic characteristics, listed in Tables 43 and 44. They are affiliated with agencies that have been in existence for over five and usually over 15 years. Entrepreneurs tend to be associated more often with visual arts agencies and seldom with theatre and music agencies. They may find that there are greater opportunities (at less cost) for their creativity, originality and experimentation in a visual arts agency.

Table 43.--Agency Type by Role Type, Percent Agreement

\begin{tabular}{lccccc}
\hline & Other & Theatre & Music & Dance & Total Row \\
\hline $\begin{array}{l}\text { Entrepreneur } \\
\text { \% Agreement } \\
(\mathrm{N})\end{array}$ & $\begin{array}{c}25.0 \\
(9)\end{array}$ & $\begin{array}{c}10.0 \\
(1)\end{array}$ & $\begin{array}{c}5.3 \\
(2)\end{array}$ & 0 & 12.6 \\
Administrator & 22.2 & 0 & 31.6 & 18.2 & $(12)$ \\
& $(8)$ & & $(12)$ & $(2)$ & $(22)$ \\
Artist & 36.1 & 40.0 & 18.4 & 36.4 & 29.5 \\
& $(13)$ & $(4)$ & $(7)$ & $(4)$ & $(28)$ \\
Caretaker & 16.7 & 50.0 & 44.7 & 45.5 & 34.7 \\
& $(6)$ & $(5)$ & $(17)$ & $(5)$ & $(33)$ \\
\cline { 2 - 6 } Total & 37.9 & 10.5 & 40.0 & 11.6 & 100.0 \\
Column & $(36)$ & $(10)$ & $(38)$ & $(11)$ & $(95)$ \\
\hline
\end{tabular}




\section{1}

Table 44.--Agency Longevity by Role Type, Percent Agreement

\begin{tabular}{|c|c|c|c|c|}
\hline & Under 5 years & $5-15$ years & Over 15 years & Total Row \\
\hline $\begin{array}{l}\text { Entrepreneur } \\
\text { \% Agreement } \\
\text { (N) }\end{array}$ & 0 & $\begin{array}{r}12.8 \\
(6)\end{array}$ & $\begin{array}{r}17.6 \\
(6)\end{array}$ & $\begin{array}{l}12.6 \\
(12)\end{array}$ \\
\hline Administrator & $\begin{array}{r}14.3 \\
(2)\end{array}$ & $\begin{array}{r}19.1 \\
(9)\end{array}$ & $\begin{array}{r}32.4 \\
(11)\end{array}$ & $\begin{array}{l}23.2 \\
\quad(22)\end{array}$ \\
\hline Artist & $\begin{array}{r}64.3 \\
(9)\end{array}$ & $\begin{array}{l}31.9 \\
(15)\end{array}$ & $\begin{array}{r}11.8 \\
(4)\end{array}$ & $\begin{array}{l}29.5 \\
(28)\end{array}$ \\
\hline Caretaker & $\begin{array}{r}21.4 \\
\quad(3)\end{array}$ & $\begin{array}{r}36.2 \\
(17)\end{array}$ & $\begin{array}{r}38.2 \\
\quad(13)\end{array}$ & $\begin{array}{r}34.7 \\
(33)\end{array}$ \\
\hline $\begin{array}{l}\text { Total } \\
\text { Column }\end{array}$ & $\begin{array}{l}14.7 \\
(14)\end{array}$ & $\begin{array}{l}49.5 \\
(47)\end{array}$ & $\begin{array}{l}35.8 \\
(34)\end{array}$ & $\begin{array}{l}100.0 \\
(95)\end{array}$ \\
\hline
\end{tabular}

Entrepreneurs describe their agencies as in the process of change and under stress. For example, one manager stressed the need to recruit longer-term board members and to give them challenging tasks. He felt that a manager should concentrate on helping the board and staff to develop strategies instead of the operational level. Another manager acknowledged that grant money is disappearing and that agencies need to become selfsupporting, which will require a better understanding of fiscal realities. One entrepreneurial manager felt that arts managers need to develop business skills because donor corporations will require convincing evidence that their support represents a wise investment of scarce funds. They will want to know if the agency has stable management and organization, and this manager felt it was important to have a creative, aggressive approach. In essence, he said, the manager needs determination, creativity, resourcefulness, open-mindedness, people-orientation, and no ego problem.

Several entrepreneurial managers stressed that a successful agency requires artistic impulses, good business sense and good people skills, and reliable intuitive thinking. One 
manager stated clearly, "My job is to sell the mission, to make things happen, to make growth and change occur, to work into the future, to capture the skills of the staff."

\section{Administrators}

Administrators, as revealed in Table 39, are less involved in program creativity: they rarely produce original work or experimental programs and never generate public controversy. Their most creative programs are educational, since they view these as necessary to generate grant funds.

In accessing organizational resources, demonstrated by Table 40 , administrators are consistently successful. Half of all the administrative managers have current endowment funds in place and over three-quarters received local government grants over the last four years. Over three-quarters of them also own fixed assets, and they lead the other role types in avoiding loans or deficits by a wide margin.

Tables 41,42 and 43 reveal that administrators are also younger managers, with equal numbers having undergraduate and graduate degrees. They are concentrated in music agencies and are underrepresented in theatre and other agencies.

Most administrators describe their agency life cycles as growing and changing, unlike the other role types, who claim that their agencies are changing or declining. Their business-like orientation helps them to cope with environmental changes. To illustrate, one respondent stated that arts agencies will increasingly require a more businesslike approach, meaning marketing will become an important tool to sell themselves. They will need to develop new strategies for subscribers. Their greatest challenge is to increase audience size because people are making economic decisions in their purchase of arts-oriented activities, this manager reported.

A more enthusiastic (and younger) administrator stated that the manager is the embodiment of the attitude of the organization. "You need to exude confidence. The manager is the key. You must be overly optimistic, constantly, and work a lot." 


\section{3}

Still another manager recounted her previous government work, which gave her experience in grant writing, public policy, and politics--all useful skills in running an arts agency. She found the skills needed for good administration were all business-oriented, such as budgeting, planning, projecting, forecasting, and demographic and competitive analysis.

\section{Artists}

Artists are the most committed to creative programming, demonstrated by their high level of agreement with program leadership shown in Table 39. They also displayed higher percentages of agreement than other role types in producing experimental programs and generating media controversy. Artists are less successful than other role types in the general area of access to organizational resources, shown in Table 40. They are the least likely of any role type to generate local government loans, establish an endowment fund, or generate at least half of their agency's revenue from earned income.

Tables 41 and 42 reveal that artists are comprised of younger and older managers in approximately equal percentages. Their education ranges from secondary to college level, with few at the graduate level. In terms of organizational factors, seen in Tables 43 and 44 , artists are heavily concentrated in very young agencies (less than 5 years), with a strong representation in theatre, dance and other, but an underrepresentation in music.

Artists reveal a lack of confidence in confronting arts competition, but reject luck as a significant factor in agency success, perceiving their agencies as growing and changing. To illustrate, a worried manager reported that it is difficult to balance artistic interests with business techniques, because the arts have a different value system without a tangible and immediate response or benefit. She asked if arts or business should take precedence, and which balance better articulates the mission--it's a delicate question.

Another manager of a now-defunct agency reported, "We were artists who were concerned with creating and sharing an artistic vision and spirit. We didn't have either [the 
realization of] need or appreciation of financial support. We used all of our own money. We felt a desire to give back to our black community." A third manager summed up the feeling of artists in agencies: "I've seen arts organizations ruined by business types who failed to see that the art must satisfy the artist as well as make a profit."

\section{Caretakers}

Caretakers are relatively low in both creativity and access to resources. According to Table 39, caretakers report rarely taking any risk or experimenting. They are unlikely to claim leadership in programming and make few changes in formats of their annual programs. Table 40 reveals that in generating revenues, only half of the caretakers report no loans or deficits, compared to almost three-quarters of other roles. They rarely meet fundraising goals and have grave difficulties generating both earned income and grants or donations in substantial amounts. Caretakers obviously demonstrate an organizational stability that impresses granting committees despite their limited involvement in creative planning and access to organizational resources. As a group, they equal entrepreneurs in wiming local government grants for the past four years.

Caretakers are generally older managers, seen in Tables 41 and 42, whose education is concentrated at the Bachelor's and Master's level. Few have any business or management education beyond sporadic coursework. Caretakers are found in agencies of varying ages and all agency types, with a smaller representation in other alternatives (See Tables 43 and 44). Caretakers are over-represented in declining and mature agencies, seen in Table 45.

A manager of a youth orchestra summed up the fears of the Caretaker manager: "I'm training 120 kids and the orchestras, and they're shaping the world I'm living in. I'm having such a hard time; I feel all alone out here." 


\section{5}

Table 45.-- Organizational Lifecycle by Manager's Role Type, Percent Agreement

\begin{tabular}{|c|c|c|c|c|c|}
\hline & Entrepreneur & Administrator & Artist & Caretaker & Total \\
\hline $\begin{array}{l}\text { Developing } \\
\text { (N) }\end{array}$ & $\begin{array}{l}8.3 \\
(1)\end{array}$ & $\begin{array}{c}9.1 \\
(2)\end{array}$ & 7.1 & $\begin{array}{l}3.0 \\
(1)\end{array}$ & $\begin{array}{l}6.3 \\
(6)\end{array}$ \\
\hline Growing & $\begin{array}{l}16.7 \\
(2)\end{array}$ & $\begin{array}{l}40.9 \\
(9)\end{array}$ & $\begin{array}{c}35.7 \\
(10)\end{array}$ & $\begin{array}{r}27.3 \\
(9)\end{array}$ & $\begin{array}{l}31.6 \\
(30)\end{array}$ \\
\hline Mature & $\begin{array}{l}8.3 \\
(1)\end{array}$ & $\begin{array}{r}13.6 \\
(3)\end{array}$ & $\begin{array}{c}7.1 \\
(2)\end{array}$ & $\begin{array}{r}15.2 \\
(5)\end{array}$ & $\begin{array}{c}11.6 \\
(11)\end{array}$ \\
\hline Declining & 0 & $\begin{array}{l}4.5 \\
(1)\end{array}$ & $\begin{array}{c}7.1 \\
(2)\end{array}$ & $\begin{array}{r}12.1 \\
(4)\end{array}$ & $\begin{array}{r}7.4 \\
(7)\end{array}$ \\
\hline \multirow[t]{2}{*}{ Restructuring } & $\begin{array}{r}66.7 \\
(8)\end{array}$ & $\begin{array}{l}31.8 \\
(7)\end{array}$ & $\begin{array}{c}42.9 \\
(12)\end{array}$ & $\begin{array}{l}42.4 \\
(14)\end{array}$ & $\begin{array}{l}43.1 \\
(41)\end{array}$ \\
\hline & $\begin{array}{l}12.6 \\
(12)\end{array}$ & $\begin{array}{l}23.2 \\
(22)\end{array}$ & $\begin{array}{l}29.5 \\
(28)\end{array}$ & $\begin{array}{c}34.7 \\
(33)\end{array}$ & $\begin{array}{r}100.0 \\
(95)\end{array}$ \\
\hline
\end{tabular}

Implications of Findings

\section{Programmatic Creativity}

Few managers of any type supported imaginative programming, reporting a concern with audience rejection and financial risks. Administrators and caretakers were especially likely to report an unwillingness to change program formats. The problem of presenting original, risky or experimental work was tackled by entrepreneurs and artists, but rarely attained the highest levels posed by the survey--a scant $20 \%$ of agency programming per year. Artists claimed greater program leadership than other role types (92.9\%) because of their commitment to art over business, but this produced other problems of priorities, such as a lack of attentiveness to standard business methods, i.e. meeting fundraising goals or earning half of their revenue through services or performances. Caretakers appeared to understand their tentative position as their responses on most creativity variables fell far short of other role groups. For example, they ranked 
lowest of the four roles in the areas of annual program format changes and program leadership. Neither administrators nor caretakers reported engagement in any controversial issue. All four role types were committed to educational programming, largely because almost every grant application requires this.

In general, the data on creativity and access to resources appear to support the opinion of one manager, who stated that while the career choice of arts administration required passion and commitment to the arts, choices must be made regarding how to tailor the artistic programming to the general economic environment. "I wouldn't do something terribly risky right now."

\section{Generating Revenue}

Among the variables access to organizational resources, as seen in Table 43, administrators were the most successful in generating local government grants, while artists were the least successful. Artists and caretakers also reported low percentages both in meeting their 1991 fundraising goals and in earning $40 \%$ percent of revenue through grants and donations. Managers in all roles realized the need to tap the corporate world as a resource: most had avoided loans and deficits.

All role types demonstrated low percentages in generating half their revenues from earned income, seen in Table 40. No role type reported more than the entrepreneur $(33.3 \%)$ in the ability to earn $50 \%$ percent of revenues. Artists displayed the lowest percentages of $17.9 \%$ percent. Administrators led the four roles in generating grants and donations (45.5\%), demonstrating that all role types were unable to earn half of their revenues. This finding was supported by anecdotal evidence by managers.

To illustrate, a symphony orchestra facing insurmountable fiscal problems in 1991 used pre-concert time to reveal the agency's financial plight to the audience. The manager and board also targeted wealthy patrons and instituted a mail campaign, raising money by crisis. The board rallied by maximizing their contacts among potential donors, while the 
agency employed the media to advertise both their plight and internal sacrifices (agency members and employees donated back a portion of their salaries).

In another example, the manager and a trustee lent money to support the agency. This group managed tenuously from concert to concert. Ultimately, the players and conductor voted to forgo pay in order to complete the season. This familiar story was repeated endlessly. In one instance a manager gave up his salary to avoid an operating deficit. The net impression here is that managers are at once immensely dedicated and highly resistant to change.

\section{Influence of Agency Type}

Role groups were affected not only by variables of creativity and access to resources, but also by selected institutional variables. Agency type (Table 43) was significant in differentiating role groupings. Entrepreneurs were underrepresented in theatre and music, and absent in dance. They were concentrated in a category called "other," which was most heavily populated by visual arts groups. Administrators, conversely, were concentrated in music groups, with a small representation in dance and not in "other" or theatre. Artists were found mostly in theatre and dance, with a strong showing in "other," but less so in music. Caretakers were evenly distributed in all agencies except "other."

There are some readily apparent reasons for these choices. Creativity, in combination with organizational resourcefulness, is a major component of entrepreneurship. While managers of performing arts agencies displayed a hesitancy to take creative risks in an uncertain environment, responding in the negative to most questions regarding creativity, entrepreneurs, who for the most part lead visual arts agencies, were able to reply positively and truthfully that they presented only original work in a constantly changing format. Compared to performing arts organizations, which only occasionally have an opportunity to present original work, visual arts agencies deal solely 
in this quantity. This difference between roles regarding agency types may not actually skew the identification of managers as entrepreneurs, but it does suggest that creative opportunities for entrepreneurship are, at present, located more in visual arts agencies, which might also include museums. The three other role types displayed characteristics which were entirely consistent with the types of agencies they led. Administrators were affiliated with large symphonies or theatres, artists led dance or small theatre or music groups, and caretakers were evenly spread around all agency types.

\section{Influence of Agency Age}

Entrepreneurs and administrators were heavily concentrated in groups with greater longevity since incorporation, especially those over 15 years old (Table 44). There were no entrepreneurs in groups under five years old. Artists were more commonly found in much younger groups and concentrated in those groups under five years old. Caretakers were evenly distributed in all three age groups.

Downs (1967) suggests that agency longevity predisposes a board and members of the agency to conservative behavior. A manager illustrated this theory, citing these major board problems: conservative behavior in programming choices, inexperience in the arts, and avoidance of leadership in the area of mission and goal setting. Another manager found that longevity bred power struggles within the board, engendered risk-averse programming, and fostered trustee passivity in fundraising. According to managers, entrenched boards tended to view a manager's artistic judgements as an affront to established patterns of operation. Managers are continually presenting ideas, educating boards, and defending their choices. The frequent turnover of boards as terms expire, members resign, or managers change, creates additional problems of board socialization and motivation. A William and Mary professor of business administration called this problem "a lack of institutional memory." 
Influence of Agency Structure

The four ways in which agencies are structured (Table 46) were defined in the questionnaire as sole management, dual management with business leadership, dual management with artistic leadership, and board-only management. An examination of the variable of agency structure, or the governing framework of an agency, reveals some interesting relationships with role types.

Table 46.--Agency Structure by Role Type Percent Agreement

\begin{tabular}{lcccc}
\hline Role Type & Single Manager & $\begin{array}{c}\text { Dual Mgmt } \\
\text { Business Leads }\end{array}$ & $\begin{array}{c}\text { Dual Mgmt } \\
\text { Artistic Leads }\end{array}$ & $\begin{array}{c}\text { Board Mgmt } \\
\text { Only }\end{array}$ \\
\hline Entrepreneur $(\mathrm{N}=12)$ & 50.0 & 16.7 & 8.3 & 25.0 \\
Administrator $(\mathrm{N}=22)$ & 50.0 & 27.3 & 18.2 & 9.1 \\
Artist $(\mathrm{N}=28)$ & 32.1 & 10.7 & 17.9 & 39.3 \\
Caretaker $(\mathrm{N}=33)$ & 30.3 & 18.2 & 15.2 & 36.4 \\
\hline
\end{tabular}

Single Manager: A single manager controls both the artistic and management functions. Entrepreneurs and administrators are disproportionately represented in agencies with single managers. Fifty percent of the respondents of each type reported from agencies with a single managerial positions. Twenty-five percent of entrepreneurs were in board management only and the remaining were largely in dual business management, with an adjunct artistic director.

Dual Management, business manager leads: A dual management structure features a business manager who runs the agency with a separate artistic director who plans program elements.

Administrators (27.3\%), many of whom are affiliated with large symphony orchestras, which normally divide the duties of business and art in a variety of ways, 
reported they controlled management functions with the assistance of a separate artistic director in charge of planning program elements. Another $18.2 \%$ percent of administrators were found in another type of dual management (typical of an orchestra or opera company): an artistically centered agency with a separate business manager who controls management elements. Few administrators were found in board-only structures.

Dual Management, artistic director leads: A dual management structure features an artistic manager/administrator and a separate business manager who controls the management elements.

No single role group predominated in artistic management with a separate business manager. Administrators, artists and caretakers were all represented in about the same percentages in this group. Entrepreneurs displayed the lowest percentages in this type of management structure.

No designated manager, board members lead: A Board of Directors handles agency business; there are no paid managerial staff.

These agencies functioned without a designated manager. The normal managerial tasks were often divided between the board's president, the chairman of a board committee, or even an artistic leader, such as a theatre director or chorale leader. Over one-third of all artists and caretakers fell into this group, as did as one-quarter of entrepreneurs. Administrators, who tend to demonstrate the ability to manage large and complex agencies with large budgets, were underrepresented in this structural group (9.1\%).

There is further evidence that structural differences influence or parallel roles, especially in the abilities of the manager to generate total gross revenues. Table 47 demonstrates that an analysis of variance was used to examine differences among mean gross revenues for the different management structures. There were significant differences between dual management (artistic director) and board only, dual management (artistic 
director and single manager, dual manager (business manager) and board only, and dual manager (business manager) and single manager. There was no difference between the two types of dual management.

Table 48 shows that dual management (business manager) displays the highest mean value of revenue, followed by dual management (artistic director) and single manager with board only management the lowest. The positions of dual management (business manager) and board management parallel the role types administrator and caretaker.

Table 47.--Analysis of Variance: Management Structure (Independent Variable) by Total Gross Revenues (Dependent Variable)

\begin{tabular}{llrcrc}
\hline \hline Source & SS & df & MS & F & Significance of F \\
\hline Between Groups & 6.6009 & 3 & 2.2003 & 7.6495 & .0001 \\
Within Groups & 3.065 & 108 & 2.8764 & & \\
Total & 3.7666 & 111 & & & \\
\hline
\end{tabular}

Table 48.--Mean Revenues by Four Management Structures

\begin{tabular}{lc}
\hline \hline Management Structure & Mean Revenue \\
\hline Single manager* & $\$ 172,394$ \\
Dual management, business manager leads* & $\$ 663,491$ \\
Dual manager, artistic director leads* & $\$ 564,539$ \\
Board management only* & $\$ 55,094$ \\
\hline
\end{tabular}

* Significant at $\mathrm{p}=.050$, Tukey $\mathrm{B}$ method

\section{Role Types and Attitudes Toward Change}

A question on managerial attitudes seen in Table 50, segmented by role type, that produced a response at the level .050 , asked does "the manager expect change as a constant in an arts agency?" The question was included in the attitude statements in order to determine the effects of diminished funding and political and philosophical attacks. For 
several decades, since the establishment of the National Endowment for the Arts and the National Endowment for the Humanities, the stability of arts agencies has been closely tied to a steady source of government funding at all levels. An additional substantial source of revenue from corporate funding further bolstered the confidence of agencies to expand their programs and services. The sudden crisis in the arts precipitated by the economic recession and the strident political attacks has caused many arts managers to expect change as a constant for the foreseeable future. This study notes differing levels of agreement among role types on the inevitability of change in arts agency management, with a high level of agreement indicating that the agency feels compelled to adjust its management behaviors to adapt to environmental shifts. The term "restructuring" is used here interchangeably with "change" to denote an agency in the process of some policy or administrative shift.

Among role types, shown in Table 50, only administrators (77.3\%) demonstrated percentages of agreement less than $90 \%$ percent on the inevitability of change, revealing they were not as completely convinced as other roles. Administrators, who run agencies of longstanding, with large and complex staffs, boards, and budgets, may feel somewhat insulated from the threat of immediate termination. They are already familiar with a bureaucratic structure and are rapidly incorporating many business-like techniques.

Change is a charged issue for most of the arts administrators in this study, however, who see the multifaceted dangers of a changing economy and a changing audience. They report a uniform trend to populism in artistic programming which, in the minds of the managers surveyed, equals a diminished quality of performance. They report that some boards of directors, in an attempt to stabilize the business side of the agency, are instituting new goals, aimed at generating revenue, which detract from the essential creativity of the original agency mission. Further changes mentioned were the new professionalism demanded of arts agencies and their managers by the critical government cutbacks and diminished philanthropy. Managers generally view their future as more bureaucratic and less spontaneous, more competitive and less artist/mission driven, more 
self-sufficient and less government subsidized. While not all of these changes are mutually exclusive, they all require changes by many of this population of managers who consider themselves generally poorly-prepared. Anecdotal evidence from managers in this study who insisted that arts agencies are moving toward business-oriented systems suggests that future arts managers could profit from experience with variety of business skills, including budgeting, marketing, advertising, grant proposal writing, telemarketing, list brokers, spread sheets, databases, word processing, computer graphics, public relations, billing, personnel administration, policy making and contracting. This multiplicity of business techniques was not suggested or affiliated with any single role type. Many managers identified similar business functions as potentially useful. One manager felt it was especially important to be able to collect and disseminate computerized information as part of the arts administrative duties, while another was already compiling a database of practitioners of a particular performing art in a specific region. The rationale for the expenditure of time and money on this database was the ability to assemble performers who could serve as a for-profit performing arm for the agency.

Some managers felt the need for a change to a business orientation so keenly that they voiced some hostility toward their associates still adhering solely to an artistic mission. A manager described the changing business climate, "In this environment agencies will need to be management driven. [It is important to] not only satisfy artistic desires, which are self-indulgent. We need the clear head of management over self-centered artists." A second manager reiterated this thought with his comment that "there is a shift in the arts from creativity to business because of economics and politics. Tension arises when the manager has the responsibility to tell the artistic director that not all monies can go to the creative side. The future means less programming, greater selectivity by the manager."

A third manager summed up the conflict with a cooperative vision: "You need to capture a partnership between the management and the artistic sides--a tension. Need to have similar strong egos, respect, dedication and a shared artistic vision. Need to move 
forward with similar energy and put cause before personality." The researcher finds that personality is a key word here, and that it can be easily interchanged with creativity. Since creativity is at the heart of the arts, this proposal may suggest that creativity should be subsumed under expediency. This may be the reality of the arts in the 1990 s.

Table 50.--Attitude Statements by Role Type Percent Agreement and Disagreement

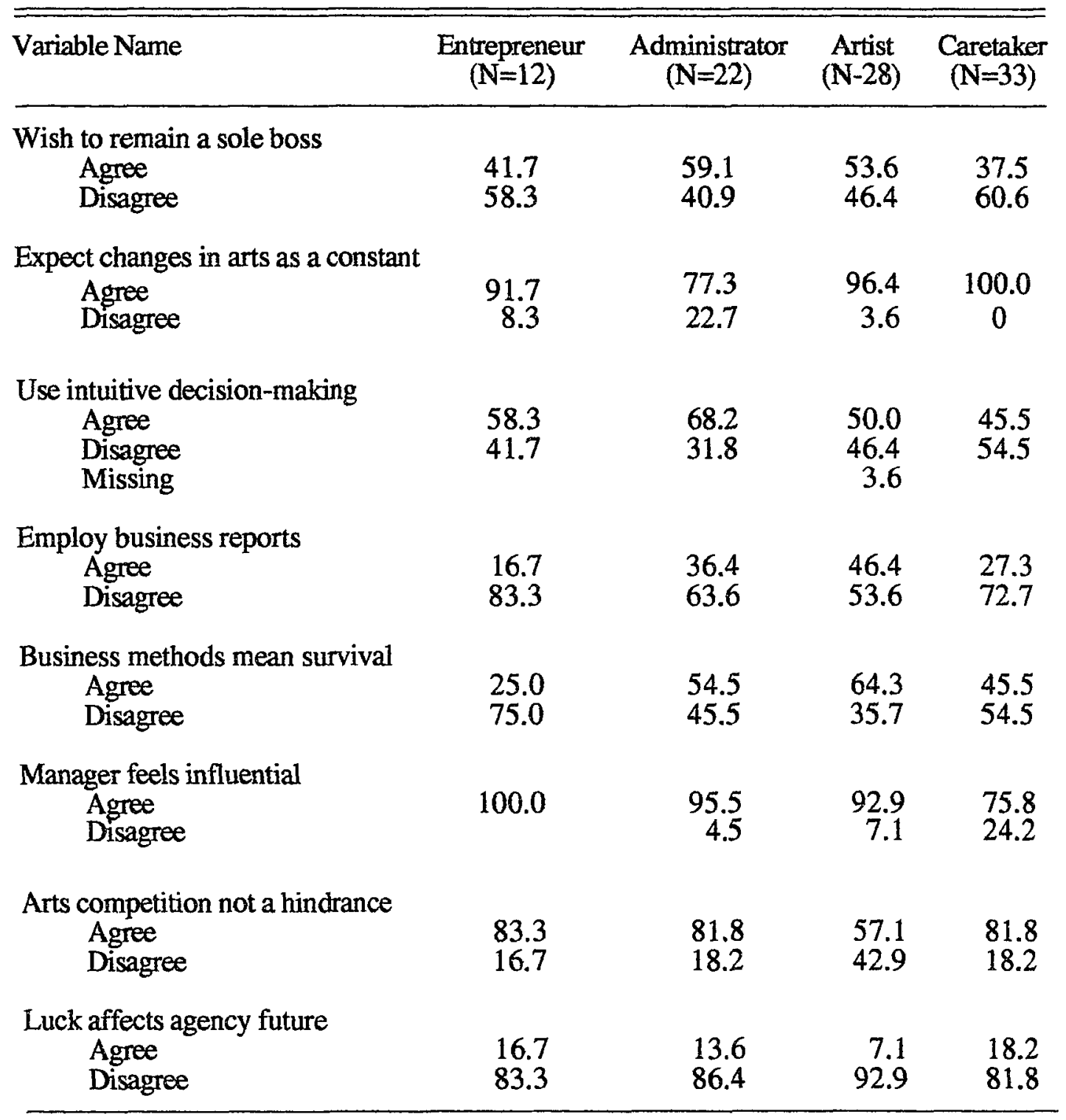




\section{Research Question 2}

Part One: Internal Arts Management

Research Question 2. How does each role type perform the management tasks involved in running an agency (internal arts management)?

Each management role will emphasize and prioritize selected aspects of internal arts management tasks.

\section{Data Analysis}

An index of Internal Agency Management Performance, seen in Table 51, displays 13 variables (mean $=6.45$, range $=0-12, \mathrm{Std}=2.56$ ) that show weak to moderate item-toitem correlations $(p=.010)$. Strong item-to-index correlations, however, suggest that this group of variables constitutes a useful measure of a single concept.

Interesting moderate correlations $(r=.43)$ appear among several variables related to fiscal management, such as "the manager and the board of directors set fundraising policy together" and "the manager and the board of directors jointly determine goals and objectives." As well, there is a significant, but modest correlation $(r=.24)$ between "separate budgeting committee on the board of directors" and "agency has an endowment fund in place." The budgeting committee appears again in a modest (and significant) correlation $(r=.23)$ among the variables "Separate budgeting committee on the board of directors" and "Annual evaluation of goals and mission." The implication is that a larger and more diverse board of directors, encompassing members skilled in fiscal policy, goal setting and annual evaluation promotes a more stable organization, demonstrated by the esiablishment of an endowment fund. 
Table 51.-- Correlations, Means, and Standard Deviations of Items in Internal Management Index

\begin{tabular}{|c|c|c|c|c|c|c|c|c|c|c|c|c|c|c|}
\hline Variable & $\mathrm{Au}$ & Go & $\mathrm{Ev}$ & $\operatorname{Pr}$ & Bd & Fd & Ad & An & Jn & II & En & $S p$ & Cr II & Index \\
\hline $\mathrm{Au}$ & 1.00 & .21 & .21 & .09 & .01 & $.22 *$ & .15 & .14 & $.23 * *$ & .06 & .07 & -.01 & .10 & .38 \\
\hline Go & & 1.00 & .19 & .12 & .03 & $.43^{* *}$ & .04 & .06 & -.04 & -.05 & -.10 & .06 & -.04 & .33 \\
\hline $\mathrm{Ev}$ & & & 1.00 & .00 & $.23 * *$ & .07 & $.26 * *$ & .18 & .09 & .17 & .18 & .16 & .14 & .49 \\
\hline Pr & & & & 1.00 & .10 & .15 & -.01 & -.01 & -.09 & .06 & .12 & .11 & .08 & .31 \\
\hline $\mathrm{Bd}$ & & & & & 1.00 & .11 & .03 & .09 & .11 & .12 & $.24^{* *}$ & .13 & $.22 * *$ & .44 \\
\hline $\mathrm{Fd}$ & & & & & & 1.00 & .04 & .09 & -.03 & .15 & -.02 & .08 & -.13 & .37 \\
\hline $\mathrm{Ad}$ & & & & & & & 1.00 & $.64^{*}$ & .21 & .20 & .09 & .16 & $.26 * *$ & * .49 \\
\hline An & & & & & & & & 1.00 & .17 & .07 & .12 & $.32 * * *$ & .26 & .50 \\
\hline Jn & & & & & & & & & 1.00 & .03 & .19 & .15 & $.38 * *$ & ". .44 \\
\hline I & & & & & & & & & & 1.00 & .17 & $.26^{*}$ & $.29 * *$ & k .42 \\
\hline En & & & & & & & & & & & 1.00 & .20 & $.34 * *$ & * .45 \\
\hline$S p$ & & & & & & & & & & & & 1.00 & $.26 * *$ & .53 \\
\hline $\mathrm{Cr}$ & & & & & & & & & & & & & 1.00 & .53 \\
\hline Mn & .87 & .71 & .70 & .76 & .54 & .69 & .14 & .12 & .50 & .47 & .20 & .50 & .33 & 6.47 \\
\hline Std & .33 & .45 & .45 & .42 & .49 & .46 & .35 & .33 & .50 & .50 & .40 & .50 & .47 & 2.57 \\
\hline
\end{tabular}

Variable Description

$\mathrm{Au}=$ Manager has autonomy with board

Go = Manager determines goals/objectives with board

Ev = Annual evaluation of goals/mission

$\operatorname{Pr}=$ Professional skills on board

$\mathrm{Bd}=$ Separate budgeting committee

$\mathrm{Fd}=$ Manager and board set fundraising policy

$\mathrm{Ad}=$ Market audit in last two years

An = Market program analysis in last two years

Jn $=$ Subscribe to management journal

Id = Identify long term facility neeils

$\mathrm{En}=$ Endowment fund in place

$\mathrm{Sp}=$ Planning committee on board

$\mathrm{Cr}=$ Attend arts management conference

** Significant at $p=<.010$

\section{Guttman Scales}

A Guttman scalogram analysis was performed to test the unidimensionality of each indexed measure and to gauge respondents' answers more precisely. A Guttman Scale created from 12 items on the Internal Agency Management Index revealed that 13 response 
patterns matched valid scale types. These constitute $11.0 \%$ percent of the survey population. The descending order of scaled items was as follows: managers claimed an autonomous relationship with their board (i.e., they were seldom overridden in their decisions), evaluation of agency goal and mission, goal setting by manager and board, and setting fundraising policy by manager and the board. The least frequently observed variables were performing marketing studies and installing in endowment fund. The items and responses constitute a valid Guttman Scale with a reproducibility of .89 , a minimum marginal reproducibility of .69 and coefficient of scalability of .65 .

\section{Hypothesis 2 \\ Part One}

Hypothesis 2, part one. The arts agency's functioning will be affected by its leader's arts management role. The entrepreneur and administrator will report higher levels of participation in internal agency management tasks than other role types.

The hypothesis is accepted as data demonstrate differences among all four managerial roles on the dimension of Internal Agency Management Tasks. An analysis of variance of Internal Agency Management Index scores by four role types, seen in Table 53, found statistically significant differences among those scores at $p=.050$ (Tukey $B$ method). There were significant differences between Entrepreneurs and Caretakers, Administrators and Caretakers,and Administrators and Artists. Table 52 reveals that Administrators recorded the highest mean score, followed by Entrepreneurs, Artists and Caretakers. 
Table 52.-Mean Values of Internal Agency Management Index Scores by Role Types

\begin{tabular}{lccccc}
\hline \hline & Entrepreneur & Administrator & Artist & Caretaker & Total \\
\hline Mean & $7.91^{*}$ & $8.86^{*}$ & $6.16^{*}$ & $5.80^{*}$ & 6.84 \\
$(\mathrm{~N})$ & $(12)$ & $(15)$ & $(24)$ & $(26)$ & $(77)$ \\
\hline
\end{tabular}

* Significant at $\mathrm{p}=.050$, Tukey B method

Table 53.--Analysis of Variance: Role Types (Independent Variable) by Internal Agency Management Index Scores (Dependent Variable)

\begin{tabular}{lcrrrr}
\hline \hline Source & SS & df & MS & F & Significance of F \\
\hline Between Groups & 114.1081 & 3 & 38.0360 & 6.90 & .0004 \\
Within Groups & 402.0218 & 73 & 5.5071 & & \\
Total & 516.1299 & 76 & & & \\
\hline
\end{tabular}

Discussion, Hypothesis 2

Part One

Sub-hypothesis 2.1

Sub-hypothesis 2.1: The entrepreneurial manager will define agency goals, interact positively with the board of directors, create reliable business practices, and be proactive by instituting long- and short-term planning.

Sub-hypothesis 2.1 is accepted. Table 54 displays that over two-thirds of all entrepreneurs characterized their work positively on all items except "I now have an endowment fund in place" and "I now have a strategic planning committee on the board." On all other items of Internal Agency Management, entrepreneurs report high levels of agreement. About two-thirds of all entrepreneurs agree with the items "I determine goals and objectives annually in joint meetings with my board of directors" and "I now have a 
budgeting committee within my board." They report higher levels of involvement with evaluating agency goals and mission, establishing autonomy within their boards, establishing long-term facility programs, and installing useful professionals as board members-all activities relevant to the task of creating reliable business practices.

Table 54.--Internal Agency Management Variables by Role Types Percentage of Agreement

\begin{tabular}{lcccccccc}
\hline \hline Role Type & $\mathrm{Gl}$ & $\mathrm{Au}$ & $\mathrm{Sk}$ & $\mathrm{Bg}$ & $\mathrm{Ev}$ & $\mathrm{En}$ & $\mathrm{Fc}$ & $\mathrm{Pl}$ \\
\hline Entrepreneur & 66.7 & 88.3 & 91.7 & 66.7 & 91.7 & 41.7 & 75.0 & 58.3 \\
$(\mathrm{~N})$ & $(8)$ & $(10)$ & $(11)$ & $(8)$ & $(11)$ & $(5)$ & $(9)$ & $(7)$ \\
Administrator & 77.3 & 86.4 & 81.8 & 63.6 & 86.4 & 50.0 & 45.5 & 63.6 \\
& $(17)$ & $(19)$ & $(18)$ & $(14)$ & $(19)$ & $(11)$ & $(10)$ & $(14)$ \\
Artist & 82.1 & 89.3 & 67.9 & 46.4 & 60.7 & 7.1 & 42.9 & 50.0 \\
& $(23)$ & $(25)$ & $(19)$ & $(13)$ & $(17)$ & $(2)$ & $(12)$ & $(14)$ \\
Caretaker & 72.7 & 87.9 & 84.8 & 45.5 & 60.6 & 9.1 & 33.3 & 39.4 \\
& $(24)$ & $(29)$ & $(28)$ & $(15)$ & $(20)$ & $(3)$ & $(11)$ & $(13)$ \\
\hline
\end{tabular}

Variable Description

$\mathrm{Gl}=$ Manager sets goals with board

$\mathrm{Au}=$ Manager has autonomy with board

$\mathrm{Sk}=$ Professionals serve on board

$\mathrm{Bg}=$ Budgeting committee within board

$\mathrm{Ev}=$ Evaluate goals and mission

$\mathrm{En}=$ Have an endowment fund

$\mathrm{Fc}=$ Have long-term facility planning committee

$\mathrm{Pl}=$ Have strategic planning committee on board

\section{Sub-hypothesis 2.2}

Sub-hypothesis 2.2: The administrative manager will determine agency goals, interact positively with the board of directors, emphasize business practices, but will be basically reactive with little interest in long-term pianning.

Sub-hypothesis 2.2 is supported as Table 54 demonstrates that administrators behave similarly to entrepreneurs in most facets of internal agency management tasks. Administrators reveal a weakness in long-term facilities planning compared to entrepreneurs, displayed as a reduced percentage of agreement with the statement "I now 
have a long-term facility planning committee." A possible explanation may be the affiliation of administrators with large and complex agencies, such as large symphonies or orchestras, which already own or rent a substantial facility. It is unlikely that a major professional symphony orchestra, opera, or theatre would have evolved into an established organization without securing a permanent performing space, and the economic situation in the 1990s likely would preclude any interest in updating or replacing such a structure, even if the need was apparent or overdue.

In the area of long-range and strategic planning, however, administrators made a strong showing. While theory suggested that an administrative manager would favor reactive over proactive management, data did not support this conjecture. Table 54 demonstrates that administrators performed as highly as entrepreneurs in establishing a strategic planning committee within the board of directors.

\section{Sub-hypothesis 2.3}

Sub-hypothesis 2.3: The artistic manager will determine the agency's artistic goals, de-emphasize interaction with the board of directors, de-emphasize the use of standard business practices, and focus on short-term rather than long-term planning.

Sub-hypothesis 2.3 is supported by the data, as shown by Table 54 . Artists displayed the highest percentages of agreement with the questionnaire statement "I determine the goals and objectives of this agency annually in joint meetings with my board of directors." The artist exceeded the entrepreneur and the administrator on this variable. The joint decision-making between the artist and board is further supported by anecdotal evidence, suggesting that this role type carefully avoids confrontation with the board. An agency administrator noted that boards tend to rely heavily on artistic managers who have demonstrated a strength in intuitive and creative issues. These managers, however, work closely with the board to achieve consensus on program issues in order to avoid the discomfort of the board if a projected program fails to achieve audience approval. Theories 
on artist-board relationships do not propose this kind of manager-board cooperation; several theorists in fact suggested that the artistic manager deliberately impedes the flow of information to the board in order to realize his artistic visions.

As hypothesized and revealed in Table 54, artists demonstrated lower percentages of agreement with business methodology than administrators or entrepreneurs. They displayed much lower percentages of agreement on the following items: establishing an endowment fund, recruiting useful professional skills on the board, performing annual evaluations, establishing long-range facilities programs, and creating planning committees. In performing each of these tasks of internal management there was a split in the data between the high levels of agreement displayed by entrepreneurs and administrators, and the much lower levels of agreement of artists and caretakers.

\section{Sub-hypothesis 2.4}

Sub-hypothesis 2.4: The caretaker manager will focus on daily operation of the agency with less emphasis on goal-setting, interacting with a board of directors, using standard business practices or long-term planning. He/she will basically manifest a holding action behavior.

This sub-hypothesis is largely supported by data in Table 54, which shows that the percentages of agreement for caretakers fall far below other role types on most variables. However, there were several areas in which caretakers demonstrated unexpected strength. Over three-quarters of caretakers agreed with the statement "I now have a working board of directors that encompasses professional skills, such as law, accounting and business." Caretakers also demonstrated a high level of involvement with the board of directors by their high percentages of agreement (72.7\%) with the item "Manager determines goals and objectives of the agency in joint meetings with the board." These variables suggest a close relationship between the manager and board that is possibly explained by the fact that many caretaker managers are the de facto agency managers in the absence of a paid or unpaid 


\section{2}

manager. In responding to these questionnaire items, the manager-respondent represented both himself and the board of directors, which accounts for the appearance of a strong manager-board bond. 


\section{Research Question 2 \\ Part Two: External Arts Management}

Research Question 2. How does each role type perform the management tasks involved in representing the agency to the larger community (external relations)?

Each management role will emphasize and prioritize selected aspects of external arts managements tasks.

\section{Data Analysis}

An index created for External Agency Management Performance included 15 variables $($ mean $=7.017$, range $=0-15$, and $\mathrm{Std}=3.867$ ) and showed moderate correlations among items suggesting agency use of marketing methodology and business techniques . Table 55 displays a moderate correlation $(r=.43)$ among the variables "assessed the local economic condition in 1991 to determine the potential for success of agency performances and services" and "produced a market study of the strengths and weaknesses of this agency ."The variable "assessed local economic condition" was similarly correlated $(r=.37)$ with "conducted a name recognition study of the agency in the community." Again, the variable "assessed the local economic condition in 1991" was correlated moderately $(r=.43)$ with "networked in the community on behalf of the agency." Efforts such as marketing and networking demonstrate arts agencies attempts to to create a larger market for their services by using new business methods to assess and evaluate audience demand. 
Table 55.--Correlations of Items in External Management Index

\begin{tabular}{|c|c|c|c|c|c|c|c|c|c|c|c|c|c|c|c|c|c|}
\hline & $\mathrm{Lg}$ & $\mathrm{Sg}$ & Ml & $\mathrm{Fg}$ & $\mathrm{Cs}$ & $\mathrm{Ci}$ & Ss & $\mathbf{M p}$ & Bs & $\mathrm{Nt}$ & $\mathrm{Ma}$ & Ls & $\mathrm{Nr}$ & $\mathrm{Ae}$ & $\mathrm{Uc}$ & Ns & Index \\
\hline $\mathrm{Lg}$ & 1.00 & $.38 * *$ & $.26 * *$ & .06 & .19 & $.18 *$ & $.26 * *$ & .16 & .06 & .13 & .01 & $.26 * *$ & .10 & .10 & .11 & $.16^{*}$ & .43 \\
\hline $\mathrm{Sg}$ & & 1.00 & $.67^{* *}$ & $.39 * *$ & .06 & .07 & $.31 * *$ & $.23 * *$ & -.03 & $.30^{* *}$ & $.15^{*}$ & $.31 * *$ & .13 & $.33 * *$ & $.26 * *$ & .12 & .56 \\
\hline MI & & & 1.00 & $.49 * *$ & .19 & .07 & $31 * *$ & $.25 * *$ & -.04 & $.49 * *$ & $.17^{*}$ & $.29 * *$ & $.16^{*}$ & $.35 * *$ & $.38 * *$ & $.22 *$ & .64 \\
\hline $\mathrm{Fg}$ & & & & 1.00 & $.31 * *$ & .07 & $.29 * *$ & $.17^{*}$ & .15 & $.49 * *$ & $.38 * *$ & $.31 * *$ & $.27 * *$ & $.60 * *$ & $.35 * *$ & .02 & .65 \\
\hline $\mathrm{Cs}$ & & & & & 1.00 & .13 & $.25 * *$ & $.18 *$ & .07 & $.23 * *$ & $.27^{* *}$ & $.22^{* * *}$ & $.21 * *$ & $.18 *$ & $.37 * *$ & .14 & .48 \\
\hline $\mathrm{Ci}$ & & & & & & 1.00 & $.35 * *$ & $.24 * *$ & .12 & $.20 *$ & -.02 & $.15^{*}$ & $.16^{*}$ & $.16^{*}$ & .13 & -.00 & .39 \\
\hline Ss & & & & & & & 1.00 & $.31 * *$ & $.29 * *$ & $.29 * *$ & $.23 * *$ & $.23 * *$ & .14 & $.18 *$ & .12 & .05 & .56 \\
\hline Mp & & & & & & & & 1.00 & $.39 * *$ & $.27 * *$ & $.20^{*}$ & $.15^{*}$ & .15 & $.17 *$ & .15 & .05 & .50 \\
\hline BS & & & & & & & & & 1.00 & .14 & $.21 * *$ & .06 & .09 & .12 & .01 & .14 & .34 \\
\hline $\mathrm{Nt}$ & & & & & & & & & & 1.00 & $.23^{* *}$ & $.23^{* * *}$ & $.27 * *$ & $.43^{* *}$ & $.27 * *$ & .12 & .62 \\
\hline $\mathrm{Ma}$ & & & & & & & & & & & 1.00 & $.26 * *$ & $.45^{* *}$ & $.30^{* * *}$ & $.22 * *$ & .15 & .48 \\
\hline Ls & & & & & & & & & & & & 1.00 & $.31^{* *}$ & $.37 * *$ & $.24 * *$ & .08 & .54 \\
\hline $\mathrm{Nr}$ & & & & & & & & & & & & & 1.00 & $.30^{* * *}$ & .12 & .13 & .46 \\
\hline $\mathrm{Ae}$ & & & & & & & & & & & & & & 1.00 & $.40^{* * *}$ & $.17 *$ & .63 \\
\hline Uc & & & & & & & & & & & & & & & 1.00 & $.27^{* *}$ & .54 \\
\hline Ns & & & & & & & & & & & & & & & & 1.00 & .33 \\
\hline Mean & .48 & .69 & .52 & .40 & .41 & .52 & .74 & .43 & .61 & .45 & .13 & .36 & .15 & .37 & .41 & .41 & 7.01 \\
\hline Std & .50 & .46 & .50 & .49 & .49 & .50 & .43 & .49 & .48 & .49 & .34 & .48 & .36 & .48 & .49 & .49 & 3.86 \\
\hline
\end{tabular}

Variable Description

$\mathrm{Lg}=$ Lobbies local government for the arts

Bs $=$ Board members speak in community

$\mathrm{Sg}=$ Lobbies state government

$\mathrm{Ml}=$ Meets state legislators for the arts

$\mathrm{Fg}=$ Lobbies federal government officials

Cs $=$ Has corporate sponsors for programs or program elements

$\mathrm{Ci}=$ Manager belongs to and is involved in $>1$ civic organization

Ss = Staff speaks in the community

$\mathrm{Mp}=$ Agency has a high quality media program

$\mathrm{Nt}=$ Manager networks with political and civic leaders about agency

$\mathrm{Ma}=$ Conducts marketing analysis of agency programs and services

Ls $=$ Manager attends local seminars on arts management

$\mathrm{Nr}=$ Conducts name recognition study

$\mathrm{Ae}=$ Conducts economic assessment of region

$\mathrm{Uc}=$ Updates movement of corporations in region

* Significant at $\mathrm{p}=.50$

$* *$ Significant at $\mathrm{p}=.010$ 


\section{Guttman Scales}

A Guttman scale was constructed from the External Agency Management Index to test the unidimensionality of each indexed measure and to gauge respondents' answers more precisely. A 15 -item scale revealed that few response patterns matched valid pure scale types, and many matched "error" types. The items and responses did not constitute a valid Guttman scale, with a coefficient of reproducibility of .88 , a minimum marginal reproducibility of .63 , and a coefficient of scalability of .67 .

For general interest, the most commonly demonstrated variable by respondents was "worked with the VCA to encourage state funding in the arts," followed by "my board is involved in community affairs, such as speaking or hosting." The least frequently observed variables included performing marketing studies, such as name recognition, market analysis, or economic assessment. 


\section{Hypothesis 2}

Part Two

Hypothesis 2, part two: Managerial roles in the arts will affect the relationship between the agency and the larger environment. The management roles of entrepreneur and administrator will include high levels of participation in external agency tasks.

The hypothesis is supported by the data, which reveal differences between all four managerial roles on the dimension of External Agency Management Tasks. Table 57 demonstrates that an analysis of variance of the External Agency Management Tasks Index, grouped by the four role types, found statistically significant differences among the roles. The differences were significant beyond the $p=.050$ level (Tukey $B$ method). The analysis of variance indicates differences of the means between the entrepreneur and the caretaker, with the entrepreneur displaying the higher mean. Table 56 shows that the indexed mean values for the entrepreneur and the administrator were very similar as were the mean values for the artist and the caretaker. The direction of the differences is as expected, declining from entrepreneur to caretaker. Data show significant differences between the role types administrator and entrepreneur and the remaining two role types on this group of variables.

Table 56.--Mean Values: External Agency Management Index Scores by Roles

\begin{tabular}{|c|c|c|c|c|c|}
\hline & Entrepreneur & Administrator & Artist & Caretaker & Total \\
\hline $\begin{array}{l}\text { Mean } \\
(\mathrm{N})\end{array}$ & $\begin{array}{r}9.08^{* *} \\
(12)\end{array}$ & $\begin{array}{r}8.40^{*} \\
(22)\end{array}$ & $\begin{array}{c}6.00 \\
(28)\end{array}$ & $\begin{array}{r}5.45^{*} \\
(33)\end{array}$ & $\begin{array}{r}6.78 \\
(95)\end{array}$ \\
\hline
\end{tabular}

* Significant at $\mathrm{p}=.050$, Tukey B method 
Table 57.--Analysis of Variance: Role Types (Independent Variable) by External Agency Management Tasks (Dependent Variable)

\begin{tabular}{lrrrrr}
\hline \hline Source & \multicolumn{1}{c}{ SS } & df & MS & F & Significance of F \\
\hline Between Groups & 189.3728 & 3 & 63.1243 & 4.4037 & .0061 \\
Within Groups & 1304.4167 & 91 & 4.3342 & & \\
Total & 1493.7895 & 94 & & & \\
\hline
\end{tabular}

\section{Sub-Hypothesis 2.2.1}

Sub-hypothesis 2.2.1: The entrepreneurial manager will be involved with fundraising, will interact with community and civic organizations, will manifest a clear interest and understanding of the larger artistic organizational environment, and will report an interest in the regional economic market. The entrepreneur will be significantly different on these items compared with the other role groups.

Sub-hypothesis 2.2 .1 is supported by data in Table 58, which show that entrepreneurs led all role types in the three levels of government lobbying, local state and federal. They were also active in local civic activities, demonstrated by high percentages of agreement to the question "do you belong to and are you active in more than one civic organization?" They established high-quality media programs more frequently and networked more than their colleagues in the the community.

Entrepreneurs, as displayed in Table 58, reported the most often that they performed a marketing analysis, attended arts management seminars, assessed the local economy, and updated the movement of local and regional corporations. All of these variables indicate the entrepreneur's involvement and interest in the regional economic market and confirm the basic nature of the entrepreneur as one who seeks opportunity.

\section{Sub-hypothesis 2.2.2}

Sub-hypothesis 2.2.2: The administrative manager will be involved with local fundraising, will network to improve organizational relationships, will display greater 
interest in the general arts environment but less interest in assessing the regional economic market for the arts.

Sub-hypothesis 2.2.2 is supported by the data in Table 58, which demonstrate that administrators reported high levels of lobbying on all levels, although less so than entrepreneurs. Administrators were also involved in networking, although here again they were eclipsed by entrepreneurs. They scored the highest levels of agreement on the variable "executing joint advertising for a program with a corporate sponsor in the last two years," which is consistent with heading a large symphony or theatre. 
Table 58.--Involvement with External Agency Management Tasks by Role Differences, Percent Agreement

\begin{tabular}{|c|c|c|c|c|c|c|c|c|c|c|c|c|c|c|c|c|}
\hline & $\mathrm{Lg}$ & $\mathrm{Sg}$ & Ml & $\mathrm{Fg}$ & Cs & $\mathrm{Ci}$ & Ss & Mp & Bs & $\mathrm{Nt}$ & $\mathrm{Ma}$ & Ls & $\mathrm{Nr}$ & $\mathrm{Ae}$ & Uc & Ns \\
\hline Entre & $\begin{array}{r}66.7 \\
(8)\end{array}$ & $\begin{array}{r}75.0 \\
\text { (9) }\end{array}$ & $\begin{array}{c}58.3 \\
(7)\end{array}$ & $\begin{array}{r}50.0 \\
(6)\end{array}$ & $\begin{array}{r}58.3 \\
(7)\end{array}$ & $\begin{array}{c}66.7 \\
(8)\end{array}$ & $\begin{array}{r}66.7 \\
(8)\end{array}$ & $\begin{array}{c}66.7 \\
(8)\end{array}$ & $\begin{array}{r}66.7 \\
(8)\end{array}$ & $\begin{array}{r}58.3 \\
(7)\end{array}$ & $\begin{array}{r}25.0 \\
\text { (3) }\end{array}$ & $\begin{array}{r}50.0 \\
(6)\end{array}$ & $\begin{array}{c}16.7 \\
\text { (2) }\end{array}$ & $\begin{array}{r}66.7 \\
(8)\end{array}$ & $\begin{array}{r}75.0 \\
\text { (9) }\end{array}$ & $\begin{array}{r}41.7 \\
\text { (5) }\end{array}$ \\
\hline Administrator & $\begin{array}{c}63.6 \\
(14)\end{array}$ & $\begin{array}{c}59.1 \\
\text { (13) }\end{array}$ & $\begin{array}{l}59.1 \\
\text { (13) }\end{array}$ & $\begin{array}{c}45.5 \\
(10)\end{array}$ & $\begin{array}{c}63.6 \\
(14)\end{array}$ & $\begin{array}{c}59.1 \\
\text { (13) }\end{array}$ & $\begin{array}{c}77.3 \\
\text { (17) }\end{array}$ & $\begin{array}{c}54.5 \\
\text { (12) }\end{array}$ & $\begin{array}{c}77.3 \\
\text { (17) }\end{array}$ & $\begin{array}{c}45.5 \\
(10)\end{array}$ & $\begin{array}{l}18.2 \\
(4)\end{array}$ & $\begin{array}{r}40.9 \\
(9)\end{array}$ & $\begin{array}{r}27.3 \\
(6)\end{array}$ & $\begin{array}{r}40.0 \\
(9)\end{array}$ & $\begin{array}{r}54.5 \\
(12)\end{array}$ & $\begin{array}{r}54.5 \\
\text { (12) }\end{array}$ \\
\hline Artist & $\begin{array}{r}32.1 \\
(9)\end{array}$ & $\begin{array}{c}71.4 \\
(20)\end{array}$ & $\begin{array}{c}53.6 \\
\text { (15) }\end{array}$ & $\begin{array}{r}42.9 \\
(12)\end{array}$ & $\begin{array}{c}42.9 \\
(12)\end{array}$ & $\begin{array}{c}39.3 \\
(11)\end{array}$ & $\begin{array}{c}60.7 \\
(17)\end{array}$ & $\begin{array}{r}25.0 \\
(7)\end{array}$ & $\begin{array}{c}50.0 \\
\text { (14) }\end{array}$ & $\begin{array}{r}32.1 \\
(9)\end{array}$ & $\begin{array}{r}10.7 \\
(3)\end{array}$ & $\begin{array}{c}35.7 \\
(10)\end{array}$ & $\begin{array}{c}3.6 \\
(1)\end{array}$ & $\begin{array}{c}39.3 \\
(11)\end{array}$ & $\begin{array}{r}32.1 \\
(9)\end{array}$ & $\begin{array}{r}28.6 \\
(8)\end{array}$ \\
\hline Caretaker & $\begin{array}{r}42.4 \\
(14)\end{array}$ & $\begin{array}{c}66.7 \\
(22)\end{array}$ & $\begin{array}{c}39.4 \\
\text { (13) }\end{array}$ & $\begin{array}{r}24.2 \\
\quad(8)\end{array}$ & $\begin{array}{r}18.2 \\
(6)\end{array}$ & $\begin{array}{c}54.5 \\
(18)\end{array}$ & $\begin{array}{c}66.7 \\
(22)\end{array}$ & $\begin{array}{c}42.4 \\
(14)\end{array}$ & $\begin{array}{c}51.5 \\
\text { (17) }\end{array}$ & $\begin{array}{c}33.3 \\
(11)\end{array}$ & $\begin{array}{c}3.0 \\
(1)\end{array}$ & $\begin{array}{r}24.2 \\
\quad(8)\end{array}$ & $\begin{array}{c}9.1 \\
\text { (3) }\end{array}$ & $\begin{array}{r}21.2 \\
(7)\end{array}$ & $\begin{array}{c}27.3 \\
\text { (9) }\end{array}$ & $\begin{array}{r}30.3 \\
\text { (1) }\end{array}$ \\
\hline
\end{tabular}

Variable Description

$\mathrm{Lg}=$ Lobbies local government for the arts

$\mathrm{Sg}=$ Lobbies state government

$\mathrm{Ml}=$ Meets state legislators for the arts

$\mathrm{Fg}=$ Lobbies federal government officials

$\mathrm{Cs}=$ Has corporate sponsors for programs or program elements

$\mathrm{Ci}=$ Manager belongs to and is involved in $>1$ civic organization

Ss $=$ Staff speaks in the community

$\mathrm{Mp}=$ Agency has a high-quality media program

$\mathrm{Bs}=$ Board members speak in the community

$\mathrm{N} t=$ Manager networks with political and civic leaders about agency

$\mathrm{Ma}=$ Conducts marketing analysis of agency programs and services

Ls = Manager attends local seminars on arts management

$\mathrm{Nr}=$ Conducts name recognition study

$\mathrm{Ae}=$ Conducts economic assessment of region

$U c=U$ pdates movement of corporations in region

$\mathrm{Ns}=$ Seeks new programming sites 
Organizations of this size, influence, and large budget routinely attract corporate sponsors, who utilize performances as a vehicle for corporate advertising, as well as for entertaining and networking with established political and civic leaders. Administrators reported high levels of agreement on the variable "establishing a high quality media program," which is also consonant with attracting corporate sponsors. The administrator's arts agency utilizes its high-quality media and advertising materials to project an image of competency that attracts corporate and foundation sponsors.

Sub-hypothesis 2.2 .2 predicted that administrators would score lower than entrepreneurs on assessing the regional economic status for the purpose of planning fundraising strategies, and this prediction is supported by the data in Table 58. A questionnaire item asked if the manager "assessed the local economic environment in 1991 to determine the potential for success of his/her annual programs and services." A second question asked if the manager "prepared a 1991 update of new or expanding corporations in order to extend funding appeals." A wide disparity exists between administrators and entrepreneurs in response to these items, with administrators trailing entrepreneurs. This finding supports the theoretical distinction between administrators and entrepreneurs, suggesting that entrepreneurs are more aggressive in initiating business strategies. A related economic assessment question asked whether the manager "canvassed the region in 1991 to select new sites for agency expansion in programs, services, and exhibits." Again, the administrator scored lower than the entrepreneur. The reason for this disparity may be the entrepreneur's predisposition to expand both his agency and its agenda. Administrators may be pressured more to expand fundraising than to generate new program responsibilities. They are often guided by large, entrenched, and conservative boards who feel compelled to deal with the fiscal shortfalls by the more common methods of cutbacks or increased fundraising activities. 


\section{Sub-hypothesis 2.2.3}

Sub-hypothesis 2.2.3: The artistic manager will be minimally involved with the mechanics of fundraising, will show little interest in forming community relationships, in developing competitive strategies, and in assessing the regional economic market.

Hypothesis 2.2 .3 is supported by data in Table 58, with the exception of a negative finding in the area of local government lobbying. As seen earlier in Table 40, the artist displays lower percentages of agreement than the caretaker in response to the statement "I have received local government grants for the past four years." A further statement asks if the manager "lobbies local government on behalf of the agency." Artists respond with the lowest percentages of agreement. A reasonable question would be to ask why do artists lobby less for local government grants? Is it because they have been refused local government grants consistently without reasonable cause, or because they have failed to prove their agency's need and artistic quality to the granting committee?

In contrast, artists report higher percentages of agreement in lobbying for state government funding, where they have obviously been more successful. Here their levels of agreement are equal with entrepreneurs and ahead of administrators. On the federal level, as predicted, artists perform slightly lower than their peers.

Sub-hypothesis 2.2 .3 is also supported by data that refer to the artists' low level of involvement in community interaction. This role type makes a poor showing in the areas of memberships in civic organizations, establishing a media program, establishing speaking engagements by the board members, and community networking. Artists scored the lowest of the four role types in the area of involving their staffs in community events.

The artists also showed a lower percentage of agreement with questions on competitive strategizing, which included such items as conducting a marketing analysis, attending conferences on arts management and conducting a name recognition study. Similarly, in the area of arts and economics, low percentages of artists assessed the local economy to determine the potential for success of their programs. Low scores appeared as 
well for updating the movement of regional corporations or searching for new performance sites. The conclusion here is that artists are essentially uninvolved with the mechanics of running an arts businesses and instead concern themselves mainly with artistic production. In many interviews, they acknowledged this bias and worried about its consequences.

\section{Sub-hypothesis 2.2 .4 .}

Sub-hypothesis 2.2.4: The caretaker manager will demonstrate little or no involvement in any of the external tasks of management.

Sub-hypothesis 2.2.4 is supported by Table 58's data, which show a poor performance by the caretaker on many dimensions. The scores of artists and caretakers parallel each other closely on most questions, and caretakers seldom display any untoward strengths. They do exert some energy toward lobbying on the state, local, and federal levels, but not in the percentages of the entrepreneurs or administrators. They belong to and are active in civic organizations in percentages approximating the administrator's which may account again for their high marks in winning local government arts grants. They do not attend seminars on arts management nor do they seek corporate support. They demonstrate not only a very low level of business acumen and activity, but also a diminished level of confidence in their ability to influence the performance of their agency, relative to other role types (see Table 50). 


\section{Research Question 3}

Research Question 3. What are the similarities and differences among the roles in instituting cutback procedures to cope with a recessionary economy?

Each managerial role will emphasize and prioritize selected aspects of cutback procedures.

Data Analysis

Two indexes were created for cutback strategies in order to separate "active" cutbacks, i.e., which involved increasing managerial and agency efforts to augment revenues, from "passive" cutbacks, i.e., those which involved a diminution of services and staff. These two indexes will be referred to as the Active Cutback Index (ACI) and the Passive Cutback Index (PCI).

The ACI, shown in Table 59, included nine items (mean $=3.153$, range $=0-8$, Std $=1.807$ ) that displayed a cluster of weakly correlated variables (correlations significant at $\mathrm{p}=<.01$ ) associating price revisions (cuts or increases) with attempts to increase the audience size by performing in new locations. The items asked if respondents "revised pricing strategy for all services in order to increase audience participation and sales" and "instituted new production locations and times in order to increase public accessibility" ( $r=$ .22). The variable "revise pricing" was also correlated moderately $(\mathrm{r}=.32)$ with "look for a similar organization to merge or absorb this agency." There were weak correlations among variables that associated increasing the volunteer force with augmented fundraising $(\mathrm{r}=.35)$, revised pricing strategies $(\mathrm{r}=.24)$, and instituting new performance locations $(\mathrm{r}$ $=.28$ ). All of these efforts work together in approaching the problem of diminished resources by engaging a larger work force (volunteers), increasing revenues (revising 
prices), opening up new markets (new performance locations), and looking for a fall-back position (considering a merger). All items were strongly correlated with the index.

Table 59.--Correlations, Means and Standard Deviations of Items in Active Cutback Index (ACI)

\begin{tabular}{lccccccccc}
\hline \hline Variable & $\mathrm{Nw}$ & $\mathrm{Rp}$ & $\mathrm{If}$ & $\mathrm{Nl}$ & $\mathrm{Iv}$ & $\mathrm{Nm}$ & $\mathrm{Ne}$ & $\mathrm{Mr}$ & $\mathrm{Index}$ \\
\hline $\mathrm{Nw}$ & 1.00 & $.23^{* *}$ & .05 & .18 & .21 & .18 & .08 & .04 & .50 \\
$\mathrm{Rp}$ & & 1.00 & .16 & $.31^{* *}$ & $.24^{* *}$ & .04 & -.02 & $.32^{* *}$ & .60 \\
If & & & 1.00 & $.22^{*}$ & $.35^{* *}$ & $.22^{* *}$ & .1 & .01 & .54 \\
$\mathrm{Nl}$ & & & & 1.00 & $.28^{* *}$ & .08 & .12 & .04 & .60 \\
$\mathrm{Iv}$ & & & & & 1.00 & .16 & .09 & .13 & .64 \\
$\mathrm{Nm}$ & & & & & & 1.00 & $.69^{* *}$ & .10 & .41 \\
$\mathrm{Ne}$ & & & & & & & 1.00 & .01 & .38 \\
$\mathrm{Mr}$ & & & & & & & & 1.00 & .35 \\
$\mathrm{Index}$ & & & & & & & & & 1.00 \\
\hline Mean & .41 & .50 & .73 & .50 & .57 & .12 & .09 & .17 & 3.15 \\
Std & .49 & .50 & .44 & .44 & .49 & .32 & .29 & .37 & 1.80 \\
\hline
\end{tabular}

Variable Description

$L s=$ Seek sources of loans

$\mathrm{Nw}=$ Introduce new services

$\mathrm{Rp}=$ Revise pricing strategies

If $=$ Increase fundraising

$\mathrm{NI}=$ Institute new performance locations

IV $=$ Increase volunteer force

$\mathrm{Nm}=$ Market study to identify current target market

$\mathrm{Ne}=$ Market Study to locate new target markets

$\mathrm{Mr}=$ Merge with or absorb another agency

*** Significant at $\mathrm{p}=.010$

A second cutback index, shown in Table 60, PCI (mean $=2.78$, range $=0-6$, Std $=1.66)$, included six items that concentrated more on internally driven measures of retrenchment, or actions that could be taken by the manager or the board of directors in response to financial weaknesses. There were weak correlations $(p=.010)$ among items here which indicated agencies in crisis. For example, the variable "tighten the budget by cuts or delayed funding" was associated with "laying off staff" $(\mathrm{r}=36)$ and "appeals to the board for a financial rescue" ( $r=.24)$. Again, the variable "consider terminating the 
agency" was weakly correlated with "layoff staff" $(r=.24)$ and "appeals to the board for a financial rescue" $(r=.22)$. All items were strongly correlated with the index.

Table 60.--Correlations, Means and Standard Deviations of Items in Passive Cutback Index (PCI)

\begin{tabular}{lccccccc}
\hline \hline Variable & $\mathrm{Bc}$ & $\mathrm{Ch}$ & $\mathrm{La}$ & $\mathrm{Rs}$ & $\mathrm{Rd}$ & $\mathrm{Tr}$ & Index \\
\hline $\mathrm{Bc}$ & 1.00 & $.30^{* *}$ & $.36^{* *}$ & $.24^{* *}$ & .07 & .12 & .65 \\
$\mathrm{Ch}$ & & 1.00 & $.26^{* *}$ & .15 & .07 & .08 & .57 \\
$\mathrm{La}$ & & & 1.00 & $.30^{* *}$ & .17 & $.24^{* *}$ & .70 \\
$\mathrm{Rs}$ & & & & 1.00 & .15 & $.22^{* *}$ & .65 \\
$\mathrm{Rd}$ & & & & & 1.00 & .09 & .51 \\
Tr & & & & & & 1.00 & .48 \\
Index & & & & & & & 1.00 \\
\hline Mean & .68 & .66 & .44 & .44 & .35 & .14 & 2.78 \\
Std & .46 & .47 & .49 & .49 & .48 & .35 & 1.66 \\
\hline
\end{tabular}

Variable Description

$\mathrm{Bc}=$ Cut the budget

$\mathrm{Ch}=$ Locate cheaper supplies and equipment

$\mathrm{La}=$ Layoff staff

Rs = Appeal to the board for a financial rescue

$\mathrm{Rd}=$ Reduce services and performances

$\mathrm{Tr}=$ Consider terminating agency

*** Significant at $\mathrm{p}=.010$

\section{Guttman Scales}

A Guttman scale was constructed from the $\mathrm{ACI}$ index in order to test the unidimensionality of each indexed measure and to gauge respondents' answers more precisely. A 7-item scale revealed that 40 response patterns matched valid scale types.

These constituted $33.8 \%$ percent of the survey population. The most commonly observed variable was "increased fundraising," followed by "increased a volunteer force" and "revised prices." The least frequently observed variables were performance of marketing studies on the current target market and on a potential target market. All items and 
responses constituted a valid Guttman scale with a coefficient of reproducibility of .91 , a minimum marginal reproducibility of .69 and a coefficient of scalability of .69 .

A second Guttman scale was constructed from the PCI index, also to determine the most and least observed activities in cutbacks. Results showed that 48 response patterns matched valid scale types. These constitute $40 \%$ percent of the survey population. The most common variables on the PCI scale were "bought cheaper supplies and equipment" followed by "cut the budget" and "instituted staff layoffs." The least common tasks were to reduce services and terminate the agency. The items and responses constituted a valid Guttman Scale with a coefficient of reproducibility of .91 , a minimum marginal reproducibility of .66 and coefficient of scalability of .72 . 


\section{Hypothesis 3}

Hypothesis 3. Arts managers will vary by role type in instituting cutback and retrenchment strategies.

This hypothesis is partially accepted as data demonstrate differences between two managerial role types on the Active Cutback Index. There is no difference between role types on the Passive Cutback Index, shown in Tables 63 and 64. An analysis of variance of the Active Cutback Index scores by four roles, seen in Table 62, revealed that differences among roles were significant beyond the $\mathrm{p}=.050$ level (Tukey $\mathrm{B}$ method). The data in Table 61 display differences among the role types administrator and the caretaker, with the administrator displaying the higher mean value.

Table 61.--Mean Values of Active Cutback Strategies Index Scores (ACI) by Managerial Roles

\begin{tabular}{lccccc}
\hline & Entrepreneur & Administrator & Artist & Caretaker & Total \\
\hline Mean & 2.77 & $3.89^{*}$ & 3.31 & $2.54^{*}$ & 3.09 \\
$(\mathrm{~N})$ & $(9)$ & $(19)$ & $(22)$ & $(31)$ & $(81)$ \\
\hline
\end{tabular}

* Significant at $\mathrm{p}=.050$, Tukey B Method

Table 62.--Analysis of Variance: Role Types (Independent Variable) by Active Cutback Strategies Index (ACI) (Dependent Variable)

\begin{tabular}{lcrccc}
\hline \hline Source & SS & df & MS & F & Significance of F \\
\hline Between Groups & 23.41 & 3 & 7.8049 & 2.7594 & .0478 \\
Within Groups & 217.7952 & 77 & 2.8285 & & \\
Total & 241.2099 & 80 & & & \\
\hline
\end{tabular}


Table 63.--Mean Values of Passive Cutback Strategies Index Scores by Managerial Roles $(\mathrm{PCI})$

\begin{tabular}{lccccc}
\hline \hline & Entrepreneur & Administrator & Artist & Caretaker & Total \\
\hline $\begin{array}{l}\text { Mean } \\
\text { (N) }\end{array}$ & 3.09 & 2.61 & 2.44 & 2.52 & 2.61 \\
& $(11)$ & $(21)$ & $(18)$ & $(25)$ & $(75)$ \\
\hline
\end{tabular}

*Significant at $\mathrm{p}=.050$, Tukey $\mathrm{B}$ method

Table 64.--Analysis of Variance: Role Types (Independent Variable) by Passive Cutback Strategies Index Scores (PCI) (Dependent Variable)

\begin{tabular}{lcrccc}
\hline \hline Source & SS & df & MS & F & Significance of F \\
\hline Between Groups & 3.24 & 3 & 1.0803 & .3863 & .7632 \\
Within Groups & 198.5459 & 71 & 2.7964 & & \\
Total & 201.7867 & 74 & & & \\
\hline
\end{tabular}

Sub-Hypothesis 3.1: The entrepreneurial manager will employ the most active and passive cutback strategies (Hay 1990).

Sub-hypothesis 3.1 is partially supported (see Table 65 ) where entrepreneurs displayed a mixed pattern of responses to cutback strategies. In the context of Active Cutbacks (ACI), entrepreneurs did increasingly conduct marketing studies (along with administrators), offer new services, increase the volunteer force, and strengthen fundraising efforts. The ACI also revealed that they did not revise prices in percentages equal to the administrator and the artist. Actually, every role type exceeded the entrepreneur in revising prices. There may be some explanation for this unexpected finding in the fact that many entrepreneurs were not involved in the performing arts, but managed visual art galleries or service agencies, where prices are not amenable to constant fluctuation. By contrast, the other three role types were concentrated in performances, which lend themselves more easily to price alterations or special "deals." A second item that does not comport with hypothesis 3.1 is the question of instituting new production 
locations or times in order to increase public accessibility. Again, the entrepreneur ranked much lower than other roles for the same reason. Entrepreneurs, heading standing galleries or agencies, would have fewer opportunities to alter their location or service times, while the other three roles types would be more likely to take advantage of this cutback strategy. In items on the Passive Cutback Index, such as buying cheaper supplies, reducing budgets, and laying off staff, entrepreneurs scored notably higher on buying cheaper supplies and equipment, reducing services/performances, and laying off staff, but acted with their peers in cutting the budget. In the area of crisis management, entrepreneurs reported less attempt either to merge with another agency or terminate, but were involved equally with their peers in appealing to the board of directors for a financial rescue. 
Table 65.--Involvement with Cutback Strategy Variables by Role Differences, Percentage Agreement

\begin{tabular}{|c|c|c|c|c|c|c|c|c|c|c|c|c|c|c|}
\hline & Ns & $\mathrm{Rp}$ & If & N1 & Iv & Ms & St & $\mathrm{Cb}$ & Lf & $\mathrm{Cs}$ & Ls & $\mathrm{Br}$ & $\mathrm{Ma}$ & $\operatorname{Tr}$ \\
\hline Entrepreneur & $\begin{array}{r}41.7 \\
(5)\end{array}$ & $\begin{array}{r}41.7 \\
(5)\end{array}$ & $\begin{array}{c}83.3 \\
(10)\end{array}$ & $\begin{array}{r}16.7 \\
(2)\end{array}$ & $\begin{array}{r}50.0 \\
(6)\end{array}$ & $\begin{array}{r}25.0 \\
(3)\end{array}$ & $\begin{array}{r}16.7 \\
(2)\end{array}$ & $\begin{array}{r}66.7 \\
(8)\end{array}$ & $\begin{array}{r}25.0 \\
\text { (3) }\end{array}$ & $\begin{array}{c}91.7 \\
(11)\end{array}$ & $\begin{array}{r}50.0 \\
(6)\end{array}$ & $\begin{array}{r}41.7 \\
(5)\end{array}$ & $\begin{array}{r}8.3 \\
\text { (1) }\end{array}$ & $\begin{array}{r}8.3 \\
(1)\end{array}$ \\
\hline Administrator & $\begin{array}{r}45.5 \\
(10)\end{array}$ & $\begin{array}{c}59.1 \\
\text { (13) }\end{array}$ & $\begin{array}{c}81.1 \\
(18)\end{array}$ & $\begin{array}{c}50.0 \\
(11)\end{array}$ & $\begin{array}{r}63.6 \\
(14)\end{array}$ & $\begin{array}{r}22.7 \\
\text { (5) }\end{array}$ & $\begin{array}{r}18.2 \\
(4)\end{array}$ & $\begin{array}{r}63.6 \\
(14)\end{array}$ & $\begin{array}{r}45.5 \\
(10)\end{array}$ & $\begin{array}{r}72.7 \\
(16)\end{array}$ & $\begin{array}{r}40.9 \\
(9)\end{array}$ & $\begin{array}{c}36.4 \\
(8)\end{array}$ & $\begin{array}{r}22.7 \\
(5)\end{array}$ & $\begin{array}{r}4.0 \\
(1)\end{array}$ \\
\hline Artist & $\begin{array}{r}46.4 \\
(13)\end{array}$ & $\begin{array}{r}57.1 \\
(16)\end{array}$ & $\begin{array}{r}75.0 \\
(21)\end{array}$ & $\begin{array}{r}57.1 \\
(16)\end{array}$ & $\begin{array}{c}71.4 \\
(20)\end{array}$ & $\begin{array}{r}3.6 \\
(1)\end{array}$ & $\begin{array}{r}3.6 \\
(1)\end{array}$ & $\begin{array}{r}67.9 \\
(19)\end{array}$ & $\begin{array}{r}32.1 \\
(9)\end{array}$ & $\begin{array}{r}53.6 \\
(15)\end{array}$ & $\begin{array}{r}32.1 \\
(9)\end{array}$ & $\begin{array}{r}39.3 \\
(11)\end{array}$ & $\begin{array}{r}25.0 \\
(7)\end{array}$ & $\begin{array}{r}21.4 \\
(6)\end{array}$ \\
\hline Caretaker & $\begin{array}{r}33.3 \\
(11)\end{array}$ & $\begin{array}{r}42.4 \\
(14)\end{array}$ & $\begin{array}{c}66.7 \\
(22)\end{array}$ & $\begin{array}{c}51.5 \\
(17)\end{array}$ & $\begin{array}{c}36.4 \\
(12)\end{array}$ & $\begin{array}{c}3.0 \\
(1)\end{array}$ & 0.0 & $\begin{array}{r}63.6 \\
(21)\end{array}$ & $\begin{array}{r}18.2 \\
(6)\end{array}$ & $\begin{array}{c}54.5 \\
(18)\end{array}$ & $\begin{array}{r}27.3 \\
(9)\end{array}$ & $\begin{array}{c}42.4 \\
(14)\end{array}$ & $\begin{array}{c}9.1 \\
(3)\end{array}$ & $\begin{array}{r}18.2 \\
(6)\end{array}$ \\
\hline
\end{tabular}

\section{Variable List}

Ns $=$ Introduce new services

$\mathrm{Rp}=$ Revise pricing strategy

If $=$ Increase fundraising efforts

$\mathrm{Nl}=$ Institute new performance locations and times

Iv $=$ Increase the volunteer force

$\mathrm{Ms}=$ Conduct market studies on current targets

$\mathrm{St}=$ Conduct market studies on potential targets

$\mathrm{Cb}=$ Cut budget

$\mathrm{Lf}=$ Loan funds for shortfall

$\mathrm{Cs}=$ Buy cheaper supplies and equipment

Ls = Layoff staff

$\mathrm{Br}=$ Ask board for financial rescue

$\mathrm{Ma}=$ Merge or absorb another agency

$\mathrm{Tr}=$ Terminate agency

$\mathrm{Ma}=$ Merge or absorb another agency

$\mathrm{Tr}=$ Terminate agency

Lf $=$ Loan funds for shortfall

$\mathrm{Cs}=$ Buy cheaper supplies and equipment

Ls = Layoff staff

$\mathrm{Br}=$ Ask board for financial rescue

$\mathrm{Ma}=$ Merge or $\mathrm{absorb}$ another agency

$\mathrm{Tr}=$ Terminate agency 


\section{Sub-hypothesis 3.2}

Sub-hypothesis 3.2: The administrative manager will initiate some projects that include new pricing strategies, increased volunteer force, augmented fundraising efforts, and locating cheaper sources of purchasing. She/he will initiate reductions ihrough budget cuts and delays as well as staff reduction.

Sub-hypothesis 3.2 is supported by data in Table 65, which demonstrate that the administrative manager responds to many active cutback strategies in percentages above $50 \%$, as predicted. Chief among these are revising pricing strategies, increasing fundraising efforts, instituting new performance locations and times, and increasing the volunteer force. Administrators were not as involved, demonstrated by their levels of agreement, in passive cutback strategies, with the exceptions of cutting the budget and purchasing cheaper supplies and equipment.

In instituting cutback strategies, administrators diverged from entrepreneurs with whom they often comport. In some areas of active cutback strategies, such as conducting marketing studies and instituting new services, the administrator performs similarly to the entrepreneur. In other active strategies such as revising prices and instituting new performance or service locations, the administrator and the entrepreneur perform differently. This could again be explained by the types of agencies with which they are affiliated. Other active cutback strategies that engaged both administrators and entrepreneurs at similar levels include increasing the volunteer force and increasing fundraising efforts.

The administrator ranked considerably higher than other role types in "identifying sources of loan funds to span an impending shortfall." Several administrators also mentioned the effort to obtain loan funds to invest in a for-profit venture or to carry the agency through a deficit period. The reluctance of banks to lend to agencies was communicated clearly; in several instances cities refused bridge loans. In one successful application for a line of credit, the agency had a board member in the banking business; still 
another agency was able to locate a community foundation loan after it was turned away by the local banks. The issue of locating funds for capital projects by agencies is complicated by certain legal restrictions on capitalization for nonprofit organizations. Arts agencies, because of public perception of tenuousness and poor business skills, are currently locked out of the benefits of loan financing for capital projects. It appears that even the most stable role type, the administrator, is unable to secure loan funds easily.

For passive cutback strategies, administrators more closely mirrored the entrepreneurs: both attempted to buy cheaper supplies and equipment, cut the budget and lay off staff. Administrators were less involved in reducing services and performances than the entrepreneurs, probably due to their respective types of agencies. In crisis cutback strategies, both the administrator and the entrepreneur resisted terminating their agencies, but they diverged on the possibility of a merger, with administrators displaying a more willing attitude than entrepreneurs.

\section{Sub-hypothesis 3.3}

Sub-hypothesis 3.3: The artistic manager will employ passive cutback strategies such as increased fundraising efforts (including a crisis appeal to the Board of directors), dramatic cutbacks in performances and staff through layoffs and a hiring freeze and an attempt to cut expenses by calculating alternative purchasing arrangements.

Sub-hypothesis 3.3 was not supported by data, as shown in Table 65 . In the area of active strategies, the artist was highly involved with instituting new services, revising prices, determining new production locations and times and increasing volunteers--and even leading all role types on these three dimensions. Artists tend to be totally immersed in performing and have few other venues of support, unlike entrepreneurs and administrators. They see performance aiteration as the only means of survival,and the responses reflect this energy and effort. The hypothesis failed to take this aspect of role difference into account. 
In the areas of passive cutback strategies, artists' responses were comparable to the other three role types, especially in cutting the budget, appealing to the board for a rescue, and reducing performances or services. In other areas, however, such as effecting a merger or terminating the agency, artists showed great anxiety. In these questions artists scored higher than other three role groups. The researcher considers these drastic actions a clear signal of the extreme distress of these agencies, far greater than had been anticipated.

\section{Sub-hypothesis 3.4}

Sub-hypothesis 3.4: The caretaker as manager will employ cutback strategies restricted to reductive efforts such as cutting the number of services and performances, reducing staff size, reducing the budget, and reducing price of services and performances below the market prices. Additionally, Table 65 illustrates how this manager may attempt to merge the agency with a similar one or liquidate it.

Sub-hypothesis 3.4 is also unsupported: caretakers showed a high percentage of agreement in several active cutback strategies, especially instituting new locations and times, and increasing fundraising efforts. In the area of passive strategies, caretakers were presumed to exert great effort, but they failed to do so, with the exception of considering termination. There are several possible explanations for this behavior. Caretakers usually manage agencies that have no staff and often no designated director. This lack of staff eliminates certain items immediately, such as laying off staff. On items such as cutting the budget, reducing services, and appealing to the board for a financial bail out, caretakers operated similarly to other role types. Caretakers differed chiefly in the area of considering agency termination, where they reported high percentages of agreement, similar to the artists and distinctly different from entrepreneurs and administrators. This feature was mentioned earlier in Hypothesis 1 where the vulnerability of caretakers was discussed. 


\section{Research Question 4}

Research Question 4. Is the role type entrepreneur more successful than other role types in maintaining an agency over time?

Introduction

Data were selected to describe role viability, a criterion that was chosen carefully to avoid measuring effectiveness or (with a for profit agency) efficiency. It is difficult to locate an overall measure of performance in the non profit world. Indeed, some writers feel there is no measure in a non profit agency which is comparable to the profit measure in a for profit business (Gies, Ott and Shafritz 1990, 231). The lack of a single criterion means that a series of value judgements and ambiguous goals take on the appearance of measurement quantities. In truth, these vague goals, objectives, values, and mission statements elude truly reliable quantitative measurement. The researcher is then reduced to substituting proxy measures (variables which are understood to stand for some indefinable quality) or to measure, grossly, some single facet of a non profit organization. The criterion selected here is viability (system maintenance). The selection of this measure stems largely from the current well-documented difficulties that arts agencies are facing in surviving. Under these stressful conditions, it has become vital to attempt to isolate those factors that may contribute to operational stability. The factors selected are the most basic units that constitute organizational functioning: budget, staff, lifecycle, durability over time, and the growth or decline of services. There is no attempt here to judge the value systems or the mission of the agencies, but simply to rate their potential for staying in business by role type. 


\section{Hypothesis 4}

Hypothesis 4: The viability of an arts agencies will vary by role type. The entrepreneurial manager will be more viable than other role types, when measured by agency longevity, lifecycle, staff sizes, record of growth and decline, and budgetary elements.

The hypothesis is unsupported: data reveal that the entrepreneur does not display greater evidence of viability when measured by agency longevity, lifecycle, staff sizes, record of growth and decline and budgetary elements. The administrator, by small margins and consistent performance, demonstrates higher revenue levels and higher contributions than the entrepreneur. In all other areas, there were no significant differences between role types.

\section{Data Analysis}

Cross-tabulation analyses were done, examining the four role types in relation to various performance measures. These analyses suggest that administrators lead the most viable agencies, measured in terms of longevity. Administrators and caretakers are found in agencies which have endured for over 15 years, while artists lead groups mostly close to or less than five years. Entrepreneurs are concentrated in agencies with ages of 5-15 years and over 15 years in comparable numbers.

Entrepreneurial managers did not lead the most viable agencies in terms of lifecycle; they were found most commonly in a changing lifecycle, and slightly represented in developing, growing and mature agencies (See Table 66). By comparison, administrators were clustered at the growth stage, and artists and caretakers at the changing stage. Only 
administrators were distinguished from other managerial role types by the lifecycle of the agency directed. There were no statistically significant differences among roles by lifecyle.

Table 66.--Agency Lifecycle by Role Type (percent)

\begin{tabular}{lccccc}
\hline & Entrepreneur & Administrator & Artist & Caretaker & Total \\
\hline Developing & 8.3 & 9.1 & 7.1 & 3.0 & 6.3 \\
GN) & $(1)$ & $(2)$ & $(2)$ & $(1)$ & $(6)$ \\
Growing & 16.7 & 40.9 & 35.7 & 27.3 & 31.6 \\
& $(2)$ & $(9)$ & $(10)$ & $(9)$ & $(30)$ \\
Changing & 66.7 & 31.8 & 42.9 & 42.4 & 43.2 \\
& $(8)$ & $(7)$ & $(12)$ & $(14)$ & $(41)$ \\
Mature & 8.3 & 13.6 & 7.1 & 15.2 & 11.6 \\
& $(1)$ & $(3)$ & $(2)$ & $(5)$ & $(11)$ \\
Declining & 0 & 4.5 & 7.1 & 12.1 & 7.4 \\
& & $(2)$ & $(4)$ & $(7)$ & $(7)$ \\
Total & 12.6 & 23.2 & 29.5 & 34.7 & 100.0 \\
& $(12)$ & $(22)$ & $(28)$ & $(33)$ & $(95)$ \\
\hline
\end{tabular}

Tables 67 and 68 display sizes of the four staffs commonly found in arts agencies: volunteer, artistic, business and board members. Data on staffing was recoded into categories that represented the most commonly appearing staff sizes. The researcher decided to characterize staff sizes as none-to-small and medium-to-large. In so doing, the researcher ended with a skewed distribution, but not badly skewed. The intention was to distinguish between those managers/agencies with and without staff as well as those managers/agencies with small to large staffs.

There are two extremes of arts agency staffing that appear immediately: 1) the agency managed only by a board of directors, with no art or business staff and few volunteers and 2) the large agency (opera, symphony or theatre), with a full business and artistic staff, plus a sizeable board and numerous volunteers. 
Tables 67 and 68 reveal that entrepreneurs were disproportionately represented in agencies with large numbers of volunteers, (6-20 per agency). and underrepresented in agencies with few volunteers ( 5 or under). Administrators as a rule also had large numbers of volunteers, but had a sizeable percentage of managers with a smaller volunteer corps. Artists and caretakers had many agencies which operated without volunteers, as well as mid-sized and large volunteer forces. There was no pattern which differentiated the entrepreneur from other three roles by the size of the volunteer staff.

In terms of artistic staff, entrepreneurs had no staff exceeding 5 individuals, while other agencies, led by those of administrators, all had larger art staffs, of between 6-20 individuals. This may be explained by agency type, i.e., agencies which are choral, orchestral or small theatre troupes would include all players in their artistic staffs. However, there was no consistent pattern that differentiated the entrepreneur from the other three roles by the size of the art staff.

In terms of the size of the board of directors, there was a split between entrepreneurs/administrators and artists/caretakers. The former tended to have boards from 6-20 individuals in over half the agencies, while the latter had boards from 1-5 in almost three-quarters of the agencies. Again, there was no clear pattern by entrepreneurs that differentiated them from all other three roles.

In terms of the size of the business staff, entrepreneurs showed that one-quarter of their agencies were managed with no delegated business individual. The remaining threequarters employed 1-5 individuals in the business of the agency. Entrepreneurs had no business staffs exceeding five people. Administrators followed the same pattern as entrepreneurs with fewer agencies having no business staff and the remaining agencies employing one to five. Artists and caretakers, with few exceptions, showed almost half of their agencies operating without any business help, and the other half employing from one to five people. Again, there was no clear pattern of operation by entrepreneurs which distinguished them from the other three roles. 
Table 67.--Volunteer and Artistic Staff Sizes by Role Type (percent)

\begin{tabular}{|c|c|c|c|c|c|}
\hline & Entrepreneur & Administrator & Artist & Caretaker & Total \\
\hline \multicolumn{6}{|l|}{ Vol Staff } \\
\hline $\begin{array}{c}0 \\
(\mathrm{~N})\end{array}$ & $\begin{array}{c}8.3 \\
(1)\end{array}$ & $\begin{array}{c}9.1 \\
(2)\end{array}$ & $\begin{array}{r}17.9 \\
(5)\end{array}$ & $\begin{array}{r}21.2 \\
(7)\end{array}$ & $\begin{array}{c}15.8 \\
(15)\end{array}$ \\
\hline $1-5$ & $\begin{array}{r}25.0 \\
(3)\end{array}$ & $\begin{array}{r}40.9 \\
(9)\end{array}$ & $\begin{array}{c}42.9 \\
(12)\end{array}$ & $\begin{array}{r}36.4 \\
(12)\end{array}$ & $\begin{array}{r}37.9 \\
(36)\end{array}$ \\
\hline $6-20$ & $\begin{array}{r}66.7 \\
(8)\end{array}$ & $\begin{array}{r}50.0 \\
(11)\end{array}$ & $\begin{array}{c}39.3 \\
(11)\end{array}$ & $\begin{array}{r}42.4 \\
(14)\end{array}$ & $\begin{array}{c}46.3 \\
(44)\end{array}$ \\
\hline Total & $\begin{array}{c}12.6 \\
(12)\end{array}$ & $\begin{array}{c}23.2 \\
(22)\end{array}$ & $\begin{array}{c}29.5 \\
(28)\end{array}$ & $\begin{array}{r}34.7 \\
(33)\end{array}$ & $\begin{array}{r}100.0 \\
(95)\end{array}$ \\
\hline \multicolumn{6}{|l|}{ Art Staff } \\
\hline $\begin{array}{c}0 \\
(\stackrel{N}{ })\end{array}$ & $\begin{array}{r}41.7 \\
(5)\end{array}$ & $\begin{array}{r}18.2 \\
(4)\end{array}$ & $\begin{array}{r}42.9 \\
(12)\end{array}$ & $\begin{array}{c}30.3 \\
(10)\end{array}$ & $\begin{array}{r}32.6 \\
(31)\end{array}$ \\
\hline $1-5$ & $\begin{array}{r}58.3 \\
(7)\end{array}$ & $\begin{array}{r}59.1 \\
(13)\end{array}$ & $\begin{array}{c}42.9 \\
(12)\end{array}$ & $\begin{array}{c}63.6 \\
(21)\end{array}$ & $\begin{array}{c}55.8 \\
(53)\end{array}$ \\
\hline $6-20$ & 0 & $\begin{array}{r}22.7 \\
(5)\end{array}$ & $\begin{array}{r}14.3 \\
(4)\end{array}$ & $\begin{array}{r}6.1 \\
(2)\end{array}$ & $\begin{array}{r}11.6 \\
(11)\end{array}$ \\
\hline Total & $\begin{array}{c}12.6 \\
(12)\end{array}$ & $\begin{array}{c}23.1 \\
(22)\end{array}$ & $\begin{array}{c}29.5 \\
(28)\end{array}$ & $\begin{array}{r}34.7 \\
(33)\end{array}$ & $\begin{array}{r}100.0 \\
(95)\end{array}$ \\
\hline
\end{tabular}


Table 68.--Business and Board Sizes by Role Type (percent)

\begin{tabular}{|c|c|c|c|c|c|}
\hline & Entrepreneur & Administrator & Artist & Caretaker & Total \\
\hline \multicolumn{6}{|l|}{ Bus Staff } \\
\hline $\begin{array}{c}0 \\
(\mathrm{~N})\end{array}$ & $\begin{array}{r}25.0 \\
\text { (3) }\end{array}$ & $\begin{array}{r}13.6 \\
(3)\end{array}$ & $\begin{array}{c}42.9 \\
(12)\end{array}$ & $\begin{array}{r}33.7 \\
(14)\end{array}$ & $\begin{array}{c}33.7 \\
(32)\end{array}$ \\
\hline $1-5$ & $\begin{array}{r}75.0 \\
(9)\end{array}$ & $\begin{array}{r}86.4 \\
(19)\end{array}$ & $\begin{array}{c}53.6 \\
(15)\end{array}$ & $\begin{array}{c}65.3 \\
(19)\end{array}$ & $\begin{array}{c}65.3 \\
(62)\end{array}$ \\
\hline $6-20$ & 0 & 0 & $\begin{array}{r}3.6 \\
(1)\end{array}$ & 0 & $\begin{array}{r}1.1 \\
(1)\end{array}$ \\
\hline Total & $\begin{array}{c}12.6 \\
(12)\end{array}$ & $\begin{array}{c}23.2 \\
(22)\end{array}$ & $\begin{array}{r}29.4 \\
(28)\end{array}$ & $\begin{array}{r}34.7 \\
(33)\end{array}$ & $\begin{array}{r}100.0 \\
(95)\end{array}$ \\
\hline \multicolumn{6}{|l|}{$p=.15$} \\
\hline \multicolumn{6}{|l|}{ Board } \\
\hline $\begin{array}{c}\overline{1-5} \\
(\mathrm{~N})\end{array}$ & $\begin{array}{r}41.7 \\
(5)\end{array}$ & $\begin{array}{r}45.5 \\
(10)\end{array}$ & $\begin{array}{r}67.9 \\
(19)\end{array}$ & $\begin{array}{r}75.8 \\
(25)\end{array}$ & $\begin{array}{c}62.1 \\
(59)\end{array}$ \\
\hline $6-20$ & $\begin{array}{r}58.3 \\
(7)\end{array}$ & $\begin{array}{r}54.5 \\
(12)\end{array}$ & $\begin{array}{r}32.1 \\
(9)\end{array}$ & $\begin{array}{r}24.2 \\
(8)\end{array}$ & $\begin{array}{r}37.9 \\
(8)\end{array}$ \\
\hline Total & $\begin{array}{r}12.6 \\
(12)\end{array}$ & $\begin{array}{c}23.1 \\
(22)\end{array}$ & $\begin{array}{c}29.4 \\
(28)\end{array}$ & $\begin{array}{r}34.7 \\
(33)\end{array}$ & $\begin{array}{r}100.0 \\
(95)\end{array}$ \\
\hline
\end{tabular}

In the measurement of service and performance change over three years (1989-91) as a factor in agency viability, Tables 69 through 71 and Figures 4, 5, and 6 show that entrepreneurs reported smaller percentages of both growth and decline than all other groups. Administrators recorded the greatest decline over three years, from $4.5 \%$ decline in 1989 to $27.3 \%$ in 1991. Artists and caretakers also reported sizeable percentages of decline. Caretakers reported the greatest degree of stability over the three year period. No role type reported growth from 1990 to 1991 ; all reported decline from 1990 to 1991 in varying percentages. Entrepreneurs did not present substantial evidence of growth or decline which distinguished them from all other groups. There were no statistically 
significant findings in agency size by role type, and no pattern which favored the entrepreneur.

Table 69.--Service and Performance Change 1989 by Role Type (percent)

\begin{tabular}{lccccc}
\hline & Entrepreneur & Administrator & Artist & Caretaker & Total \\
\hline $\begin{array}{l}\text { Growth } 1989 \\
\text { (N) }\end{array}$ & 72.7 & 81.8 & 42.9 & 42.4 & 75.3 \\
Decline 1989 & $(8)$ & $(18)$ & $(22)$ & $(19)$ & $(67)$ \\
& 18.2 & 4.5 & 8.0 & 16.1 & 11.2 \\
Stable 1989 & $(2)$ & $(1)$ & $(2)$ & $(5)$ & $(10)$ \\
& 9.1 & 13.6 & 4.0 & 22.7 & 13.5 \\
Missing & $(1)$ & $(3)$ & $(1)$ & $(7)$ & $(12)$ \\
& $(1)$ & & $(3)$ & $(2)$ & $(6)$ \\
Total & 12.6 & 23.1 & 29.4 & 34.7 & 100.0 \\
& $(12)$ & $(22)$ & $(28)$ & $(33)$ & $(95)$ \\
\hline $\mathrm{p}=.28$ & & & & &
\end{tabular}

Table 70.--Service and Performance Change 1990 by Role Type (percent)

\begin{tabular}{|c|c|c|c|c|c|}
\hline & Entrepreneur & Administrator & Artist & Caretaker & Total \\
\hline $\begin{array}{c}\text { Growth } 1990 \\
\text { (N) }\end{array}$ & $\begin{array}{r}75.0 \\
(9)\end{array}$ & $\begin{array}{c}81.8 \\
(18)\end{array}$ & $\begin{array}{c}81.5 \\
(22)\end{array}$ & $\begin{array}{c}60.6 \\
(20)\end{array}$ & $\begin{array}{c}73.4 \\
(69)\end{array}$ \\
\hline Decline 1990 & $\begin{array}{c}8.3 \\
(1)\end{array}$ & $\begin{array}{c}4.5 \\
(1)\end{array}$ & $\begin{array}{r}14.8 \\
(4)\end{array}$ & $\begin{array}{r}12.1 \\
(4)\end{array}$ & $\begin{array}{r}10.6 \\
(10)\end{array}$ \\
\hline Stable 1990 & $\begin{array}{r}16.7 \\
(2)\end{array}$ & $\begin{array}{r}13.6 \\
(3)\end{array}$ & $\begin{array}{r}3.7 \\
(1)\end{array}$ & $\begin{array}{r}27.3 \\
(9)\end{array}$ & $\begin{array}{r}16.0 \\
(15)\end{array}$ \\
\hline Missing & & & (1) & & \\
\hline Total & $\begin{array}{c}12.8 \\
(12)\end{array}$ & $\begin{array}{c}23.4 \\
(22)\end{array}$ & $\begin{array}{c}29.4 \\
(28)\end{array}$ & $\begin{array}{c}35.1 \\
(33)\end{array}$ & $\begin{array}{r}100.0 \\
(95)\end{array}$ \\
\hline
\end{tabular}




\section{1}

Table 71.--Service and Performance Change 1991 by Role Type (percent)

\begin{tabular}{cccccc}
\hline & Entrepreneur & Administrator & Artist & Caretaker & Total \\
\hline Growth & 66.7 & 63.6 & 77.8 & 54.5 & 64.9 \\
$(\mathrm{~N})$ & $(8)$ & $(14)$ & $(21)$ & $(18)$ & $(61)$ \\
Decline & 16.7 & 27.3 & 18.5 & 21.2 & 21.3 \\
& $(2)$ & $(6)$ & $(5)$ & $(7)$ & $(20)$ \\
Stable & 16.7 & 9.1 & 3.7 & 24.2 & 13.8 \\
& $(2)$ & $(2)$ & $(1)$ & $(8)$ & $(13)$ \\
Missing & & & $(1)$ & & \\
& & & & & \\
\multicolumn{1}{c}{ Total } & 12.8 & 23.4 & 29.4 & 35.1 & 100.0 \\
& $(12)$ & $(22)$ & $(28)$ & $(33)$ & $(95)$ \\
\hline
\end{tabular}

$\mathrm{p}=.33$ 
Service and Performance Change (Growth)

by Role Type and Year

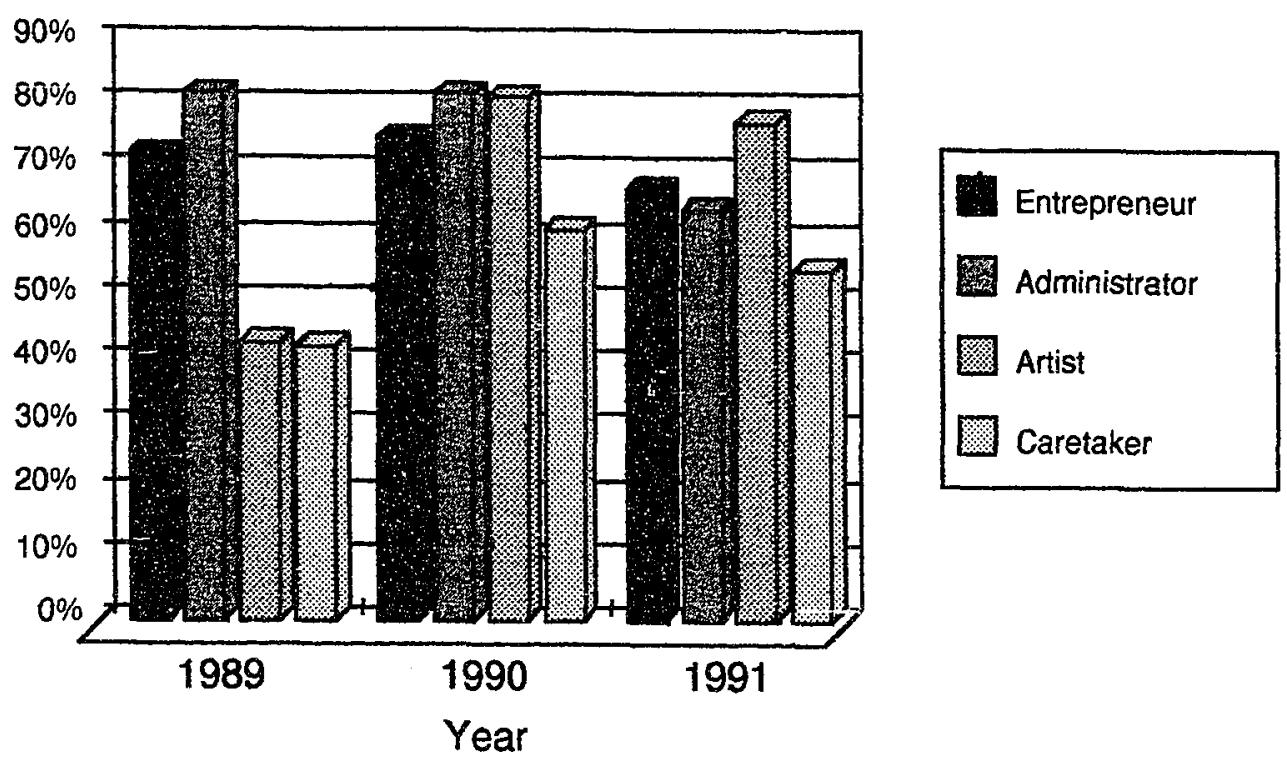

Figure 4. Service and Performance Change (Growth)

by Role Type and Year 


\section{Service and Performance Change (Decline) \\ by Role Type and Year}

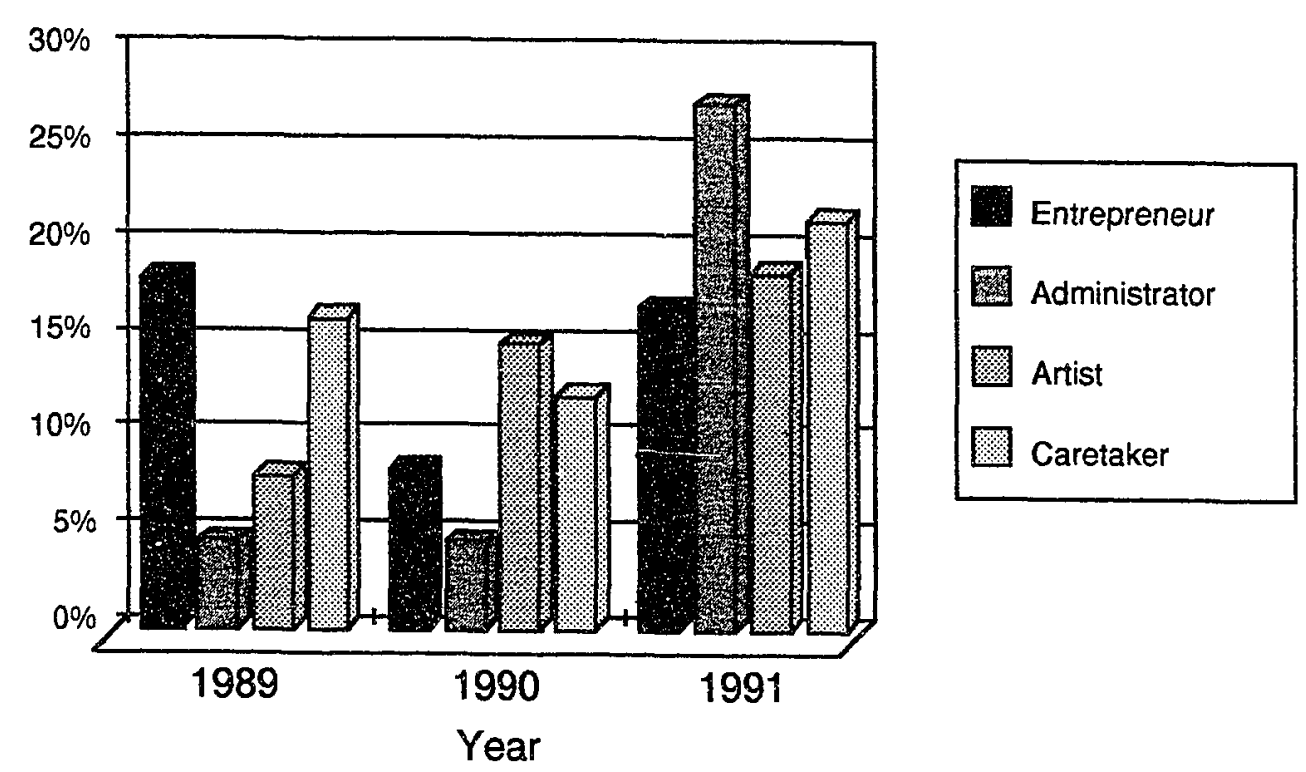

Figure 5. Service and Performance Change

(Decline) by Role Type and Year 


\section{Service and Performance Change (Stable) by Role Type and Year}

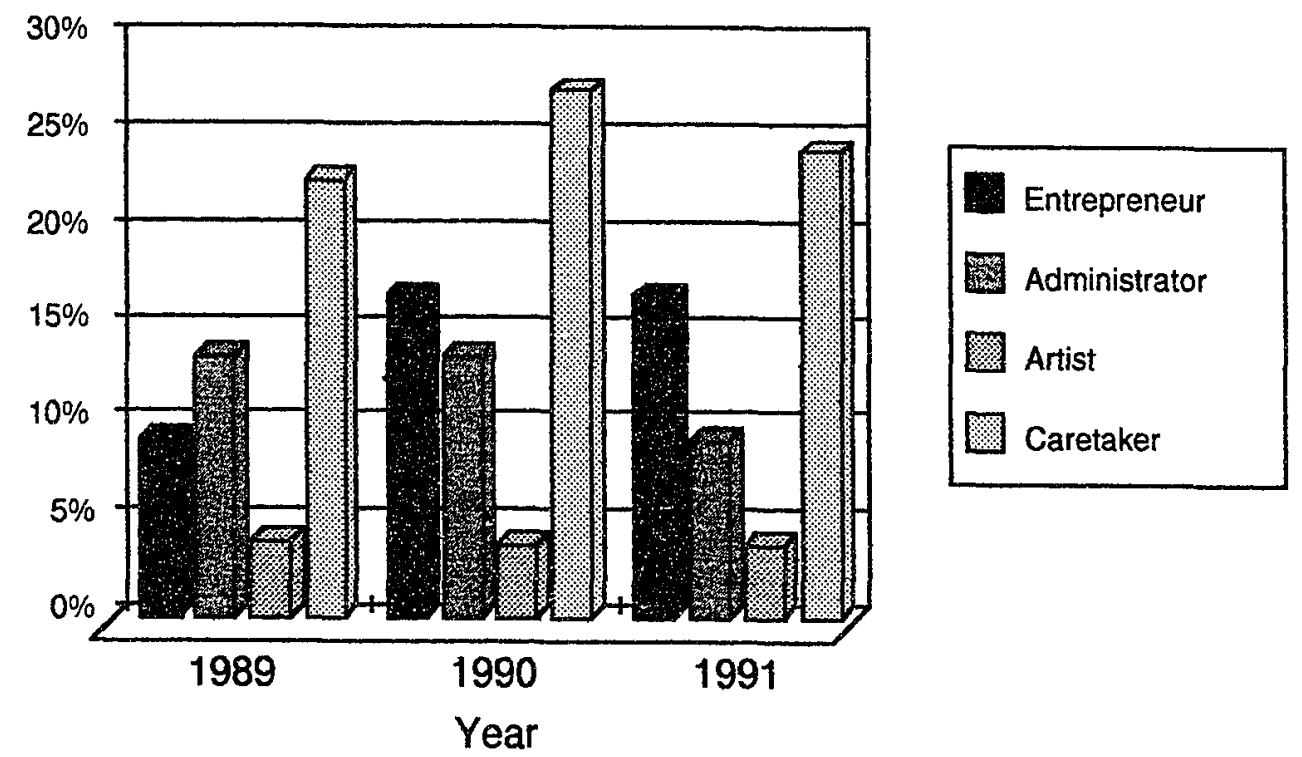

Figure 6. Service and Performance Change (Stable) by Role Type and Year 


\section{Analysis of Variance}

An analysis of variance performed on budgetary variables by role types, seen in

Table 73, indicated that entrepreneurs were secondary to administrators in generating Total Gross Revenue. In generating revenues, entrepreneurs earned slightly over half the revenues of administrators and not substantially more than artists. Caretakers earned about one-third of entrepreneurs and less than one-fifth of administrators. There was a statistically significant difference in total revenue between administrators and caretakers (see Table 72).

Table 72.--Mean Values of Roles by Total Gross Revenue 1991 from IRS \# 990

\begin{tabular}{lccccc}
\hline \hline & Entrepreneur & Administrator & Artist & Caretaker & Total \\
\hline Mean & 301,675 & $585,202^{*}$ & 236,462 & $101,932 *$ & 278,729 \\
$(\mathrm{~N})$ & $(12)$ & $(22)$ & $28)$ & $(33)$ & $95)$ \\
\hline
\end{tabular}

* Significant at $\mathrm{p}=.050$, Tukey B method

Table 73.--Analysis of Variance: Role Types (Independent Variable) by Total Gross Revenues 1991 from IRS Form \#990 (Dependent Variable)

\begin{tabular}{lrrrrc}
\hline Source & SS & df & MS & F & Significance of F \\
\hline Between Groups & 3.1542 & 3 & 1.0514 & 3.4257 & .0204 \\
Within Groups & 2.7930 & 91 & 3.0692 & & \\
Total & 3.1084 & 93 & & & \\
\hline
\end{tabular}

In the variable "percent of earnings from programming," which calculated the percentage of managerial total revenue that came from earned income (i.e., from performances or services ), there was a major surprise seen in Table 74. The caretaker was able to generate over half his/her revenue compared with about one-third for the other three roles. The reason for this stems from the caretakers' strong involvement in active cutback 
strategies that include augmenting performance schedules and location. Caretakers are only marginally successful at generating funds by donation; they tend to try to earn a substantial proportion of their income through performances or services and keep their expenses minimal. An analysis of variance, seen in Table 74, displayed a statistically significant difference between the caretaker and all other roles on the variable "percent earned income."

Table 74. Mean Values of Roles by Percent Earned Income

\begin{tabular}{lccccc}
\hline \hline & Entrepreneur & Administrator & Artist & Caretaker & Total \\
\hline $\begin{array}{l}\text { Mean } \\
\text { (N) }\end{array}$ & $34.583^{*}$ & $35.0143^{*}$ & $38.444^{*}$ & $54.645^{*}$ & 42.662 \\
& $(12)$ & $(21)$ & $(27)$ & $(31)$ & $(91)$ \\
\hline
\end{tabular}

* Significant at $\mathrm{p}=.050$, Tukey $\mathrm{B}$ method

Table 75.--Analysis of Variance: Role Types (Independent Variable) by Percent Earned Income (Dependent Variable)

\begin{tabular}{lrrrrr}
\hline \hline Source & SS & df & MS & F & Significance of F \\
\hline Between Groups & 6943.1617 & 3 & 2314.38 & 5.2641 & .0022 \\
Within Groups & 38249.7658 & 87 & 439.6525 & & \\
Total & 45192.9330 & 90 & & & \\
\hline
\end{tabular}

In terms of the dollar amounts of contributions, the administrator and entrepreneur led all roles, respectively and the caretaker made an extremely poor showing. This finding reinforces the impression that the caretaker counts on performances and services to bring in the majority of income, and either neglects fundraising or judges it to be unproductive. There were significant differences in fundraising between the administrator and the caretaker, shown in Tables 76 and 77. 
Table 76.--Mean Values of Roles by Amount of Contributions

\begin{tabular}{lccccc}
\hline \hline & Entrepreneur & Administrator & Artist & Caretaker & Total \\
\hline $\begin{array}{l}\text { Mean } \\
(\mathrm{N})\end{array}$ & 145,398 & $230,849^{*}$ & 78,751 & $22,754^{*}$ & 103,563 \\
& $(12)$ & $(21)$ & $(27)$ & $(31)$ & $(91)$ \\
\hline
\end{tabular}

* Significant at $\mathrm{p}=.050$, Tukey B method

Table 77. Analysis of Variance: Role Types (Independent Variable) by Amount of Contributions (Dependent Variable)

\begin{tabular}{|c|c|c|c|c|c|}
\hline Source & SS & df & MS & F & Significance of $F$ \\
\hline $\begin{array}{l}\text { Between Groups } \\
\text { Within Groups }\end{array}$ & $\begin{array}{l}5.8029 \\
4.3419\end{array}$ & $\begin{array}{r}3 \\
87\end{array}$ & $49907127459^{1.9343}$ & 3.8758 & .0119 \\
\hline Total & 4.9222 & 90 & & & \\
\hline
\end{tabular}

The variable "percent of contributions," shown in Tables 78 and 79 , reveals the strengths of the administrators and entrepreneurs, as well as the weaknesses of the artists and caretakers. The entrepreneur led all roles in this category, perhaps reflecting the aggressive stance of the manager in Internal and External Agency Management Tasks. There were statistically significant differences between the entrepreneur and the caretaker at .05 level.

Table 78.--Mean Values of Roles by Percent of Contributions

\begin{tabular}{lccccc}
\hline \hline & Entrepreneur & Administrator & Artist & Caretaker & Total \\
\hline $\begin{array}{l}\text { Mean } \\
\text { (N) }\end{array}$ & $\begin{array}{c}47.9167^{*} \\
(12)\end{array}$ & $\begin{array}{c}40.4091 \\
(22)\end{array}$ & $\begin{array}{c}37.2692 \\
(26)\end{array}$ & $\begin{array}{c}28.2667^{*} \\
(30)\end{array}$ & $\begin{array}{c}36.4556 \\
(90)\end{array}$ \\
\hline
\end{tabular}

* Significant at $p=.050$, Tukey $B$ method 
Table 79.--Analysis of Variance: Role Types (Independent Variable) by Percent of Contributions (Dependent Variable)

\begin{tabular}{lrrrrr}
\hline \hline Source & SS & df & MS & F & Significance of F \\
\hline Between Groups & 3949.1053 & 3 & 1316.3684 & 3.6267 & .0162 \\
Within Groups & 31215.2169 & 86 & 362.9676 & & \\
Total & 35164.3222 & 89 & & & \\
\hline
\end{tabular}

There were data gathered on percentage of grants by role, but the data were unconvincing in that some agencies, using a variant IRS form, did not detail a clear division between grants and other revenues. For this reason, percentage of grants has been dropped as a variable.

Data on the variable "does one-half of agency income come from earned income?" displayed no statistically significant difference at the .05 level between the four roles, seen in Tables 80 and 81.

Table 80.-- Mean Values of Roles by Does Agency Earn One-half Income

\begin{tabular}{lccccc}
\hline \hline & Entrepreneur & Administrator & Artist & Caretaker & Total \\
\hline Mean & .2500 & .3182 & .2963 & .5758 & .3936 \\
$(\mathrm{~N})$ & $(12)$ & $(22)$ & $(27)$ & $(33)$ & $(94)$ \\
\hline
\end{tabular}

* Significant at $\mathrm{p}=.050$, Tukey $\mathrm{B}$ method

Table 81.--Analysis of Variance: Role Types (Independent Variable) by Does Agency Earn One-half Income (Dependent Variable)

\begin{tabular}{lrrrrc}
\hline Source & SS & df & MS & F & Significance of F \\
\hline Between Groups & 1.7232 & 3 & .5744 & 2.4958 & .0649 \\
Within Groups & 20.7130 & 90 & .2301 & & \\
Total & 22.4362 & 93 & & & \\
\hline
\end{tabular}


On the variable "does the agency earn $40 \%$ of income from grants and donations?" in Tables 82 and 83 , there were significant differences between caretakers and administrators, as well as between caretakers and entrepreneurs. There was little difference between the percentages of entrepreneurs and administrators or artists and caretakers. There is an apparent split between the two sets of role types (entrepreneurs and administrators vs. artists and caretakers) on the variables of earning income through performances vs. contributions. Entrepreneurs and administrators depend much more heavily upon fundraising to earn revenues than do artists and caretakers.

Table 82.--Mean Values of Roles by Grants and Donations Equal 40\% Agency Income

\begin{tabular}{llllll}
\hline & Entrepreneur & Administrator & Artist & Caretaker & Total \\
\hline $\begin{array}{l}\text { Mean } \\
\text { (N) }\end{array}$ & $1.0000^{*}$ & $.9091^{*}$ & .7857 & $.6364^{*}$ & .7895 \\
\hline
\end{tabular}

* Significant at $\mathrm{p}=.050$, Tukey $\mathrm{B}$ method

Table 83.--Analysis of Variance: Role Types (Independent Variable) by Grants and Donations Equal 40\% Agency Income (Dependent Variable)

\begin{tabular}{lrrrrc}
\hline Source & SS & df & MS & F & Significance of F \\
\hline Between Groups & .6206 & 3 & .5402 & 3.4696 & .0194 \\
Within Groups & 4.1688 & 91 & .1557 & & \\
Total & 15.7895 & 94 & & & \\
\hline
\end{tabular}

The final data in Tables 84 and 85 from IRS data detail the percent of profit or loss by four roles. The mean percentage of profit or loss for all agencies is $-2.74 \%$ percent. $\mathrm{A}$ range for all agencies is $-121.00 \%$ percent to $+42.00 \%$ percent. Entrepreneurs reported the highest percent of deficit, $-12.2 \%$ percent; administrators lost considerably less and the remaining role types had a minimal loss. While there were no statistically significant 
differences between role types on this variable, there was a striking impression that entrepreneurs and administrators are experiencing serious financial difficulty.

While the entrepreneur did not achieve an overall level of viability comparable to the administrator, he/she did outperform the other role types (artist and caretaker) on nearly every dimension. This observation becomes important when the subject of creativity is factored into agency viability. The administrator, while achieving more impressive business success, performs poorly on creative programming, raising the issue of a potential for exchanging the goal of excellence in the arts for the goal of an "arts centered" business. Perhaps this trend of diverting emphasis from creative programs to sophisticated business techniques is inevitable after the changes in government and private funding in the arts. This issue will be addressed in the next chapter.

Table 84.--Mean Values of Roles by Percent Profit or Loss

\begin{tabular}{lccccc}
\hline \hline & Entrepreneur & Administrator & Artist & Caretaker & Total \\
\hline Mean & -12.29 & -2.76 & -.43 & -.90 & -2.74 \\
$(\mathrm{~N})$ & $(10)$ & $(15)$ & $(13)$ & $(18)$ & $(56)$ \\
\hline
\end{tabular}

* Significant at $\mathrm{p}=.050$, Tukey B method

Table 85.--Analysis of Variance: Role Types (Independent Variable) by Percent Profit or Loss (Dependent Variable)

\begin{tabular}{lrrrrr}
\hline \hline Source & \multicolumn{1}{c}{ SS } & df & MS & F & Significance of F \\
\hline Between Groups & 219.8457 & 3 & 406.6152 & .6491 & .5871 \\
Within Groups & 32573.0727 & 52 & 626.4052 & & \\
Total & 33792.9184 & & & & \\
\hline
\end{tabular}




\title{
CHAPTER VI
}

\section{SUMMARY AND CONCLUSIONS}

\author{
Background to the Study
}

\section{Research Approach}

The target population for this study was comprised of one hundred and twenty three top managers of non profit arts agencies in Virginia who received financial grants from the Virginia Commission for the Arts in 1991 or FY 1990-1991. There were 118 managerial responses, which were reduced to 95 active respondents after the data were entered. Data were generated by a questionnaire covering managerial programming creativity, access to organizational resources, behaviors in internal and external agency management tasks, behaviors in cutback strategies, and general attitudes toward the management of the arts as a business. Interviews were conducted by telephone and in person. Data were entered electronically on the SPSSx program for analysis. Data analyses included descriptive statistics, Pearson's correlation matrices, cross tabulations, indexes, Guttman scalogram analysis and analyses of variance.

Managers were divided by role type according to their scores on the two variables of programmatic creativity and access to organizational variables. The scores on these two variables revealed a normal distribution in the survey population. Accordingly, scores above the mean were characterized as high, while those below the mean were scored as low. Taken together, the two-attribute variables created a four-cell property space that was used to classify role performance. Managers were then assigned to roles on the basis of self-reported degrees of creativity and their manifested involvement in generating 
organizational resources for the agency. There was no attempt by the researcher to assign managers to cells on the basis of their identification with any particular role type, nor were managers asked if they viewed themselves as embodying the characteristics of any role type.

The resulting typology of arts managers has face validity and is consonant with organizational theory and research.

\section{Population Profile}

One hundred and eighteen mangers were relatively evenly divided among the three major urban centers of Virginia: Hampton Roads (29.1\%), Richmond (35.0\%), and Northern Virginia (35.9\%). Caucasians (94.9\%) and women (61.5\%) were overrepresented, and most managers held the bachelor's degree with no major field of study in the arts (32.5\%) or business management (39.3\%). Over half of the managers had more than eight years of experience and $39 \%$ percent ran their agencies as a sole executive. More than one-third of agencies operated only with a board of directors. One-third of all managers took no salary, while $13.7 \%$ percent earned over $\$ 41,000$.

Musical performance was the most common type of agency represented (35.0\%) followed by theatre and dance. Agencies underrepresented were multi-cultural arts (2.6\%), funding agencies $(1.7 \%)$, and community centers ( $3.4 \%)$. While many agencies had been operating for over 15 years (43.2\%), less than one-third considered themselves still growing. Almost half of the agencies reported they were in the process of changing some aspect of their operations. Some agencies reported a rapid decline (11.1\%) in their services and performances between 1990 and 1991.

Most agencies displayed difficulties in generating revenues, either through performances and services, or grants and contributions. They reported a mean operating deficit in 1991 of nearly three percent. While only one-third of the agencies were able to 
earn half of their revenues through performance and service fees, two-thirds earned almost half of their revenues through grants and donations.

When questioned about attitudes toward business management in the arts, many managers $(84.7 \%)$ agreed that a larger purpose or goal guided their selection of the arts as a life's work, but a greater percentage $(94.1 \%)$ agreed that changes in the arts have become a constant expectation. One-half of respondents looked to business methods as a means of guaranteeing an agency's survival, but half also relied heavily on intuitive decision making. Most managers (85.6\%) felt confident they could influence the course of events in their agencies and few (16.1\%) allowed that luck was a determinant in agency success.

Table 86 lists the main hypotheses that were posed in this study as well as the results. A summary discussion of these findings follows.

Table 86.--Distribution of Findings that Support, Fail to Support and Partially Support Hypotheses

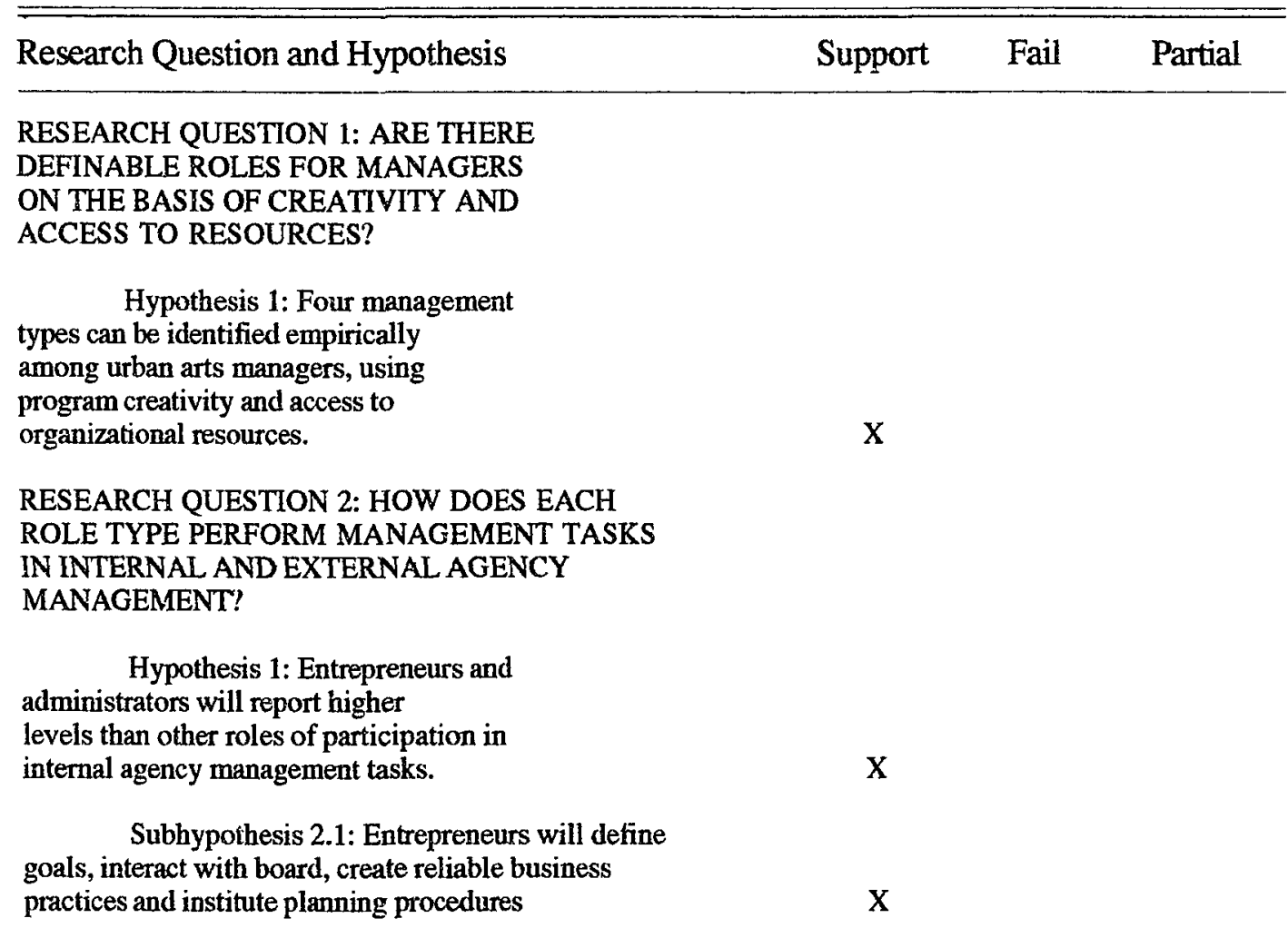


Table 86.--Distribution of Findings that Support, Fail to Support and Partially Support Hypotheses (Continued)

\begin{tabular}{llll}
\hline Research Question and Hypothesis & Support & Fail & Partial \\
\hline
\end{tabular}

Subhypothesis 2.2: Administrators will determine goals, interact with boards, create reliable business practices, but have little interest in long-term planning

$\mathrm{X}$

Subhypothesis 2.3: Artists will determine goals and de-emphasize all other aspects of internal agency management tasks

Subhypothesis 2.4: Caretakers will manifest the least interest in internal agency management tasks of all role types

$\mathrm{X}$

Hypothesis 2: Entrepreneurs and administrators will have high levels of participation in external agency management tasks

$\mathrm{X}$

Subhypothesis 2.2.1: Entrepreneurs will lead all role types in external agency management tasks

Subhypothesis 2.2.2: Administrators will emphasize local fundraising and networking, but will show less interest in assessing regional economic marketing for the arts

Subhypothesis 2.2.3: Artists will be partially involved with fundraising, but less interested in community involvement, developing competitive strategies for the agency and assessing the regional economic environment

Subhypothesis 2.2.4: Caretakers will demonstrate little or no involvement in external agency management tasks

\section{RESEARCH QUESTION 3: HOW DOES EACH ROLE TYPE INSTTTUTE CUTBACK PROCEDURES?}

Hypothesis 1: Managerial performance varies by role type in instituting cutback procedures

Subhypothesis 3.1: Entrepreneurs will be the most aggressive in instituting active and passive cutback procedures

Subhypothesis 3.2: Administrators will selectively use some active and some passive cutback procedures 
Table 86.--Distribution of Findings that Support, Fail to Support and Partially Support Hypotheses (Continued)

\begin{tabular}{|c|c|c|c|}
\hline Research Question and Hypothesis & Support & Fail & Partial \\
\hline $\begin{array}{l}\text { Subhypothesis 3.3: Artists disproportionately } \\
\text { will use passive cutback strategies }\end{array}$ & & $\mathrm{x}$ & \\
\hline $\begin{array}{l}\text { Subhypothesis 3.4: Caretakers will use only } \\
\text { passive cutback procedures }\end{array}$ & & $\mathrm{x}$ & \\
\hline $\begin{array}{l}\text { RESEARCH QUESTION 4: IS THE } \\
\text { ENTREPRENEUR MORE SUCCESSFUL IN } \\
\text { RUNNING A VIABLE ARTS AGENCY? }\end{array}$ & & & \\
\hline $\begin{array}{l}\text { Hypothesis 1: Entrepreneurial managers } \\
\text { will lead more viable agencies as measured by } \\
\text { agency longevity, agency lifecycle, staff sizes, } \\
\text { record or growth and decline, and budgetary } \\
\text { elements }\end{array}$ & & $\mathrm{x}$ & \\
\hline
\end{tabular}




\section{Summary of Findings}

\section{Research Question 1}

Research Question 1: What are the definable roles to which arts administrators can be assigned on the basis of factors of programmatic creativity and access to organizational resources?

As seen in Table 86, data supported Hypothesis 1 , which revealed that arts managers can be described and grouped into four roles on the two variables of creativity and access to resources. The four role types identified were entrepreneurs, administrators, artists and caretakers. The division of respondents into four role types allowed an examination of the patterns of managerial behavior by role type. Role types were defined as follows:

1) the entrepreneur is a proactive leader with high artistic creativity and high access to organizational resources

2) the administrator builds a stable organizational base with a high access to resources, but lacks a strong commitment to artistic creativity

3) the artist is committed to and involved in artistic programming and performing, but lacks the skills, time, and training to create a stable business organization and has limited access to organizational resources.

4) the caretaker is a reactive leader without the capability to generate creative programming and build organizational strength

Data further revealed that the four role types were significantly different from each other with the least apparent differences between administrators and entrepreneurs. A description of role types revealed that entrepreneurs are younger than 55 , educated at the B.A. and M.A./Ph.D. levels, and anticipated changes in the arts. They are largely affiliated 
with visual arts agencies that are more than five years old. Administrators are concentrated in music agencies, which they described as growing rather than changing or declining. They are very interested in securing the viability of their agencies through business techniques such as endowment funds, corporate sponsorship and the purchase of fixed assets. Artists generate considerable energy on planning programs and performing, with little or no focus on the business aspect of their agencies. They often receive no local government support and view business techniques as hostile to the main goal of the arts. They have less formal education than other role types and are located in very young agencies, largely theatre and dance. Caretakers are older managers educated at the B.A. and M.A. level with little business or management education. They feel vulnerable in a changing arts environment because they have few creative or business skills. They are equally represented in all types of agencies and in agencies of varying longevity.

\section{Research Question 2}

Research Question 2: How does each role type perform the internal and external tasks involved in running an arts agency?

Hypothesis 2 and all subhypotheses predicting that each role type will differ in performing the internal and external tasks of management were supported by the data (see Table 86).

The data also suggest that the divisions of managers into role types on the basis of levels of creativity in programming and access to organizational resources is not an arbitrary segmentation. The clear differences in managerial functioning by role types reveal four separate patterns of behavior resembling their theoretical descriptions. This is a major finding from the research: by knowing the role type of a manager and certain characteristics of his/her agency, largely agency type and budget, we can predict the types of behaviors that managers will use to build arts organizations and relate them to communities. 
Additional studies such as factor analysis and regression analysis substantiated this finding and are detailed in Appendix F.

The data reveal that the although the four role types differ significantly on the tasks of internal agency management, which include activities such as goal and mission planning, developing agency structure, establishing basic management techniques, and instituting strategic and long-range planning, administrators and entrepreneurs show comparable proficiency overall. Each role type displays a proficiency on selected items consonant with its role. They are followed by artists and caretakers.

The role types similarly differ on the external management tasks, which include activities such as lobbying governments for the arts, involving the agency in the life of the community, coping with the competitive environment, and preparing economic assessment studies. Administrators and entrepreneurs behave similarly, as do artists and caretakers. There are minimal differences between the administrators and the entrepreneurs or between the artists and the caretakers. The four roles are described as follows:

1) Entrepreneurs: The research supported Hypothesis 2 and subhypotheses 2.1 and 2.2.1 that entrepreneurs and administrators will engage in higher levels of internal and external management tasks than do the other two role types. In particular, entrepreneurs exceeded all other role types in several external management tasks. Entrepreneurs reported activities that characterize the role type, including initiating change by accessing information, opportunities and challenges. They demonstrate a style of management that concentrates on creative programming (challenges), providing stable management (funding opportunities) and networking in the community (accessing information).

2) Administrators: Administrators are theoretically differentiated from entrepreneurs by their failure to seek opportunity and change. This role type concentrates 
on developing a continuous, stable, coordinating organization, as shown in the data. Data bearing on subhypotheses 2.2 and 2.2.2 supported Hypothesis 2, by describing a role type that demonstrates skills in daily internal and external management, but fails to engage in high levels of creative, experimental or original programming. There were clear differences between entrepreneurs and administrators on this item. While administrators mimicked the performance of entrepreneurs on many internal and external management tasks, they lacked the vision for long-range planning, evident in their failure to provide committees or plans for long-range facilities.

Administrators concentrated on providing the stability necessary to meet the obligations of the foreseeable future by generating large budgets, lobbying for the arts, conducting marketing studies and evaluations and sustaining a large and complex organization. Administrators performed some sophisticated marketing procedures to ensure audience response and approval, but failed to assess, by technical study, the economics of communities in relation to their organizations. The research suggested that administrators, who already have a committed base of support from corporate sponsors, may have felt that a steady and ample revenue stream of contributions insulated them from the vagaries of the economic climate. These clear divisions between entrepreneurs and administrators provide further evidence of the presence of two definable role types.

3) Artists: Artists, hypothesized in subhypotheses 2.3 and 2.2.3 to demonstrate little interest in either internal or external organizational tasks, focused their attention on the short-term tasks of producing and performing. Data for these subhypotheses supported Hypothesis 2, indicating that artists displayed a third distinctly different role type. They immersed themselves more in generating and producing programs, as well as generating support for these programs by their boards of directors. Intense work on actual programs by these young artists precluded attentiveness to many business matters. Many artistmanagers were either performers themselves, or took a far greater part in performances 
than their managerial peers. The data provide display evidence that artists managed their agencies in concert with their greatest concern: performing.

4) Caretakers:_As presented in subhypotheses 2.4 and 2.2.4, caretakers were presumed to demonstrate a low level of interest in business and management tasks and a lack of confidence in mastering these skills, and data supported the subhypotheses. The reasons for this support may lie as much in the manager as in the structure of the agency. Many caretaker agencies were managed by a diffuse board of directors and reflected the lack of a single and directed leadership. These boards generally had scant arts background or experience in managing the organizational needs of an agency. The members rotated frequently, leaving the arts initiator or board president the onerous task of simultaneously educating new members and performing all managerial tasks. Caretaker agencies that lacked staff and organizational expertise in this study appropriately sensed their potential inability to sustain an agency. Data for subhypotheses 2.4 and 2.2 .4 demonstrated the support for Hypothesis 2, which predicted that each manager will demonstrate a discernable style of operating. We can conclude here that caretakers present a clearly distinguishable pattern of management, which includes their volunteer status and lack of leadership.

\section{Research Question 3}

Research Question 3: How do managers institute cutback procedures to cope with a recessionary economy?

Data relevant to hypothesis 3 and all the subhypotheses, as displayed in Table 86, reveal that cutback strategies vary by role type; i.e., that each managerial role group exhibits behaviors consistent with the description of that role type.

Cutback questionnaire items allowed descriptions of two general strategies. A passive cutback index included items such as cutting the budget, buying cheaper supplies 
and equipment, laying off staff, asking the board of directors to donate funds to rescue the agency, reducing services and performances, and considering termination of the agency. An active cutback index included items such as: introducing new services, revising prices, increasing fundraising, instituting new performance locations, increasing volunteers, conducting marketing studies, and merging with another agency.

The data reveal no differences among role types on the passive cutback strategies, which represented the most extreme and irrevocable types of decisions--laying off staff, cutting the budget, seeking loans, looking for a board rescue, and considering merger or termination. In active cutback strategies however, there were differences among roles that departed from the establisheci theories. These differences are attributed largely to the types of agencies managed and the constraints that these agency types placed on managerial activities. Entrepreneurs, as managers of mostly visual arts agencies, could not revise prices or change locations. Similarly, only administrators, with their strong and influential boards and their long, stable record of operation, could apply for loans. Artists, who dealt exclusively in performing, used this strength to increase revenues and ward off demise. Caretakers behaved similarly, rallying to survive by employing some active cutback strategies.

The mean values on the active cutback index suggest that administrators and artists are more likely to employ these measures than entrepreneurs or caretakers. A discussion of managerial cutback strategies by role type follows:

1) Entrepreneurs: Subhypothesis 3.1 posed that entrepreneurs would act more aggressively than other role types in both active and passive cutback strategies. The hypothesis was only partially supported because the type of agency managed by entrepreneurs in this study precluded certain types of cutbacks, such as revising prices or performing in new locations. On the whole, however, entrepreneurs viewed active cutback strategies as opportunities for exploration and growth. Entrepreneurs did not differ substantially from other role types on passive cutback strategies. 
2) Administrators: As suggested by subhypothesis 3.2, administrators were active in all phases of active cutbacks, similar to entrepreneurs, and did not differ substantively on passive cutbacks. Administrators' use of active cutback strategies was not a departure from their manner of insuring stable operations. The active cutback strategies presented in this study did not represent risky ventures; they encompassed the kinds of actions that any responsible manager might take to increase revenues (fundraising), augment manpower (increase volunteers), offer price incentives (revise pricing strategies), and increase audiences (offer new schedules and locations). Administrators, however, revealed their business acumen over other role types in one area: administrators looked for loans to span impending shortfalls. No other role type tried as hard to secure a loan. The size of the administrator's agency, the diversity and sophistication of the board members, and the close ties to the corporate community as well as civic leaders, allowed this role type to operate in this regard more as a traditional business than as a non profit agency.

3) Artists: Subhypothesis 3.3 was not supported by the data: artists did not use only passive cutbacks, such as budget cuts and staff layoffs, to weather the recession. Instead, they employed their most valuable resource to increase revenues--they augmented their performing schedules. Their poor record in fundraising and winning local grants as well as the precariousness of their situation left them few other choices. They displayed evidence of their tenuous state by a high percentage of agreement on terminating as a cutback strategy.

4) Caretakers: Caretakers were hypothesized in subhypothesis 3.4 to engage only in passive cutback strategies. In fact, they performed somewhat differently. The reasons are varied. Because caretakers had little to no managerial staff, they had, in effect, already performed many aspects of passive cutbacks. Their only means of survival was to attempt 
to raise more money through fundraising and to increase performances. Caretakers, like artists, reported high percentages of agreement on the possibility of termination.

\section{Research Question 4}

Research Question 4: is the entrepreneur more successful than other managers in maintaining an agency over time.

Hypothesis 4 was not supported by data detailing agency longevity, lifecycle, staff sizes, record of growth and decline from 1989-1991, or a variety of budgetary elements, including total gross revenues, percent of earned and donated income, and percent of profit or loss. Among role types, the administrator demonstrated higher levels than the entrepreneur on some of these items. No single role type emerged as more viable than the others in ability to generate sufficient revenues to support the agency and to stem a pattern of declining services and performances.

The reasons for the failure of the entrepreneur to achieve greater viability in this study appear to lie in three areas: 1) observation was limited by the small number of entrepreneurs in the study, 2) general restrictions on non profit organizations, and 3) internal conflicts for non profit entrepreneurs.

\section{Too few Entrepreneurs}

The target population in this study was large enough to gain an appreciation of the general characteristics of urban arts managers and to describe their behaviors by role types. However, only 12 respondents were identified as entrepreneurs. This small size constrains a reliable observation of variations. It is likely that a larger group of respondents would reveal greater variance--and perhaps significant patterns.

There also is reason to believe that entrepreneurship has its limits. Downs (in Shafritz and Hyde 1987, 349) makes a point about the need for an entrepreneurial agency to find a supportive environment in order to prosper. "Bureaus created through 
entrepreneurship," he says, "are generally not successful until the zeal of the nucleus group coincides with environmental conditions favorable to the function they are promoting."

\section{Non-Profit Obstacles to Entrepreneurship}

The elements of non profit management that impede entrepreneurial activity fall into three separate areas: mission, skills, and restrictions, which act alone and in combination to stymie purposeful activity. Non profit agencies tend to operate with diffuse, ambiguous and conflicting goals. Often these goals are driven by the multiplicity of publics that the agency serves and/or that contribute to the agency. Anthony and Young (in Gies, Ott and Shafritz 1990,224$)$ note that boards of directors have difficulty agreeing on a tangible goal that will serve these many publics and satisfy the conditions of the initial charter of the agency. If, by hard work and motivated board effort, the agency settles on a goal that meets the demands of the public and the agency charter, it must then look for venture capital. According to Anthony and Young (1988), however, non profit law prohibits agencies from obtaining "equity capital from outside investors. .. their equity capital must be donated."

Even agencies that have established tangible and agreed-upon goals must demonstrate clearly to lending agencies that they possess the necessary technical skills and professional expertise to build and sustain their projects (Young 1985). Funding agencies look askance at evidences of business instability and threats of demise such as the lack of a constant revenue stream or attacks by political extremists. They are intolerant of staffs that lack the required skills and experience to build a successful enterprise. If all other avenues to securing a loan are satisfactory, financiers can always refuse loans on the basis of providing an unfair competitive advantage (federal tax relief) to a non profit agency vs. a commercial business (Anthony and Young 1988). 


\section{Internal Obstacles to Entrepreneurship}

There are also internal obstacles that hamper entrepreneurship in the arts. Boards of directors generally are conservative and avoid risks in their decision making. They are not always well-informed about the consequences of certain artistic decisions, and their actions may be influenced by political or social factors. Board members often are unwilling to support a venture for which they may be held publicly, legally and (at least partially) financially liable.

There also are conflicting goals between artistic and business managers, each of whom responds to innovations in characteristic and mutually exclusive ways. Artistic managers are more willing to take some risks and they are more concerned about the quality of agency programs. Business managers typically operate conversely. They are concerned about funding and audience support and are less willing to take changes with creative programs.

Young (1985) and Drucker (1992) further isolate the factor of an overall agency mission as a significant barrier to entrepreneurship. Arts agencies typically have difficulty defining a clear mission that incorporates both creative programs and the use of businesslike methods of operation. Managers in this study were asked about their devotion to the arts (idealism) and to business. While the data revealed that most managers identified both with artistic idealism and business efficacy, few managers expressed any willingness to integrate business techniques into management operations. Managers agreed that business methods may guarantee survival, but most were not willing (or able) to inculcate the techniques of business into their everyday tasks. This uneasy devotion to both artistic quality and business methods (in theory) causes managers to promote ambiguous goals and objectives. There is no clear path that integrates the two qualities. Artists see creativity as a means of exploring life's potential with the intent to explain or remake the world, while administrators attempt to impose discipline and order on the creative process. Entrepreneurs attempt to piece together different parts of the business and creative aspects 
of the arts without losing the importance or the essence of each, perhaps a near-toimpossible task. 


\section{CONCLUSIONS}

While the data do not support the anticipated strong link between the role type entrepreneur and enhanced agency viability, they do reveal the strengths of the role types entrepreneur and administrator over the artist and the caretaker. Essentially there were no differences between entrepreneurs and administrators in most tests for viability. The entrepreneurs were described similarly to the administrators in many areas, lagging behind only in total revenue and amount of contributions. A logical conclusion from these data suggests that both entrepreneurs and administrators demonstrate the necessary components for agency viability. The data also demonstrate that artists and caretakers exhibit fewer strengthts in management tasks that lead to agency viability. One can infer from these data that a viable arts agency in the current environment will have to select a manager who displays a working combination of both entrepreneurial and administrative skills, a union that has been scarce in the past.

The new arts manager will have to adapt to rapid changes in public taste, politics, and economics, with no clear direction of the changes. Theory suggests that the unpredictability of these environmental changes can spell either success or failure for agencies, depending upon the manager's ability to mesh the agency's interests with the public interest. Downs, in Shafritz and Hyde 1987, finds that "the major causes of both growth and decline in bureaus are rooted in exogenous factors in their environment" (350). As the current environment is marked by retrenchment and conservatism, with an interest in populist programming, managers will need to plan strategically in order to prosper. The skills that offer the best chance for managerial success now lie in professional arts management and innovative programming. A new role will arise that links the creative impulses, personal resiliancy and risk tolerance of the entrepreneur with the business sophistication of the administrator. This new combination of professional business and 
management skills with visionary leadership will be vital components for the "adaptive" arts agency of the next century.

Writing a quarter of a century prior to this study, Bennis (1967, see Shafritz and Hyde 1987, 330) identified two of the key problems of organizations as the need to adapt (the ability of an organization to respond to a "dynamic and uncertain" environment) and the need to revitalize ("self-renewal" in light of changes in personnel, tasks, values, and goals). He warned that "how organizations cope with and manage these tasks will undoubtedly determine the viability and growth of the enterprise" (330).

Kaufman (1991), writing 20 years later, took Bennis a step further by posing organizational demise as a failure or an inability to respond to environmental challenges.

Organizations are not easily changed, but they do inhabit an environment that is extremely volatile and therefore dangerous to them. Whether they are extinguished or survive depends in large measure on the chance compatibility of their characteristics with the circumstances in which the organizations happen to find themselves. They are thus caught up in a process analogous to Darwinian evolution in the biological world.

Kaufman contends that organizations are generally only able to make small changes, while environmental demands often require sweeping revisions. He adds that organizational flexibility has both costs and benefits in terms of constant adaptability. Kaufman explains that organizations adapt to their environments by a process of increasing complexity and refinement, leading to a replacement of the original organization in favor of new models--an evolutionary means of adaptation.

On the basis of data collected in this study, both adaptive change and organizational demise appear possible. The pressures of resource decline on the arts in Virginia pose both challenges and threats to managers, who are being forced to alter their management styles. The new management of the arts requires the incorporation of standard business procedures and accounting methods, an attentive, involved and educated board, and a concerted effort to expand fundraising. Managers are earnestly looking for programs that will entice repeat and new audiences while avoiding political or religious controversies. In the light of 
intense fiscal adversities and constant political scrutiny, it is not surprising that almost half of the managers (43.2\%) describe their agencies as changing, with entrepreneurs leading all roles at $66.7 \%$ percent. Demise is also a real threat, however, as $20 \%$ percent of artists and caretakers are considering termination.

\section{Termination as a Failure to Adapt}

Kaufman (1991) suggests several organizational factors that lead to organizational decay and demise. Chief among these is the resistance to change, and the embedded conservatism in the power structure (board of directors) of the agency. A second cause of organizational decay, according to Kaufman, is goal diffusion--a constant problem for non profit agencies as the artistic and management needs constantly vie for power. An agency managed by a sole boss feels an internal tug between the artistic duties and the fundraising duties, while a complex agency feels the constant warring between the artistic and managerial forces. Management considers artists too temperamental, inflexible and illequipped for business. Artists see management as demonstrating a reactionary and infantile state of artistic development.

Kaufman continues with a complex list of reasons for organizational decay, including faulty decision-making, interest group pressures, a failure of expected resources and a turbulent environment. This study has attempted to show how each of these factors can be linked to current problems in the arts in Virginia. For example, many of the managers interviewed in this study revealed a lack of business or management expertise in such vital areas as basic accounting, cost/benefit analysis, service marketing or strategic planning. These are the kinds of management techniques that would enhance managers' abilities to make more judicious decisions. Again, the requirements and/or strictures of government granting agencies or political pressures could influence decision-making in creative programming. Religious affiliates within the agency's audience or board of directors could also influence creative decision-making. Organizational decay can also arise when resources from government sources, private/foundation sources and individual and 
corporate donors fail to materialize. Many managers are wary of proposing or supporting highly controversial programs because of the recent heated political exchanges regarding government sponsorship of the arts vs. censorship.

There are also clear indications that art patrons are no longer strong supporters of traditional art forms. In our turbulent and rapidly changing environment a high proportion of arts patrons have demonstrated little interest in the more subtle and intellectual challenges of the fine arts, preferring the electronic vibrancy, the ethnic relevance, and emotional immediacy of the popular offerings. The differences in attendance between popular and fine arts offerings are a clear signal that the popular art forms are both more relevant and more enticing to patrons. One may conjecture that this change reflects the rising numbers and influence of minority populations in America, as well as the failure of the public schools to teach and support the fine arts. One can also consider that the easy availability of fine arts performances and exhibitions by art books, videotapes and television special broadcasts makes live performances an unecessary luxury. It is an irony that in an age of rapid communications and electronic reproduction that makes possible the dissemination of the arts to virtually any location in the country (a true democratization of the arts), arts agencies are struggling simply to survive. These major changes in public taste, however, may also signal opportunities for some entrepreneurial arts managers.

\section{Change as Adaptation}

Bennis (1967) proposed various changes over 20 years ago that appear entirely relevant to arts agencies today. He suggested the formation of problem-solving teams (335), which he called "synergetic teams"--groups that reach a higher level of performance as a result of a collaborative effort. He further advocated the development of "supraorganizational" goals and leaders. Bennis described these leaders as "individuals who provide articulation between seemingly inimical interests, who break down the pseudospecies, and who transcend vested interests, regional ties and professional biases in 
arriving at the solution to problems," (336) to counter fractionalization by regional, specialist and professional orientations.

There are numerous examples in this study, especially in the anecdotal evidence, that some agencies and their localities are undertaking such collaborative and transcendent changes. In Hampton Roads, for example, an Executive Directors' Advisory Council for 76 full-time arts agency directors and recreation department managers meets three to four times a year to discuss strategies and shared planning. In Norfolk, the City Manager has established a Roundtable for downtown activities. Many agencies cited specific examples of collaborative programming, such as the programming combinations of orchestra and chorus. Some theatre groups advertised together with other like agencies, providing a concentration of dramatic events. One community planned an overall focus on local artists to promote a sense of community identity. Another turned an old school into free artists' studios with technical support in order to increase the liveability factor for the city. One Virginia city provides space, telephone and business machinery at low rent to over 12 agencies--a sort of arts incubator--which then share the cost of a volunteer coordinator. One entrepreneur also spoke presciently about intra-agency collaboration, "There's too much stress on top management decision-making. We need to delegate authority. A large agency gets attention through a personality, but the best results come from a team approach. A hierarchical, pyramidal style is a dying style of management. We need to empower the employees."

To summarize, arts agencies and their managers are forced into a posture of change and adaptation by the deep reductions in public and private financial support, by dwindling audience support, by a changing population mix, by a lack of substantive arts education, by the assaults on creative programs from the both political conservatives and liberals, and by the contemporary advances in electronic communication. In response to these pressures, some managers are taking adaptive measures including: redefining creativity as program innovation (such as merging several artistic talents from disparate agencies in a single 
program), promoting thematic programming with other agencies, and including popular arts in programs to appeal to a wider range of patrons. Some communities are providing incentives to support arts agencies, such as arts colonies, which provide low rent and subsidized technical support. A few larger agencies are undertaking commercial enterprises, such as real estate development, catalog sales, food services, or musical groups-for-hire, to support the non profit arm. Most agencies are deeply involved in increasing fundraising and instituting more efficient and business-like methods of operation. Most agencies are also feeling the disapproval of adherents to traditional culture as they attempt to move, at least partially, toward more populist programming.

\section{Opposition to Change}

A long history of intellectual warfare between artistic purists and cultural populists presages the contemporary conflict. It was noted in America in 1835 by Alexis DeToqueville, who predicted the leveling of the arts in a democratic society as a natural outgrowth of a populist orientation. Indeed, the nineteenth and twentieth century history of American culture has been a continual polemic between the philosophical adherents of culture as morality, and the presentation of culture as entertainment (Rubin 1992). The cultural purists, which included such intellectual luminaries as Ralph Waldo Emerson and Charles Eliot Norton, believed that it was necessary for literature and art to stand apart from wealth in order to comment freely upon the enobling and moralistic themes of mankind. They opposed those who would debase culture by including simple entertainments, such as those that arose naturally from the major nineteenth century changes of "immigration, urbanization, and industrialization" (22). Populism as a cultural trend, however, continued to escalate into the early 20th century, when a third function of culture--as an economic promoter--appeared. The debasement of the arts was vigorously opposed.

In 1960 critic Dwight Macdonald proposed a solution to avoid arts democratization that would split arts audiences into factions with specialized tastes. Writing in an era of 
heightened attentiveness to the arts with the inception for the National Endowment of the Arts, Macdonald advanced a tripartite theory of cultural offerings that exalted cultural purity, allowed plebeian entertainments and ignored any middle ground:

So let the masses have their Masscult, let the few who care about good writing, painting, music, architecture, philosophy, etc., have their High Culture, and don't fuzz up the distinction with Midcult (Rubin 1992).

A more contemporary arts critic, Roger Kimball (1992), took a more rigorous stance, arguing for the necessity to maintain a bulwark of artistic quality against a "postmodern" (degenerate) mentality that defines culture as simply another option in an everwidening array of entertainments. He found a sympathetic voice in the lament of Alain Finkielkraut (1988), a contemporary French philosopher:

'Democracy once implied access to culture for everybody. From now on it's is going to mean everyone's right to the culture of his choice. . . The footballer and the choreographer, the painter and the couturier, the writer and the ad-man, the musician and the rock-and-roller, are all the same: creators. . It is not just that high culture must be demystified; sport, fashion and leisure now lay claim to high cultural status.'

\section{A New Arts Mission}

A potentially synthesizing reflection on the nature and meaning of culture, was presented by Giamatti (1989), who, speaking chiefly about the culture of sports, described the essential human value of all human artistic activity as a striving for a paradisical state. Giamatti made no distinction between the fine and the popular arts; he found the same motivation behind all artistry--an attempt to transcend human limitations:

'Winning' for player or spectator is not simply outscoring; it is a way of talking about betterment, about making oneself, one's fellows, one's city, one's adherents, more noble because of a temporary engagement of a high human plane of existence. . .The painter or sculptor, poet, architect, or composer, whether he worships a deity or not. . .is basically driven to express what begins as a gnawing hunger and becomes a rage to perfection...

Giamatti's thesis of cultural democracy may be the most acceptable to struggling arts administrators who are attempting to survive by forging an alliance between commercialism and culture. These managers are attempting to broaden the arts mission by 
applying traditional business techniques, such as service and product marketing, strategic planning and consumer segmentation. They are striving to find a cultural middle ground that will encompass the tradition of cultural integrity and quality, while broadening the programmatic aspects of their offerings to attract more diverse (and larger) audiences. Innovative artists, managers and even critics, while regretfully acknowledging the demise of support for art because it embodies such universal abstractions as "truth and beauty," see a new range of audience enhancement possibilities in adaptations such as broad collaborative and thematic programming.

A new director of programming at the national arts pace-setter, New York's Lincoln Center, Jane S. Moss (New York Times, September 16, 1992 and December 3, 1992) is said to "see the creative and performing arts as part of the larger fabric of society, ... she has very broad musical interests. . . [is expected to] include multi-cultural offerings and other kinds of series outside the institution's traditional interests" to appeal to a multiplicity of constituencies. She refuses to limit herself to programs that feature traditional classical music of Western Civilization, and plans to offer a menu of adjunctive programs such as lecture and seminars to debate issues in the arts and look for areas that relate the arts to each other. Similarly, American Symphony Orchestra conductor Leon Botstein (New York Times, September 22, 1992) finds new challenges in "thematic concerts organized around ideas... prefacing [concerts] with lectures and ... even coordinating them with exhibits at museums and other cultural institutions."

These managers, harnessing their natural proclivities to innovate, are rising to the intellectual, fiscal, and programming challenges by redefining the goals of arts agencies, enlarging the scope and content of presentations, promoting the unifying aspects of the arts through collaborative and thematic programming, and providing a secure financial base by earned revenues through increased productions, services and the establishment of adjunctive for-profit centers. The successful entrepreneurial arts agency of the new century is likely to be marked by a greater democratization in the arts, an increased level of 
professionalism in management and a major diminution in government support. The successful arts manager of the new century will exhibit the traits of both the role type entrepreneur and administrator.

While there is little doubt that some arts agencies will not survive the current economic and political stresses by adapting to the new requirements, others are already expending considerable effort to take part in the fertile opportunities for entrepreneurship. It is hoped that a repeat of this study in the next decade could find the arts revitalized and enriched by today's stimuli to change. 


\section{BIBLIOGRAPHY}

Aday, David P., Jr 1991. Organizational Research, Structural Data and the Informant Method: Problems of Reliability. In Studies in Organizational Sociology: Essays in Honor of Charles K. Warriner, Ed. Gale Miller. Greenwich CT.: JAI Press.

Abu-Tayeh, Sultan Nayef. 1988. An Exploratory Study of the Relationship Between Organizational Effectiveness and Leadership Performance Ph.D. diss., State University of New York.

Aldrich, Howard E. 1979. Organizations and Environments. Englewood Cliffs, N.J.: Prentice-Hall.

Babbie, Earl 1986. The Practice of Social Research. Belmont, CA.: Wadsworth Publishing Co.

1990. Survey Research Methods. Belmont, CA.: Wadsworth Publishing Co.

Backman, Jules. 1983. Entrepreneurship and the Outlook for America. New York: The Free Press.

Banfield, Edward C. 1984. The Democratic Muse. Visual Arts and the Public Interest. New York: Basic Books, Inc.

Barnard, Chester. 1938. The Functions of the Executive. Cambridge, Ma.: Harvard University Press.

Bartunek, Jean M. 1988. The Dynamics of Personal and Organizational Reframing. In Paradox and Transformation: Toward a Theory of Change in Organization and Management, ed. Robert E. Quinn and Kim S. Cameron. Cambridge: Ballinger Publishing Company.

Baugher, Dan, ed. 1981. Measuring Effectiveness. San Francisco: Jossey-Bass, Inc., Publishers.

Baumol, William J. and William G. Bowen. 1966. Performing Arts--The Economic Dilemma. Cambridge, Ma. and New York: M.I.T. Press and Twentieth Century Fund.

Bearse, Peter J. 1982. A Study of Entrepreneurship by Region and SMSA Size. In Frontiers of Entrepreneurial Research. Proceedings of the 1982 Conference on Entrepreneurship, ed. Karl H. Vesper. Wellesley, Ma.: Babson College Center for Entrepreneurial Studies.

Becker, Howard S. 1982. Art Worlds. Berkeley: University of California Press.

Bellone, Carl J. 1988. Public Entrepreneurship: New Role Expectations for Local Government. Urban Analysis 9, 71-86.

Biddle, Bruce J. 1979. Role Theory: Expectations, Identities and Behaviors New York: Academic Press. 
Blau, Judith R. and Richard H. Hall. 1986. The Supply of Performing Arts in Metropolitan Places. Urban Affairs Quarterly 22,1: 42-65.

Bingham, Richard JB. 1976. The Adoption of Innovation by Local Government. Lexington: D.C. Heath and Company.

Bird, Barbara J. 1989. Entrepreneurial Behavior. Glenview, Il.: Scott, Foresman and Company.

Birley, Sue. 1985. The Role of Networks in the Entrepreneurial Process. In Frontiers of Entrepreneurial Research 1985. Proceedings of the 5th Annual Babson College Entrepreneurship Research Conference. Wellesley, Ma.: Center for Entrepreneurship Studies, Babson College.

Blaug, Marc. 1976. The Economics of the Arts. Boulder Co. and London: Westview Press and Martin Robertson.

Bolton, Richard, ed. 1992. Culture Wars. Documents from the Recent Controversies in the Arts. New York: New Press.

Bowers, Raymond, ed. 1966. Studies on Behavior in Organizations. A Research Symposium. Athens: University of Georgia Press.

Bruno, Albert V. and Tyzoon T. Tyebjee. 1982. The Environment for Entrepreneurship. In Encyclopedia of Entrepreneurship, ed. Calvin A.Kent, Donald L. Sexton and Karl H. Vesper. Englewood Cliffs, N.J.: Prentice-Hall, Inc.

Burns, Joan Simpson. 1975. The Awkward Embrace. New York: Aflred A. Knopf.

Campbell, D.T. and Stanley, J.C. 1963. Experimental and Quasi-Experimental Designs for Research. Chicago: Rand McNally.

Carland, J.W., F. Hoy, W.R. Boulton and J.C. Carland. 1984. Differentiating Entrepreneurs from Small Business Owners: A Conceptualization. Academy of Management Review 9, 2: 354-359.

Carsrud, Alan L., Connie Marie Gaglio and Kenneth W. Olm. 1986. Entrepreneurs, Mentors, Networks, and Successful New Venture Development. An Exploratory Study. In Frontiers of Entrepreneurship Research, 1986. Proceedings of the Sixth Annual Babson College Entrepreneurship Research Conference, ed. Robert Ronstadt, John A. Hornaday, Rein Peterson and Karl H. Vesper. Wellesley, Ma.: Center For Entrepreneurial Studies, Babson College.

Carter, Robert A. 1971. Manhattan Primitive. New York: Stein and Day.

Cauthorn, Robert C. 1989. Contributions to a Theory of Entrepreneurship. New York: Garland Publishing,Inc.

Churchill, Neil C. 1983. Entrepreneurs and their Enterprises: A Stage Model.In Frontiers of Entrepreneurship Research. Proceedings of the 1983 Conference on Entrepreneurship at Babson College, ed. John A. Hornaday, Jeffry A. Timmons and Karl H. Vesper. Wellesley, Ma.: Center for Entrepreneurial Studies, Babson College. 
Cole, Arthur H. 1959. Business Enterprise in its Social Setting. Cambridge, Ma.: Harvard University Press.

Cole, B. Graham, Jr., and Steven W. Hays. 1986. Managing the Public Organization. Washington, D.C.: CQ Press.

Covin, Jeffrey G. and Dennis P. Slevin. The Development and Testing of an Organizational Level Entrepreneurship Scale. 1986. In Frontiers of Entrepreneurship Research 1986. Proceedings of the Sixth Annual Babson College Entrepreneurship Research Conference, ed. Robert Ronstadt, John A. Hornaday, Rein Peterson and Karl H. Vesper. Wellesley, Ma.: Center for Entrepreneurial Studies, Babson College.

Crimmons, James C. and Mary Keil. 1983. Enterprise in the Nonprofit Sector Washington, D.C.: Partners for Livable Places.

Cwi, David and Susanne Moore. 1982. City Arts Support: Status and Issues. Baltimore: The Cultural Policy Institute.

Cwi, David. 1981. How Cities Support the Arts. Washington, D.C.: United States Conference of Mayors.

1979. Merit Good and Market Failure Arguments for Subsidy of the Arts. Journal of Behavioral Economics, 8,2 (Summer)

Cohen, Michael D., James G. March and Johan P. Olsen. A Garbage Can Model of Organizational Choice. Administrative Science Quarterly, 17: 1-26.

Dandridge, Thomas C. and Michael A. Ford. 1987. Use of a Self-Assessment Profile to Differentiate Among Professional Groups on Entrepreneurail Characteristics. In Frontiers of Entrepreneurship Research 1987. Proceedings of the Seventh Annual Babson College Entrepreneurship Research Conference, ed. Neil C. Churchill, John A.Hornaday, Bruce A. Kirchhoff, O.J. Krasner and Karl H. Vesper. Wellesley, Ma.: Center for Entrepreneurial Studies, Babson College.

Davids, L. E., 1963. Characteristics of Small Business Founders in Texas and Georgia. Washington, D.C.: Small Business Administration.

Davidsson, Per. 1988. Type of Man and Type of Company Revisited. A Confirmatory Cluster Analysis Approach. In Frontiers of Entrepreneurship Research, 1988. Proceedings of the Eighth Annual Babson College Entrepreneurship Research Conference, ed. Bruce A. Kirchhoff, Wayne A. Long, W. Edward McMullan, Karl H. Vesper and William E. Wetzel, Jr. Wellesley, Ma.: Center for Entrepreneurial Studies, Babson College.

Doig, Sameson W. and Erwin C. Hargrove. 1987. Leadership and Innovation.A Bibliographic Perspective on Entrepreneurs in Government.Baltimore: The Johns Hopkins University Press.

Douglas, Mary. 1980. The World of Goods. New York: Basic Books.

Downs, Anthony. 1967. Inside Bureaucracy. Boston: Little Brown and Company.

Downs, George W., Jr. 1976. Bureaucracy, Innovation and Public Policy.Lexington: Lexington Books. 
Drabek, Thomas E. and J. Eugene Haas. 1974. Understanding Complex Organizations.

Dubuque, Ia.: William C. Brown Company, Publishers.

Drucker, Peter F. 1966. The Effective Executive. New York: Harper \& Row, Publishers. 1992. Managing for the Future. The 1990's and Beyond. New York: Truman Talley Books/Dutton.

Edwards, Allen L. 1957. Techniques of Attitude Scale Construction. New York: AppletonCentury-Crofts, Inc.

Ely, R.T. and R.H. Hess. 1937. Outlines of Economics. New York: MacMillan Books.

Etzioni, Amitai. 1959. Authority Structure and Organizational Effectiveness. Administrative Science Quarterly 4: 43-67.

1960. New Directions in the Study of Organizations and Society. Social Research: 223-228.

1960. Two Approaches to Organizational Analysis: A Critique and a Suggestion. Administrative Science Quarterly 5: 257-278.

1961. Complex Organizations. A Sociological Reader. New York: Holt, Rinehart and Winston, Inc.

. 1964. Modern Organizations. Englewood Cliffs, N.J.: Prentice-Hall, Inc.

1961. A Comparative Analysis of Complex Organizations. New York: The Free Press, reprint 1975.

Fayol, H. 1949. General and Industrial Management. In Organization Behavior and the Practice of Management, ed. David R. Hampton, Charles E. Summer and Ross A. Webber. Glenview, Il.: Scott, Foresman and Company, 1982.

Feld, Alan L., Michael O'Hare and J. Mark Davidson Schuster. 1983. Patrons Despite Themselves: Taxpayers and Arts Policy. New York and London: New York University Press.

Filer, John. 1975. The Filer Commission Report. In The Nonprofit Organization. Essential Readings, ed. David L. Gies, J. Steven Ott and Jay M. Shafritz. Pacific Grove, Ca.: Brooks/Cole Publishing Company, 1990.

Fleischaker-Suarez, Deborah. 1982. A Descriptive Study of Management in Selected Nonprofit Organizations. Ph.D. diss., University of Oklahoma.

Follett, Mary Parker. 1926. Scientific Foundations of Business Administration. In Classics of Public Administration, ed. Jay M. Shafritz and Albert C. Hyde. Chicago: The Dorsey Press, 1987. 
Gartner, William B. 1984. Problems in Business Startup: The Relationships Among Entrepreneurial Skills and Problem Identification for Different Types of New Ventures. In Frontiers of Entrepreneurship Research. Proceedings of the 1984 Entrepreneurship Research Conference, ed. John A. Hornaday, Fred A. Tardley, Jr., Jeffry A. Timmons and Karl H. Vesper. Wellesley, Ma.: Center for Entrepreneurial Studies, Babson College.

1989. Who is an Entrepreneur? is the Wrong Question. Entrepreneurship Theory and Practice 13, 4: 47-68.

Gasse, Yvon. 1978. Characteristics, Functions and Performance of Small Firm OwnerManagers in Two Industrial Environments. Ph.D. diss, Northwestern University.

1977. Entrepreneurial Characteristics and Practices. A Study of the Dynamics of Small Business Organizations and Their Effectiveness in Different Environments. Sherbrooke, Que.: Faculte d'administration University of Sherbrooke.

Gerth, H. and C. Wright Mills. 1946. From Max Weber: Essays in Sociology. London: Oxford University Press, renewed 1973. In Classics of Public Administration, ed. Jay M. Shafritz and Albert C. Hyde. Chicago: The Dorsey Press, 1987.

Ghorpade, Jarsingh, ed. 1971. Assessment of Organizational Effectiveness. Pacific Palisades: Goodyear.

Giamatti, A. Bartlett. 1989. Take Time for Paradise. Americans and Their Games. New York: Summit Books.

Gies, David L., J. Steven Ott and Jay M. Shafritz, ed. 1990. The Nonprofit Organization. Essential Readings. Pacific Grove, Ca.: Brooks/Cole Publishing Company.

Grayson, Leslie E. and Curtis J. Tompkins. 1984. Management of Public Sector and Nonprofit Organizations. Reston, Va.: Reston Publishing Company, Inc.

Gross, Edward and Amitai Etzioni. 1985. Organizations in Society. Englewood Cliffs, N.J.: Prentice-Hall.

Gulick, L. and Urwick, L. 1937. Papers on the Science of Administration. New York: Institute of Public Administration. In Classics of Public Administration, ed. Jay M. Shafritz and Albert C. Hyde. Chicago: The Dorsey Press, 1987.

Hage, Jerald and Michael Aiken. 1970. Social Change in Complex Organizations. New York: Random House.

Hall, Peter Dobkin. 1987. A Historical Overview of the Private Nonprofit Sector. In The Nonprofit Sector. A Research Handbook, ed. Walter W. Powell. New Haven: Yale University Press.

Hall, Richard H. 1982, Organizational Structure and Process. Englewood Cliffs, N.J.: Prentice-Hall.

Hansmann, Henry B. and John M. Quigley. 1982. Population Heterogeneity and Sociogenesis of Homicide. Social Forces 61: 206-224. 
Hartman, H. 1959. Managers and Entrepreneurs: A Useful Distinction? Administrative Science Quarterly 3: 429-457.

Hendon, William. 1979. Analyzing an Art Museum. New York: Praeger.

Hay, Robert D. 1990. Strategic Management in Nonprofit Organizations. An Administrator's Handbook. New York: Quorum Books.

Hendon, William S. and James L. Shanahan, ed. 1983. Economics of Cultural Decision. Cambridge, Ma.: Abt Books.

Hendon, William S., James L. Shanahan and Alice J. MacDonald. 1980. Economic Policy for the Arts. Cambridge, Ma.: Abt Books.

Hisrich, Robert D., ed. 1986. Entrepreneurship, Intrapreneurship and Venture Capital. Lexington: Lexington Books.

Holt, David H. 1987. Network Support Systems: How Communities Can Encourage Entrepreneurship. In Frontiers of Entrepreneurship Research, 1987. Proceedings of the Seventh Annual Babson College Entrepreneurship Research Conference, ed. Neil Churchill, John JA. Hornaday, Bruce A. Kirchhoff, O.J. Krasner and Karl H. Vesper. Wellesley, Ma.: Center for Entrepreneurial Studies, Babson College.

Hornaday, John A. and J. Aboud. 1971. Characteristics of Successful Entrepreneurs. Personnel Psychology 24: 141-153.

Hornaday, John A. and C. Bunker. 1970. The Nature of the Entrepreneur. Personnel Psychology 23: 47-54.

Hornaday, John A. and Hancy B. Tieken. 1983. Capturing Twenty-one Heffalumps. In Frontiers of Entrepreneurship Research 1983. Proceedings of the 1983 Conference on Entrepreneurship at Babson College, ed. John A. Hornaday, Jeffry A. Timmons and Karl H. Vesper. Wellesley, Ma.: Center for Entrepreneurial Studies, Babson College.

Horowitz, Tem. 1978. Arts Administration. How to Set up and Run Successful Nonprofit Arts Organizations. Chicago: Chicago Review Press.

Howell, R.P. 1972. Comparative Profiles: Entrepreneurs versus the Hired Executive. San Francisco Peninsula Semiconductor Industry. In Technical Entrepreneurship: A Symposium, ed. A.C. Cooper and J.L. Komives. Milwaukee: Center for Venture Management.

Hurst, David. 1984. Of Boxes, Bubbles and Effective Management. Cited in Rohrer, Grace J. 1985. The Nature of Managerial Work in Cultural Organizations. Ph.D. diss, University of North Carolina.

Jeffri, Joan 1980. The Emerging Arts. Management, Survival and Growth. New York: Praeger Publishers.

Kaufman, Herbert 1991. Chance and Organizational Survival: An Open Question (Part I). Journal of Public Administration Research and Theory, 1,2: 213-227. 
1985. Time Chance, and Organizations. Natural Selection in a Perilous Environment. Chatham, New Jersey: Chatham House Publishers, Inc.

Kazanjian, Robert K. 1984. Operationalizing Stage of Growth: An Empirical Assessment of Dominant Problems. In Frontiers of Entrepreneurship Research. Proceedings of the 1984 Conference on Entrepreneurship ai Babson College, ed. John A. Hornaday, Fred A. Tardley, Jr., Jeffry A. Timmons and Karl H. Vesper. Wellesley, Ma.: Center for Entrepreneurial Studies, Babson College.

Katz, D. and Kahn, R.L. 1966. The Social Psychology of Management. New York: John Wiley \& Sons.

Keeley, Michael. 1984. Impartiality and the Participant Interest. Theories of Organizational Effectiveness. Administrative Science Quarterly 29: 1-25.

Kent, Calvin A., Donald L. Sexton and Karl H. Vesper. 1982. Encyclopedia of Entrepreneurship. Englewood Cliffs, N.J.: Prentice-Hall, Inc.

Kent, Calvin A., ed. 1984. The Environment for Entrepreneurship. Lexington: Lexington Books.

Kent, Calvin A., Donald Z. Sexton, Philip Van Auken and Dean M. Young. 1982. Managers and Entrepreneurs: Do Lifetime Experiences Matter? In Frontiers of Entrepreneurial Research. Proceedings of the 1982 Conference on Entrepreneurship at Babson College, ed. Karl H. Vesper. Wellesley, Ma.: Center for Entrepreneurial Studies, Babson College.

Kelby, Peter, ed. 1971. Entrepreneurship and Economic Development. New York: The Free Press.

Khandwalla, P.N. 1977. The Design of Organizations. New York: Harcourt, Brace and Jovanovich.

Kimball, Roger. 1992. Thre Treason of the Intellectuals \& "The Undoing of Thought." The New Criterion 2,4 (December): 10-16.

Kimberly, John R. and Robert E. Quinn. 1984. Managing Organizational Transitions. Homewood, Il.: Richard JD. Irwin, Inc.

Klink, William R. 1987. William Carlos Williams's Paterson. Literature and Urban History. Urban Affairs Quarterly 23, 2.

Koehler, David H. and Margaret T. Wrightson. 1987. Inequality in the Delivery of Urban Services: A Reconsideration of the Chicago Parks. The Journal of Politics 49: 80-99.

Kotter, John P. 1982. The General Managers. New York: The Free Press. 1978. Organizational Dynamics. Diagnosis and Intervention. Reading, Ma.: Addison-Wesley Publishing Company.

Kraus, Richard G. and Joseph E. Curtis. 1986. Creative Management in Recreation, Parks and Leisure Services. St. Louis: Mirror/Mosby College Publishing. 
Kreps, Gary A., ed. 1989. Social Structure and Disaster. Newark: University of Delaware Press.

Lachman, R. 1980. Toward Measurement of Entrepreneurial Tendencies. Management International Review 20, 2: 108-116.

Lawrence, P. and J. Lorsch. 1967. Organization and Environment. Boston: Harvard Business School.

Lavington, F. 1922. Trade Cycle: An Account of the Causes Producting Rhythmical Changes in the Activity of Business, Vol 3. London: P.S. King.

Leibenstein, H. 1968. Entrepreneurship and Development. American Economic Review 58: 72-83.

Levene, Victoria F. and William J. Buckley. 1977. A Bibliography on Arts Administration. Binghamton, N.Y.: State University of New York, School of Management, School of Arts and Sciences.

Levine, Charles H. 1978. Organizational Decline and Cutback Management. Public Administration Review (July/August): 316-325.

Levine, Lawrence W. 1988. Highbrow/Lowbrow. The Emergence of Cultural Hierarchy in America. Cambridge: Harvard University Press.

Levy, F. A.A. Meltsner and Aaron Wildavsky. 1974. Urban Outcomes: Schools Streets and Libraries. Berkeley: University of California Press.

Lieberson, Stanley. 1985. Making it Count. The Improvement of Social Research and Theory. Berkeley: University of California Press.

Liles, P. 1974. Who are the Entrepreneurs? MSU Business Topics 22: 5-14.

Lindzey, Gardner and Elliot Aronson, ed. 1985. Handbook of Social Psychology, Vol. 1. Theory and Method. New York: Randon House.

1985. Handbook of Social Psychology. Vol. 2. Special Fields and Applications. New York: Random House.

Litzinger, W.D. 1965. The Motel Entrepreneurs and the Motel Manager. Academy of Management Journal 8: 268-281.

Lynes, Russell. 1985. The Lively Audience. New York: Harper \& Row, Publishers.

Manfredi, John. 1982. The Social Limits of Art. Amherst: The University of Massachusetts Press.

Mankin, Lawrence David. 1976. The National Government and the Arts: From the Great Depression to 1973. Ph.D. diss, University of Illinois at Urbana-Champaign.

Mann, Danis Alan, ed. 1977. The Arts in a Democratic Society. Bowling Green: The Poplar Press.

March, James G. 1969. Handbook of Organizations. Chicago: Rand-McNally. 
March, James G. and Herbert A. Simon. 1965. Organizations. New York: John Wiley and Sons.

Mayo, Elton. 1933. The Human Problems of an Industrial Civilization. New York: MacMillan Publishing Company.

Meier, Richard L. 1962. A Communications Theory of Urban Development.New York: Wiley.

Middleton, Melissa. 1987. Nonprofit Boards of Directors: Beyond the Governance Function. In The Nonprofit Sector. A Research Handbook, ed. Walter W. Powell. New Haven: Yale University Press.

Mintzberg, Henry. 1989. Mintzberg on Management. Inside Our Strange World of Organizations. New York: The Free Press. 1973. The Nature of Managerial Work. New York: Harper \& Row.

Mouzelis, Nicos P. 1967. Organisation and Bureaucracy. An Analysis of Modern Theories. Chicago: Aldine Publishing Company.

Mulcahy, Kevin V. and C. Richard Swaim, ed. 1982. Public Policy and the Arts. Boulder, Co.: Westview Press.

McCarthy, Anne M., David A. Kreuger and Timothy S. Schoenecker. 1989. Entrepreneurial Time Allocation Patterns Across Early Stages of Development. In Frontiers of Entrepreneurship Research 1989. Proceedings of the Ninth Annual Babson College Entrepreneurship Research Conference, ed. Robert H. Brockhaus, Sr., Neil C. Churchill, Jerome A. Katz, Bruce A. Kirchhoff, Karl H. Vesper and William E. Wetzel, Jr. Wellesley, Ma.: Center for Entrepreneurial Studies, Babson College.

McClelland, D.C. 1961. The Achieving Society. Princeton: Van Nostrand.

McCurdy, Howard. 1991. Organizational Decline: NASA and the Life Cycle of Bureaus. Public Administration Review, 51,4, (July/August): 308-315.

McKelvey, Bill. 1982. Organizational Systematics. Taxonomy, Evolution, Classification. Berkeley: University of California Press.

Miller, Gale, Ed. 1991. Studies in Organizational Sociology: Essays in Honor of Charles K. Warriner. Greenwich, CT.: JAI Press, Ind.

Myers, Kristen A. 1990. A Dialectical Analysis of Role Enactment During the Emergency Period of Natural Disaster. M.A. thesis, College of William and Mary.

National Research Center of the Arts, 1975. Museums U.S.A.: A Survey Report Frepared for the National Endowment for the Arts. Washington, D.C.: United States Government Printing Office.

Netzer, Dick. 1978. The Subsidized Muse: Public Support for the Arts in the United States. London: Cambridge University Press.

O'Connell, Brian. 1989. What Voluntary Activity Can and Cannot do for America. Public Administration Review 49, 5 (September/October): 486-491. 
Ogum, George Ougo. 1990. The Impact of Corporate Entrepreneurship on Financial Performance of Nonprofit Organization: The Case of Hospitals in Tennessee. Ph.D. diss, Memphis State University.

Olm, Kenneth W. and George G. Eddy. 1985. Entrepreneurship and Venture Management. Columbus: Charles E. Merrill Publishing Company.

O'Neill, Michael and Dennis R. Young, ed. 1988. Educating Managers of Non-profit Organizations. New York: Praeger.

Palumbo, Dennis, Michael Musheno and Steven Maynard-Moody. 1986. Public Sector Entrepreneurs: The Shakers and Doers of Program Innovation. In Performance and Credibility. Developing Excellence in Public and Nonprofit Organizations, ed. Joseph S. Wholey, Mark A. Abramson and Christopher Bellavita. Lexington: Lexington Books.

Peters, Thomas J. and Robert H. Waterman. 1982. In Search of Excellence.New York: Harper \& Row, Publishers.

Perrow, Charles. 1986. Complex Organizations. A Critical Essay. New York: Random House.

Pinchot, Gifford III. 1985. Intrapreneuring. Why You Don't Have to Leave the Corporation to Become an Entrepreneur. New York: Harper \& Row, Publishers.

Powell, Walter W., ed. 1987. The Nonprofit Sector. A Research Handbook, New Haven: Yale University Press.

Prieve, E. Arthur. 1977. Administration in the Arts. An Annotated Bibliography of Selected References. Madison, Wi.: Center for Arts Administration, Graduate School of Business, University of Wisconsin.

Quinn, Robert E. and Kim Cameron. Organizational Life Cycles and Shifting Criteria of Effectiveness: Some Preliminary Evidence. Management Science 29, 1: 33-51.

Quinn, Robert E. and Kim S. Cameron, ed. 1988. Paradox and Transformation: Toward a Theory of Change in Organization and Management. Cambridge: Ballinger Publishing Company.

Raymond, Thomas J.C. and Stephen A. Greyser. 1978. The Business of Managing the Arts. Harvard Business Review 56 (July/August): 123-133.

Reiss, Alvin H. 1974. The Arts Management Handbook, 2nd edition. New York: Law-Arts Publishers, Inc.

Riley, Martha White. 1963. Sociological Research. A Case Approach. New York: Harcourt, Brace and World, Inc.

Rohrer, Grace J. 1985. The Nature of Managerial Work in Cultural Organizations. Ph.D. diss, University of North Carolina.

Rubin, Joan Shelley. 1992. The Making of Middlebrow Culture, Chapel Hill, N.C.: The University of North Carolina Press. 
Rudney, Gabriel. 1981. A Quantitative Profile of the Nonprofit Sector. Yale University Program on Nonprofit Organizations. Working Paper \#40.

1987. The Scope and Dimensions of Nonprofit Activity. In The Nonprofit Sector. A Research Handbook, ed. Walter W. Powell. New Haven: Yale University Press.

Rudney, Gabriel and Murray Weitzman. 1983. Significance of Employment and Earnings in the Philanthropic Sector, 1972-1982. Yale University Program on Nonprofit Organizations. Working Paper \#77.

Salamon, Lester M. 1987. Partners in Public Service: The Scope and Theory of GovernmentNonprofit Relations. In The Nonprofit Sector. A Research Handbook, ed. Walter W. Powell. New Haven: Yale University Press.

Schendel, Dan E. and Charles W. Hofer. 1979. Strategic Management. A New View of Business Policy and Planning. Boston: Little Brown and Company.

Scherer, Robert F., Janet S. Adams, Susan S. Carley and Frank A. Wiebe. 1989. Role Model Performance Effects on Development of Entrepreneurial Career Performance. Entrepreneurship Theory and Practice 13, 3: 53-72.

Schlesinger, Arthur M., Jr. 1986. The Cycles of American History. Boston Houghton Mifflin Company.

Schumpter, Joseph A. 1934. The Theory of Economic Development. An Inquiry into Profits, Capital, Credit, Interest and the Business Cycle. Cambridge: Harvard University Press, reprint 1961.

Schwalbe, Douglas and Janet Baker-Carr. 1977. Conflict in the Arts: The Relocation of Authority. Cambridge: Arts Administration Research Institute.

Scitovsky, Tibor. 1976. The Joyless Economy. Oxford: Oxford University Press.

1972. What is Wrong with the Arts is What's Wrong With Society. American Economic Review XXII, 2 (May).

Sexton, Donald L. and Raymond W. Smilor. 1986. The Art and Science of Entrepreneurship. Cambridge: Ballinger Publishing Company.

Shaw, Roy. 1987. The Arts and the People. London: Jonathan Cape Ltd.

Shepherd, Herbert A. 1967. Innovation-resisting and Innovation-producing Organizations. The Journal of Business. The Graduate School of Business of the University of Chicago 40, 4 (October): 470-478.

Shore, Harvey. 1987. Arts Administration and Management. New York: Quorum Books.

Shuman, Jeffrey C., John A. Segar and Nicholas C. Teebagy. 1987. Entrepreneurial Activity and Educational Background. In Frontiers of Entrepreneurship Research. Proceedings of the Seventh Annual Babson College Entrepreneurship Conference, ed. Neil C. Churchill, John A. Hornaday, Bruce A. Kirchhoff, O.J. Krasner and Karl H. Vesper. Wellesley: Center for Entrepreneurial Studies, Babson College. 
Simon, Herbert. 1957. Rational Behavior and the Structure of the Environment. In Models of Man. New York: Wiley.

Skloot, Edward. 1987. Enterprise and Commerce in Nonprofit Organizations. In The Nonprofit Sector. A Research Handbook, ed. Walter W. Powell. New Haven: Yale University Press.

Smith Norman R. 1967. The Entrepreneur and his Firm. The Relationship Between Type of Man and Type of Company. East Lansing, Mi.: Michigan State University, Graduate School of Business Administration. Occasional Paper.

Smith, Norman R. and John B. Miner. 1983. Type of Entrepreneur, type of Firm and Managerial Motivation: Implications for Organizational Life Cycle. Frontiers of Entrepreneurship Research. Proceedings of the 1983 Conference on Entrepreneurship at Babson College, ed. John A. Hornaday, Jeffry A. Timmons and Karl H. Vesper. Wellesley: Center for Entrepreneurial Studies, Babson College.

Sorensen, Theodore C. 1988. "Let the Word Go Forth." The Speeches, Statements, and Writings of John F. Kennedy, 1947-1963. New York: Dell Publishing.

Stevens, William R. 1985. A Comparison of For-profit and Not-for-profit Organizations: Chief Executive, Officers' and Officials' Perceptions. Ph.D. diss., University of Arkansas.

Svara, James H. 1990. Official Leadership in the City. Patterns of Conflict and Cooperation. New York: Oxford University Press.

Taylor, Frederick W. 1912. Scientific Management. Testimony Before the United States House of Representatives, January 25, 1912. In Classics of Public Administration, ed. Jay M. Shafritz and Albert C. Hyde. Chicago: The Dorsey Press.

Toulmin, Llewellyn M. 1988. Equity as a Decision Rule in Determining Distribution of Urban Public Services. Urban Affairs Quarterly 23,3 (March): 389-413.

Tropman, John E. 1989. Human Service Entrepreneurship: The Four ' $C$ ' Approach. Administrative Leadership in the Social Sciences 13, 3: 219-242.

Tropman, John E. and Gersh Morningstar. 1989. Entrepreneurial Systems for the 1990's. Their Creation. Structure and Management. New York: Quorum Books.

Unterman, Israel and Richard H. Davis. 1984. Strategic Management for Not-for-profit Organizations. From Survival to Success. New York: Praeger.

Vander Zanden, James W. 1987. Social Psychology. New York: Random House.

Vesper, Karl L. 1983. Entrepreurship and National Policy. Carnegie-Mellon University:The Graduate School of Industrial Administration, Heller Institute for Small Business Papers.

ed. 1982. Frontiers of Entrepreneurship Reseach. Proceedings of the 1982 Conference on Entrepreneurship. Wellesley: Center for Entrepreneurial Studies, Babson College. 
Wainer, H.A. and I. M. Rubin. 1969. Motivation of Research and Development Entrepreneurs: Determinants of Company Success. Journal of Applied Psychology 53, 3: $178-184$.

Warren, Robert, Mark S. Rosentraub and Louis P. Weschler. 1988. Community Services Budget. Public, Private and Third-sector Roles in Urban Services. Urban Affairs Quarterly 23, 3 (March): 414-431.

Warriner, Charles K. ;and Jane Emery Prather. 1965. Four Types of Voluntary Associations. Social Inquiry 35: 135-149.

Wehle, Mary. 1975. Financial Management for Arts Crganizations. Cambridge: Arts Administration Research Institute.

Welsh, John A. and Jerry F. White. 1981. Converging on the Characteristics of Entrepreneurs. In Frontiers of Entrepreneurship Research. Proceedings of the 1981 Conference on Entreneurship at Babson College, ed. Karl H. Vesper. Wellesley: Center for Entrepreneurial Studies, Babson College.

Whitt, J. Allen. 1987. Mozart in the Metropolis. The Arts Coalition and the Urban Growth Machine. Urban Affairs Quarterly 23,1 (September).

Wilken, Paul H. 1979. Entrepreneurship. A Comparative and Historical Study. Norwood, N.J.: ABLEX Publishing Company.

Wilson, James Q. 1966. Innovation in Organizations: Notes Toward a Theory. In Approaches to Organizational Design, ed. James D. Thompson. Pittsburgh: University of Pittsburgh: 193-218.

Wohl, R. Richard. 1949. An Historical Context for Entrepreneurship. Explorations in Entrepreneurial History 1, 2: 8-16.

Wolf, Thomas. 1990. Managing a Nonprofit Organization. New York: Simon \& Schuster.

Young, Dennis R. 1983. If Not for Profit for What? A Behavioral Theory of the Non-profit Sector Based on Entrepreneurship. Lexington: Lexington Books.

1985. Casebook of Management for Nonprofit Organizations. Entrepreneurship and Organizational Change in the Human Services. New York: The Haworth Press.

1987. Executive Leadership in Nonprofit Organizations. In The Nonprofit Sector. A Research Handbook, ed. Walter W. Powell. New Haven: Yale University Press.

Zaltman, Gerald, Robert Duncan and Jonny Holbeck. 1973. Innovations and Organizations. New York: John Wiley and Sons. 


\section{APPENDIX A \\ VIRGINIA COMMISSION FOR THE ARTS, GUIDELINES}

The VCA guidelines for grant applicants require that the organizations are Virginia based or perform in Virginia, whose primary purpose is the arts, which are tax-exempt from Federal income tax under Section 501 (c) (3) of the IRS code, which present, produce or support dance, literary arts, media arts, music, theater, visual and related arts, which comply with the Civil Rights Act of 1964, Title VI, Section 601, and which comply with Educational Amendments of 1972, the Age Discrimination Act of 1975 and the Rehabilitation Act of 1973. Organizations which meet these criteria are eligible for a variety of grants which are awarded on the basis of agency quality of presentation and quality of management. Grant awards include General Operating Support, Project Grants, Local Government Challenge Grants, Salary Assistance, Individual artist, Technical Assistance, Touring Assistant, Virginia Prizes for Individual Artists, Project Grants for Individual Artists and Artists-in-Education. The sample drawn for this survey includes only applicants from three urban centers in Virginia which were reviewed only by the regional panels. Grants for Touring Assistance, Virginia Prizes, Project Grants for Individual Artists and Artists-in-Education are not included in the sample as these applications are reviewed by separate panels.

Grant amounts are decided by a series of calculations which assess the budget and fund-raising efforts. Grant awards are made by panel consensus. Panels are convened in each of the six arbitrary areas of the state (Area I, Western Virginia; Area II, Lynchburg; Area III, Lexington, Roanoke; Area IV, Northern Virginia; Area V, Richmond and Area VI, Hampton Roads) to examine and discuss the history of a group's past projects and consider a future project. Panelists review the biographical, educational and financial history of the group or individual artist. 


\title{
APPENDIX B
}

\section{SAMPLE FOR ARTS MANAGEMENT SURVEY}

\section{Area IV Northern Virginia}

\author{
Alexandria Choral Society \\ Alexandria Civic Symphony Association \\ Alexandria Commission for the Arts \\ American Showcase Theatre Company \\ Arlington Arts Center \\ Arlington County Cultural Affairs Division \\ Arlington Metropolitan Chorus \\ Arlington Players \\ Arlington Symphony \\ Artisans United \\ Bluemont Concert Series \\ Capital Area Performers Organization \\ Manassas Center for the Arts \\ Children's Theatre of Arlington \\ Classical Ballet Theater \\ Fairfax Choral Society \\ Fairfax County Council of the Arts \\ Fairfax Symphony Orchestra \\ Fredericksburg Center for the Creative Arts \\ Fredericksburg Theater Company \\ Friends of the Torpedo Factory Art Center \\ Great Falls Concert Series \\ Greater Reston Arts Center \\ Hispanic Cultural Society \\ Interact Theatre Company \\ McLean Choral Society \\ McLean Orchestra \\ McLean Project for the Arts \\ McLean Symphony \\ Mount Vernon Chamber Orchestra Association \\ Northern Virginia Fine Arts Association \\ Northern Virginia Youth Symphony \\ Opera Americana \\ Opera Theatre of Northem Virginia \\ Performing Arts Association of Alexandria \\ Springwater Fiber Workshop \\ Virginia Chamber Orchestra \\ Virginia Jazz Service Organization \\ WETA-FM \\ Wordstage Reader's Theatre \\ Youth Orchestras of Prince William
}




\section{Area V Richmond}

Art Services Network

Arts Council of Richmond

Ash Lawn

Barksdale Theatre

CAFUR

CALLALOO

CHALFA

Chihamba of Dancescape

Downtown Presents

City of Emporia

Folk Art Society of America

Gilpin Stage Company

Hand Workshop

James River Chamber Opera Company

Last Stop Gallery

Meadow Farm Museum

Miki Liszt Dance Company

Miles B. Carpenter Museum

Mixed Media

New Virginia Review

$\mathrm{Nu}$-Visions Cultural Center

Oratorio Society of Charlottesville/Albemarle

Petersburg Symphony Orchestra

Piedmont Council of the Arts

Production Company

Richmond Ballet

Richmond Chamber Players

Richmond Children's Museum

Richmond Classical Guitar Society

Richmond Community Orchestra

Richmond Jazz Society

Richmond Printmaking Workshop

Richmond Symphony

Richmond Theatre Company

Roxbury Chamber Players

Second Street Gallery

Studio Theatre of Richmond

Theatre IV

TheatreVirginia

University of Richmond

Virginia Commonwealth University

Virginia Museum of Fine Arts

Wakefield Foundation

Youth Orchestra of Charlottesville/Albemarle

1708 EAST MAIN

\section{Area VI Hampton Roads}

Capriole

CenterStage

Chesapeake Civic Chorus 
Contemporary Ballet Theatre

Cultural Alliance of Greater Hampton Roads

Cultural Experiences Unlimited

Dockside Art Review of Tidewater

Eastern Virginia Brass Society

Hampton Arts Commission

Hampton University Museum

Hurrah Players, Inc.

Institute for Dance

Natchel' Blues Network, Inc.

On Cue Productions, Inc.

Peninsula Fine Arts Center

Peninsula Youth Orchestra

Portsmouth Museums

Riddick's Folly

Southeastem Virginia Arts Association

Tidewater Area Musicians

Tidewater Ballet Association

Tidewater Classic Guitar Society

Tidewater Performing Arts Society

Tidewater Winds

Virginia Beach Center for the Arts

Virginia Beach Community Orchestra

Virginia Beach Orchestral Association

Virginia Choral Society

Virginia Opera

Virginia Pro Musica

Virginia Stage Company

Virginia Symphony

Williamsburg Music Association

Williamsburg Players

York River Community Orchestra

Yorktown Arts Foundation

Young Audiences of Virginia 


\section{APPENDIX C}

\section{ARTS MANAGEMENT SURVEY}

213

Reproduced with permission of the copyright owner. Further reproduction prohibited without permission. 


\section{ARTS MANAGEMENT SURVEY}

This survey forms the core of a dissertation on current management practices (1991) in non-profit urban arts agencies in Virginia, with particular emphasis upon handling recent government funding cuts The survey is designed to determine the role and behaviors of the arts manager and his/her involvement in the artistic and business aspects of an arts agency. While every question may not be relevant to your management task or style, please take the time to answer them all. Questions are scored from 0 to 5 , with four gradations between. These numbers refer to the level of your agreement with the issue as it relates to your performance in your agency now. The answers concern only your opinion and your personal experience with your arts agency. There are no "right" answers.

Thank you in advance for your cooperation and participation.

\section{Beth Rossheim}

Doctoral Candidate, Public Administration

Old Dominion University

Norfolk, Virginia 23529 


\section{Section A: Managerial Demographics}

In this section we would like to know about your education and experience. Please fill in the blanks and mark the most appropriate response.

1. Age:

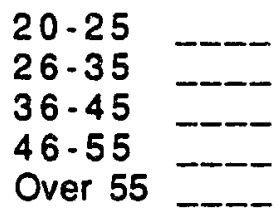

2. Sex

$$
\text { Male }
$$

Female

3. Race or Ethnic Background

Asian-American

African-American

Hispanic

Caucasian

Other

4. Highest Level of Arts Education

None

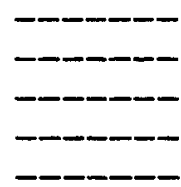

\section{Associate's degree
Bachelor's degree
Advanced coursework \\ Associate's degree
Bachelor's degree
Advanced coursework \\ Associate's degree
Bachelor's degree
Advanced coursework}

5. Major field in art

$\begin{array}{ll}\text { Art history } & \text { Studio art } \\ \text { Dance } \\ \text { Drama }\end{array} \quad \begin{gathered}\text { Music } \\ \text { None } \\ \text { Other }\end{gathered}$

6. Highest Level of Education in Business, Management or Arts Administration None

Associate's degree

Master's degree

Bachelor's degree

Doctorate degree

Advanced coursework or management seminar

7. Total Years of Experience in Arts Administration less than one year one to three years 
8. Years of Experience in Current Job less than one year one to three years

over eight years four to eight years

9. Type of Arts Agency Performing Arts Display Arts Educational Arts Arts Service Organization Discipline

Funding Agency

Community Center

Multi-cultural Arts

Presenting Agency

10. Size of Organization number of artistic staff (performing, curatorial or educational)

_ number of business staff (management, marketing, public relations) number of active volunteers size of Board of Directors

11. Budget of the Agency in 1990-91 under $\$ 50,000$

51,000 to 100,000
101,000 to 200,000 200,000 to 500,000

Actual 1991 Budget

12. Number of Years since Agency Incorporation less than five years six to nine years ten to fifteen years over fifteen years

13. Agency Budget change over four years expressed as a percentage

$$
\begin{aligned}
& \text { growth or } 1-5 \% \quad 6-10 \% \quad 11-15 \% \quad 16-20 \% \quad \text { over } 20 \% \\
& \text { decline }
\end{aligned}
$$

1987 to 1988

1988 to 1989

1989 to 1990

1990 to 1991

14. Percentage of Agency Budget from earned income in 1991

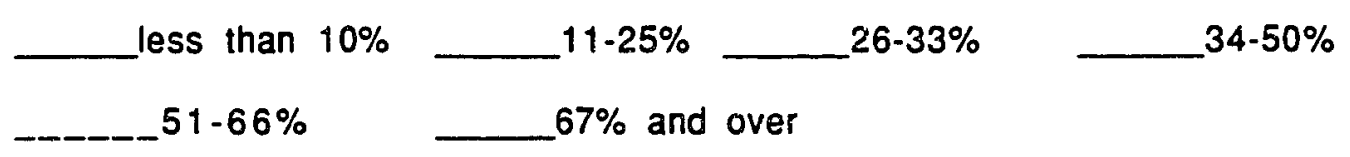


15. Percentage of Agency Budget from fundraising in 1991

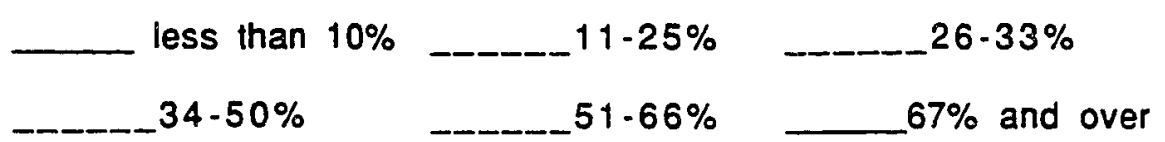

16. Percentage of the Agency Budget from grants in 1991:

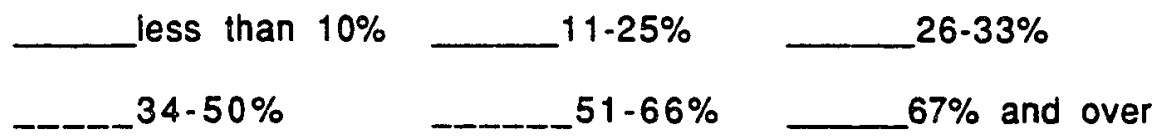

17. Life cycle of the agency in 1991:

developing and emerging
growing
in process of changing
mature
maclining

18. Service/performance change over past three years:

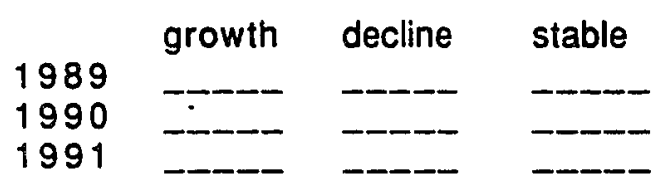

19. Annual Salary 1991 (calculate on a full-time basis)

less than $\$ 15,000$
$\$ 16,000$ to $\$ 20,000$
$\$ 21,000$ to $\$ 25,000$
$\$ 26,000$ to $\$ 30,000$
$\$ 31,000$ to $\$ 35,000$
$\$ 36,000$ to $\$ 40,000$
over $\$ 41,000$
unsalaried


Section B. Artistic and Business Philosophy and Style (Covin and Slevin 1986, Gasse 1978, Ogum 1990)

The statements below refer to the managerial style which can be found in an arts agency. They describe some artistic decisions of an arts manager in the area of programming.

1. Based on your own managerial experience in your agency in 1991 only, indicate your degree of participation in each artistic activity by circling the appropriate number, 0 to 5 .

$0=$ Not Applicable

$5=$ More than $20 \%$

$4=16-20 \%$

$3=11-15 \%$

$2=6-10 \%$

$1=0-5 \%$

$\begin{array}{llllllll}0 & 5 & 4 & 3 & 2 & 1 & \text { What percentage of your programming format }\end{array}$ is different in 1991 from last year?

$\begin{array}{llllllll}0 & 5 & 4 & 3 & 2 & 1 & \text { What percentage of your arts programming }\end{array}$ in 1991 consisted of original works never performed before?

$\begin{array}{llllllll}0 & 5 & 4 & 3 & 2 & 1 & \text { What percentage of your arts programs in }\end{array}$ 1991 was considered risky for your urban/suburban locale?

$\begin{array}{llllllll}0 & 5 & 4 & 3 & 2 & 1 & \text { What percentage of your programming in }\end{array}$ 1991 was thought to provide leadership in your field, i.e., other agencies wanted to copy these programs?

$\begin{array}{llllllll}0 & 5 & 4 & 3 & 2 & 1 & \text { What percentage of your programming in }\end{array}$ 1991 was considered experimental?

$\begin{array}{lllllll}0 & 5 & 4 & 3 & 2 & 1 & \text { What percentage of your arts programs in }\end{array}$ 1991 was accompanied by educational or interpretive programs?

$\begin{array}{lllllll}0 & 5 & 4 & 3 & 2 & 1\end{array}$ What percentage of your arts programming in 1991 generated controversy in the popular media in the form of Letters to the Editor, editorials or news features? 
If the answer to the above question was a 3,4 , or

5 , please answer the next three questions.

$\begin{array}{llllllll}0 & 5 & 4 & 3 & 2 & 1 & \text { What percentage of your controversials arts }\end{array}$ programming in 1991 generated phone calls or letters directly to the agency?

$\begin{array}{llllllll}0 & 5 & 4 & 3 & 2 & 1 & \text { What percentage of your controversial arts }\end{array}$ programming in 1991 was supported/encouraged by your locale or community?

$\begin{array}{llllllll}0 & 5 & 4 & 3 & 2 & 1 & \text { What percentage of your controversial arts }\end{array}$ programming in 1991 was supported/encouraged by your Board of Directors?

$\begin{array}{llllllll}0 & 5 & 4 & 3 & 2 & 1 & \text { Would controversial programming be supported }\end{array}$ by your locale or community?

$\begin{array}{llllllll}0 & 5 & 4 & 3 & 2 & 1 & \text { Would controversial programming be supported }\end{array}$ by your Board of Directors?

2. The following items describe your managerial business actions in generating resources for your arts agency. Using the new scale, please select the response (0-5) that best reflects the results of your efforts in the time frames indicated:

$0=$ Not applicable

$\mathbf{5}=$ Agree strongly

$4=$ Agree on the whole

$3=$ Somewhat agree

$2=$ Disagree on the whole

$1=$ Disagree strongly

$\begin{array}{llllllll}0 & 5 & 4 & 3 & 2 & 1 & 1\end{array}$ year for the past four years.

$\begin{array}{llllll}0 & 5 & 4 & 3 & 2 & 1\end{array}$

1 produced at least $50 \%$ of agency budget in 1991 from earned income.

$\begin{array}{llllll}0 & 5 & 4 & 3 & 2 & 1\end{array}$

I produced at least $40 \%$ of agency budget in 1991 from grants and donations.

$\begin{array}{llllll}0 & 5 & 4 & 3 & 2 & 1\end{array}$

I produced at least $10 \%$ of agency budget in 1991 from unrelated business activities, suchas a gift shop.

$\begin{array}{llllll}0 & 5 & 4 & 3 & 2 & 1\end{array}$

I have met our fundraising goal each year for past two years. 
$\begin{array}{llllll}0 & 5 & 4 & 3 & 2 & 1\end{array}$

$\begin{array}{llllll}0 & 5 & 4 & 3 & 2 & 1\end{array}$

$\begin{array}{llllll}0 & 5 & 4 & 3 & 2 & 1\end{array}$

$\begin{array}{llllll}0 & 5 & 4 & 3 & 2 & 1\end{array}$

$\begin{array}{llllll}0 & 5 & 4 & 3 & 2 & 1\end{array}$
My agency has owned fixed assets, such as artifacts, real estate, props, equipment, scripts or scores, at least for the past two years.

I received funding from corporate sponsors in 1991.

I have incurred no loans or other deficit obligationsfor the past two years.

I plan to establish an endowment fund in the next two years.

I now have an endowment fund.

\section{Section C: Internal Agency Performance}

The statements below list functions of an arts manager within an agency. Please indicate your level of agreement or disagreement with each of these functions based upon your actions in your arts agency in the time frames indicated.

1. In planning my agency's goal and mission:

$0=$ Not applicable; $5=$ Agree strongly; $4=$ Agree on the whole; $3=$ Somewhat agree; $2=$ Disagree on the whole; $1=$ Disagree strongly

$\begin{array}{llllll}0 & 5 & 4 & 3 & 2 & 1\end{array}$

$\begin{array}{llllll}0 & 5 & 4 & 3 & 2 & 1\end{array}$

$\begin{array}{llllll}0 & 5 & 4 & 3 & 2 & 1\end{array}$

$\begin{array}{llllll}0 & 5 & 4 & 3 & 2 & 1\end{array}$
I now have a significant amount of autonomy and discretion in my agency, i.e., my decisions are seldom overridden by my Board of Directors.

I determine the goals and objectives of this agency annually in joint meetings with my Board of Directors.

I have defined a specific niche for this agency in the arts for at least the past two years.

I evaluate our mission and goals annually.

2. In developing a sound and cooperative arts organization: $0=$ Not Applicable; $5=$ Agree strongly; $4=$ Agree on the whole; $3=$ Somewhat agree; $2=$ Disagree on the whole; $1=$ Disagree strongly 
$\begin{array}{llllllll}0 & 5 & 4 & 3 & 2 & 1 & \text { I now have a working Board of Directors that }\end{array}$ encompasses professional skills, such as law, accounting and business.

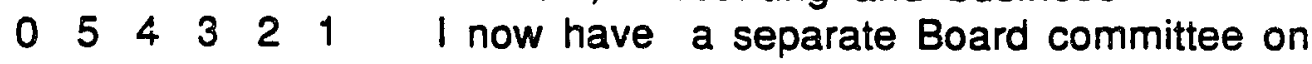
budgeting.

Select one of the following answers:

$\begin{array}{llllllll}0 & 5 & 4 & 3 & 2 & 1 & \text { I now have an agency in which I control both the }\end{array}$ artistic and management functions.

CR

$\begin{array}{lllllll}0 & 5 & 4 & 3 & 2 & 1 & \text { I now have a management centered agency with }\end{array}$

a separate artistic director who plans program elements.

CR

$\begin{array}{llllllll}0 & 5 & 4 & 3 & 2 & 1 & \text { I now have an artistic centered agency with a }\end{array}$ separate business manager who controls the management elements.

CR

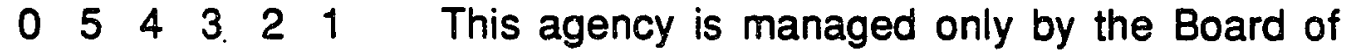

Directors with no paid managerial staff.

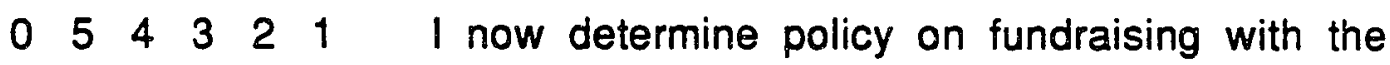
involvement of my Board.

3. To establish basic management techniques:

$0=$ Not applicable; $5=$ Agree strongly; $4=$ Agree on the whole; $3=$

Somewhat agree; $2=$ Disagree on the whole; $1=$ Disagree strongly

$\begin{array}{llllllll}0 & 5 & 4 & 3 & 2 & 1 & \text { I create an annual budget which identifies the }\end{array}$ costs and revenues of each program or service element.

$\begin{array}{llllllll}0 & 5 & 4 & 3 & 2 & 1 & \text { I conducted or commissioned a marketing audit }\end{array}$ within the past two years in order to determine the target market and its description, such as size, potential size, needs and level of satisfaction.

$\begin{array}{llllllll}0 & 5 & 4 & 3 & 2 & 1 & \text { I prepared or commissioned a marketing }\end{array}$ analysis of the offerings of this agency within the past two years in order to review items such as programming, price, promotion and funding.

$\begin{array}{lllllll}0 & 5 & 4 & 3 & 2 & 1\end{array}$. I now write all grant proposals for my agency. 


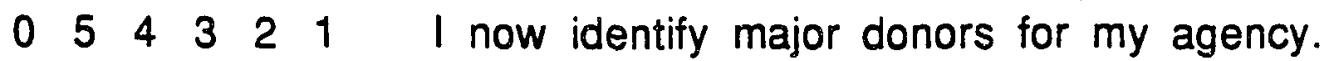

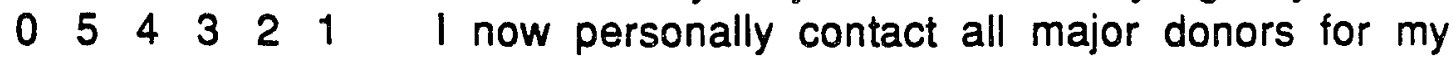
agency.

4. To help my agency plan:

$0=$ Not applicable; $5=$ Agree strongly; $4=$ Agree on the whole; $3=$ Somewhat agree; $2=$ Disagree on the whole; $1=$ Disagree strongly

$\begin{array}{llllllll}0 & 5 & 4 & 3 & 2 & 1 & \text { I now subscribe to an arts management journal }\end{array}$ or newsletter which identifies new artistic opportunities such as services, products, personnel, programs or management techniques.

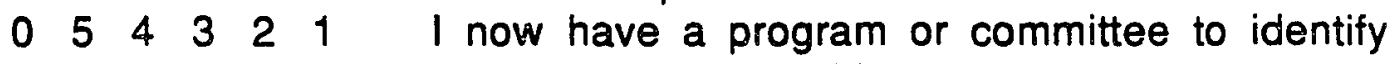
long-term facilities needs.

$\begin{array}{llllllll}0 & 5 & 4 & 3 & 2 & 1 & 1\end{array}$ now have an endowment fund for the agency.

$\begin{array}{llllllll}0 & 5 & 4 & 3 & 2 & 1\end{array}$ I now have a separate planning committee within my Board of Directors.

$\begin{array}{lllllll}0 & 5 & 4 & 3 & 2 & 1 & \mathrm{I} \\ \text { attend an annual regional or national arts }\end{array}$ management conference.

Section D: External Agency Performance (Kotter 1982)

The statements below indicate areas in the greater environment of an arts agency which involve the arts manager. Please indicate your agreement or disagreement based upon your actions in your arts agency.

1. In order to help make public resources available in the arts:

$0=$ Not applicable; $5=$ Agree strongly; $4=$ Agree on the whole; $3=$ Somewhat agree; $2=$ Disagree on the whole; $1=$ Disagree strongly
$\begin{array}{llllll}0 & 5 & 4 & 3 & 2 & 1\end{array}$
I join annually with other arts leaders to advocate financing of the arts by local government

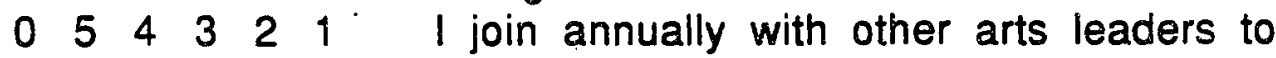 encourage state government arts funding.
$\begin{array}{llllllll}0 & 5 & 4 & 3 & 2 & 1 & \text { I meet at least annually with state legislators }\end{array}$ from my district to encourage state government arts funding. 


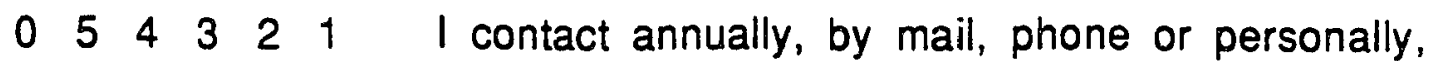
federal legislators from my district to encourage federal arts funding.

$\begin{array}{llllllll}0 & 5 & 4 & 3 & 2 & 1 & 1 \text { have executed joint advertising for programs }\end{array}$ with our corporate sponsors in at least the past two years.

2. In order to involve my agency with our larger community: $0=$ Not applicable; $5=$ Agree strongly; $4=$ Agree on the whole; $3=$ Somewhat agree; $2=$ Disagree on the whole; $1=$ Disagree strongly
$\begin{array}{lllll}0 & 5 & 4 & 3 & 2\end{array}$
I now belong to and am active in more than one civic organization.
$\begin{array}{llllll}0 & 5 & 4 & 3 & 2 & 1\end{array}$
At least one staff member was actively involved in 1991 in a community affair, such as speaking, hosting or appearing as a guest in a program.
$\begin{array}{llllllll}0 & 5 & 4 & 3 & 2 & 1\end{array}$ I now have a high quality media image program, such as slides, video, tapes, graphics, brochures, newsletter, flyers, postcards.or a logo.
$\begin{array}{lllllll}0 & 5 & 4 & 3 & 2 & 1 & \text { At least one Board member spoke to a civic }\end{array}$ group in 1991 about our agency's programs and goals .

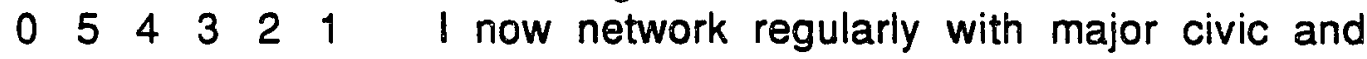 political organization leaders in support of our agency.

3. In order to cope with the competitive environment in the arts:

$0=$ Not applicable; $5=$ Agree strongly; $4=$ Agree on the whole; $3=$ Somewhat agree; $2=$ Disagree on the whole; $1=$ Disagree strongly

$\begin{array}{llllllll}0 & 5 & 4 & 3 & 2 & 1 & \text { I have prepared a market analysis within the }\end{array}$ past two years in order to determine the strengths and weaknesses of my agency.

$\begin{array}{llllllll}0 & 5 & 4 & 3 & 2 & 1 & \text { I attended a local or regional arts }\end{array}$ management seminar this year.

$\begin{array}{llllllll}0 & 5 & 4 & 3 & 2 & 1\end{array}$ I have surveyed the community within the past two years in order to determine my agency's name recognition and reputation. 
4. To assess the impact of the economic situation in my region:

$0=$ Not applicable; $5=$ Agree strongly; $4=$ Agree on the whole; $3=$ Somewhat agree; $2=$ Disagree on the whole; $1=$ Disagree strongly

$\begin{array}{llllllll}0 & 5 & 4 & 3 & 2 & 1 & 1 \text { assessed the local economic environment in }\end{array}$ 1991 to determine the potential for success of our annual programs and services

$\begin{array}{llllllll}0 & 5 & 4 & 3 & 2 & 1 & \text { I prepared a } 1991 \text { update of new or expanding }\end{array}$ corporations in order to extend funding appeals.

$\begin{array}{llllllll}0 & 5 & 4 & 3 & 2 & 1 & \text { I canvassed the region in } 1991 \text { to select new }\end{array}$ sites for agency expansion in programs, services and/or exhibits.

Section E: Cutback strategy (Hay 1990, Frohnmayer 1991)

Cutbacks are a major focus of this study and constitute the greatest current challenge to arts agencies. The list of options below includes many standard business methods used to face a cutback environment.

My cutback strategy in 1991 was:

$0=$ Not applicable; $5=$ Agree strongly; $4=$ Agree on the whole; $3=$ Somewhat agree; $2=$ Disagree on the whole; $1=$ Disagree strongly

$\begin{array}{lllllllll}0 & 5 & 4 & 3 & 2 & 1 & \text { To introduce new services, such as }\end{array}$ performances, productions, exhibits or products in order to increase the target market.

$\begin{array}{llllllll}0 & 5 & 4 & 3 & 2 & 1 & \text { To revise pricing strategy for all services in }\end{array}$ order to increase audience participation and sales.

$\begin{array}{lllllll}0 & 5 & 4 & 3 & 2 & 1 & \text { To increase fundraising efforts to avoid a }\end{array}$ possible deficit.

$\begin{array}{llllllll}0 & 5 & 4 & 3 & 2 & 1\end{array}$ To institute new production locations and times

in order to increase public accessibility.

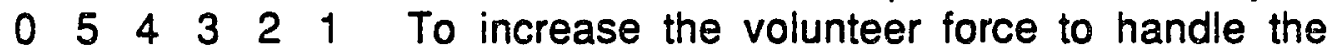
increased work load of an augmented schedule.

$\begin{array}{lllllll}0 & 5 & 4 & 3 & 2 & 1\end{array}$ To conduct market studies to identify current target market and secondary markets. 
$\begin{array}{lllllll}0 & 5 & 4 & 3 & 2 & 1 & \text { To conduct market studies to locate new target }\end{array}$ markets and potential users of services and products.

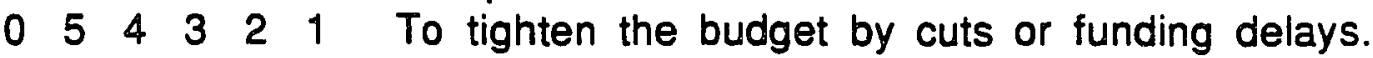

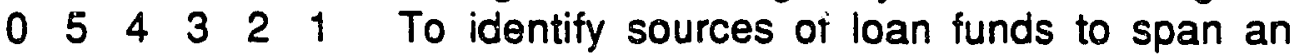
impending shortfall.

$\begin{array}{lllllll}0 & 5 & 4 & 3 & 2 & 1 & \text { To locate cheaper sources of supplies and }\end{array}$ equipment by discount or cooperative purchasing.

$\begin{array}{lllllllll}0 & 5 & 4 & 3 & 2 & 1 & \text { To reduce staff through layoffs.or hiring freezes }\end{array}$

$\begin{array}{llllllll}0 & 5 & 4 & 3 & 2 & 1 & \text { To appeal to Board of Directors for financial }\end{array}$ rescue

$\begin{array}{lllllll}0 & 5 & 4 & 3 & 2 & 1 & \text { To reduce the number of services and }\end{array}$ performances.

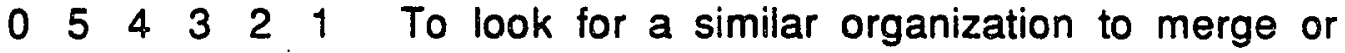
absorb this agency.

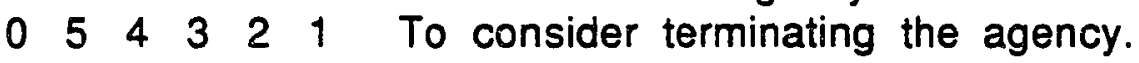

Section F: Beliefs About Arts Management (Gasse, 1978)

This final section deals with some commonly held attitudes about business and management by arts managers. Please mark your agreement or disagreement with these statements as you feel about them in your arts management experience.

$0=$ Not applicable; $5=$ Agree strongly; $4=$ Agree on the whole; $3=$ Somewhat agree; $2=$ Disagree on the whole; $1=$ Disagree strongly

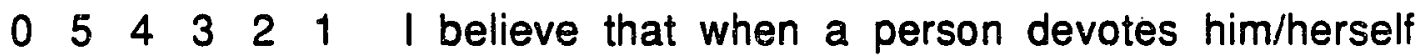
to an idea or cause, his/her life becomes meaningful.

$\begin{array}{lllllll}0 & 5 & 4 & 3 & 2 & 1 & \text { I think the average subordinate in a job prefers to }\end{array}$ be independent, to assume responsibility and to display ambition.

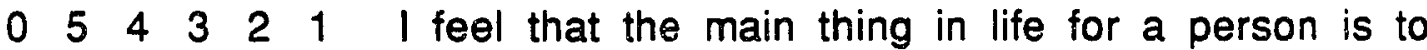
do something that he/she considers important.

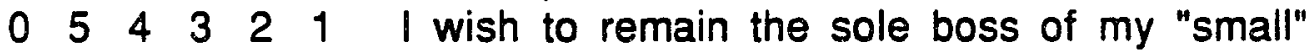
agency rather than become an associate in a larger agency.

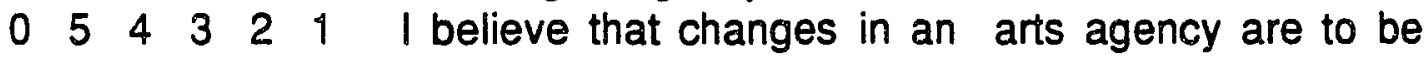
expected. 


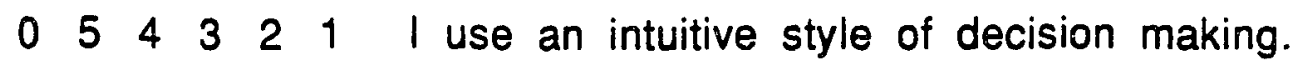

$\begin{array}{lllllll}0 & 5 & 4 & 3 & 2 & 1 & 1 \text { delegate only those decisions which I have no }\end{array}$ time to make by myself.

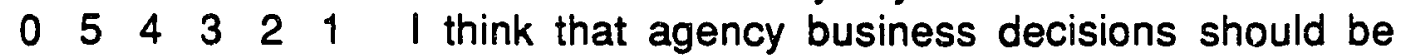
based upon business studies and reports.

$\begin{array}{llllllll}0 & 5 & 4 & 3 & 2 & 1 & \text { I think that heavy use of business methods, }\end{array}$ techniques and practices will help to guarantee my agency's survival.

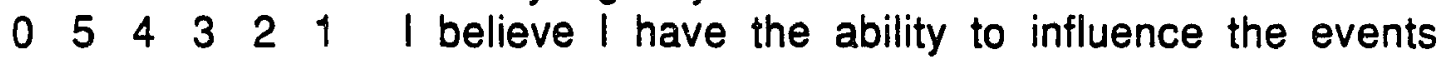
which occur in an arts agency.

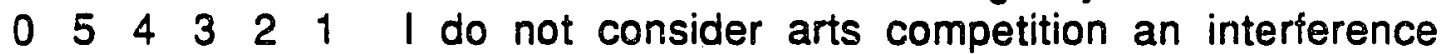
with business operations.

$\begin{array}{llllllll}0 & 5 & 4 & 3 & 2 & 1 & 1\end{array}$ think that many events in the arts world turn out to be a matter of good or bad fortune.

$\begin{array}{llllllll}0 & 5 & 4 & 3 & 2 & 1 & \text { I think this survey captures the essential roles }\end{array}$ of an arts manager.

$\begin{array}{llllllll}0 & 5 & 4 & 3 & 2 & 1 & 1 \text { think this survey captures the essential }\end{array}$ activities of an arts manager. 


\section{APPENDIX D \\ PRETEST COVER LETTER FOR ARTS MANAGEMENT SURVEY}

Dear

I am a doctoral candidate at Old Dominion University writing my dissertation on Management Roles in Nonprofit Urban Arts Agencies in Virginia in order to determine current management practices during the present funding crisis in the arts. My dissertation is a descriptive-analytical survey of arts managers that will present an aggregate picture of arts management in three metropolitan areas of the state.

Your agency was selected at random as a suitable candidate to pretesi the survey instrument for this dissertation. I would appreciate the opportunity to meet with you for about one hour to administer the questionnaire and hear your comments.

I will telephone you within a week to set an appointment date and time.

I realize that your time is limited and I would be very grateful for your participation in this pretest. I believe that the results will be insightful for all arts managers in Virginia.

Sincerely yours,

Beth Rossheim 


\section{APPENDIX E}

\section{SAMPLE COVER LETTER}

\section{Dear}

I am a doctoral candidate at Old Dominion University in the Department of Public Administration and Urban Studies, completing a dissertation on Management Roles in Nonprofit Urban Arts Agencies in Virginia. My research and academic interest stem from my own education and experience as an art historian and museum curator/developer in Hampton Roads. I have selected this topic because of the need for substantive research on arts management. The current cutback in arts funding has made the need for arts management research even more pressing.

The survey I have devised covers several phases of arts management and is designed to give an aggregate picture of arts management in selected areas of the state. Your agency was selected as part of a sample of well-managed arts agencies that have received grant funds from the Virginia Commission for the Arts. Any information that you provide, however, will be used only as part of a total picture and will remain totally confidential. I stress the confidentiality of the survey because I need your candor in completing the survey.

The survey is enclosed in this packet. Please do not complete the survey by yourself. I plan to administer the survey to you by telephone and to record the answers for you. There will be no need for you to mail back a completed survey, but please have it available for a reference.

I will telephone you within one week to discuss the administration of the survey. I hope you will be willing to respond to the telephone survey at a time which is mutually convenient for us. The survey will take about 40 minutes to administer.

Results of the survey will be available to you following completion of data analysis. Your contribution to this research is sincerely appreciated.

Very truly yours,

Beth Rossheim 


\section{APPENDIX F}

\section{ADDITIONAL STUDIES}

Additional studies were conducted to examine the effect of role type on role behavior in conjunction with the following intervening variables: city/county size, agency structure, metropolitan statistical area, agency type, and total gross revenue. These studies included a factor analysis and a multiple regression analysis.

The factor analysis revealed clusters of variables that mirrored several indexes used in the study. For example, Factor 1 included business and management items similar to the External Agency Management Tasks Index, Factor 2 listed a related group of marketing and planning/evaluation items, Factor 3 revealed items largely from the Creative Programming Index, and Factor 4 was strongly related to the Passive Cutback Index (indicating agencies in acute distress or failing). (See Table 87: Factor Analysis)

Regression analyses were done using each of the four agency management task indexes (Internal Agency Tasks, External Agency Tasks, Active Cutback Strategies, and Passive Cutback Strategies) as dependent variables. The analyses examined the effects of four role types and the following intervening variables upon the dependent variables: city/county size, agency structure, agency type, and metropolitan statistical area. In the analysis of Internal Agency Tasks, External Agency Tasks and Active Cutback Strategies, substantial or significant predictors were agency budget, agency type, role type and the Richmond MSA. These findings are consistent with those reported earlier in this research study and were discussed in Chapter V. No other intervening variable, including city/county size, metropolitan statistical area or agency structure was a significant predictor of the dependent variables. (See Table 88: Multiple Regression Analysis) 
Table 87.--Factor Analysis of Managerial Tasks*

Factor Names and the High Loading Variables

Factor Loadings

Factor I: BUSINESS ORIENTATION

Meet state legislators $\quad .65$

Total gross revenue for agency $\quad .64$

Attend management conferences $\quad .60$

Encourage state arts funding $\quad .57$

Track local corporate movement $\quad .52$

Subscribe to management journal $\quad .52$

Board has a budgeting committee $\quad .49$

Agency has corporate sponsors $\quad .49$

Agency executed programs with corporate sponsors $\quad .48$

Manager contacts federal legislators for the arts $\quad .47$

Manager networks with community leaders $\quad .43$

Dual management structure, business manager leads $\quad .43$

Staff speaks at community events $\quad .41$

Agency receives local government grants $\quad .42$

Manager attends state seminars $\quad .40$

Manager increases fundraising $\quad .39$

Board has planning committee $\quad .35$

Factor II: MARKETING AND PLANNING ITEMS

Identify current target market $\quad .72$

Conduct program and price analysis $\quad .72$

Conduct audit of subscribers $\quad .68$

Analyze agency strengths and weaknesses $\quad .67$

Identify potential target market $\quad .66$

Conduct name recognition study $\quad .63$

Assess local economy $\quad .42$

Select sites for agency program expansion $\quad .37$

Evaluate agency mission and goals $\quad .33$

Manager and board set fundraising policy $\quad .30$

* Items included with factor loadings $>.30$. 
Table 87.--Factor Analysis of Managerial Tasks* (continued)

Factor Names and the High Loading Variables

Factor Loadings

Factor III: PLANNING CREATIVE PROGRAMS

Presented original works 1991

.66

Presented experimental programs 1991

.59

Presented risky programs 1991

.51

Manager is acknowledged programmatic leader

Manager effected program format changes 1991

Presented controversial programs 1991

.46

Presented educational programs 1991

.44

Introduced new programs/services 1991

.44

.43

.37

Factor IV: HALLMARKS OF FAILING AGENCIES

Staff layoffs

Agency terminates

Cut budget

Buy cheaper supplies and equipment

Need financial resuce by board

Increase volunteer force

Merge agency with another

Review program pricing strategies

* Items included with factor loadings $>.30$ 
Table 88.--Multiple Regression, Indexes by Demographic Variables and Role Types

\begin{tabular}{|c|c|c|c|c|}
\hline \multirow[t]{2}{*}{$\begin{array}{l}\text { Demographic Variables } \\
\text { and Role Types }\end{array}$} & $\begin{array}{l}\text { Internal } \\
\text { Agency } \\
\text { Tasks }\end{array}$ & $\begin{array}{l}\text { External } \\
\text { Agency } \\
\text { Tasks }\end{array}$ & $\begin{array}{l}\text { Active } \\
\text { Cutback } \\
\text { Strategies }\end{array}$ & $\begin{array}{l}\text { Passive } \\
\text { Cutback } \\
\text { Strategies }\end{array}$ \\
\hline & & \multicolumn{3}{|c|}{ Beta Weights } \\
\hline $\begin{array}{l}\text { City size } \\
\text { Sole Manager } \\
\text { Theatrical Agency } \\
\text { Entrepreneur role } \\
\text { Total Gross Revenues } \\
\text { Artist role } \\
\text { Richmond MSA } \\
\text { Dual Managers, Artist } \\
\text { Musical Agency } \\
\text { Administrator role } \\
\text { Northern Virginia MSA } \\
\text { Dual Manager, Business } \\
\text { Visual Arts Agency }\end{array}$ & $\begin{array}{l}.017 \\
.054 \\
.205 \\
.151 \\
.361^{*} \\
-.044 \\
.111 \\
.177 \\
.155 \\
.173 \\
. .103 \\
.129 \\
.298\end{array}$ & $\begin{array}{l}-.112 \\
.076 \\
.119 \\
.089 \\
.332^{*} \\
-.016 \\
.263^{*} \\
.162 \\
.184 \\
.141 \\
.104 \\
.131 \\
.337^{*}\end{array}$ & $\begin{array}{l}.002 \\
.134 \\
.105 \\
.067 \\
.144 \\
.340^{*} \\
.004 \\
.093 \\
-.007 \\
.248^{*} \\
. .120 \\
.148 \\
-.059\end{array}$ & $\begin{array}{l}-.017 \\
.133 \\
-.206 \\
.123 \\
.084 \\
.040 \\
-.115 \\
.078 \\
-.311 \\
.031 \\
-.006 \\
.097 \\
-.235\end{array}$ \\
\hline ADJUSTED $\mathrm{R}^{2}$ & .26 & .27 & .10 & -.01 \\
\hline
\end{tabular}

*Significant at $\mathrm{p}=.050$ 